\title{
CATALYTIC CONVERSION OF NITROGEN TO AMMONIA BY AN IRON MODEL COMPLEX
}

\author{
Thesis by \\ John S. Anderson \\ In Partial Fulfillment of the Requirements for the \\ Degree of Doctor of Philosophy
}

California Institute of Technology

Pasadena, CA

2014

(Defended September 3, 2013) 
(C) 2013

John S. Anderson

All Rights Reserved 


\section{Acknowledgements}

Throughout the course of my doctoral studies, I have been blessed to be surrounded by some of the most intelligent, helpful, and enjoyable people in the world. Any success that I may have had during my Ph.D. reflects more on the capabilities of the people around me than on any trait of my own. A large number of people have contributed to this work either directly in the form of co-workers and collaborators, or indirectly in the form of people who did not work on the science herein, but without whom this work would not have been possible. I will do my best to thank all of them.

Firstly, I have to thank Professor Jonas Peters. As many will tell you, Jonas is a fantastic advisor and I could not have asked for a better mentor for the past five years. Jonas is far more intelligent than he gives himself credit for and has a unique gift in the design and implementation of research projects. His approach to scientific problems and his thought process in designing experiments is something I hope I will take with me as I leave my doctoral studies. I also have to thank him for the patience he has shown in developing me as a scientist. I am far from a finished product, but any progress that I have made is largely a result of his efforts. Aside from his scientific prowess, Jonas has been a thoroughly helpful and thoughtful person to work with and, in general, an exceptional human being. Any professor can attest that time comes as a premium, but Jonas has consistently managed this research lab in a remarkable manner and has been a pleasure to work with. Although it is difficult to be friends with your advisor during the course of one's Ph.D., I have enjoyed my time working for him immensely and look forward to our future interactions. 
During the move from M.I.T. to CalTech, I spent a brief "sabbatical" in the laboratories of Professor Greg Fu. Although the joint project I was working on during that time was an unmitigated disaster, I enjoyed the members of the Fu lab that I met during that time, some of whom I still talk to today. I also have to thank Greg for letting me work in his lab, and for our interactions during that time and since. The Fu lab has since moved to CalTech as well and having them across the hall has been great.

Four graduate students started in the same year as I did, and then there was one. I find it unlikely that I was the only person during my year that graduated with a Ph.D. from the Peters lab, considering the exceptionally talented group of students that I came in with. I would like to thank Laura Gerber, Kenny Lotito, and Alicia Chang for the social and scientific interactions that we had during our time together. I hope our paths will cross again in the future.

Outside of my classmates, the Peters lab has been filled with a an outstanding group of people. I shared a glovebox with Caroline Saouma during my early time in the lab and I have to thank her for getting me started in the laboratory. Although the time that we spent together was relatively short, Professor Neal Mankad is an impressive scientist and continues to host our yearly fantasy football league. Professor Yunho Lee brought an incredibly cheerful demeanor to the lab every day and I thank him for it. I would also like to thank Professor Nate Szymczak for getting me started on electrochemistry and for, despite being a vegan, being an overall good labmate. I did not interact with Professor Louise Berben very much during my time in the Peters Lab, but I still have the koala she brought back from Australia for everyone in the lab. Samantha Macmillan was also a part-time glovebox mate as well as perhaps the best person in the 
lab to talk to. Charlene Tsay was also a glovebox partner for some time and I have to thank her for putting up with my mess frequently.

Daniel Suess has been a brilliant, eccentric, and hysterical co-worker throughout my Ph.D. I have learned a great deal about chemistry through my discussions with Dan and I have to thank him for all of the help he has given me over the past five years. Similarly, Professor Hill Harman has brought a unique, and sometimes belligerent, outlook on chemical problems. In many ways his insights have made me re-evaluate the way I think about molecules. Dr. Ayumi Takaoka was a good friend before he fled this country for Japan. Early on in my Ph.D. Ayumi frequently referred to me as being "too much of a cowboy." Although I didn't realize it at the time, I had a lot to learn from Ayumi about scientific rigor. Fortunately, he had a lot to learn from me about fantasy football, and the lessons are ongoing. I frequently enjoyed talking to Professor Chris Uyeda, and his knowledge of synthesis has been a great resource during my doctoral studies.

Dr. Marc-Etienne Moret was a co-author with me, and is in general more enthusiastic about chemistry than any other person I know. He thinks deeply about chemical problems and one can not help but be enlightened by discussions with him. Dr. Charles McCrory has put up with many hours of my questions about electrochemistry and other physical methods which are frequently beyond the scope of my knowledge. Although he is often grumpy, I personally enjoy Charles' dour moods, and must sincerely thank him for all of his help. More recently, I have had the pleasure of working with Dr.'s Yichen Tan and Tzu-Pin Lin, who I have to thank for discussions about chemistry 
and life in general. Dr. David Lacy has been a great person to talk to and I specifically have to thank him for our discussions on oxo species.

Henry Fong is likely the nicest person in the lab, and we have spent time together both in outreach (which was often laborious) as well as on the basketball court. I always look forward to seeing Henry, and I suspect that I may see more of him in the future in Chicago. Sid Creutz has had to sit in the same cubicle with me for a number of years. While Sid has never complained, he rarely speaks at all, so I can only assume that he doesn't mind. Sid has, however, been a great and very intelligent co-worker who continues to do excellent work in the lab.

During the last portion of my Ph.D., I had the privilege of monopolizing a glovebox with Jon Rittle, hereafter referred to as JR. JR is an incredibly gifted chemist and has a nearly unmatched intensity with which he attacks scientific problems. While this intensity can often lead to bad moods and arguments, JR is usually right and possesses a keen mind for chemistry. Additionally, JR has been my, potentially unwilling, partner in crime on a great deal of my Ph.D. work, and I certainly would not have been able to complete these projects without his help. Despite his love of country music, JR has been a pleasure to work with and I will miss the time we have spent together both in the lab and outside of it. Bridget Connor is a recent undergraduate addition to the lab who JR and I have both mentored. Although just beginning her research career, Bridget has already shown a knack for synthesis and it would be a shame if the lab lost her. Tanvi Ratani, Mark Nesbit, Trevor Del Castillo, Ben Matson, and Kareem Hannoun are the newest crop of Peters Lab students and I have enjoyed the time I have spent with them. I look forward to reading their papers in the future. 
A number of collaborators have helped me on projects and publications during my Ph.D. I would like to specifically thank Limei Zhang, Jens Kaiser, George Cutsail, and Ruchira Chatterjee for their help in answering my sometimes incessant questions and fortheir assistance in collecting and interpreting data. MIT and CalTech have excellent staff members and I would like to thank David VanderVelde, Larry Henling, Mike Takase, Peter Muller, Bruce Brunschwig, Jay Winkler, Jeff Simpson, and Angelo DiBilio for their help in discussing and fixing scientific or chemical problems.

Outside of the Peters lab members, I have been fortunate to be surrounded by an exceptional group of people at both MIT and CalTech. Although too numerous to name individually, I have had the pleasure of interacting with a number of students from the Schrock, Fu, Cummins, Nocera, Grubbs, Agapie, Drennan, Lippard, Rees, Gray and Bercaw labs and I anticipate crossing paths with many of them in the future. I also participated in various recreational sports including volleyball, softball, and basketball during the past few years. My participation in IM basketball leagues at CalTech in particular may mark the most pitiful streak of futility in an athletic endeavor, as the collective wins for teams that I have been a part of likely number less than seven over the course of three years. Nevertheless, the people that I have been able to play with have enriched my time both on the court and off it.

My thesis committee consisted of Professors John Bercaw, Theo Agapie, and Brian Stoltz. This group has collectively referred to themselves as "The Ream Team." While I feel that I did not fully live up to their expectations during my candidacy and Ph.D. studies, I am thoroughly grateful for the time and effort they put into reading my 
work and offering criticism. I believe that I am a better scientist because of my interactions with them.

I would also like to thank my undergraduate advisor Professor Greg Hillhouse for taking me under his wing as a naïve undergraduate and starting me along this path. I would certainly never have made it this far without his efforts and the time that he devoted towards my education. I learned a great deal from my time working in his lab that I continue to use to this day.

I have been funded by a NSF graduate research fellowship, a Presidential Scholarship from MIT, and through the NIH. These funding agencies have made this research possible and I would like to thank them for funding the fundamental science that has gone into this dissertation.

Outside of the world of chemistry I have had an exceptional group of friends and family that have supported me for the past five years. I must certainly thank my parents Rick and Karin Anderson for raising me and giving me the opportunity to pursue this career path. My parents, along with my brother Keith, have also been a fountain of unconditional love and support throughout my life and there is no possible way to thank them enough. My Ph.D. studies have kept me from seeing the rest of my family and friends as much as I would like and I hope that living in Chicago for the next few years will allow me to spend more time with them. I also would like to thank Don and Laura Holm for visiting frequently and supporting both Emily and myself; I could not ask for better in-laws.

Finally, and most importantly, I have to thank my wife Emily Anderson. Going through a Ph.D. is a challenging process and tests virtually every area of a person's life. 
Living with a person who is going through their Ph.D. is just as difficult, as we are frequently miserable humans to be around. Emily has supported my career for the past five years, moving across a continent and away from her family and friends to be with me. Although I hope that she has enjoyed some of the things we have been able to see and do in Boston and Los Angeles, I know that she has given a vast amount of herself for me to get this degree. There are no words sufficient to express my gratitude for having her support and love, but I look forward to using the rest of our lives together paying her back for it. 


\section{Abstract}

Threefold symmetric Fe phosphine complexes have been used to model the structural and functional aspects of biological $\mathrm{N}_{2}$ fixation by nitrogenases. Low-valent bridging Fe-S-Fe complexes in the formal oxidation states $\mathrm{Fe}(\mathrm{II}) \mathrm{Fe}(\mathrm{II}), \mathrm{Fe}(\mathrm{II}) / \mathrm{Fe}(\mathrm{I})$, and $\mathrm{Fe}(\mathrm{I}) / \mathrm{Fe}(\mathrm{I})$ have been synthesized which display rich spectroscopic and magnetic behavior. A series of cationic tris-phosphine borane (TPB) ligated Fe complexes have been synthesized and been shown to bind a variety of nitrogenous ligands including $\mathrm{N}_{2} \mathrm{H}_{4}, \mathrm{NH}_{3}$, and $\mathrm{NH}_{2}{ }^{-}$. These complexes are all high spin $S=3 / 2$ and display EPR and magnetic characteristics typical of this spin state. Furthermore, a sequential protonation and reduction sequence of a terminal amide results in loss of $\mathrm{NH}_{3}$ and uptake of $\mathrm{N}_{2}$. These stoichiometric transformations represent the final steps in potential $\mathrm{N}_{2}$ fixation schemes.

Treatment of an anionic $\mathrm{FeN}_{2}$ complex with excess acid also results in the formation of some $\mathrm{NH}_{3}$, suggesting the possibility of a catalytic cycle for the conversion of $\mathrm{N}_{2}$ to $\mathrm{NH}_{3}$ mediated by Fe. Indeed, use of excess acid and reductant results in the formation of seven equivalents of $\mathrm{NH}_{3}$ per Fe center, demonstrating Fe mediated catalytic $\mathrm{N}_{2}$ fixation with acids and protons for the first time. Numerous control experiments indicate that this catalysis is likely being mediated by a molecular species.

A number of other phosphine ligated Fe complexes have also been tested for catalysis and suggest that a hemi-labile Fe-B interaction may be critical for catalysis. Additionally, various conditions for the catalysis have been investigated. These studies further support the assignment of a molecular species and delineate some of the conditions required for catalysis. 
Finally, combined spectroscopic studies have been performed on a putative intermediate for catalysis. These studies converge on an assignment of this new species as a hydrazido(2-) complex. Such species have been known on group 6 metals for some time, but this represents the first characterization of this ligand on Fe. Further spectroscopic studies suggest that this species is present in catalytic mixtures, which suggests that the first steps of a distal mechanism for $\mathrm{N}_{2}$ fixation are feasible in this system. 


\section{Table of Contents}

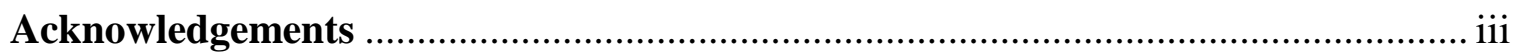

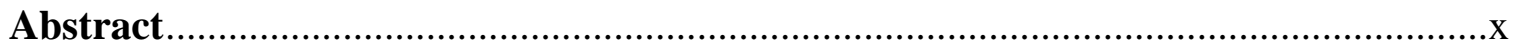

Table of Contents ............................................................................................ xii

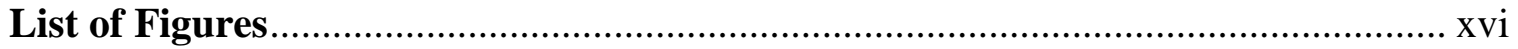

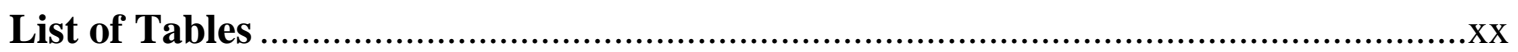

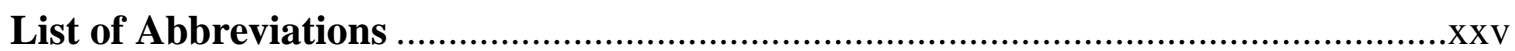

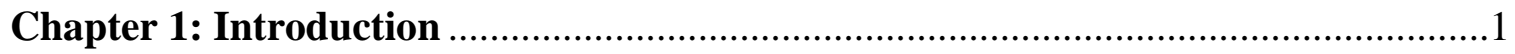

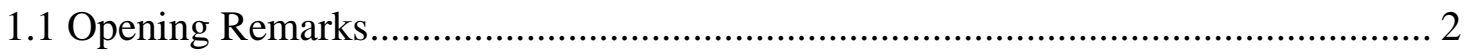

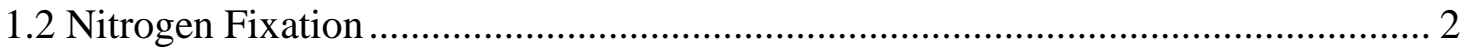

1.3 Unusually Low Valent Fe-S-Fe Complexes ...................................................... 8

1.4 Conversion of $\mathrm{FeNH}_{2}$ to $\mathrm{FeN}_{2}$ with Release of $\mathrm{NH}_{3}$....................................... 9

1.5 Catalytic Conversion of $\mathrm{N}_{2}$ to $\mathrm{NH}_{3}$ by an Fe Model Complex ........................... 11

1.6 The Effect of Ligand and Reaction Conditions on Fe Mediated $\mathrm{N}_{2}$ Fixation......... 13

1.7 Spectroscopic Characterization of the Putative Catalytic Intermediate [(TPB)Fe $\equiv \mathrm{N}$ -

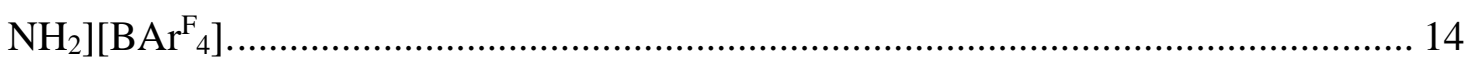

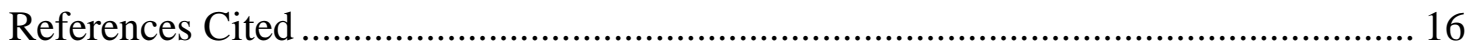

Chapter 2: Unusually Low Valent Fe-S-Fe Complexes........................................19

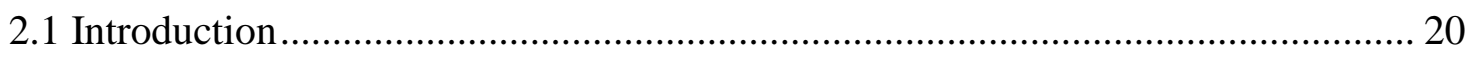

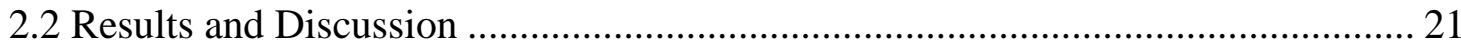

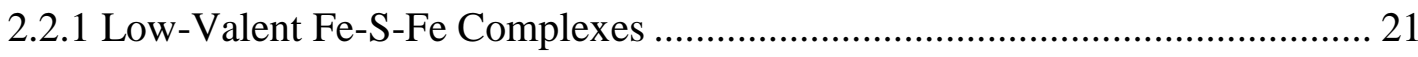

2.2.2 Reactivity with Small Molecules ............................................................... 32

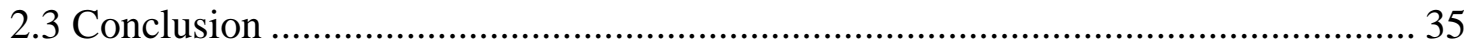

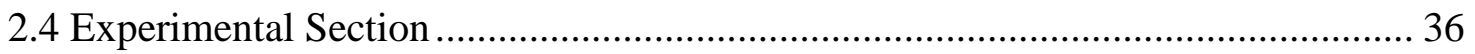

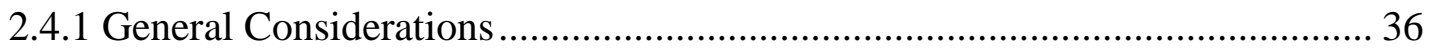

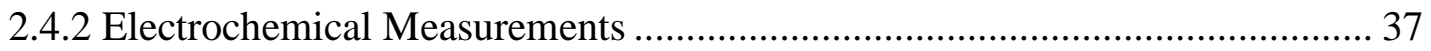

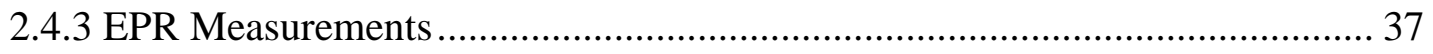

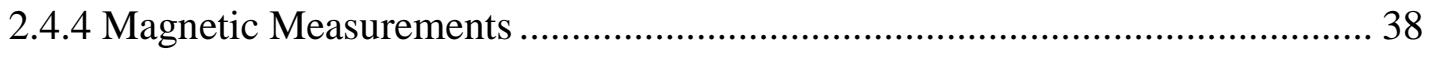

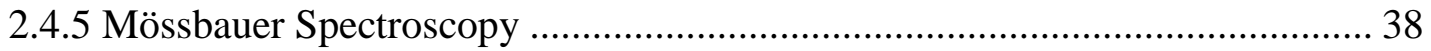




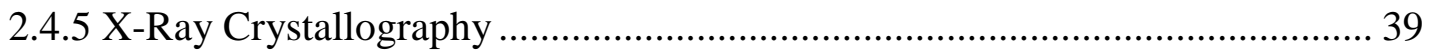

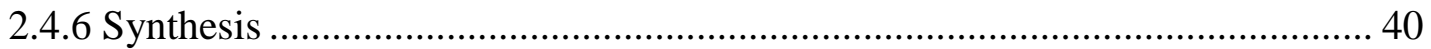

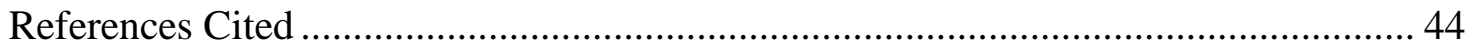

Chapter 3: Conversion of $\mathrm{FeNH}_{2}$ to $\mathrm{FeN}_{2}$ with Release of $\mathrm{NH}_{3} \ldots \ldots \ldots \ldots \ldots \ldots \ldots \ldots \ldots \ldots \ldots . . . .47$

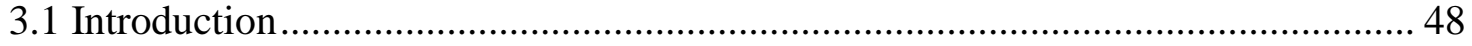

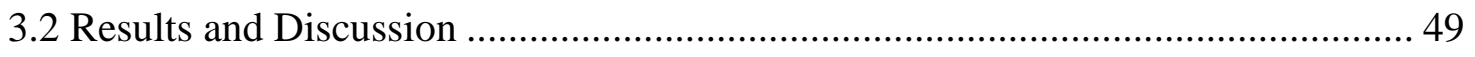

3.2.1 Formation of a Cationic Fe(I) Synthon.......................................................... 49

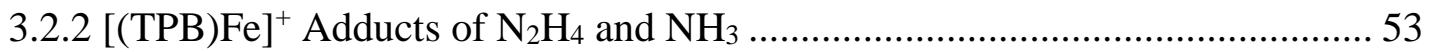

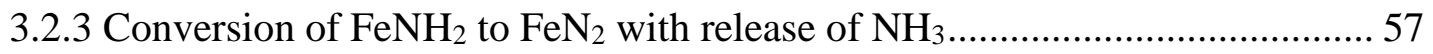

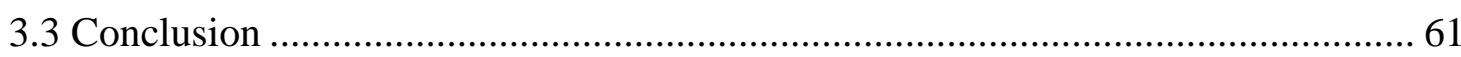

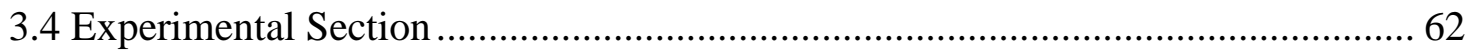

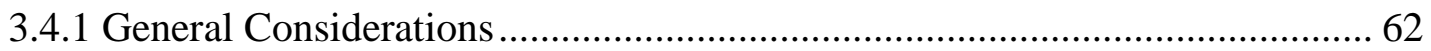

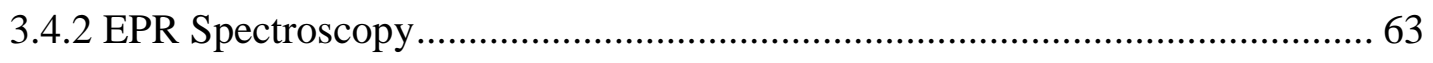

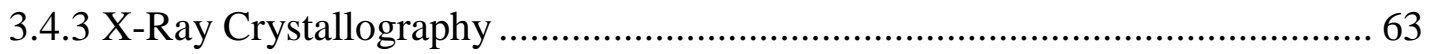

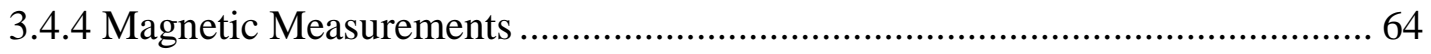

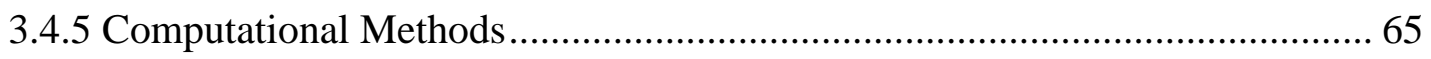

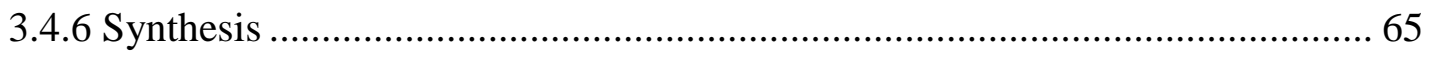

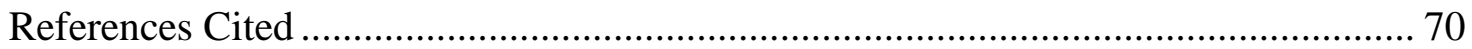

Chapter 4: Catalytic Conversion of $\mathrm{N}_{2}$ to $\mathrm{NH}_{3}$ by an Fe Model Complex..................74

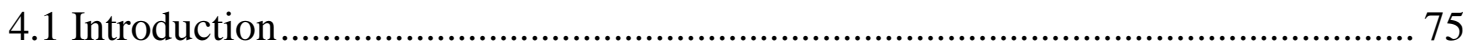

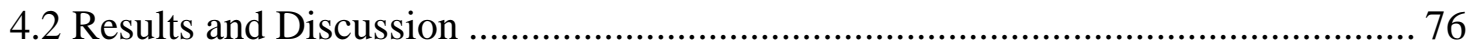

4.2.1 Initial Protonation Studies .......................................................................... 76

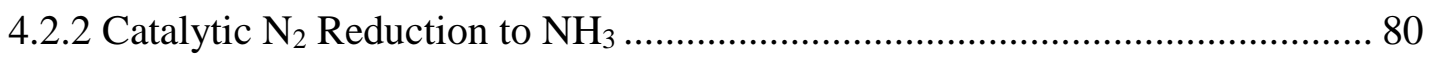

4.2.3 Catalyst Speciation..................................................................................... 85

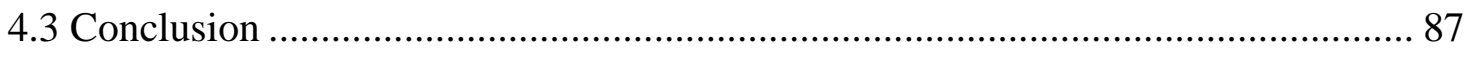

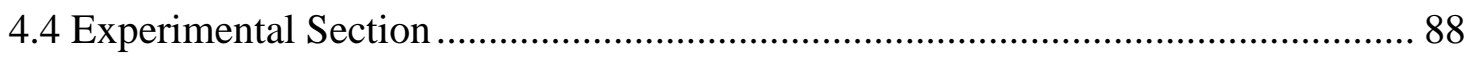

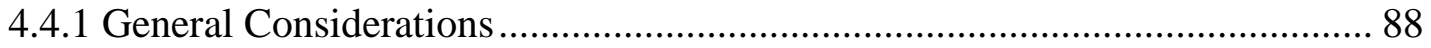

4.4.3 Standard Catalytic Protocol ............................................................................ 89

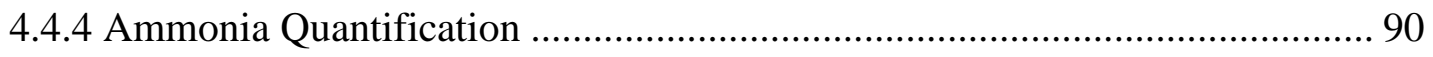

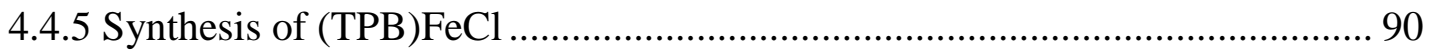

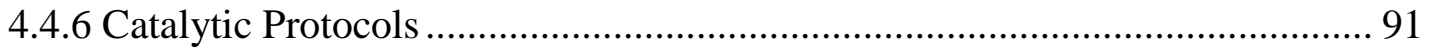


4.4.7 Other Reaction Protocols ............................................................................. 94

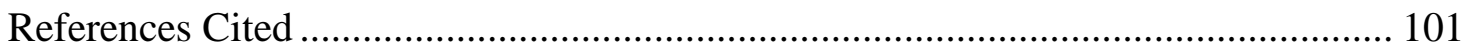

Chapter 5: The Effect of Ligand and Reaction Conditions on Fe Mediated $\mathrm{N}_{2}$

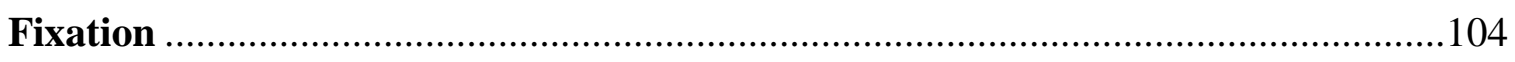

5.2 Results and Discussion .................................................................................. 106

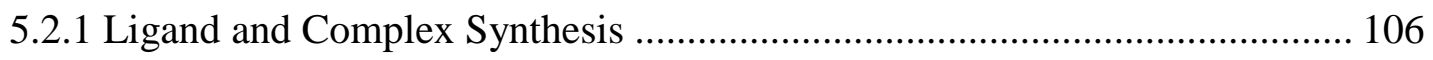

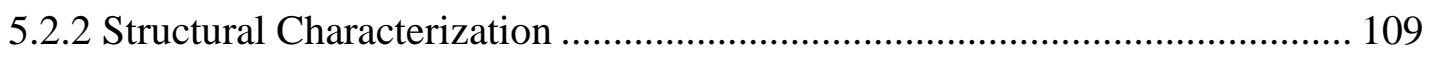

5.2.3 Comparison of Pre-Catalysts ................................................................... 112

5.2.4 Comparison of Catalytic Conditions.............................................................. 115

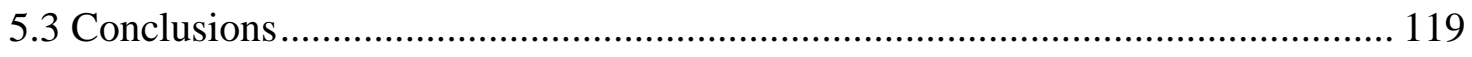

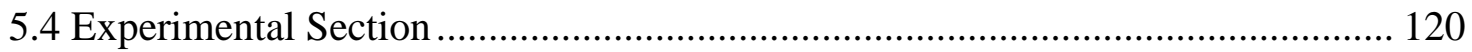

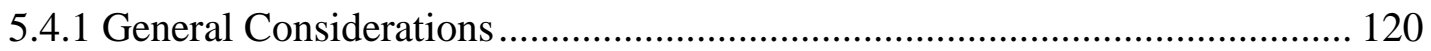

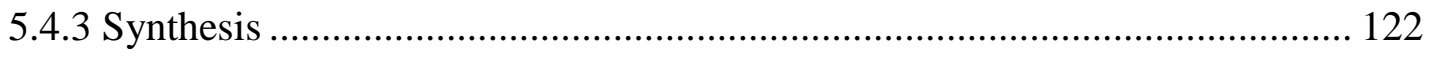

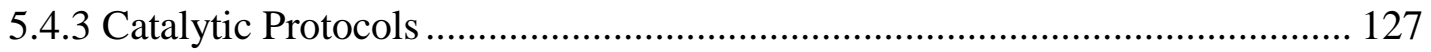

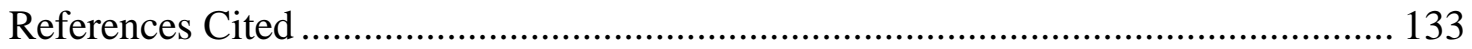

Chapter 6: Spectroscopic Characterization of the Putative Catalytic Intermediate

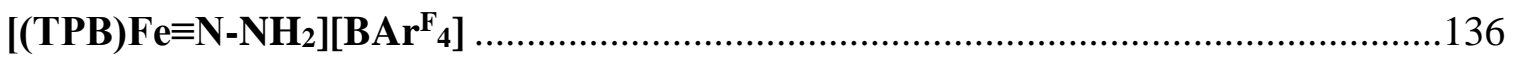

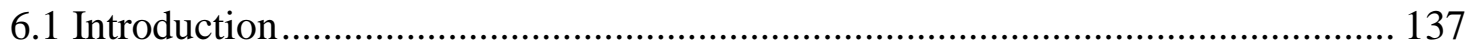

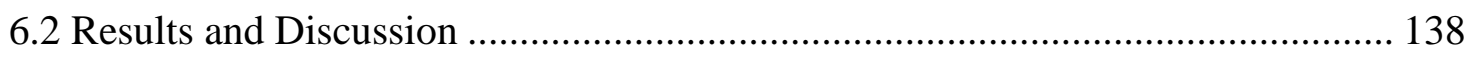

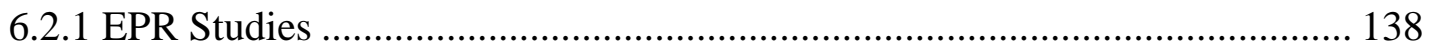

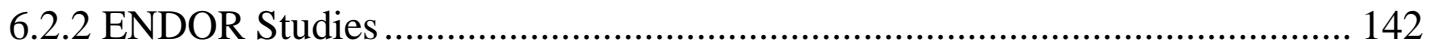

6.2.3 Fe K-Edge X-ray Absorption Spectroscopy Measurements ........................... 145

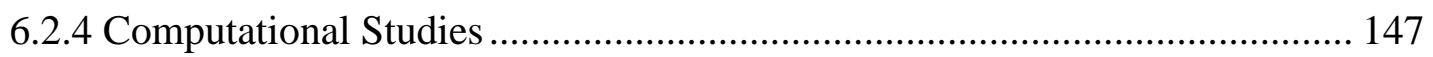

6.2.5 Decomposition Studies ………………………...................................... 150

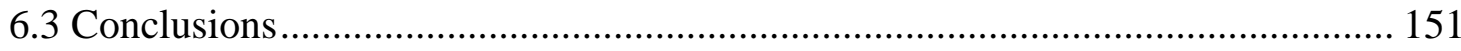

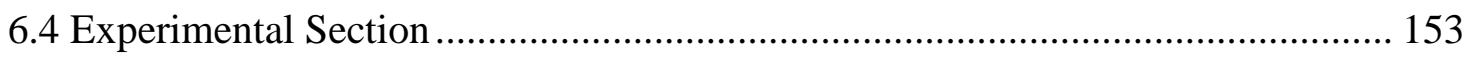

6.4.1 General Considerations ............................................................................... 153

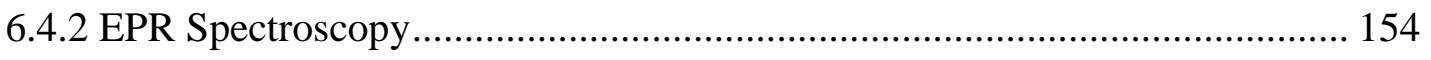

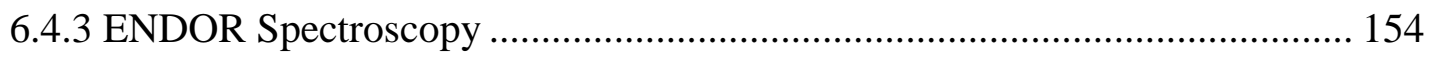

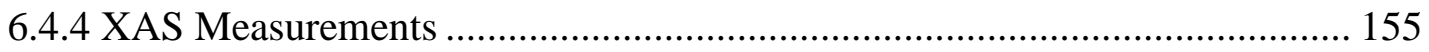

6.4.5 Computational Methods ................................................................................ 156 


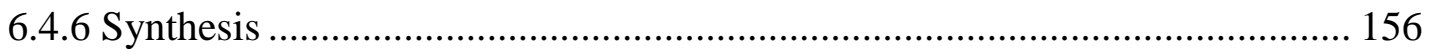

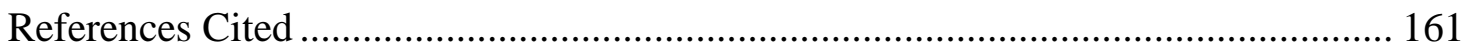

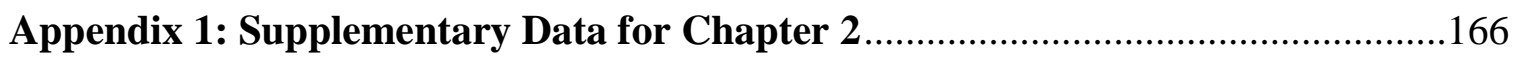

Appendix 2: Supplementary Data for Chapter 3 ……………………..................175

Appendix 3: Supplementary Data for Chapter 4 ………………………………....194

Appendix 4: Supplementary Data for Chapter 5 ……………………………....206

Appendix 5: Supplementary Data for Chapter 6 ………………….........................219 


\section{List of Figures}

Chapter 1: Introduction 1

Figure 1.1. X-Ray Diffraction (XRD) structure and chemical line drawing representation

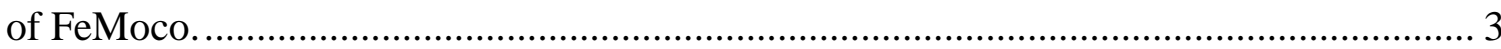

Figure 1.2. Mo complexes that mediate the catalytic reduction of $\mathrm{N}_{2}$ to $\mathrm{NH}_{3} \ldots \ldots \ldots \ldots \ldots . . . . . .4$ Figure 1.3. Qualitative d-orbital splitting diagrams and examples of complexes that feature pseudo-tetrahedral and trigonal bipyramidal geometries stabilizing $\pi$-bases and $\pi$ acids respectively. Note that Fe-Si or Fe-B bonding orbitals may be near or within the dmanifold, but are not shown for reasons of clarity.

Figure 1.4. Generation of a di-protonated intermediate which partially decomposes to an

$\mathrm{NH}_{3}$ complex 14

Chapter 2: Unusually Low Valent Fe-S-Fe Complexes. .19

Figure 2.1. CV of 2.1.

Figure 2.2. XRD structures of complexes 2.1 (A), 2.2 (B), and 2.3 (C) with ellipsoids at $50 \%$ and hydrogens omitted for clarity.....

Figure 2.3. Variable temperature magnetic susceptibility measurements on complexes

2.1-2.3. 25

Figure 2.4. (A) Near-IR spectrum of complex 2.2. (B) 4 K X-band EPR spectrum of 2.2.

Figure 2.5. $80 \mathrm{~K}$ Mössbauer spectra of solid samples of complexes 2.1-2.3.................. 29

Figure 2.6. Qualitative d-orbital splitting diagrams illustrating the coupling in 2.1-2.3. . 30 Figure 2.7. XRD structures of the cores of complexes 2.4 and 2.5 with ellipsoids at $50 \%$.

Figure 2.8. (A) CV of 2.5 at $10 \mathrm{mV} / \mathrm{s}$. (B) CV's of 2.5 at differing scan rates. (C) $\mathrm{CV}$ of 2.5 at $10 \mathrm{mV} / \mathrm{s}$ with the listed concentrations of $p$-toluenesulfonic acid. 34 
Figure 3.1. XRD structures of complexes 3.1 and 3.2 with ellipsoids at 50\%. Most hydrogens and counterions have been omitted for clarity 50

Figure 3.2. DFT optimized geometries at the B3LYP/6-31G(d) level of theory for (A) 3.2 and $(\mathrm{B})\left[\left(\mathrm{Me}_{2} \mathrm{PhP}\right)_{3} \mathrm{Fe}\right]^{+}$

Figure 3.3. XRD structures of complexes 3.3 and 3.4 with $\mathrm{C}-\mathrm{H}$ hydrogens and counterions omitted for clarity. 54

Figure 3.4. Reaction kinetics of the thermolysis of 3.3 to 3.4 at $60{ }^{\circ} \mathrm{C}$ in a $6: 1$ mixture of $\mathrm{C}_{6} \mathrm{D}_{6}: \mathrm{THF}-d_{8}$. .55

Figure 3.5. XRD structures of complexes 3.5 and 3.6 with $\mathrm{C}-\mathrm{H}$ hydrogens omitted for clarity. 58

Figure 3.6. Low-temperature X-Band EPR spectra for complexes 3.1-3.6. 59

Chapter 4: Catalytic Conversion of $\mathrm{N}_{2}$ to $\mathrm{NH}_{3}$ by an Fe Model Complex..... .74

Figure 4.1. UV-Visible spectrum of the indophenol dye generated from $\mathrm{NH}_{3}$ 81

Figure 4.2. ${ }^{1} \mathrm{H}$ NMR spectra of $\left[{ }^{14} \mathrm{NH}_{4}\right][\mathrm{Cl}]$ and $\left[{ }^{15} \mathrm{NH}_{4}\right][\mathrm{Cl}]$ in DMSO- $d_{6}$ obtained from correspondingly labeled $\mathrm{N}_{2}$ gas via catalytic reduction with complex 4.1 using the standard catalytic protocol described in the text. 83

Chapter 5: The Effect of Ligand and Reaction Conditions on Fe Mediated $\mathrm{N}_{2}$

Fixation .104

Figure 5.1. Complexes synthesized and studied towards $\mathrm{N}_{2}$ reduction. 106 Figure 5.2. XRD structures of complexes 5.1, 5.3, 5.9, 5.10, and 5.11 with ellipsoids at $50 \%$ and hydrogens and counterions omitted for clarity. 110

\section{Chapter 6: Spectroscopic Characterization of the Putative Catalytic Intermediate

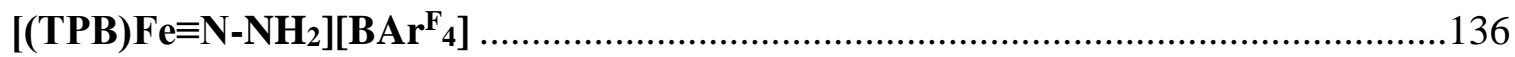

Figure 6.1. X-Band EPR spectra of: (A) Complex 4.1 and (B) (TPB)FeN ${ }_{2} \mathrm{SiMe}_{3} \ldots \ldots . . .139$ Figure 6.2. X-Band EPR spectra of the species generated from adding excess $\mathrm{HBAr}_{4} \cdot 2$ $\mathrm{Et}_{2} \mathrm{O}$ to 4.1. (A) Scan from 2800 to 2500 gauss (B) Scan from 0 to $4000 \mathrm{G}$. 140 
Figure 6.3. X-Band EPR spectra of (A) 6.1, (B) $\left[(\mathrm{TPB}) \mathrm{Fe} \equiv \mathrm{N}\left(\mathrm{C}_{6} \mathrm{H}_{4} \mathrm{OMe}\right)\right]^{+}$, and (C) $[(\mathrm{TPB}) \mathrm{Fe} \equiv \mathrm{NAd}]\left[\mathrm{BAr}_{4}{ }_{4}\right]$

Figure 6.4. (A) Proton CW-ENDOR at $12.4 \mathrm{kG}$ and $35.24 \mathrm{GHz}$ of 4.1 (black) and 6.1 (red). (B) $35.01 \mathrm{GHz} \mathrm{CW}-\mathrm{ENDOR}$ of 6.1 at the variable fields shown. 143

Figure 6.5. 35.0 GHz Davies ${ }^{14} \mathrm{~N}$ and ${ }^{15} \mathrm{~N}$ ENDOR spectra from 4.1 and 6.1 acquired at $g$ $=2.005$ 144

Figure 6.6. (A) EXAFS data. (B) Fourier transform of the EXAFS data. 146 Figure 6.7. (A) Computed geometry for $\left[(\mathrm{TPB}) \mathrm{Fe} \equiv \mathrm{N}-\mathrm{NH}_{2}\right]^{+}$and (B) spin density plot for $\left[(\mathrm{TPB}) \mathrm{Fe} \equiv \mathrm{N}-\mathrm{NH}_{2}\right]^{+}$ 148

Figure 6.8. $77 \mathrm{~K} \mathrm{X}$-Band EPR spectrum comparing the addition of acid to 4.1 at different temperatures and the effect of thawing this sample to different temperatures. 151

Appendix 1: Supplementary Data for Chapter 2 .166

Figure A1.1. XRD Structure of $\left(\left(\mathrm{PhBP}_{3}\right) \mathrm{Fe}\right)\left(\mu-\eta^{1}: \eta^{1}-\mathrm{N}_{2} \mathrm{H}_{4}\right)\left(\mu-\eta^{2}: \eta^{2}-\mathrm{N}_{2} \mathrm{H}_{2}\right)\left(\left(\mathrm{PhBP}_{2} \mathrm{PS}\right) \mathrm{Fe}\right)$ (2.4) with ellipsoids at 50\% and $\mathrm{C}-\mathrm{H}$ hydrogens and solvents removed for clarity. 171 Figure A1.2. XRD Structure of $\left(\left(\mathrm{PhBP}_{3}\right) \mathrm{Fe}(\mathrm{CO})\right)_{2}(\mu-\mathrm{S})(2.5)$ with ellipsoids at $50 \%$ and hydrogens and solvents removed for clarity. 173

\section{Appendix 2: Supplementary Data for Chapter 3}

Figure A2.1. Crystal Structure for (TPB)FeOH (3.6) with ellipsoids at 50\% and C-H hydrogens omitted for clarity. 182

Figure A2.2. NMR traces of the monitored decomposition of 3.3 to 3.4 ..................... 183

Figure A2.3. Titration of THF into a $4 \mathrm{~mL}$ ethereal solution of 3.2 ............................. 184

Figure A2.4. MO and spin density diagram of [(TPB)Fe $]^{+}(3.2)$ optimized at the B3LYP/6-31G(d) level. 185

Figure A2.5. MO diagram addressing the T-shaped distortion in 3.2 ......................... 186

Figure A2.6. Variable Temperature Magnetic data for 3.2-3.5. 187

\section{Appendix 3: Supplementary Data for Chapter 4}

Figure A3.1. Crystal Structure for (TPB)FeCl with ellipsoids at 50\% and C-H hydrogens omitted for clarity. 196 
Figure A3.2. ${ }^{1} \mathrm{H}$ NMR spectrum of the reaction mixture following protonation of $\left[(\mathrm{TPB}) \mathrm{Fe}\left(\mathrm{N}_{2}\right)\right][\mathrm{Na}(12$-crown-4) 2$]$ compared with an authentic sample of

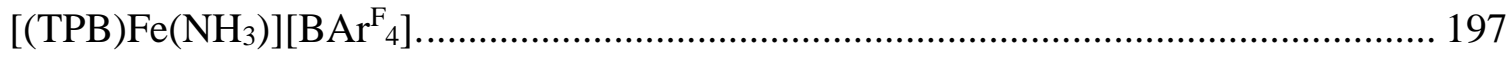

Figure A3.3. Calibration Curves for $\mathrm{NH}_{3}$ and $\mathrm{N}_{2} \mathrm{H}_{4} \mathrm{UV}-\mathrm{V}$ is quantification. ................ 198 Figure A3.4. IR spectra of addition of 10 equiv $\mathrm{HBAr}^{\mathrm{F}} \cdot 2 \mathrm{Et}_{2} \mathrm{O}$ to $\left[(\mathrm{TPB}) \mathrm{Fe}\left(\mathrm{N}_{2}\right)\right]\left[\mathrm{Na}\left(12\right.\right.$-crown-4) 2 , followed by 12 equiv $\mathrm{KC}_{8}$.

Figure A3.5. ${ }^{31} \mathrm{P}\left\{{ }^{1} \mathrm{H}\right\}$ NMR spectra of addition of 10 equiv $\mathrm{HBAr}_{4} \cdot 2 \mathrm{Et}_{2} \mathrm{O}$ to $\left[(\mathrm{TPB}) \mathrm{Fe}\left(\mathrm{N}_{2}\right)\right]\left[\mathrm{Na}\left(12\right.\right.$-crown-4) 2 , followed by 12 equiv $\mathrm{KC}_{8}$

\section{Appendix 5: Supplementary Data for Chapter 6}

Figure A5.1. $77 \mathrm{~K} \mathrm{EPR} \mathrm{spectrum} \mathrm{of} \mathrm{the} \mathrm{addition} \mathrm{of} 1$ equivalent of $\mathrm{HBAr}_{4} \cdot 2 \mathrm{Et}_{2} \mathrm{O}$ to

complex 4.1

Figure A5.2. $10 \mathrm{~K}$ EPR spectrum of the addition of 10 equivalents of $\mathrm{HBAr}_{4} \cdot 2 \mathrm{Et}_{2} \mathrm{O}$ to complex 4.1 followed by the addition of 20 equivalents of $\mathrm{KC}_{8}$.

Figure A5.3. M06L/TZVP(Fe)/SVP(P,N,B)/6-31G(C, H) optimized structure of $[(\mathrm{TPB}) \mathrm{Fe}(\mathrm{HNNH})]^{+}$.

Figure A5.4. M06L/TZVP(Fe)/SVP(P,N,B)/6-31G(C, H) optimized structure of $[(\mathrm{TPB}) \mathrm{Fe}(\mathrm{HNNH})]^{+}$with spin density plotted with an isovalue of 0.006 . 223 


\section{List of Tables}

Chapter 2: Unusually Low Valent Fe-S-Fe Complexes.............................................19

Table 2.1. Selected metrics for complexes 2.1, 2.2, and 2.3........................................ 24

Table 2.2. Simulation parameters for complexes 2.1, 2.2, and 2.3 for the fits shown in

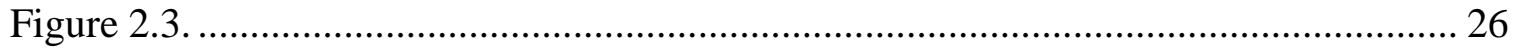

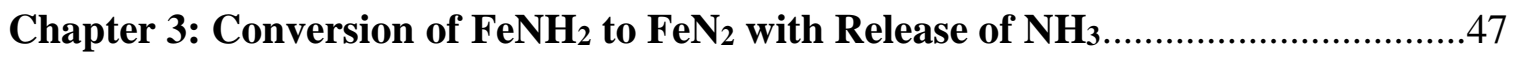

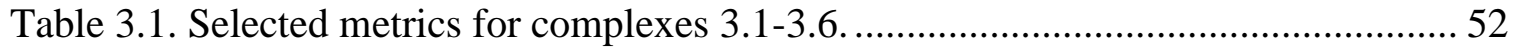

Chapter 4: Catalytic Conversion of $\mathrm{N}_{2}$ to $\mathrm{NH}_{3}$ by an Fe Model Complex.................74

Table 4.1. Catalytic runs using the standard conditions described in the text with any

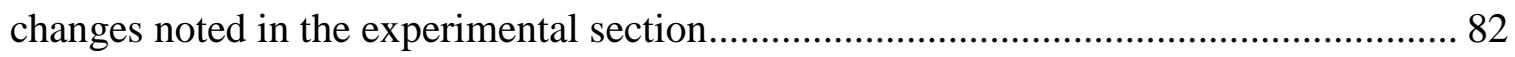

\section{Chapter 5: The Effect of Ligand and Reaction Conditions on Fe Mediated N2}

Fixation

Table 5.1. Selected bond lengths $(\AA)$ and $\tau_{4}$ values for complexes 5.1, 5.3, 5.9, 5.10, and

5.11

Table 5.2. $\mathrm{N}_{2}$ reduction with phosphine Fe complexes.

Table 5.3. Effect of different solvents on the catalytic reduction of $\mathrm{N}_{2}$ to $\mathrm{NH}_{3}$ by complex

4.1.

Table 5.4. Effect of different reductants on the catalytic reduction of $\mathrm{N}_{2}$ to $\mathrm{NH}_{3}$ by

complex 4.1

Table 5.5. Effect of different acids on the catalytic reduction of $\mathrm{N}_{2}$ to $\mathrm{NH}_{3}$ by complex 4.1

Chapter 6: Spectroscopic Characterization of the Putative Catalytic Intermediate $\left[(\mathrm{TPB}) \mathrm{Fe} \equiv \mathrm{N}-\mathrm{NH}_{2}\right]\left[\mathrm{BAr}^{\mathrm{F}}\right]$

Table 6.1. Extended X-ray absorption fine structure (EXAFS) curve-fitting results ..... 147 
Appendix 1: Supplementary Data for Chapter 2 ……………………………........166

Table A1.1. Crystal data and structure refinement for $\left(\left(\mathrm{PhBP}_{3}\right) \mathrm{Fe}\right)_{2}(\mu-\mathrm{S})(2.1) \ldots \ldots \ldots . . . .167$

Table A1.2. Crystal data and structure refinement for $\left[\left(\left(\mathrm{PhBP}_{3}\right) \mathrm{Fe}\right)_{2}(\mu-\mathrm{S})\right][\mathrm{Na}(12$-crown-

4) 2 ] (2.2). 168

Table A1.3. Crystal data and structure refinement for $\left[\left(\left(\mathrm{PhBP}_{3}\right) \mathrm{Fe}\right)_{2}(\mu-\mathrm{S})\right][\mathrm{Na}(12$-crown-

$\left.4)_{2}\right]_{2}(2.3)$ 169

Table A1.4. Crystal data and structure refinement for $\left(\left(\mathrm{PhBP}_{3}\right) \mathrm{Fe}\right)\left(\mu-\eta^{1}: \eta^{1}-\mathrm{N}_{2} \mathrm{H}_{4}\right)\left(\mu-\eta^{2}: \eta^{2}\right.$ $\left.\mathrm{N}_{2} \mathrm{H}_{2}\right)\left(\left(\mathrm{PhBP}_{2} \mathrm{PS}\right) \mathrm{Fe}\right)(2.4)$. 170

Table A1.5. Crystal data and structure refinement for $\left(\left(\mathrm{PhBP}_{3}\right) \mathrm{Fe}(\mathrm{CO})\right)_{2}(\mu-\mathrm{S})(2.5) \ldots 172$

\section{Appendix 2: Supplementary Data for Chapter 3} .175

Table A2.1. Crystal data and structure refinement for (TPB)FeMe (3.1)....................... 176

Table A2.2. Crystal data and structure refinement for [(TPB)Fe][BAr $\left.{ }_{4}{ }_{4}\right](3.2) \ldots \ldots \ldots \ldots . .177$

Table A2.3. Crystal data and structure refinement for [(TPB) $\left.\mathrm{Fe}\left(\mathrm{N}_{2} \mathrm{H}_{4}\right)\right]\left[\mathrm{BAr}{ }^{\mathrm{F}}{ }_{4}\right](3.3)$. . 178

Table A2.4. Crystal data and structure refinement for [(TPB) $\left.\mathrm{Fe}\left(\mathrm{NH}_{3}\right)\right]\left[\mathrm{BAr}_{4}{ }_{4}\right]$ (3.4)... 179

Table A2.5. Crystal data and structure refinement for (TPB)FeNH $\mathrm{F}_{2}$ (3.5) .................... 180

Table A2.6. Crystal data and structure refinement for (TPB)FeOH (3.6) ...................... 181

Table A2.7. Product quantification for the decomposition of 3.3 to 3.4 ........................ 183

Table A2.8. Simulation parameters for the variable temperature data for complexes 3.2-

3.5 . 188

Table A2.9. B3LYP/6-31G(d) DFT Optimized coordinates [ $\AA$ ] for [(TPB)Fe $]^{+}$(3.2).. 189

Table A2.10. B3LYP/6-31G(d) DFT Optimized coordinates $[\AA]$ for $\left[\left(\mathrm{Me}_{2} \mathrm{PhP}\right)_{3} \mathrm{Fe}\right]^{+} .192$

\section{Appendix 3: Supplementary Data for Chapter 4}

Table A3.1. Crystal data and structure refinement for (TPB) $\mathrm{FeCl}$

Table A3.2. $\mathrm{N}_{2}$ reduction catalysis absorption data using [(TPB)Fe( $\left.\left.\mathrm{N}_{2}\right)\right][\mathrm{Na}(12$-crown-

4) 2 . 201

Table A3.3. $\mathrm{N}_{2}$ reduction catalysis absorption data using [(TPB)Fe][BAr ${ }_{4}{ }^{2}$. 201 
Table A3.4. Attempted $\mathrm{N}_{2}$ reduction catalysis absorption data using (TPB)( $\mu$ -

$\mathrm{H}) \mathrm{Fe}(\mathrm{H})\left(\mathrm{N}_{2}\right)$. 202

Table A3.5. Attempted $\mathrm{N}_{2}$ reduction catalysis absorption data using $\mathrm{FeCl}_{2} \cdot 1.5$ THF. .. 202

Table A3.6. Attempted $\mathrm{N}_{2}$ reduction catalysis absorption data using $\mathrm{FeCl}_{3}$................ 202

Table A3.7. Attempted $\mathrm{N}_{2}$ reduction catalysis absorption data using $\mathrm{Fe}(\mathrm{CO})_{5} \ldots \ldots \ldots \ldots . . . .202$

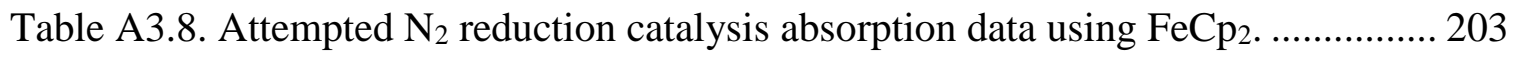

Table A3.9. Attempted $\mathrm{N}_{2}$ reduction catalysis absorption data in the absence of an $\mathrm{Fe}$

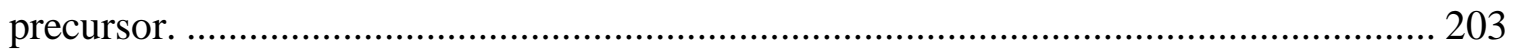

Table A3.10. Attempted $\mathrm{N}_{2}$ reduction catalysis absorption data using (TPB)FeCl....... 203

Table A3.11. Attempted $\mathrm{N}_{2}$ reduction catalysis absorption data using (TPB)FeN $\mathrm{N}_{2} \ldots . . .203$

Table A3.12. Attempted $\mathrm{N}_{2}$ reduction catalysis absorption data using

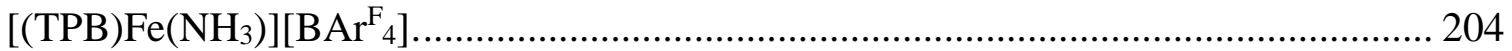

Table A3.13. Attempted $\mathrm{N}_{2}$ reduction catalysis absorption data using

$\left[(\mathrm{TPB}) \mathrm{Fe}\left(\mathrm{N}_{2} \mathrm{H}_{4}\right)\right]\left[\mathrm{BAr}_{4}{ }^{\mathrm{F}}\right]$. 204

Table A3.14. Absorption data for a standard catalytic run in which $\mathrm{N}_{2} \mathrm{H}_{4}$ was added prior

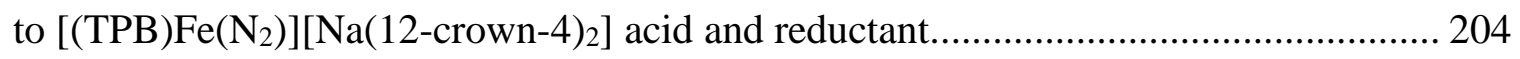

Table A3.15. Absorption and gas chromatograph integration data for standard catalytic runs. 204

Table A3.16. Gas chromatograph $\mathrm{H}_{2}$ yields for runs in the absence of an Fe precursor. 205

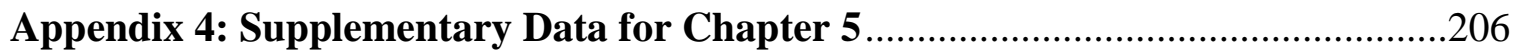

Table A4.1. Crystal data and structure refinement for $\left[\left(\mathrm{TPB}^{\mathrm{Cy}}\right) \mathrm{Fe}\left(\mathrm{N}_{2}\right)\right][\mathrm{Na}(12$-crown-4) 2$]$

Table A4.2. Crystal data and structure refinement for $\left[(\mathrm{DPB}) \mathrm{Fe}\left(\mathrm{N}_{2}\right)\right][\mathrm{K}(\mathrm{Bz} 15$-crown-5)2] 208

Table A4.3. Crystal data and structure refinement for $\left(\mathrm{TPB}^{\mathrm{Cy}}\right) \mathrm{FeCl}(5.9)$................... 209

Table A4.4. Crystal data and structure refinement for $\left(\mathrm{TPB}^{\mathrm{Ph}}\right) \mathrm{FeCl}$........................ 210

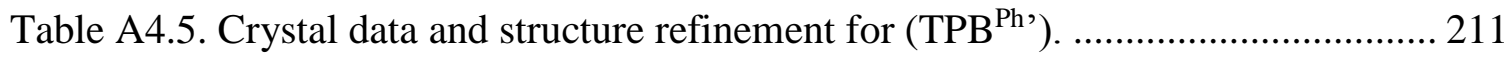

Table A4.6. $\mathrm{N}_{2}$ reduction catalysis absorption data using [ $\left.\left(\mathrm{TPB}^{\mathrm{Cy}}\right) \mathrm{Fe}\left(\mathrm{N}_{2}\right)\right][\mathrm{Na}(12$-crown-

4) 2 ] (5.1). 
Table A4.7. $\mathrm{N}_{2}$ reduction catalysis absorption data using [ $\left.\left(\mathrm{TPB}^{\mathrm{Ph}}\right) \mathrm{Fe}\left(\mathrm{N}_{2}\right)\right][\mathrm{Na}(12$-crown-

$\left.4)_{2}\right](5.2)$.

Table A4.8. Attempted $\mathrm{N}_{2}$ reduction catalysis absorption data using

$\left[(\mathrm{DPB}) \mathrm{Fe}\left(\mathrm{N}_{2}\right)\right]\left[\mathrm{K}(\mathrm{Bz} 15-\mathrm{crown}-5)_{2}\right](5.3)$.

Table A4.9. Attempted $\mathrm{N}_{2}$ reduction catalysis absorption data using

$\left[\left(\mathrm{SiP}^{\mathrm{iPr}}\right) \mathrm{Fe}\left(\mathrm{N}_{2}\right)\right]\left[\mathrm{Na}(12 \text {-crown-4) })_{2}\right]$.

Table A4.10. Attempted $\mathrm{N}_{2}$ reduction catalysis absorption data using

$\left[\mathrm{PhBP}_{3}^{\mathrm{iPr}}{ }_{3} \mathrm{FeN}_{2} \mathrm{MgCl} \cdot 2 \mathrm{THF}\right.$

Table A4.11. Attempted $\mathrm{N}_{2}$ reduction catalysis absorption data using

$\left(\mathrm{C}_{2} \mathrm{H}_{4} \mathrm{PCy}\right)_{3} \mathrm{PFe}\left(\mathrm{N}_{2}\right)$.

Table A4.12. Attempted $\mathrm{N}_{2}$ reduction catalysis absorption data using $\mathrm{Fe}(\mathrm{depe})_{2} \mathrm{~N}_{2} \ldots \ldots .214$

Table A4.13. $\mathrm{N}_{2}$ reduction catalysis absorption data using $\mathrm{P}_{2} \mathrm{O}$.............................. 214

Table A4.14. $\mathrm{N}_{2}$ reduction catalysis absorption data using DME. ............................. 214

Table A4.15. $\mathrm{N}_{2}$ reduction catalysis absorption data using $\mathrm{Bu}_{2} \mathrm{O}$............................. 214

Table A4.16. Attempted $\mathrm{N}_{2}$ reduction catalysis absorption data using toluene............. 215

Table A4.17. $\mathrm{N}_{2}$ reduction catalysis absorption data using 6:1 toluene: $\mathrm{Et}_{2} \mathrm{O}$............. 215

Table A4.18. Attempted $\mathrm{N}_{2}$ reduction catalysis absorption data using $\mathrm{CoCp}{ }_{2} \ldots \ldots \ldots . . .215$

Table A4.19. Attempted $\mathrm{N}_{2}$ reduction catalysis absorption data using $\mathrm{CrCp}^{*}{ }_{2}$........... 215

Table A4.20. Attempted $\mathrm{N}_{2}$ reduction catalysis absorption data using $\mathrm{NaC}_{10} \mathrm{H}_{8} \ldots \ldots \ldots .216$

Table A4.21. Attempted $\mathrm{N}_{2}$ reduction catalysis absorption data using $\mathrm{K}$ as the reductant.

216

Table A4.22. Attempted $\mathrm{N}_{2}$ reduction catalysis absorption data using $\mathrm{MgC}_{14} \mathrm{H}_{10} \cdot 3 \mathrm{THF}$. 216

Table A4.23. $\mathrm{N}_{2}$ reduction catalysis absorption data using $\mathrm{Na} / \mathrm{Hg}$. 216

Table A4.24. Attempted $\mathrm{N}_{2}$ reduction catalysis absorption data using

trifluoromethanesulfonic acid.

Table A4.25. Attempted $\mathrm{N}_{2}$ reduction catalysis absorption data using anhydrous $\mathrm{HCl} .217$

Table A4.26. Attempted $\mathrm{N}_{2}$ reduction catalysis absorption data using

[Lutidinium] $\left[\mathrm{BAr}^{\mathrm{F}}{ }_{4}\right]$ as the acid.

Table A4.27. $\mathrm{N}_{2}$ reduction catalysis absorption data using [2,6-dimethylanilinium][OTf]. 
Table A4.28. $\mathrm{N}_{2}$ reduction catalysis absorption data using [2,6-

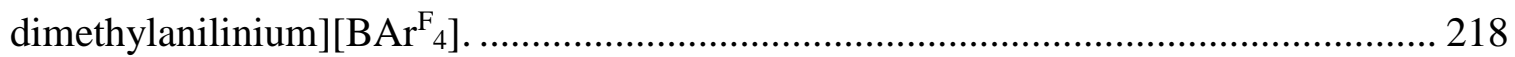

Table A4.29. Attempted $\mathrm{N}_{2}$ reduction catalysis at RT absorption data......................... 218

Table A4.30. $\mathrm{N}_{2}$ reduction catalysis absorption data using [2,6-

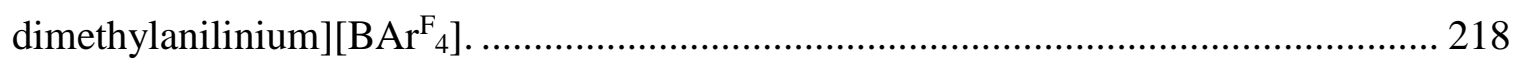

Appendix 5: Supplementary Data for Chapter 6 …………………………….....219

Table A5.1. M06L/TZVP(Fe)/SVP(P,N,B)/6-31G(C, H) DFT Optimized coordinates [Å]

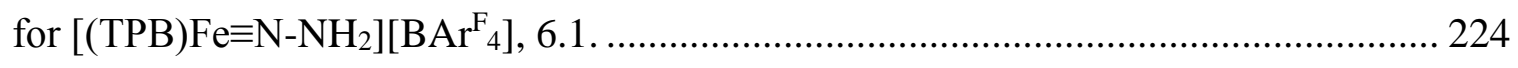

Table A5.2. M06L/TZVP(Fe)/SVP(P,N,B)/6-31G(C,H) DFT Optimized coordinates [Å]

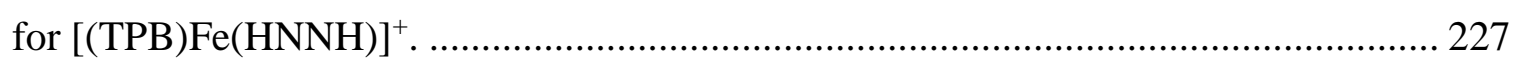

Table A5.3. DFT Optimized coordinates energies $[\mathrm{kcal} / \mathrm{mol}]$ for $\left[(\mathrm{TPB}) \mathrm{Fe}\left(\mathrm{N}_{2} \mathrm{H}_{2}\right)\right]^{+}$

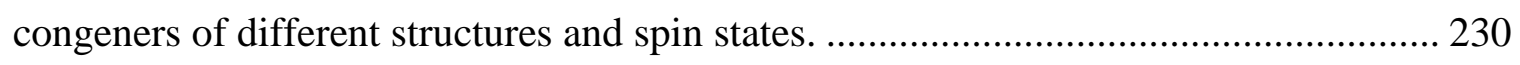




\section{List of Abbreviations}

\begin{tabular}{|c|c|}
\hline$A^{X}$ & Hyperfine coupling constant due to nucleus $\mathrm{X}$ \\
\hline Ad & 1-Adamantyl \\
\hline Anal & Analysis \\
\hline atm & Atmosphere \\
\hline Avg & Average \\
\hline $\mathrm{BAr}_{4}{ }^{-}$ & $\mathrm{B}\left(3,5-\mathrm{C}_{6} \mathrm{H}_{3}\left(\mathrm{CF}_{3}\right)_{2}\right)_{4}^{-}$ \\
\hline br & broad \\
\hline $\mathrm{Bu}$ & n-Butyl \\
\hline $\mathrm{ca}$ & Circa \\
\hline calcd & Calculated \\
\hline $\mathrm{CCD}$ & Charge-coupled device \\
\hline $\mathrm{cm}$ & Centimeter \\
\hline $\mathrm{cm}^{-1}$ & Wave number \\
\hline $\mathrm{Cp}$ & Cyclopentadienyl \\
\hline $\mathrm{Cp}^{*}$ & Pentamethylcyclopentadienyl \\
\hline CSD & Cambridge Structural Database \\
\hline $\mathrm{CV}$ & Cyclic voltammogram \\
\hline Cy & Cyclohexyl \\
\hline $\mathrm{d}$ & Doublet or deuterium \\
\hline dd & Doublet of doublets \\
\hline$d_{x}$ & Compound with $\mathrm{x}$ deuterium atoms \\
\hline depe & 1,2-Bis(diethylphosphino)ethane \\
\hline
\end{tabular}




\begin{tabular}{|c|c|}
\hline DFT & Density Functional Theory \\
\hline DME & 1,2-dimethoxyethane \\
\hline dmpe & 1,2-Bis(dimethylphosphino)ethane \\
\hline DMSO & Dimethylsulfoxide \\
\hline $\mathrm{e}$ & Electron \\
\hline ENDOR & Electron nuclear double resonance \\
\hline EPR & Electron paramagnetic resonance \\
\hline Et & Ethyl \\
\hline eq & Equivalents \\
\hline equiv & Equivalents \\
\hline EXAFS & Extended X-ray absorption fine structure \\
\hline $\mathrm{eV}$ & Electron volt \\
\hline $\mathrm{F}$ & Structure factor \\
\hline $\mathrm{Fc}$ & Ferrocene \\
\hline FeMoco & Iron-Molybdenum cofactor \\
\hline G & Gauss \\
\hline g & Gram \\
\hline$g$ & Electron g-factor \\
\hline GC & Gas chromatography \\
\hline $\mathrm{GHz}$ & Gigahertz \\
\hline $\mathrm{H}_{\mathrm{ab}}$ & Electronic coupling parameter for mixed valent complexes \\
\hline $\mathrm{Hz}$ & Hertz \\
\hline Inc & Incorporated \\
\hline
\end{tabular}




\begin{tabular}{|c|c|}
\hline $\mathrm{iPr}$ & Isopropyl \\
\hline IR & Infrared \\
\hline IVCT & Inter valence charge transfer \\
\hline${ }^{x} J_{A B}$ & NMR coupling constant between atoms $\mathrm{A}$ and $\mathrm{B}$ along $\mathrm{X}$ number of bonds \\
\hline$J$ & NMR coupling constant or magnetic coupling constant \\
\hline K & Kelvin \\
\hline $\mathrm{L}$ & Generic neutral dative ligand \\
\hline kcal & Kilocalorie \\
\hline $\mathrm{keV}$ & Kiloelectron volt \\
\hline $\mathrm{m}$ & Multiplet \\
\hline M & Concentration in molarity \\
\hline $\max$ & Maximum \\
\hline $\mathrm{Me}$ & Methyl \\
\hline MeTHF & Methyltetrahydrofuran \\
\hline $\mathrm{mg}$ & Milligram \\
\hline $\mathrm{MHz}$ & Megahertz \\
\hline $\mathrm{mL}$ & Milliliter \\
\hline $\mathrm{mM}$ & Millimolar \\
\hline $\mathrm{mm}$ & Millimeter \\
\hline $\mathrm{mV}$ & Millivolt \\
\hline mmol & Millimole \\
\hline MO & Molecular orbital \\
\hline mol & Mole \\
\hline
\end{tabular}




\begin{tabular}{|c|c|}
\hline $\mathrm{n}$ & Generic number \\
\hline NIR & Near infrared \\
\hline $\mathrm{nm}$ & nanometer \\
\hline NMR & Nuclear magnetic resonance \\
\hline $\mathrm{N}_{\mathrm{x}} \mathrm{H}_{\mathrm{y}}$ & Generic nitrogenous ligand with $\mathrm{x} \mathrm{N}$ atoms and $\mathrm{y} \mathrm{H}$ atoms \\
\hline$o$ & Ortho \\
\hline $\mathrm{Ph}$ & Phenyl \\
\hline $\mathrm{PhBP}_{3}$ & $\mathrm{PhB}\left(\mathrm{CH}_{2} \mathrm{PPh}_{2}\right)_{3}{ }^{-}$or generically $\mathrm{PhB}\left(\mathrm{CH}_{2} \mathrm{PR}_{2}\right)_{3}^{-}$ \\
\hline $\mathrm{PhBP}_{3}{ }_{3}{ }_{3}$ & $\mathrm{PhB}\left(\mathrm{CH}_{2} \mathrm{PiPr}_{2}\right)_{3}^{-}$ \\
\hline $\mathrm{pK}_{\mathrm{a}}$ & Acid dissociation constant \\
\hline PNP & Pincer ligand with two phosphine and one nitrogen donors \\
\hline $\mathrm{q}$ & Quartet \\
\hline $\mathrm{R}$ & Generic organic group or R-factor \\
\hline RT & Room temperature \\
\hline$S$ & Spin quantum number \\
\hline $\mathrm{s}$ & Singlet or second \\
\hline $\mathrm{SiP}_{3}$ & $\left(o-\mathrm{PR}_{2} \mathrm{C}_{6} \mathrm{H}_{4}\right)_{3} \mathrm{Si}^{-}$ \\
\hline SQUID & Superconducting quantum interference device \\
\hline $\mathrm{t}$ & Triplet or time \\
\hline TBA & Tetra- $n$-butyl ammonium \\
\hline $\mathrm{tBu}$ & Tert-Butyl \\
\hline $\mathrm{Tf}$ & $\mathrm{SO}_{2} \mathrm{CF}_{3}$ \\
\hline THF & Tetrahydrofuran \\
\hline
\end{tabular}


xxix

\begin{tabular}{|c|c|}
\hline TMS & Trimethylsilyl \\
\hline TPB & $\left.o-\mathrm{i} \mathrm{Pr}_{2} \mathrm{P}\left(\mathrm{C}_{6} \mathrm{H}_{4}\right)\right)_{3} \mathrm{~B}$ or generically $\left.o-\mathrm{R}_{2} \mathrm{P}\left(\mathrm{C}_{6} \mathrm{H}_{4}\right)\right)_{3} \mathrm{~B}$ \\
\hline TPP & Tetraphenylporphyrin \\
\hline UV & Ultraviolot \\
\hline $\mathrm{V}$ & Volt \\
\hline $\mathrm{vbr}$ & Very broad \\
\hline Vis & Visible \\
\hline$w R$ & Weighted R-factor \\
\hline $\mathrm{X}$ & Generic anionic atom or molecule \\
\hline XAS & X-ray absorption spectroscopy \\
\hline XRD & $\mathrm{X}$-ray diffraction \\
\hline$\delta$ & Chemical shift or Mössbauer isomer shift \\
\hline$\circ$ & Degree \\
\hline${ }^{\circ} \mathrm{C}$ & Degrees Celsius \\
\hline$\varepsilon$ & Extinction coefficient in units of $\mathrm{M}^{-1} \mathrm{~cm}^{-1}$ \\
\hline$\eta^{\mathrm{x}}$ & Hapticity of order $x$ \\
\hline$\lambda$ & Wavelength \\
\hline$\lambda_{\max }$ & Wavelength of local maximum intensity \\
\hline$\mu \mathrm{A}$ & Microamps \\
\hline$\mu-X$ & Bridging X ligand \\
\hline$\mu_{\mathrm{B}}$ & Bohr magneton \\
\hline$\mu_{\text {eff }}$ & Effective magnetic moment \\
\hline$\mu \mathrm{L}$ & Microliter \\
\hline
\end{tabular}




$\begin{array}{ll}v_{\mathrm{xy}} & \text { Vibrational frequency between atoms } \mathrm{x} \text { and } \mathrm{y} \\ \Sigma & \text { Summation } \\ \sigma & \text { Sigma symmetry orbital or interaction } \\ \pi & \text { Pi symmetry orbital or interaction } \\ \tau_{4} & \text { Index of geometry between tetrahedral and trigonal pyramidal } \\ \Theta & \text { Weiss temperature } \\ \AA & \text { Angstrom } \\ { }^{12-\mathrm{C}-4} & \text { 12-crown-4 } \\ { }^{1} \mathrm{H} & \text { Hydrogen-1 } \\ { }^{11} \mathrm{~B} & \text { Boron-11 } \\ { }^{13} \mathrm{C} & \text { Carbon-13 } \\ { }^{15} \mathrm{~N} & \text { Nitrogen-15 } \\ { }^{31} \mathrm{P} & \text { Phosphorus-31 } \\ \left\{{ }^{1} \mathrm{H}\right\} & \text { Proton-decoupled } \\ { }^{6-31 \mathrm{G}, \text { etc. }} & \text { Basis sets for DFT } \\ { }_{\mathrm{BP}} \mathrm{B} 6 \text { etc. } & \text { DFT functional }\end{array}$


Chapter 1: Introduction 


\subsection{Opening Remarks}

All of the work discussed in this thesis involves the study of complexes either indirectly or directly relevant to the Fe mediated reduction of $\mathrm{N}_{2}$ to $\mathrm{NH}_{3}$. Additionally, while this thesis work has been performed exclusively with synthetic complexes, a strong motivation for this work has been found in the enzymes that perform $\mathrm{N}_{2}$ fixation that are known as nitrogenases. Whether this work has any relevance to the natural systems invoked is yet to be seen, but the conclusions drawn here at least motivate and validate new lines of thought and inquiry in the study of the natural systems. This introductory chapter will introduce the topic of $\mathrm{N}_{2}$ fixation in a general sense, and then give a brief motivation and synopsis of the major results for each of the subsequent chapters as they relate to this over-arching theme.

\subsection{Nitrogen Fixation}

$$
\begin{aligned}
& \text { (A) } \mathrm{N}_{2}+3 \mathrm{H}_{2} \rightarrow 2 \mathrm{NH}_{3} \\
& \text { (B) } \mathrm{N}_{2}+8 \mathrm{H}^{+}+8 \mathrm{e}^{-} \rightarrow 2 \mathrm{NH}_{3}+\mathrm{H}_{2}
\end{aligned}
$$

Equation 1.1. Reactions for (A) the Haber-Bosch process and (B) $\mathrm{N}_{2}$ fixation mediated by nitrogenase.

Biogeochemical cycles play a critical role in the availability and conversion of massive amounts of elements and molecules throughout the planet. Of the myriad cycles that regulate important elements or molecules, one of the most fascinating is the nitrogen cycle, wherein elemental nitrogen is transformed between its stable gaseous $\mathrm{N}_{2}$ form and other reduced, such as $\mathrm{NH}_{3}$, or oxidized, such as $\mathrm{NO}_{3}{ }^{-}$, molecules. 1 The strength of the 
triple bond found in $\mathrm{N}_{2}(220 \mathrm{kcal} / \mathrm{mol})$ and its non-polarity make the activation of this molecule exceptionally challenging and have motivated interest in understanding the conversion of $\mathrm{N}_{2}$ into reduced species such as $\mathrm{NH}_{3}$. Due to the importance of fixed nitrogen molecules such as $\mathrm{NH}_{3}$ in fertilizing crops, mankind has developed an acute need of a catalytic process for the production of $\mathrm{NH}_{3}$. The Haber-Bosch process, wherein $\mathrm{N}_{2}$ and $\mathrm{H}_{2}$ are converted to $\mathrm{NH}_{3}$ over an Fe-based catalyst at high temperatures and pressures (Equation 1.1A), has been applied on a globally massive scale as a means to effectively feed burgeoning human populations. ${ }^{1}$
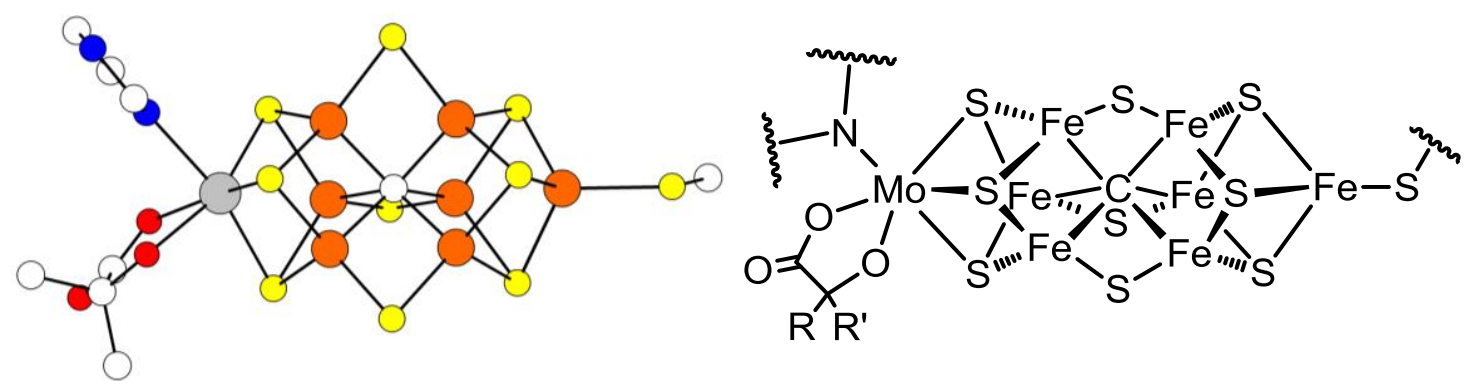

Figure 1.1. X-Ray Diffraction (XRD) structure and chemical line drawing representation of FeMoco. The XRD figure was made with coordinates from Reference $4 \mathrm{~b}$.

In nature, $\mathrm{N}_{2}$ is fixed to $\mathrm{NH}_{3}$ by bacteria known as diazotrophs, which are frequently found on root nodules, via the reaction shown in Equation 1.1B. ${ }^{2}$ The precise enzymatic machinery with which these organisms bind $\mathrm{N}_{2}$ and the mechanism they employ to reduce it have been topics of great interest. Multiple studies have implicated a series of cofactors as the site of $\mathrm{NH}_{3}$ formation (Figure 1.1). ${ }^{3}$ These cofactors always consist of primarily Fe and S (FeFeco) and can additionally incorporate Mo (FeMoco) or V (FeVco) when these elements are bio-available. Despite crystallographic information on the structures of these sites, recently revealing a carbon as the central atom of the 
cofactor, ${ }^{4}$ consensus on the atom(s) at which $\mathrm{N}_{2}$ reduction occurs has not been reached. Because Mo was once thought to be an essential component of all nitrogenases, the site of $\mathrm{N}_{2}$ binding was initially thought to be the single Mo atom in the FeMoco.2 This assumption found support in studies on synthetic inorganic Mo complexes that bind and reduce $\mathrm{N}_{2} \cdot{ }^{5}$
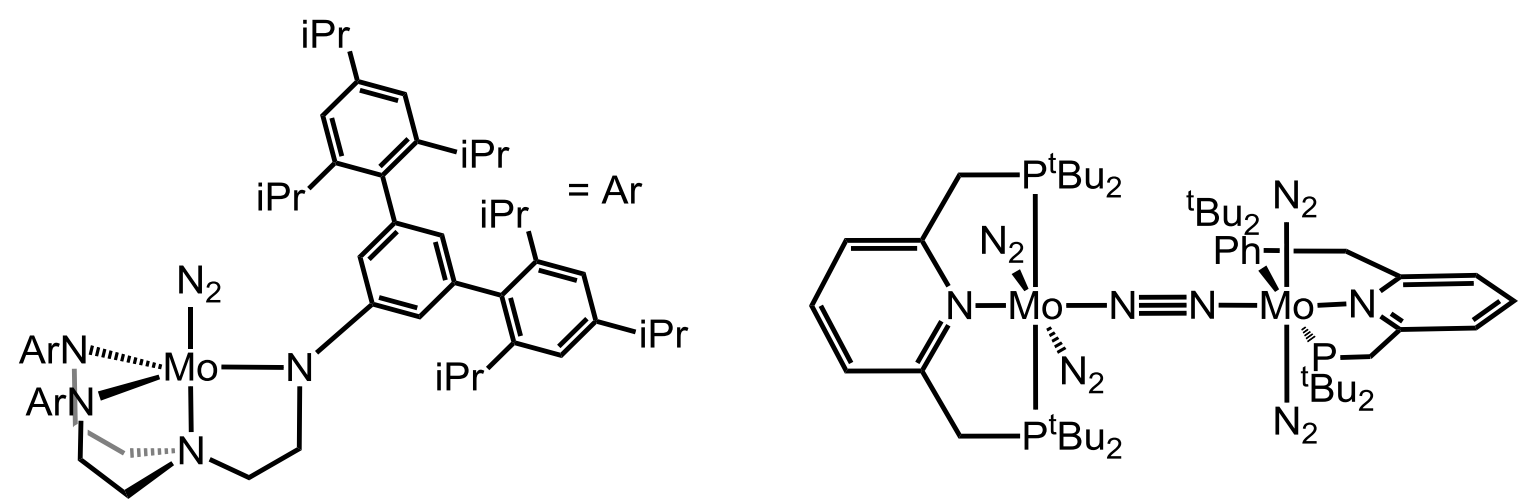

Figure 1.2. Mo complexes that mediate the catalytic reduction of $\mathrm{N}_{2}$ to $\mathrm{NH}_{3}$. Left: Schrock's tri-amidoamine system (Reference 9). Right: Nishibayashi's PNP system (Reference 11).

Although some ill-defined mixtures with transition metals have been shown to generate $\mathrm{NH}_{3}$ from $\mathrm{N}_{2}$, these systems do not allow for insight into the mechanism of reduction. ${ }^{6}$ One avenue of research that has helped to guide discussion about possible $\mathrm{N}_{2}$ reduction mechanisms has been the synthesis of molecular transition metal complexes that bind and reduce $\mathrm{N}_{2}$. Since the discovery of the first $\mathrm{N}_{2}$ complex by Allen and Senoff in 1965, there has been great interest in developing molecular species that will mimic or provide insight into biological $\mathrm{N}_{2}$ fixation. ${ }^{7}$ In the context of $\mathrm{Mo}$, discoveries by Chatt, Hidai, and others have demonstrated that reduced metal centers can bind $\mathrm{N}_{2}$ and functionalize it towards both silylation and protonation.5 Additionally, the feasibility of 
electrochemical reduction of $\mathrm{N}_{2}$ to $\mathrm{NH}_{3}$ was reported by Pickett and co-workers. ${ }^{8}$ These studies, as well as the synthesis of a variety of other nitrogenous species, led to the proposal of a mechanism now known as the "Chatt" or "distal" mechanism (Scheme 1.1, bottom) for $\mathrm{N}_{2}$ reduction.5 Despite this understanding, realization of a well-defined molecular system for the catalytic reduction of $\mathrm{N}_{2}$ to $\mathrm{NH}_{3}$ at atmospheric pressure remained elusive until Schrock and Yandulov's landmark discovery in 2003 that a Mo tri-amidoamine (Figure 1.2) system can produce up to 8 equivalents of $\mathrm{NH}_{3}$ per Mo from $\mathrm{N}_{2} .{ }^{9} \quad$ This report, and the accompanying characterization of multiple proposed intermediates that implicated a "distal" mechanism for $\mathrm{N}_{2}$ reduction in this system, ${ }^{10}$ represented the first well-defined molecular system for catalyzing $\mathrm{N}_{2}$ reduction to $\mathrm{NH}_{3}$.

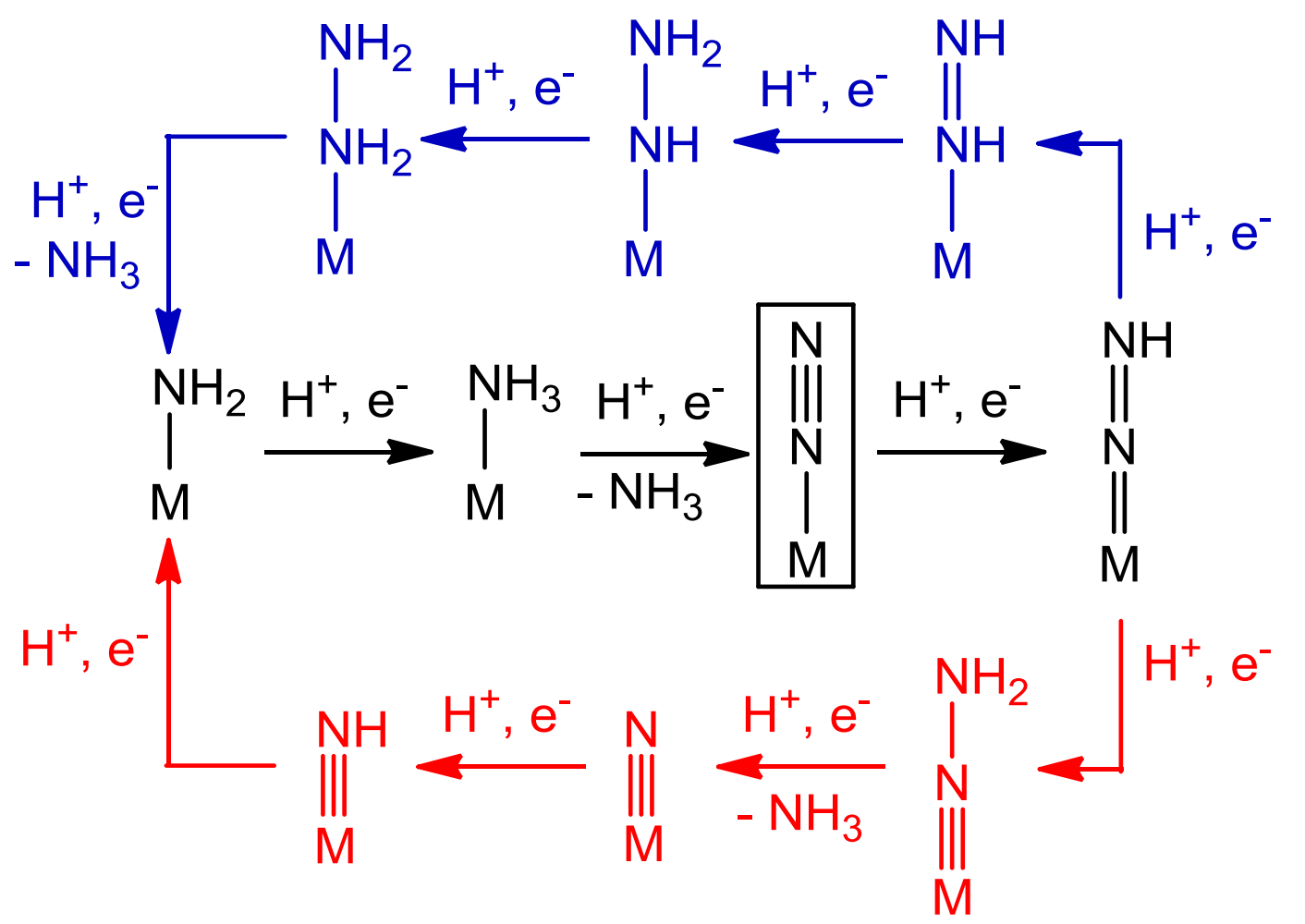

Scheme 1.1. Proposed limiting mechanisms for transition metal mediated $\mathrm{N}_{2}$ reduction. An "alternating" mechanism is shown on top in blue while a "distal" mechanism is shown on bottom in red. Black intermediates are common to both mechanisms. Not 
shown are possible crossover pathways between mechanisms. Note that while M could feasibly be any transition metal, Mo and $\mathrm{Fe}$ are the most salient elements for this discussion.

More recently, Nishibayashi and co-workers have reported a phosphine ligated Mo center that improves slightly on Schrock's system (Figure 1.2). ${ }^{11}$ This PNP ligated Mo complex is competent for up to 12 equivalents of $\mathrm{NH}_{3}$ per Mo center. The combined synthetic studies of Schrock and Nishibayashi were consistent with the hypothesis that Mo serves as the active metal for nitrogenase under turnover conditions.2 Despite these results, however, the functionality of nitrogenases without Mo incorporated into the cofactor and other data began to suggest that Mo was not the active $\mathrm{N}_{2}$ binding site within nitrogenases.

A number of spectroscopic studies on nitrogenase have recently indicated that $\mathrm{Fe}$ may in fact be the site where $\mathrm{N}_{2}$ is bound and reduced, and have further supported an "alternating" mechanism wherein protons are alternately added to $\mathrm{N}_{2}$ to form intermediates such as $\mathrm{HN}=\mathrm{NH}$ and $\mathrm{H}_{2} \mathrm{~N}-\mathrm{NH}_{2}$ (Scheme 1.1 top).3.12 Such a mechanism directly contrasts with the "distal" mechanism previously mentioned, wherein protons are added consecutively to single nitrogen atoms to generate intermediates such as nitrides (Scheme 1.1 bottom). Due to this proposed binding site and differing mechanism, there has been demand for Fe complexes that can (a) serve as structural, spectroscopic, or functional models of the Fe sites in FeMoco, (b) stabilize putative intermediates along a $\mathrm{N}_{2}$ fixation pathway (Scheme 1.1), or (c) serve as models for the highly reduced states of the FeMoco that precede $\mathrm{N}_{2}$ binding. As such, significant effort has been directed 
towards developing synthetic Fe complexes that can structurally or functionally model nitrogenase or proposed catalytic intermediates. ${ }^{13}$ Indeed, several groups have demonstrated various Fe complexes that bind $\mathrm{N}_{\mathrm{x}} \mathrm{H}_{\mathrm{y}}$ ligands or display corresponding reactivity directly relevant to $\mathrm{N}_{2}$ reduction schemes. ${ }^{14}$

The Peters lab has had an ongoing interest in developing Fe systems that can functionally model the chemistry of nitrogenase enzymes. A guiding hypothesis for this research has been the postulation that $\mathrm{N}_{2}$ reduction occurs at a single Fe site at the FeMoco and that this site samples multiple geometries in order to mediate catalytic turnover (Scheme 1.2). In order to model such a site, soft electron donating trisphosphine ligands have been utilized to stabilize low-valent Fe complexes in a number of geometries. Initially, pseudo-tetrahedral complexes of Fe with the tris-phosphine borate zwitterion $\mathrm{PhB}\left(\mathrm{CH}_{2} \mathrm{PR}_{2}\right)_{3}{ }^{-}\left(\mathrm{PhBP}_{3}\right)$ were targeted. ${ }^{15}$ These ligands stabilize low-valent and multiply bonded metal species on Fe. There was, however, a dearth of research into sulfur based chemistry on these scaffolds, which motivated further study into these types of complexes.

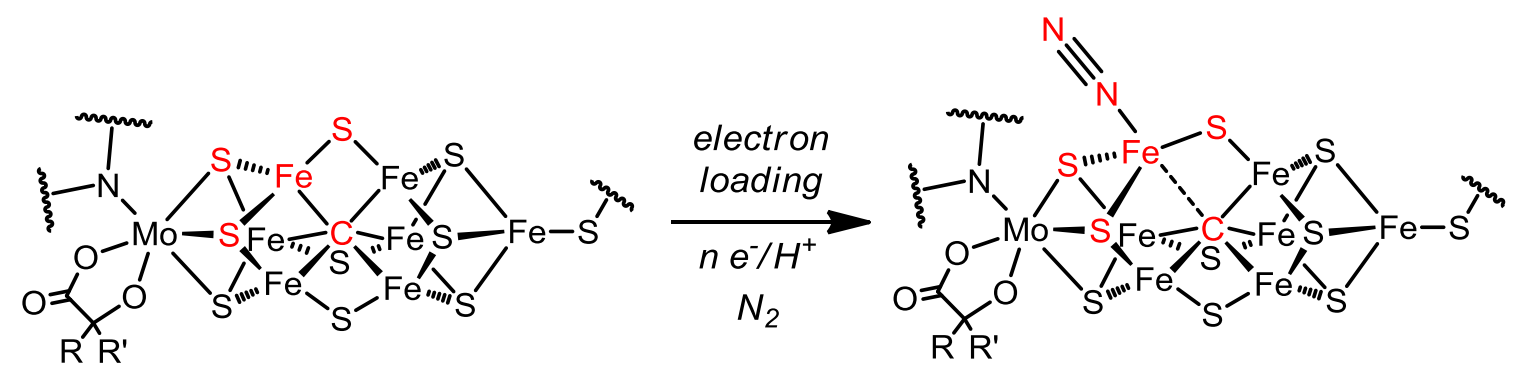

Scheme 1.2. Scheme depicting a potential mechanism for $\mathrm{N}_{2}$ binding to FeMoco utilizing a flexible Fe-C interaction. Possible sites of protonation prior to or concurrent with $\mathrm{N}_{2}$ binding are not shown. 


\subsection{Unusually Low Valent Fe-S-Fe Complexes}

The active site FeMoco consists of a cluster composed primarily of Fe-S-Fe linkages.3 As such, research into the synthesis and characterization of model complexes of these linkages has been an area of significant study. ${ }^{16}$ Unusually low formal oxidation states of iron have been implicated as important to the function of nitrogenase, and it is of increasing interest to understand whether the $\mathrm{S}^{2-}$ structural unit is compatible with such low-valent iron.3 In this context, Holland and co-workers have recently reported $\left\{\left[\mathrm{HC}\left(\mathrm{CMeN}[2,6 \text {-diisopropylphenyl] })_{2}\right] \mathrm{Fe}\right\}_{2}\{\mu-\mathrm{S}\}\right.$ and its interactions with nitrogenous substrates, as well as recently reporting the reduction of this complex to form the first example of a stable $\mathrm{Fe}(\mathrm{I})$ sulfide. ${ }^{17}$ It was of further interest to determine whether other geometries at low-valent Fe could be stable in the presence of sulfide and furthermore, whether a mixed-valent $\mathrm{Fe}(\mathrm{II}) / \mathrm{Fe}(\mathrm{I})$ species could be isolated and what its electronic structure might be.

Chapter 2 outlines the synthesis and characterization of a series of unusually lowvalent $\left[\left(\mathrm{PhBP}_{3}\right) \mathrm{Fe}\right]_{2}(\mu-\mathrm{S})$ complexes in the formal oxidation states $\mathrm{Fe}(\mathrm{II}) / \mathrm{Fe}(\mathrm{II})$, $\mathrm{Fe}(\mathrm{II}) / \mathrm{Fe}(\mathrm{I})$, and $\mathrm{Fe}(\mathrm{I}) / \mathrm{Fe}(\mathrm{I})$. As mentioned, these complexes represent rare examples of $\mathrm{Fe}(\mathrm{I})$ ligated to $\mathrm{S}^{2-}$, and possess fascinating structural and electronic features distinguished by exceptionally short Fe-S bonds and a high degree of magnetic coupling between the two metal centers. Furthermore, the Fe centers in these complexes undergo a transition to low-spin states upon reduction, resulting in unusual examples of tetrahedral low-spin Fe(I). Finally, these dimers display interesting reactivity towards small molecule substrates broadly relevant to $\mathrm{N}_{2}$ fixation such as $\mathrm{CO}, \mathrm{H}^{+}$, and $\mathrm{N}_{2} \mathrm{H}_{4}$. 


\subsection{Conversion of $\mathrm{FeNH}_{2}$ to $\mathrm{FeN}_{2}$ with Release of $\mathrm{NH}_{3}$}

Pseudo-Tetrahedral
Stabilizes $\pi$-bases

Trigonal Bipyramidal

Stabilizes $\pi$-acids
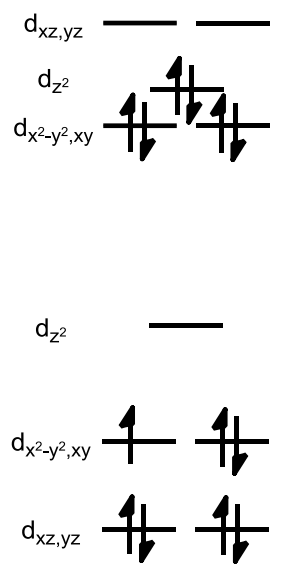
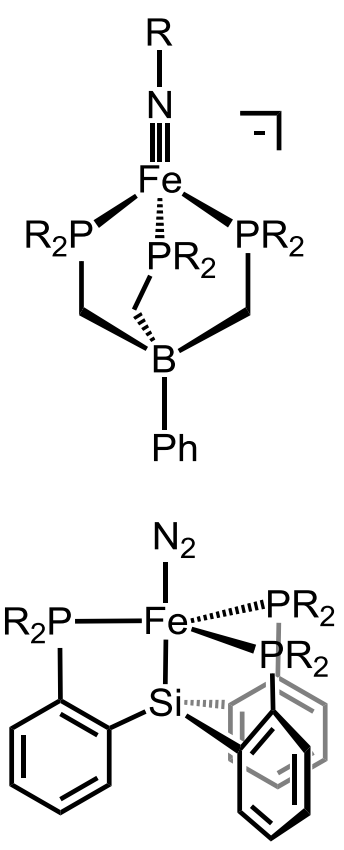

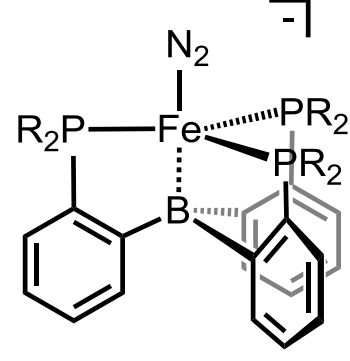

Flexible Geometry

Stabilizes both $\pi$-acids and $\pi$-bases

Figure 1.3. Qualitative d-orbital splitting diagrams and examples of complexes that feature pseudo-tetrahedral and trigonal bipyramidal geometries stabilizing $\pi$-bases and $\pi$ acids respectively. Note that Fe-Si or Fe-B bonding orbitals may be near or within the dmanifold, but are not shown.

As was mentioned, a key feature of $\left(\mathrm{PhBP}_{3}\right) \mathrm{Fe}$ complexes was the stabilization of strong $\pi$-donors in species such as Fe nitrides or imides that would be found along a distal mechanism. Such stabilization was engendered from the pseudo-tetrahedral geometry enforced by the $\mathrm{PhBP}_{3}$ ligand scaffold (Figure 1.3). ${ }^{15 \mathrm{~d}}$ A drawback to this design, however, was the limited activity of these systems towards functionalization of $\mathrm{N}_{2}$, potentially due to more facile population of high spin states in a pseudo-tetrahedral geometry as well as the propensity of these systems to form bridging $\mathrm{N}_{2}$ species. To 
access complexes better capable of functionalizing $\mathrm{N}_{2}$ molecules, a shift to a trigonal bipyramidal geometry was sought with a new tris-phosphino silyl ligand $\left(o-\mathrm{PR}_{2} \mathrm{C}_{6} \mathrm{H}_{4}\right)_{3} \mathrm{Si}^{-}$ $\left(\mathrm{SiP}_{3}\right)$. This shift resulted in a system poised for $\mathrm{N}_{2}$ uptake and functionalization most clearly illustrated by the stabilization of terminal $\left(\mathrm{SiP}_{3}\right) \mathrm{FeN}_{2}$ complexes in three formal oxidation states and the subsequent silylation of $\mathrm{N}_{2}$ on this scaffold. ${ }^{18}$ A drawback to this system, however, is that the shift to trigonal bipyramidal geometry results in the lowering of the $\mathrm{d}_{\mathrm{xz}}$ and $\mathrm{d}_{\mathrm{yz}}$ orbitals such that stabilization of $\pi$-basic ligands is no longer favorable (Figure 1.3). This is most clearly evidenced by the low temperature observation of an $\mathrm{Fe}$ nitrene species which decays upon warming to $\mathrm{RT}$, in contrast to the $\mathrm{PhBP}_{3}$ systems which readily stabilize imide species. ${ }^{19}$

In order to combine the $\mathrm{N}_{2}$ binding capabilities and functionalization capabilities of the trigonal bipyramidal system with the stability of the pseudo-tetrahedral systems towards $\pi$-basic ligands, a new tris-phosphine borane (TPB) ligand set was utilized. ${ }^{20} \mathrm{~A}$ key feature to this ligand set is a flexible Fe-B interaction that allows the metal center to sample both trigonal bipyramidal and pseudo-tetrahedral geometries (Figure 1.3). Indeed, this ligand has shown the ability to both readily bind $\mathrm{N}_{2}$ as well as stabilize $\pi$ basic nitrogenous ligands, which allows for di-functionalization of $\mathrm{N}_{2}$ with silyl electrophiles. ${ }^{21}$ Despite these results, little research into the installation of ligands with $\mathrm{N}-\mathrm{H}$ bonds had been investigated.

Chapter 3 focuses on the installation of $\mathrm{N}_{\mathrm{x}} \mathrm{H}_{\mathrm{y}}$ ligands onto the (TPB)Fe platform. While complexes featuring substituted $\mathrm{NR}, \mathrm{N}_{2} \mathrm{R}$, and N-NR functionalities had been synthesized with this ligand set, ${ }^{21}$ no substrates, aside from (TPB)Fe( $\left(\mathrm{N}_{2}\right)$, that would actually take part in a $\mathrm{N}_{2}$ reduction scheme had yet been isolated. Utilizing the 4- 
coordinate pseudo-trigonal pyramidal cationic precursor [(TPB)Fe $]^{+}$as a synthon, $\mathrm{N}_{2} \mathrm{H}_{4}$, $\mathrm{NH}_{3}$, and $\mathrm{NH}_{2}{ }^{-}$functionalities were installed. All of these species are high-spin $S=3 / 2$ and display characteristic quartet EPR signals. Finally, sequential protonation and reduction of (TPB)Fe( $\left.\mathrm{NH}_{2}\right)$ results in loss of $\mathrm{NH}_{3}$ and uptake of $\mathrm{N}_{2}$ to yield (TPB) $\mathrm{Fe}\left(\mathrm{N}_{2}\right)$. Significantly, this reaction sequence represents the first time that a single Fe system has been shown to mediate the final two common reductive protonation steps of a $\mathrm{N}_{2}$ reduction scheme (Scheme 1.1). This result motivated studies into whether $\mathrm{NH}_{3}$ could be produced from $\mathrm{N}_{2}$ with this scaffold.

\subsection{Catalytic Conversion of $\mathrm{N}_{2}$ to $\mathrm{NH}_{3}$ by an Fe Model Complex}

While progress has been made towards stabilizing nitrogenous species relevant to $\mathrm{N}_{2}$ reduction on Fe platforms, an $\mathrm{Fe}$ system in which $\mathrm{N}_{2}$ can be directly transformed into $\mathrm{NH}_{3}$ in a catalytic fashion was unknown. Prior to the studies described herein, even stoichiometric conversion of $\mathrm{FeN}_{2}$ into $\mathrm{NH}_{3}$ was limited to yields of $\sim 0.1$ equivalents of $\mathrm{NH}_{3}$ per Fe center. ${ }^{13,22}$ Recent advances in a related context include a system reported by Holland and co-workers capable of splitting $\mathrm{N}_{2}$ into two nitrides which can then release nearly stoichiometric $\mathrm{NH}_{3}$ upon protonolysis or hydrogenolysis and a report from Nishibayashi and co-workers describing the catalytic silylation of $\mathrm{N}_{2}$ with simple Fe salts and complexes. ${ }^{23,24}$ Despite these interesting and important examples, distinct issues are associated with the direct conversion of $\mathrm{N}_{2}$ into $\mathrm{NH}_{3}$ with protons and electrons, most notably the need to circumvent formation of $\mathrm{H}_{2}$ which prevented the realization of a welldefined Fe system for the catalytic reduction of $\mathrm{N}_{2}$ to $\mathrm{NH}_{3}$. 


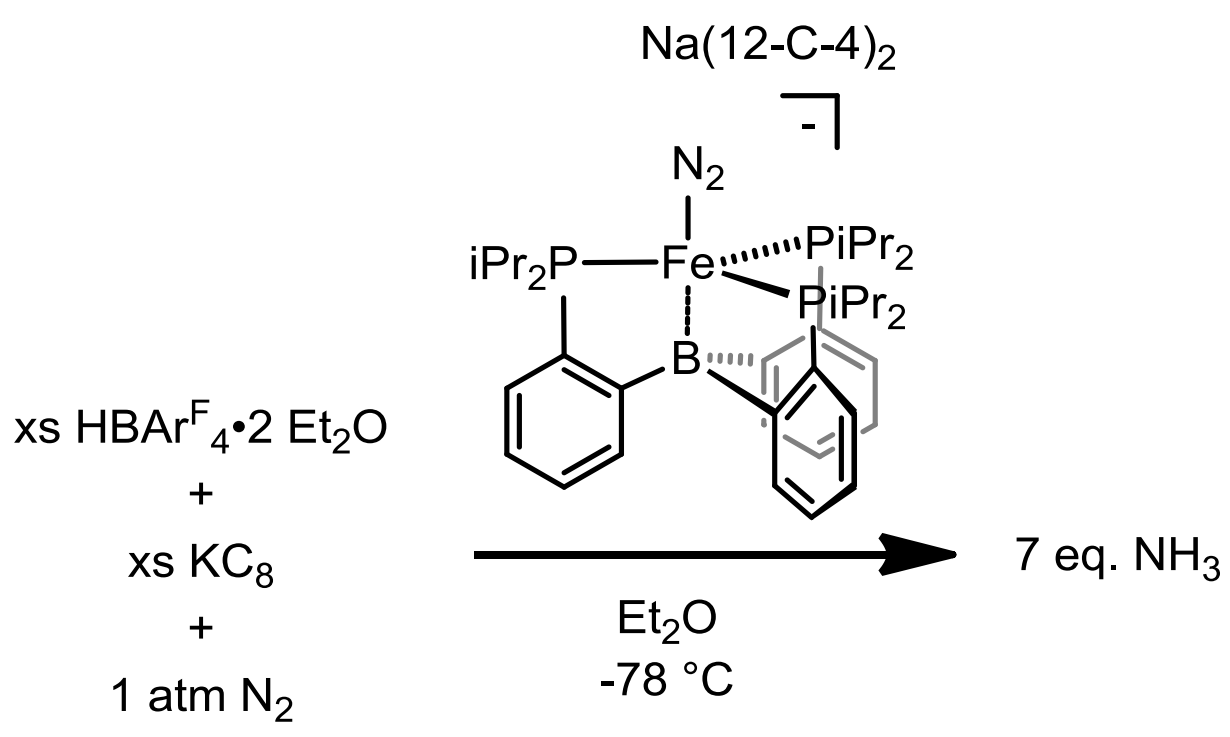

Scheme 1.3. Catalytic reduction of $\mathrm{N}_{2}$ to $\mathrm{NH}_{3}$ by a molecular Fe pre-catalyst.

Chapter 4 outlines the initial studies and development of a molecular Fe based catalyst for the reduction of $\mathrm{N}_{2}$ to $\mathrm{NH}_{3}$. While preliminary protonation studies with (TPB)Fe $\left(\mathrm{N}_{2}\right)$ complexes resulted in oxidation, use of excess acid and low temperatures enabled the observation of an $\left[(\mathrm{TPB}) \mathrm{Fe}\left(\mathrm{NH}_{3}\right)\right]^{+}$being formed from bound $\mathrm{N}_{2}$. In Chapter 3 , the reduction of $\left[(\mathrm{TPB}) \mathrm{Fe}\left(\mathrm{NH}_{3}\right)\right]^{+}$to release $\mathrm{NH}_{3}$ and uptake $\mathrm{N}_{2}$ had already been shown, and canvassing several reaction conditions resulted in the discovery that anionic $\left[(\mathrm{TPB}) \mathrm{Fe}\left(\mathrm{N}_{2}\right)\right]^{-}$can produce an average of 7 equivalents of $\mathrm{NH}_{3}$ per Fe, resulting in a yield of $>40 \%$ of protons being reliably delivered to $\mathrm{N}_{2}$ (Scheme 1.3). Control studies with simple Fe salts that shown negligible $\mathrm{NH}_{3}$ formation combined with the initial reactions that show the formation of a molecular $\mathrm{NH}_{3}$ adduct upon acidification, offer strong support that this is indeed a molecular catalyst. The speciation of the Fe complexes under catalysis furthermore suggests that net $\mathrm{H}_{2}$ addition to Fe could be 
responsible for catalyst degradation. Overall, the exciting discovery of $\mathrm{N}_{2}$ reduction by $\left[(\mathrm{TPB}) \mathrm{Fe}\left(\mathrm{N}_{2}\right)\right]^{-}$motivated further studies of the catalytic system.

\subsection{The Effect of Ligand and Reaction Conditions on Fe Mediated $\mathrm{N}_{2}$ Fixation}

With the discovery that (TPB)Fe systems can catalyze $\mathrm{N}_{2}$ reduction to $\mathrm{NH}_{3}$, there was an added impetus to determine the scope of the catalysis and the effect of varying the catalytic conditions. Additionally, investigations of the competency of different precatalysts were pursued as probes of what structural features of the (TPB)Fe system were essential for catalysis. Towards this end, Chapter 5 outlines comparative studies where both the catalytic conditions and pre-catalysts have been varied.

Variations on the standard catalytic conditions by changing factors such as solvent, temperature, acid, and reductant on catalysis have been examined, revealing that while no improvement in $\mathrm{NH}_{3}$ yield was observed, general trends in reactivity indicate that the reaction must be performed in an ethereal solvent. Despite the limited solvent scope, some flexibility in the choice of acid and reductant is available with anilinium acids and $\mathrm{Na} / \mathrm{Hg}$ amalgam as a reductant proving competent for catalysis. Canvassing a variety of either novel or previously reported Fe phosphine complexes for efficacy as precatalysts for $\mathrm{N}_{2}$ reduction leads to the empirical conclusion that only TPB complexes are competent for producing > 2 equivalents of $\mathrm{NH}_{3}$ per Fe center. The cause for this observation is unclear, but a possible explanation is the requirement of a flexible Fe-B interaction, potentially in keeping with the hypothesis that a flexible geometry at Fe is required for catalysis. Furthermore, the differences in activity between (TPB)Fe and other poly-phosphine complexes further supports that this catalyst system is indeed 
molecular. Were a heterogeneous decomposition product were responsible for the catalysis, a strong dependence on the ligand set would likely not be observed.

\subsection{Spectroscopic Characterization of the Putative Catalytic Intermediate $\left[(\mathrm{TPB}) \mathrm{Fe}=\mathrm{N}-\mathrm{NH}_{2}\right]\left[\mathrm{BAr}^{\mathrm{F}}\right]$.}

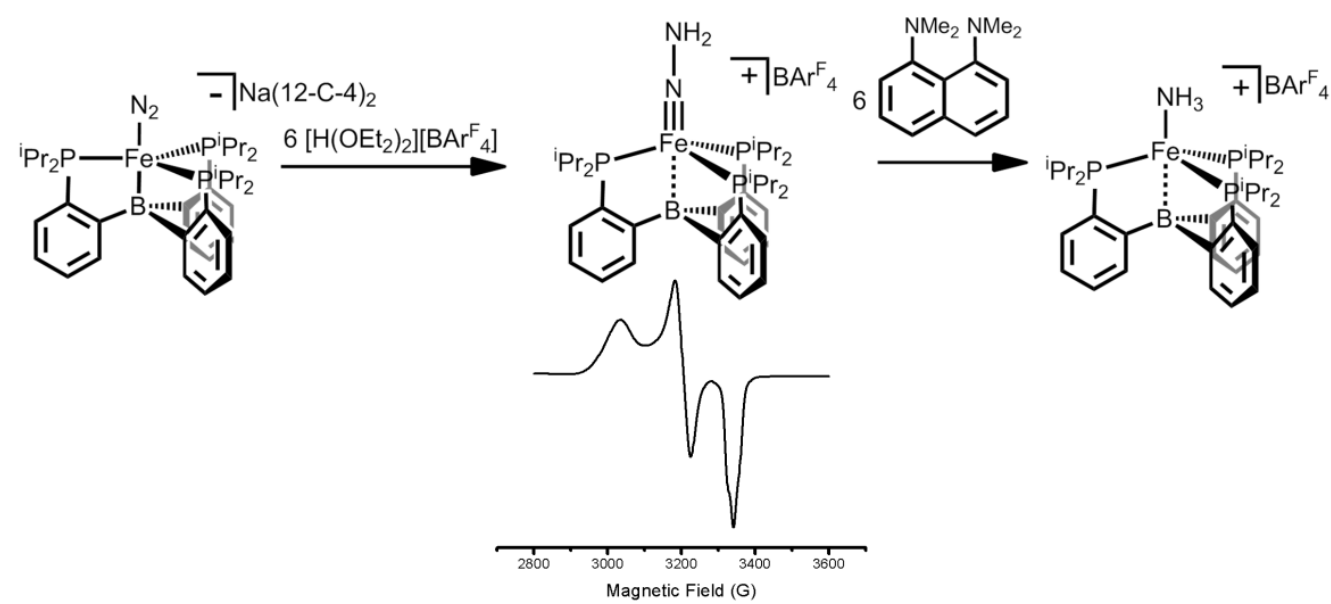

Figure 1.4. Generation of a di-protonated intermediate which partially decomposes to an $\mathrm{NH}_{3}$ complex.

Despite the realization of catalysis in the (TPB)Fe system, there remains little to no mechanistic information on how $\mathrm{N}_{2}$ reduction is mediated. Specifically, questions about whether this system is going through a "distal," "alternating," or other hybrid type mechanism are of great interest. While direct probing of the molecular species under turnover is challenging due to the heterogeneous nature of the favored reductant $\left(\mathrm{KC}_{8}\right)$ and the paramagnetic Fe species involved, it was still of interest to see if a protonated $\mathrm{N}_{2}$ 
ligand on Fe could be generated from the pre-catalyst. With this goal in mind, lowtemperature protonation studies were undertaken.

Chapter 6 details the synthesis and spectroscopic characterization of a thermally unstable cationic $\left[(\mathrm{TPB}) \mathrm{Fe}\left(\mathrm{N}_{2} \mathrm{H}_{2}\right)\right]^{+}$species. Combined EPR, ENDOR, and EXAFS analysis indicates that this complex is $S=1 / 2$ and doubly protonated. Furthermore, this species possesses a short Fe-N interaction, consistent with an Fe-N triple bond. Computational studies on this complex also support the presence of an Fe-N triple bond, providing reasonable agreement with spectroscopic measurements. Such an assignment is consistent with double protonation at the $\beta \mathrm{N}$ of $\mathrm{N}_{2}$, as would be found in a "distal" mechanism. While the assignment of this intermediate and its presence in pre-catalytic mixtures is convincing, its relevance to an active species under catalysis, or downstream processes following formation of this species, is still unclear. Further studies aimed at elucidating the mechanism of catalysis and whether this doubly protonated species is involved along the catalytic pathway will be of great interest. 


\section{References Cited}

1 Smil, V. Enriching the Earth; MIT Press: Cambridge, MA, 2001.

2 (a) Burgess, B. K.; Lowe, D. J. Chem. Rev. 1996, 96, 2983-3011; (b) Eady, R. R. Chem. Rev.1996, 96, 3013-3030.

3 (a) Dos Santos, P. C.; Igarashi, R. Y.; Lee, H. I.; Hoffman, B. M.; Seefeldt, L. C.; Dean, D. R. Acc. Chem. Res. 2005, 38, 208-214; (b) Howard, J. B.; Rees, D. C. Proc. Natl. Acad. Sci. 2006, 103, 17088-17093; (b) Peters, J. C.; Mehn, M. P. In Activation of Small Molecules; Wiley: 2006, p 81-119; (c) Schwarz, G.; Mendel, R. R.; Ribbe, M. W. Nature 2009, 460, 839-847; (d) Seefeldt, L. C.; Hoffman, B. M.; Dean, D. R. Annu. Rev. Biochem. 2009, 78, 701-722.

4 (a) Lancaster, K. M.; Roemelt, M.; Ettenhuber, P.; Hu, Y. L.; Ribbe, M. W.; Neese, F.; Bergmann, U.; DeBeer, S. Science 2011, 334, 974-977; (b)Spatzal, T.; Aksoyoglu, M.;

Zhang, L.; Andrade, S. L. A.; Schleicher, E.; Weber, S.; Rees, D. C.; Einsle, O. Science 2011, 334, 940 .

5 (a) Chatt, J.; Dilworth, J. R.; Richards, R. L. Chem. Rev. 1978, 78, 589-625; (b) Hidai, M.; Mizobe, Y. Chem. Rev. 1995, 95, 1115-1133.

6 (a) Shilov, A.; Denisov, N.; Efimov, O.; Shuvalov, N.; Shuvalova, N.; Shilova, A.

Nature 1971, 231, 460-461; (b) Bazhenova, T. A.; Shilov, A. E. Coord. Chem. Rev. 1995, 144, 69-145.

7 Allen, A. D.; Senoff, C. V. Chem. Comm. 1965, 621-622.

8 Pickett, C. J.; Talarmin, J. Nature 1985, 317, 652-653.

9 Yandulov, D. V.; Schrock, R. R. Science 2003, 301, 76-78.

10 Schrock, R. R. Acc. Chem. Res. 2005, 38, 955-962. 
11 Arashiba, K.; Miyake, Y.; Nishibayashi, Y. Nature Chem. 2011, 3, 120-125.

12 Hoffman, B. M.; Dean, D. R.; Seefeldt, L. C. Acc. Chem. Res. 2009, 42, 609-619.

13 (a) Crossland, J. L.; Tyler, D. R. Coord. Chem. Rev. 2010, 254, 1883-1894; (b)

MacLeod, K. C.; Holland, P. L. Nat. Chem. 2013, 5, 559-565.

14 For a few examples see: (a) Smith, J. M.; Lachicotte, R. J.; Pittard, K. A.; Cundari, T.

R.; Lukat-Rodgers, G.; Rodgers, K. R.; Holland, P. L. J. Am. Chem. Soc. 2001, 123, 9222-9223; (b) Gilbertson, J. D.; Szymczak, N. K.; Tyler, D. R. J. Am. Chem. Soc.

2005, 127, 10184-10185. (c) Field, L. D.; Li, H. L.; Magill, A. M. Inorg. Chem. 2008, $48,5-7$.

15 (a) Brown, S. D.; Betley, T. A.; Peters, J. C. J. Am. Chem. Soc. 2002, 125, 322-323;

(b) Betley, T. A.; Peters, J. C. J. Am. Chem. Soc. 2003, 125, 10782-10783; (c) Betley,

T. A.; Peters, J. C. J. Am. Chem. Soc. 2004, 126, 6252-6254. (d) Saouma, C. T.; Peters,

J. C. Coord. Chem. Rev. 2011, 255, 920-937.

16 Holm, R. H. Acc. Chem. Res. 1977, 10, 427-434.

17 Vela, J.; Stoian, S.; Flaschenriem, C. J.; Münck, E.; Holland, P. L. J. Am. Chem. Soc. 2004, 126, 4522-4523; (b) Rodriguez, M. M.; Stubbert, B. D.; Scarborough, C. C.;

Brennessel, W. W.; Bill, E.; Holland, P. L. Angew. Chem. 2012, 124, 8372-8375.

18 Lee, Y.; Mankad, N. P.; Peters, J. C. Nat. Chem. 2010, 2, 558-565.

19 Mankad, N. P.; Müller, P.; Peters, J. C. J. Am. Chem. Soc. 2010, 132, 4083-4085.

20 Sircoglou, M.; Bontemps, S.; Bouhadir, G.; Saffon, N.; Miqueu, K.; Gu, W.; Mercy,

M.; Chen, C.-H.; Foxman, B. M.; Maron, L.; Ozerov, O.V.; Bourissou, D. J. Am. Chem. Soc. 2008, 130, 16729-16738. 
21 (a) Moret, M.-E.; Peters, J. C. Angew. Chem. Int. Ed. 2011, 50, 2063-2067; (b) Moret, M.-E.; Peters, J. C. J. Am. Chem. Soc. 2011, 133, 18118-18121.

22 Hills, A.; Hughes, D. L.; Jimenez-Tenorio, M.; Leigh, G. J.; Rowley, A. T. J. Chem. Soc. Dalton 1993, 3041-3049.

23 Rodriguez, M. M.; Bill, E.; Brennessel, W. W.; Holland, P. L. Science 2011, 334, 780783.

24 Yuki, M.; Tanaka, H.; Sasaki, K.; Miyake, Y.; Yoshizawa, K.; Nishibayashi, Y. Nature comm.. 2012, 3, 1254-1254. 
Chapter 2: Unusually Low Valent Fe-S-Fe Complexes 


\subsection{Introduction}

The Fe-S-Fe unit is common to a host of metalloenzymes that mediate metabolic transformations central to life. These include proteins or cofactors that act as electron transfer conduits ${ }^{1}$, as well as metalloenzymes that transform small molecules such as the hydrogenases ${ }^{2}$ and nitrogenases. ${ }^{3}$ As such, research into the synthesis and characterization of model complexes of these cofactors has been an area of significant study. ${ }^{4}$ Holm pioneered the synthesis of lower valent iron-sulfur clusters exemplified by the synthesis of the all iron(II) cluster $\left[\mathrm{Fe}_{4} \mathrm{~S}_{4}\left(\mathrm{Pr}_{2} \mathrm{NHCMe}_{2}\right)_{4}\right] .{ }^{5}$ Unusually low formal oxidation states of iron (e.g., $\mathrm{Fe}(\mathrm{I})$ and $\mathrm{Fe}(0)$ ) have been implicated as important to the function of hydrogenase and nitrogenase enzymes and it is of increasing interest to understand whether the $\mathrm{S}^{2-}$ structural unit is compatible with such low-valent iron. In this context, Holland and co-workers have recently reported $\{[\mathrm{HC}(\mathrm{CMeN}[2,6-$ diisopropylphenyl $\left.\left.)_{2}\right] \mathrm{Fe}\right\}_{2}\{\mu-\mathrm{S}\}$ and the first all $\mathrm{Fe}(\mathrm{I})$ sulfide $\{[\mathrm{HC}(\mathrm{CMeN}[2,6-$ diisopropylphenyl] $\left.\left.)_{2}\right] \mathrm{Fe}\right\}_{2}\{\mu-\mathrm{S}\}^{2-}$ and interactions of the former with nitrogenous substrates. ${ }^{6}$ The Peters lab has also had an interest in the study of unusually low-valent Fe-X-Fe linkages that relate to $\mathrm{N}_{2}$ reduction, with examples being where the bridging $\mathrm{X}$ unit is either imide $\left(\mathrm{NH}^{2-}\right)$ or nitride $\left(\mathrm{N}^{3-}\right) .{ }^{7}$ Herein this narrative is extended by reporting a series of $\mathrm{Fe}-\mathrm{S}-\mathrm{Fe}$ complexes in the formal oxidation states $\mathrm{Fe}(\mathrm{II}) / \mathrm{Fe}(\mathrm{II}), \mathrm{Fe}(\mathrm{II}) / \mathrm{Fe}(\mathrm{I})$,

and $\mathrm{Fe}(\mathrm{I}) / \mathrm{Fe}(\mathrm{I})$. This series of complexes possess rich magnetic and spectroscopic characteristics indicative of a spin-state change to unusual low-spin Fe(I) centers upon reduction. In addition to the thorough characterization of these species, the $\mathrm{CO}$ uptake and subsequent $\mathrm{H}^{+}$reduction chemistry of the $\mathrm{Fe}(\mathrm{II}) / \mathrm{Fe}(\mathrm{II})$ system, as well as its reactivity towards $\mathrm{N}_{2} \mathrm{H}_{4}$, have been investigated. 


\subsection{Results and Discussion}

\subsubsection{Low-Valent Fe-S-Fe Complexes}

In order to install a $\mu$-S unit to bridge two $\left(\mathrm{PhBP}_{3}\right) \mathrm{Fe}\left(\mathrm{PhBP}_{3}=\mathrm{PhB}\left(\mathrm{CH}_{2} \mathrm{PPh}_{2}\right)_{3}{ }^{-}\right)$

units, a soluble source of $\mathrm{S}^{2-}$ was sought as a salt metathesis partner with $\left(\mathrm{PhBP}_{3}\right) \mathrm{FeCl}$. While $\mathrm{S}_{8}$ and simple alkali metal $\mathrm{SH}^{-}$salts did not provide clean products, use of $[\mathrm{TBA}][\mathrm{SH}]\left(\mathrm{TBA}=\mathrm{NBu}_{4}{ }^{+}\right)$reacted with $\left(\mathrm{PhBP}_{3}\right) \mathrm{FeCl}$ to generate the ferrous complex $\left(\left(\mathrm{PhBP}_{3}\right) \mathrm{Fe}\right)_{2}(\mu-\mathrm{S})(\mathbf{2 . 1})$ as a dark brown material in moderate yield (Scheme 2.1$)$. The cyclic voltammogram (CV) of $\mathbf{2 . 1}$ in THF displays two reversible reduction events at $1.52 \mathrm{~V}$ and $-2.30 \mathrm{~V}$ vs. $\mathrm{Fc} / \mathrm{Fc}^{+}$which are assigned as the $\mathrm{Fe}(\mathrm{II}) \mathrm{Fe}(\mathrm{II}) / \mathrm{Fe}(\mathrm{II}) / \mathrm{Fe}(\mathrm{I})$ and $\mathrm{Fe}(\mathrm{II}) \mathrm{Fe}(\mathrm{I}) / \mathrm{Fe}(\mathrm{I}) \mathrm{Fe}(\mathrm{I})$ couples respectively (Figure 2.1 ). The reversibility of the $\mathrm{CV}$ suggested that the reduced species could be stable and thus chemical reductions were investigated.

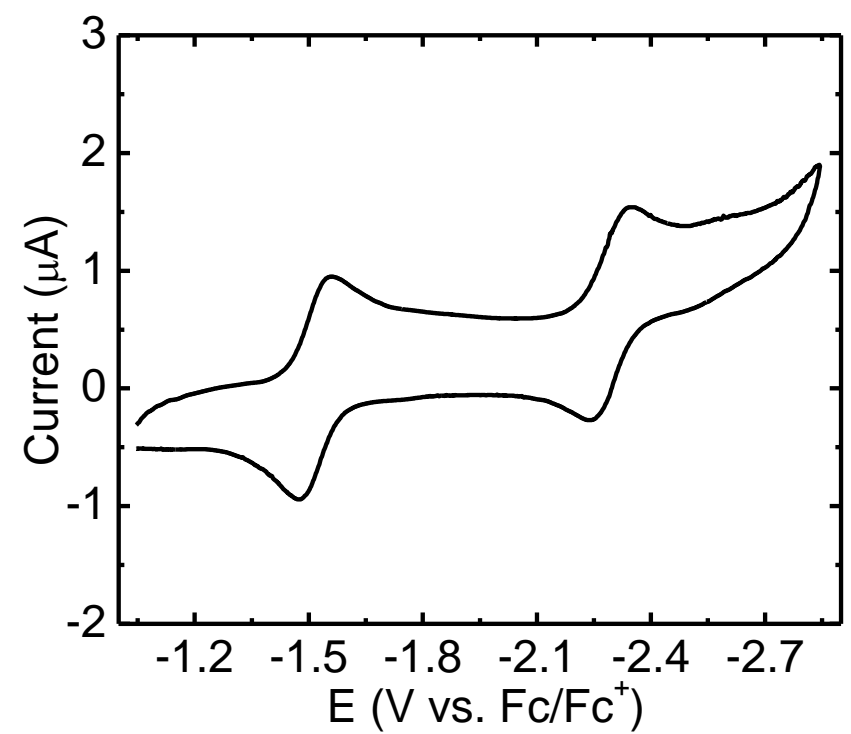

Figure 2.1. $\mathrm{CV}$ of 2.1. Conditions: $100 \mathrm{mV} / \mathrm{s} \mathrm{THF}, 0.01 \mathrm{M}\left[\mathrm{NBu}_{4}\right]\left[\mathrm{PF}_{6}\right], \mathrm{THF}$, glassy carbon working, $\mathrm{Pt}$ auxiliary, $\mathrm{Ag} /[\mathrm{Ag}]\left[\mathrm{NO}_{3}\right]$ reference. 
Reduction of 2.1 with an excess of $\mathrm{Na} / \mathrm{Hg}$ in $\mathrm{THF}$ for fifteen minutes results in a color change from dark brown to deep green. Addition of 12-crown-4 and crystallization results in the isolation of $\left[\left(\left(\mathrm{PhBP}_{3}\right) \mathrm{Fe}\right)_{2}(\mu-\mathrm{S})\right]\left[\mathrm{Na}(12 \text {-crown-4) })_{2}\right](\mathbf{2 . 2})$ as nearly black crystals (Scheme 2.1). If a stronger reductant is used and $\mathbf{2 . 1}$ is instead reduced with two equivalents of $\mathrm{NaC}_{10} \mathrm{H}_{8}$ a black solution results, which upon addition of 12-crown-4 and crystallization results in the formation of $\left[\left(\left(\mathrm{PhBP}_{3}\right) \mathrm{Fe}\right)_{2}(\mu-\mathrm{S})\right]\left[\mathrm{Na}(12 \text {-crown-4 })_{2}\right]_{2}(\mathbf{2 . 3})$ as an extremely air sensitive black solid (Scheme 2.1).

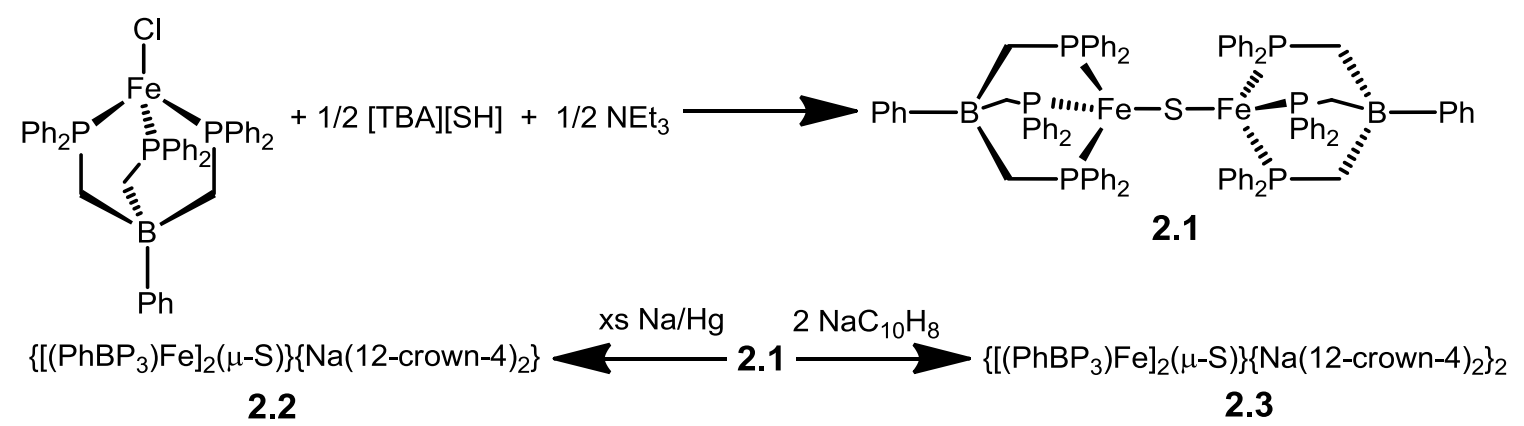

Scheme 2.1. Synthesis of complexes 2.2 and 2.3.

Complexes 2.1, 2.2, and 2.3 have been structurally characterized and display several structural features of note (Figure 2.2). The most striking features present in these complexes are the uniformly short Fe-S distances that are substantially shorter than the average reported Fe-S bond length in bridging sulfides $(2.2 \AA) .{ }^{8}$ The Fe-S distance of 2.071(1) (Table 2.1) $\AA$ in complex 2.3 is, within error, the shortest Fe-S distance reported in the CSD, with a close example of 2.078(8) ^ reported by Coucouvanis and coworkers. ${ }^{9}$ Such short distances are indicative of multiple bonding between Fe and S and such bonding has been invoked in other M-S-M units of the first row transition metals. ${ }^{10}$ 
Additionally, the marginal differences in Fe-S bond lengths in 2.1-2.3 (0.032 $)$ suggest little to no perturbation of the bonding upon reduction.

All three complexes display nearly, or perfectly in the case of $\mathbf{1}$, linear Fe-S-Fe angles. Sulfides of Fe are typically bent as illustrated in the example from Coucouvanis.9 The steric profile of the $\left(\mathrm{PhBP}_{3}\right)$ framework allows for substantially bent $\mathrm{Fe}-\mathrm{X}-\mathrm{Fe}$ geometries $7^{\mathfrak{c}}$ and so the linearity in complexes 2.1-2.3 is also likely indicative of an electronic preference for this geometry such as multiple bonding across the Fe-S-Fe unit. Outside of the Fe-S-Fe core, two structural features deserve mention.
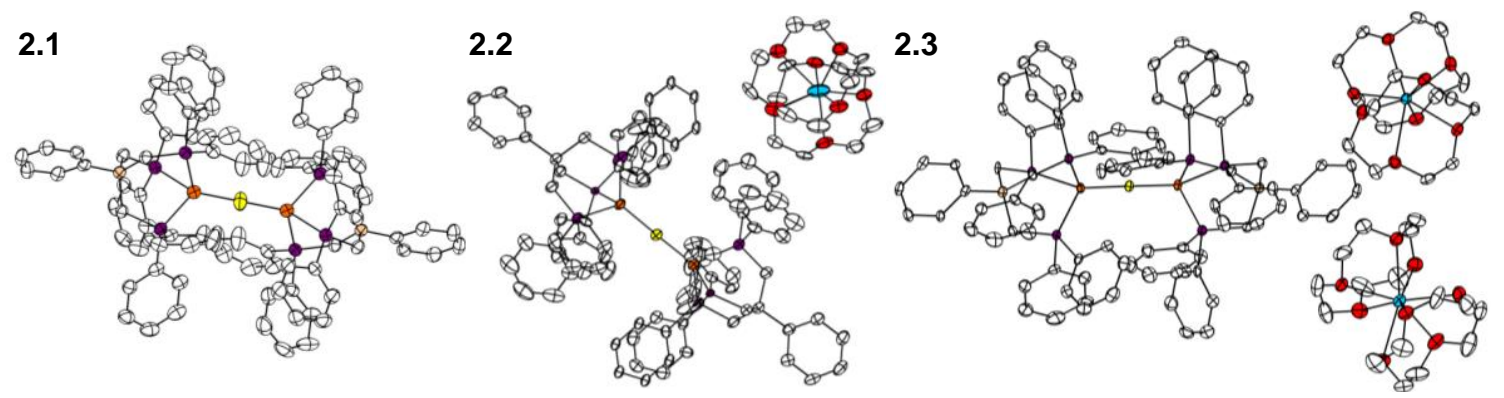

Figure 2.2. XRD structures of complexes 2.1, 2.2, and $\mathbf{2 . 3}$ with ellipsoids at 50\% and hydrogens omitted for clarity. Fe atoms are shown in orange, $\mathrm{S}$ in yellow, $\mathrm{P}$ in purple, $\mathrm{Na}$ in blue, $\mathrm{O}$ in red, and $\mathrm{C}$ in white.

Firstly, the P-Fe-Fe-P torsion angles in $\mathbf{1}$ are $60^{\circ}$ as demanded by the crystallographic inversion center in this complex. Upon reduction, the complex adopts a more "eclipsed" geometry, with P-Fe-Fe-P angles of $18^{\circ}$ in $\mathbf{2 . 2}$ and $13^{\circ}$ in $\mathbf{2 . 3}$. The origin of this structural change is not clear, as the $\pi$-bonding across the Fe-S-Fe unit should not change upon going from $D_{3 d}$ to $D_{3 h}$ symmetry. Secondly, and more curiously, a drastic contraction in Fe-P bond distances is apparent upon reduction of the series of complexes. While complex 2.1 possesses Fe-P bond distances consistent with other 
examples of high-spin Fe(II) from our laboratory, $7^{\mathrm{a}}$ a contraction of $0.22 \AA$ in the average Fe-P bond lengths is apparent upon reduction from $\mathbf{2 . 1}$ to 2.3, resulting in an exceptionally short average Fe-P bond distance of $2.17 \AA$ in $\mathbf{2 . 3}$ (The average Fe-P distance in the CSD is $2.24 \AA$ ). 8 Some contraction in these lengths might be expected from increased back-bonding from the reduced Fe centers, but the short distance of 2.17 $\AA$ is indicative of a low-spin state at Fe, suggesting that a spin-state change has occurred.

\begin{tabular}{ccccc}
\hline Complex & $\begin{array}{c}\mathbf{F e}-\mathbf{S} \\
(\AA)\end{array}$ & $\begin{array}{c}\text { Fe-S-Fe } \\
\left({ }^{\circ}\right)\end{array}$ & $\begin{array}{c}\text { Avg. Fe-P } \\
(\mathbf{A})\end{array}$ & $\begin{array}{c}\Delta \text { Fe-P } \\
(\mathbf{\AA})\end{array}$ \\
\hline $\mathbf{2 . 1}$ & $2.079(8)$ & 180 & 2.393 & 0.04 \\
$\mathbf{2 . 2}$ & $2.1035(3)$ & $173.18(5)$ & 2.215 & 0.19 \\
$\mathbf{2 . 3}$ & 2.077 & $178.83(6)$ & 2.170 & 0.04 \\
\hline
\end{tabular}

Table 2.1. Selected metrics for complexes 2.1, 2.2, and 2.3.

Complexes 2.1, 2.2, and 2.3 all display paramagnetically shifted ${ }^{1} \mathrm{H}$ NMR shifts at RT and so variable temperature magnetic susceptibility measurements were acquired by SQUID magnetometry (Figure 2.3). Complex 2.1 displays a magnetic moment of $2.0 \mu_{\mathrm{B}}$ at $300 \mathrm{~K}$ which decreases relatively linearly upon cooling to $75 \mathrm{~K}$. The room RT magnetic moment, which is substantially smaller than the value of $6.9 \mu_{\mathrm{B}}$ that would be expected for two non-interacting high-spin Fe(II) centers, and the decrease of moment with temperature are both consistent with antiferromagnetic coupling between the two $\mathrm{Fe}$ centers in 2.1. A simulation of the data (Figure 2.3) indicates that the coupling constant between the two Fe centers in 2.1 is $J=-154 \mathrm{~cm}^{-1}$, suggesting strong coupling across the $\mathrm{S}^{2-}$ bridge. Such coupling across linear one-atom bridges is not uncommon and has been observed in other Fe-S-Fe complexes. ${ }^{10,11}$ It should also be noted that the $S_{1}=S_{2}=2$ and $S_{1}=S_{2}=1$ cases should appear similar in the magnetic data and so distinguishing 
between intermediate spin Fe centers by this method is challenging. The long Fe-P bond distances and the Mössbauer data (vide infra) for 2.1 seem to support the high spin $S_{1}=$ $S_{2}=2$ case as more likely.

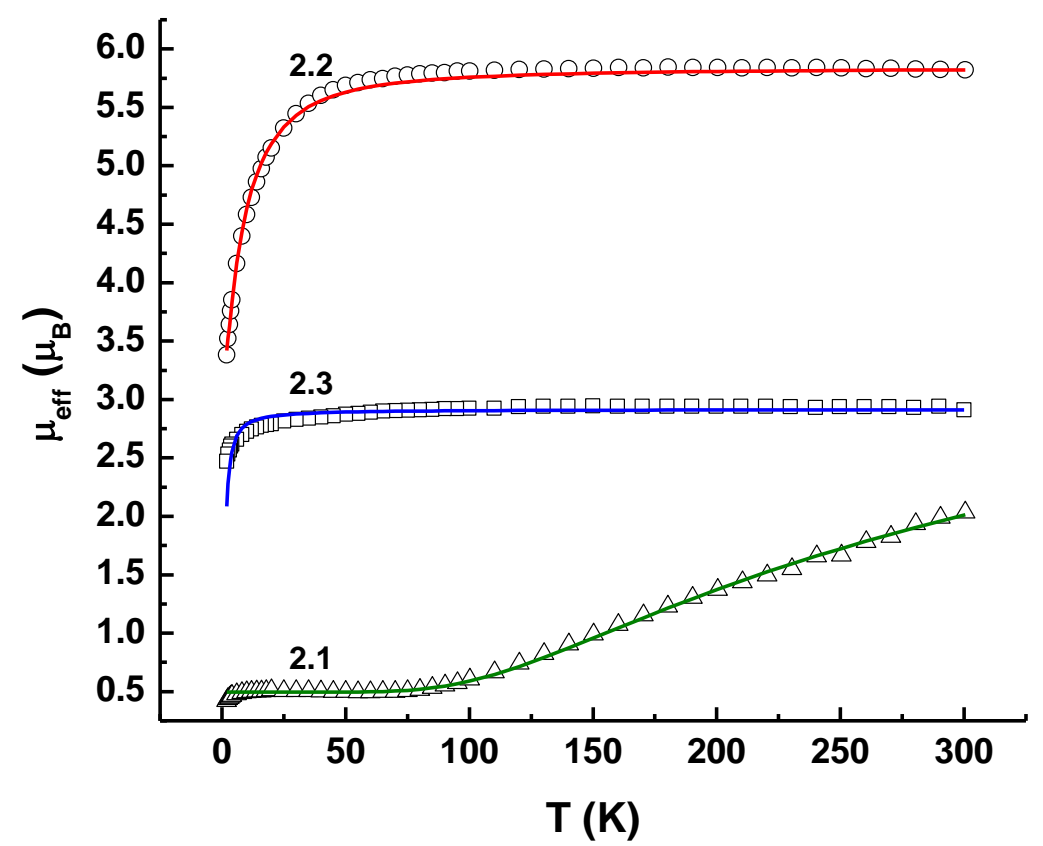

Figure 2.3. Variable temperature magnetic susceptibility measurements on complexes 2.1-2.3.

Unlike complex 2.1, complex 2.2 shows a high magnetic moment of $5.8 \mu_{\mathrm{B}}$ at 300 $\mathrm{K}$ which does not substantially decrease until $\sim 50 \mathrm{~K}$, after which it drops, likely due to intermolecular antiferromagnetic interactions. The lack of a downward slope suggests little to no antiferromagnetic coupling. The possible spin states for a $\mathrm{Fe}(\mathrm{II}) / \mathrm{Fe}(\mathrm{I})$ dimer are $S_{1}=2 S_{2}=3 / 2, S_{1}=2 S_{2}=1 / 2, S_{1}=1 S_{2}=3 / 2, S_{1}=1 S_{2}=1 / 2$, or $S_{1}=0 S_{2}=1 / 2$. If both Fe centers were high spin, as in complex 2.1, a spin-only moment of $6.2 \mu_{\mathrm{B}}$ for two weakly interacting Fe centers might be expected. The fact that the moment of 2.2 is lower than this predicted value and that the moment shows a relatively flat temperature profile down to $50 \mathrm{~K}$ suggests that a high-spin state assignment is likely not reasonable 
for this complex. Accordingly, simulations with $S_{1}=2$ and $S_{2}=3 / 2$ provide poor fits to the data.

\begin{tabular}{cccccc}
\hline Complex & $\boldsymbol{S}_{\boldsymbol{1}}$ & $\boldsymbol{S}_{\mathbf{2}}$ & $\boldsymbol{g}$ & $\boldsymbol{J}\left(\mathbf{c m}^{-\mathbf{1}}\right)$ & $\boldsymbol{\Theta}(\mathbf{K})$ \\
\hline $\mathbf{2 . 1}$ & 2 & 2 & 2.00 & -154 & 0 \\
$\mathbf{2 . 2}$ & 2 & $1 / 2$ & 2.01 & 110 & -5.7 \\
$\mathbf{2 . 3}$ & $1 / 2$ & $1 / 2$ & 2.06 & 197 & -1
\end{tabular}

Table 2.2. Simulation parameters for complexes $\mathbf{2 . 1}, \mathbf{2 . 2}$, and $\mathbf{2 . 3}$ for the fits shown in Figure 2.3.

The moment for 2.2 of $5.8 \mu_{\mathrm{B}}$ at $300 \mathrm{~K}$ is close to the spin-only value for a single $S=5 / 2$ center $\left(5.9 \mu_{\mathrm{B}}\right)$, suggesting that an $S_{1}=2, S_{2}=1 / 2$ or $S_{1}=1, S_{2}=3 / 2$ spin state assignment with strong ferromagnetic coupling seems appropriate. While simulation with either of these parameters provides a reasonable fit, a strongly ferromagnetically coupled $S_{1}=2, S_{2}=1 / 2$ state is the preferred assignment for reasons that will be discussed shortly. As an additional note, ferromagnetic coupling between two metal centers typically results in a magnetic moment that increases with decreasing temperature. When the coupling is very strong, however, the temperature profile can adopt a much flatter gradual slope to a plateau temperature as $J$ becomes large. ${ }^{12}$ The strong coupling between the Fe centers in $\mathbf{2 . 2}$ leads to almost exclusive population of the high-spin state even at RT, as illustrated by the magnetic data. Furthermore, although a value for $J$ is obtained in the fit for the moment of 2.2, it must be stressed that the lack of a significant slope for this complex precludes the accurate determination of $J$, with the data merely requiring a large positive value of $J$. 
The large $J$ value in $\mathbf{2 . 2}$ suggests that there should be some degree of electronic coupling between the two metal centers. Classically, in the case of mixed-valence complexes like $\mathbf{2 . 2}$, one way to probe this coupling has been to examine the line shape of the inter-valence charge transfer (IVCT) band via near-IR spectroscopy. ${ }^{13}$ Complex 2.2 does indeed show a relatively strong IVCT band at $6750 \mathrm{~cm}^{-1}$ (Figure 2.4A) in its near-IR spectrum. Analysis of the lineshape of this band indicates that $\mathrm{H}_{\mathrm{ab}}$ for this complex is $562 \mathrm{~cm}^{-1}$, suggesting a moderate degree of electronic coupling and classifying $\mathbf{2 . 2}$ as class II using the Robin-Day classification system. ${ }^{14}$ In addition to the near-IR data mentioned, low temperature X-band EPR data on 2.2 have been acquired (Figure 2.4B). The $4 \mathrm{~K}$ spectrum of $\mathbf{2 . 2}$ in 2-MeTHF displays a broad signal with a large feature at $g=$ 5.64 and a smaller feature at $g=2.12$. Although the magnetic moment at $4 \mathrm{~K}$ is substantially decreased, likely due to inter-molecular effect, the EPR data suggests that $S$ $>1 / 2$ states are populated even at very low temperatures, consistent with the ferromagnetic coupling observed.

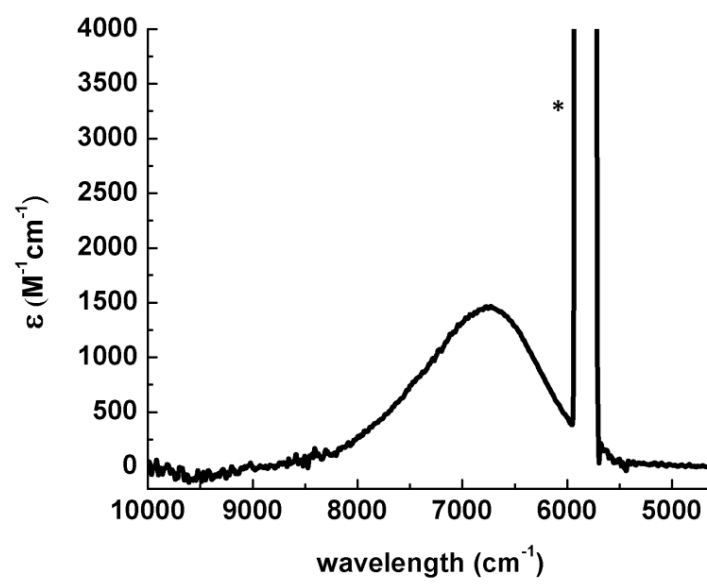

A

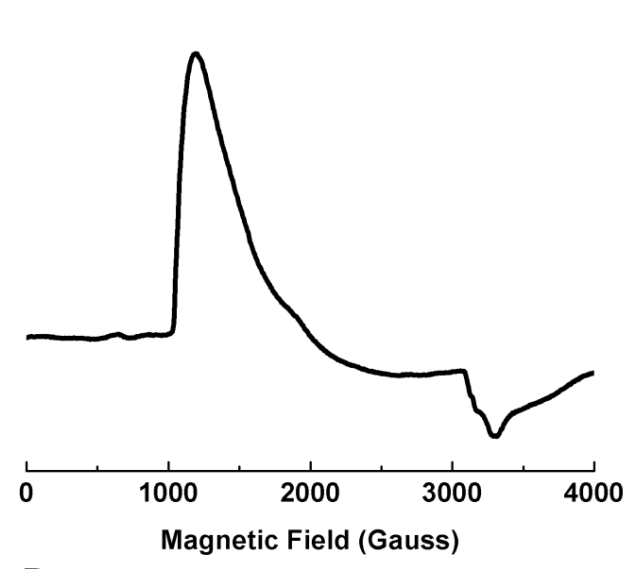

B

Figure 2.4. (A) Near-IR spectrum of complex 2.2. (B) 4 K X-band EPR spectrum of 2.2. Conditions for (A): THF, 0.013 M. Note that the asterisk denotes a large feature due to 
solvent background subtraction. Conditions for (B): microwave power, $20.313 \mathrm{~mW}$; microwave frequency, 9.380 GHz; modulation amplitude, $4.00 \mathrm{G}$; gain, 5020 .

The dianionic complex $\mathbf{2 . 3}$ was analyzed similarly to monoanionic 2.2. Complex 2.3 displays a similar temperature dependence to that observed in complex 2.2 with little to no change from the $\mu_{\mathrm{eff}}=2.8 \mu_{\mathrm{B}}$ value observed at $300 \mathrm{~K}$ until the temperature drops below $\sim 100 \mathrm{~K}$. It is even more apparent for this sample that a high-spin assignment for the two Fe centers is inappropriate, as two $S=3 / 2$ centers without antiferromagnetic coupling, which can again be excluded by the dependence of the moment on temperature, should have a minimum $\mu_{\mathrm{eff}}$ of $5.5 \mu_{\mathrm{B}}$. A similar analysis to that performed for $\mathbf{2 . 2}$ leads to the conclusion that an $S_{1}=S_{2}=1 / 2$ spin state assignment with a large degree of ferromagnetic coupling between the two magnetic centers adequately describes the magnetic behavior and these parameters provide a reasonable fit to the data (Figure 2.3, table 2.2). As was found in the case of 2.2, the absence of a well-defined slope for $\mathbf{2 . 3}$ precludes the accurate determination of $J$, but a large positive value seems required. These combined crystallographic and magnetic data suggest that the reduced Fe centers in 2.2 and 2.3 are undergoing a spin transition to $S=1 / 2$ upon reduction. Low-spin $\mathrm{Fe}(\mathrm{I})$ centers are uncommon in general, and are even more rare in tetrahedral geometries. In order to obtain more confirmation of this assignment, Mössbauer data were collected on the redox series of complexes.

Complex 2.1 displays a quadrupole doublet with an isomer shift of $\delta=0.49 \mathrm{~mm} / \mathrm{s}$ and a quadrupole splitting of $\Delta \mathrm{E}_{\mathrm{q}}=1.91 \mathrm{~mm} / \mathrm{s}$ in its $80 \mathrm{~K}$ Mössbauer spectrum (Figure 2.4). Related high-spin Fe(II) complexes on the $\mathrm{PhBP}_{3}$ scaffold have shown parameters 
that are quite similar to these values. ${ }^{15}$ Upon reduction, a new spectrum is obtained that can be fit as two independent sites in a 1:1 ratio. The parameters for the two signals indicate one site having $\delta=0.47 \mathrm{~mm} / \mathrm{s}$ and $\Delta \mathrm{E}_{\mathrm{q}}=1.14 \mathrm{~mm} / \mathrm{s}$ and the other site having drastically different parameters of $\delta=0.16 \mathrm{~mm} / \mathrm{s}$ and a small poorly resolved quadrupole splitting of $\Delta \mathrm{E}_{\mathrm{q}}=0.01 \mathrm{~mm} / \mathrm{s}$. The reasonable assignment for this spectrum is that the two Fe sites are resolved on the Mössbauer timescale. While the first site is still relatively consistent with high-spin Fe(II) centers, the second site, and its negligible quadrupole splitting, suggest a different electronic structure.

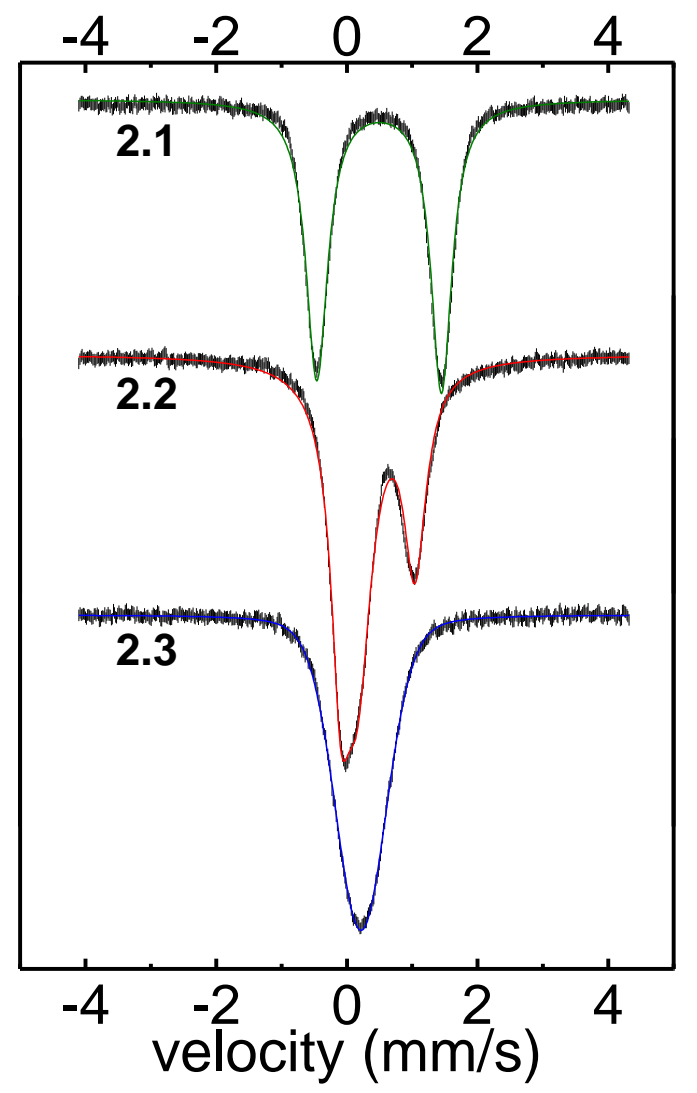

Figure 2.5. $80 \mathrm{~K}$ Mössbauer spectra of solid samples of complexes 2.1-2.3 and corresponding fits. 
Upon further reduction to $\mathbf{2 . 3}$, the quadrupole doublet signal disappears and the remaining signal has $\delta=0.22 \mathrm{~mm} / \mathrm{s}$ with no resolvable quadrupole splitting. Previously reported $\mathrm{Fe}(\mathrm{I})$ complexes on $\mathrm{PhBP}_{3}$ are high-spin, and their Mössbauer parameters do not show good agreement with the parameters found in $\mathbf{2 . 3}$, suggesting that this site is not well modeled as a high-spin $\mathrm{Fe}(\mathrm{I})$ site, leaving a low-spin $\mathrm{Fe}(\mathrm{I})$ site as the most plausible alternative, especially when considering the magnetic and structural data already presented. The values for the isomer shifts of the reduced Fe centers in 2.2 and $\mathbf{2 . 3}$ deserve some mention, as one typically observes an increase in $\delta$ upon reduction. ${ }^{16}$ The observed negative change in $\delta$ is likely a result of the high covalency and greater backbonding into the phosphine ligands in this series of complexes as well as the proposed spin-state change.

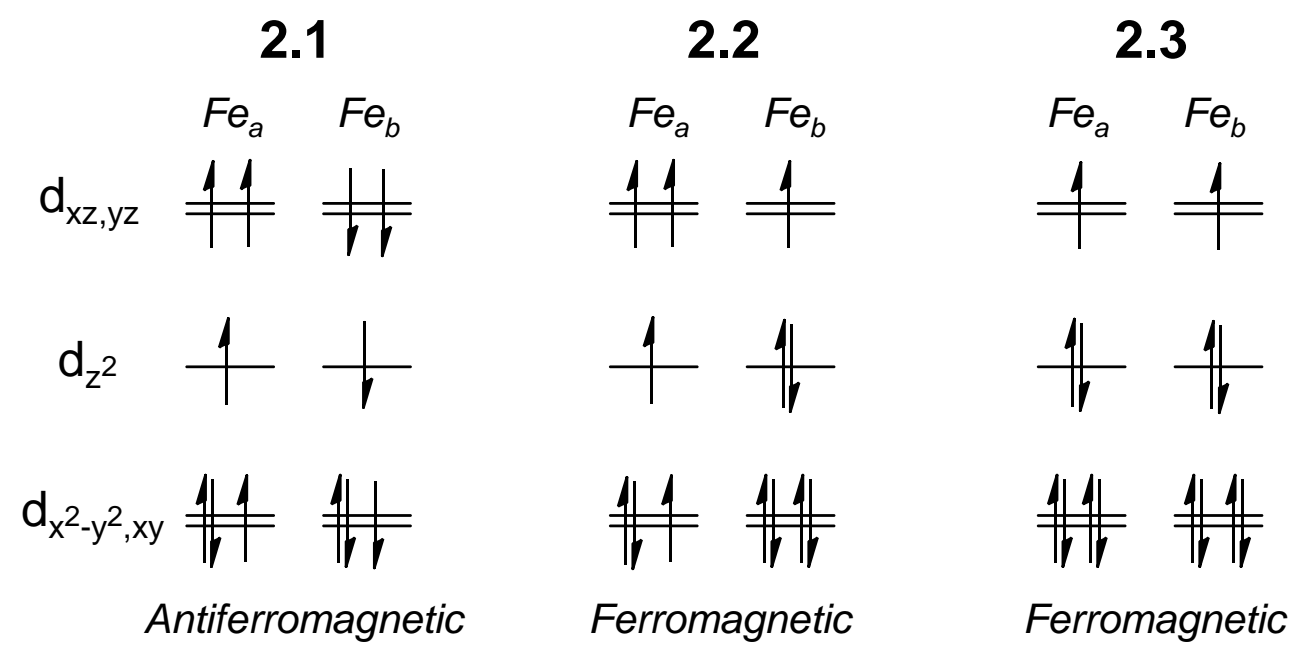

Figure 2.6. Qualitative d-orbital splitting diagrams illustrating the coupling in 2.1-2.3.

A satisfying explanation for the observed structural, magnetic, and spectroscopic data for this series of redox complexes warrants consideration. The structural data, 
especially the short Fe-P bond distances in the reduced complexes, certainly suggest a low-spin configuration at Fe. The magnetic data, however, show an increase in the magnetic moment, which has been attributed to change in the magnetic coupling between the Fe centers from antiferromagnetic in 2.1 to ferromagnetic in 2.2 and 2.3. While this change may seem capricious, consideration of a qualitative orbital diagram and the interactions involved in magnetic coupling provides a clear rationale for this phenomenon (Figure 2.6).

In all three complexes there are two avenues by which magnetic coupling can occur through the diamagnetic $\mathrm{S}^{2-}$ linker: one $\sigma$-symmetry interaction involving metal orbitals of $\mathrm{d}_{\mathrm{z}^{2}}$ parentage and two degenerate $\pi$-symmetry interactions involving metal orbitals of $d_{x z, y z}$ parentage. In high-spin 2.1, both the $\sigma$ and $\pi$ orbitals are half-filled on both metal centers, resulting in an antiferromagnetic interaction through both manifolds. Upon reduction to $\mathbf{2 . 2}$ and subsequent transition of one Fe center to low-spin states, however, the $\sigma$ manifold will have one filled orbital and one half-filled orbital, resulting in a ferromagnetic interaction. ${ }^{17}$ While it is unclear whether the interaction in the $\pi$ manifold will be ferromagnetic or antiferromagnetic, it is likely that the $\sigma$ coupling will dominate the overall magnetism of the complex. When both Fe centers are low spin, as in $\mathbf{2 . 3}$, the $\sigma$ set of orbitals will be completely filled, excluding coupling through this manifold. Each metal center will have a quarter filled E set of orbitals which, due to their degeneracy, will result in a ferromagnetic interaction as required by Hund's rule. ${ }^{17}$ When this explanation is compared with the available data, the observed change in magnetic coupling meshes well with the proposed spin-state transition and neatly ties together the observed properties of complexes 2.1-2.3. 


\subsubsection{Reactivity with Small Molecules}

With this redox series of complexes well characterized, further studies of the reactivity of these complexes with small molecules relevant to nitrogenase and other $\mathrm{Fe}$ S-Fe containing enzymes were of interest. As an initial foray into these investigations, the reactivity of $\mathrm{N}_{2} \mathrm{H}_{4}$ and $\mathrm{CO}$ with complex 2.1 was investigated (Scheme 2.2). Reaction of 2.1 with excess $\mathrm{N}_{2} \mathrm{H}_{4}$ results in a gradual color change from dark brown to dark red-orange. XRD data obtained on red crystals indicate that the diamagnetic product is $\left(\left(\mathrm{PhBP}_{3}\right) \mathrm{Fe}\right)\left(\mu-\eta^{1}: \eta^{1}-\mathrm{N}_{2} \mathrm{H}_{4}\right)\left(\mu-\eta^{2}: \eta^{2}-\mathrm{N}_{2} \mathrm{H}_{2}\right)\left(\left(\mathrm{PhBP}_{2} \mathrm{PS}\right) \mathrm{Fe}\right)\left(\left(\mathrm{PhBP}_{2} \mathrm{PS}\right)=\right.$ $\left.\left[\mathrm{PhB}\left(\mathrm{CH}_{2} \mathrm{PPh}_{2}\right)_{2}\left(\mathrm{CH}_{2} \mathrm{P}(\mathrm{S}) \mathrm{Ph}_{2}\right)\right]^{-}\right)($2.4) $($Figure 2.7). This complex features an unusual $\mathrm{SFe}_{2} \mathrm{~N}_{4} \mathrm{H}_{6}$ core similar to a previously reported example from our laboratory. ${ }^{18}$ If $\mathbf{2 . 1}$ is instead reacted with 1 atm of $\mathrm{CO}$, a deep purple solution is obtained that is indicative of the product $\left[\left(\mathrm{PhBP}_{3}\right) \mathrm{Fe}(\mathrm{CO})\right]_{2}(\mu-\mathrm{S})(\mathbf{2 . 5})$. Complex 2.5 is diamagnetic and displays a strong C-O stretch at $v_{\mathrm{CO}}=1950 \mathrm{~cm}^{-1}$.

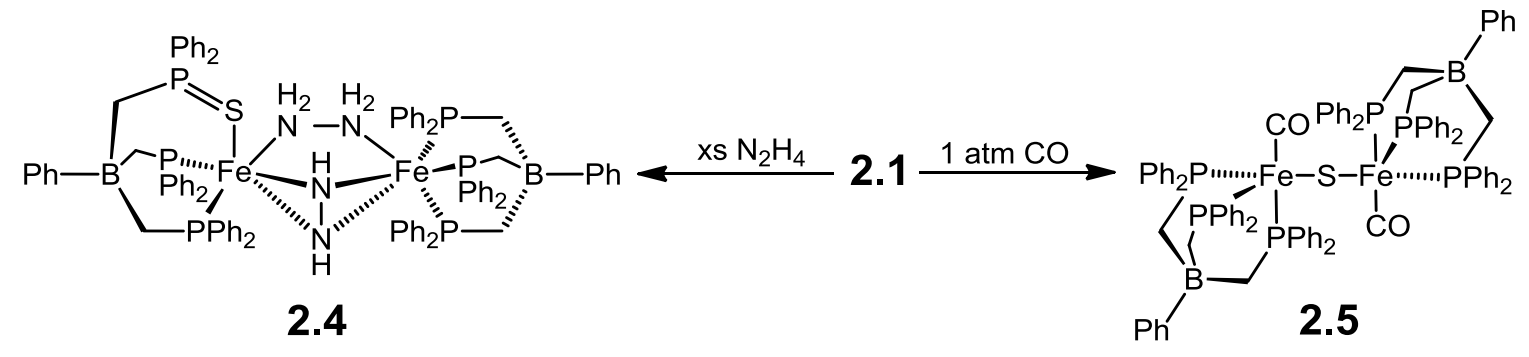

Scheme 2.2. Synthesis of complexes 2.4 and 2.5.

Both complexes $\mathbf{2 . 4}$ and $\mathbf{2 . 5}$ have been crystallographically characterized and their core atoms are shown in Figure 2.7. In 2.4, the once-bridging sulfur atom has migrated to a phosphine arm, forming a phosphine sulfide exemplified by a short P-S distance of 
1.997(2). The two nitrogenous ligands are best described as a hydrazine and a hydrazido(2-) as indicated by long $\mathrm{N}-\mathrm{N}$ distances of 1.449(5) and 1.451(4) respectively. The migration of $\mathrm{S}$ onto $\mathrm{P}$ is likely favorable due to the formation of a relatively strong $\mathrm{P}$ $\mathrm{S}$ bond as well as the driving force to form the octahedral and diamagnetic $\mathrm{Fe}_{2} \mathrm{~N}_{4} \mathrm{H}_{4}$ core. $\mathrm{XRD}$ data for $\mathbf{2 . 5}$ indicate that one $\mathrm{CO}$ molecule is coordinated to each iron center to give a pseudo-trigonal bipyramidal geometry about Fe. The Fe-S bond distances do not change significantly from those in $\mathbf{2 . 1}$, elongating slightly to $2.1027(7) \AA$ while the Fe-SFe linkage maintains an angle of about $162^{\circ}$. These bond metrics suggest some maintenance of multiple bonding across the Fe-S-Fe unit. The observed diamagnetism of 2.5 when compared with $\mathbf{2 . 1 - 2 . 3}$ is likely a result of the combination of a stronger ligand set with the addition of a $\mathrm{CO}$ ligand, the higher coordination number at $\mathrm{Fe}$, and potential antiferromagnetic coupling across the $S^{2-}$ bridge.

\section{4}

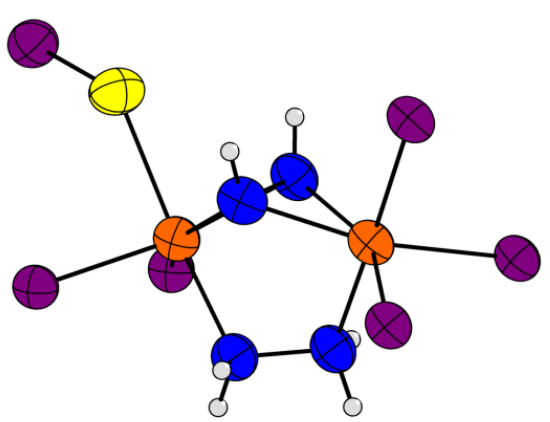

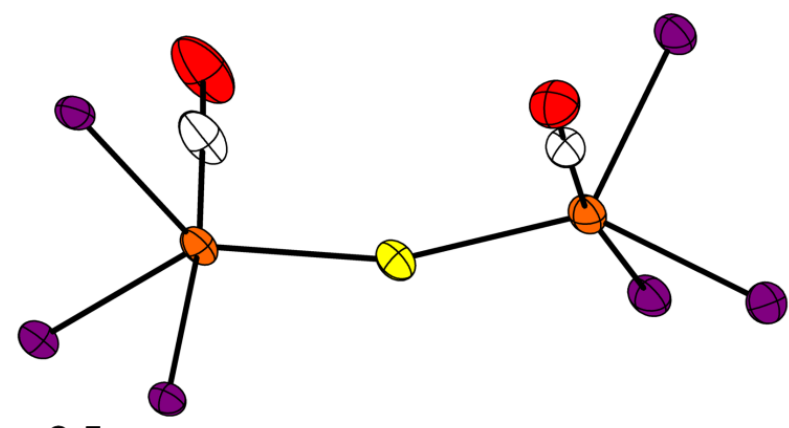

2.5

Figure 2.7. XRD structures of the cores of complexes $\mathbf{2 . 4}$ and $\mathbf{2 . 5}$ with ellipsoids at $50 \%$. Fe atoms are shown in orange, $\mathrm{S}$ in yellow, $\mathrm{P}$ in purple, $\mathrm{Na}$ in blue, $\mathrm{O}$ in red, $\mathrm{H}$ in gray, and $\mathrm{C}$ in white. Selected bond lengths $(\AA)$ and angles $\left(^{\circ}\right)$ for 2.4: $\mathrm{Fe}(2)-\mathrm{S}(1)=$ 2.3382(12), $\mathrm{N}(1)-\mathrm{N}(2)=1.449(5), \mathrm{N}(3)-\mathrm{N}(4)=1.451(4), \quad \mathrm{S}(1)-\mathrm{P}(6)=1.9970(17)$.

Selected bond lengths $(\AA)$ and angles $\left(^{\circ}\right)$ for 2.5: $\mathrm{Fe}(1)-\mathrm{S}(1)=2.1027(7), \operatorname{Fe}(2)-\mathrm{S}(1)=$ 2.1028(7), $\mathrm{Fe}(2)-\mathrm{S}(1)-\mathrm{Fe}(1)=162.10(4)$. 
The CV of $\mathbf{2 . 5}$ displays similar electrochemistry to that of $\mathbf{2 . 1}$ showing two reductions at $-1.25 \mathrm{~V}$ and $-2.09 \mathrm{~V}$ with respect to the $\mathrm{Fc} / \mathrm{Fc}^{+}$couple (Figure $2.8 \mathrm{~A}$ ). Additionally, a new quasi-reversible oxidation appears at $0.20 \mathrm{~V}$. Despite these new waves, no chemical reductions provided tractable products. The second reduction couple at $-2.09 \mathrm{~V}$ versus $\mathrm{Fc} / \mathrm{Fc}^{+}$displays a typical cathodic increase in current upon scanning negatively, but upon reversal of the scan polarity two re-oxidation peaks are observed. Analysis of the scan-rate dependence of these two peaks (Figure 2.8B) shows the more negative peak increasing in intensity with faster scan rates. This observation may be explained by a ligand dissociation event in which one redox event is observed with the ligand still bound at more negative potentials and one redox event is observed where a ligand is not bound at more positive potentials. This phenomenon has been observed previously in TPPFeCl (TPP = tetraphenylporphyrin). ${ }^{19}$ In the case of 2.5 the ligand dissociation event likely involves reversible loss of a phosphine arm.
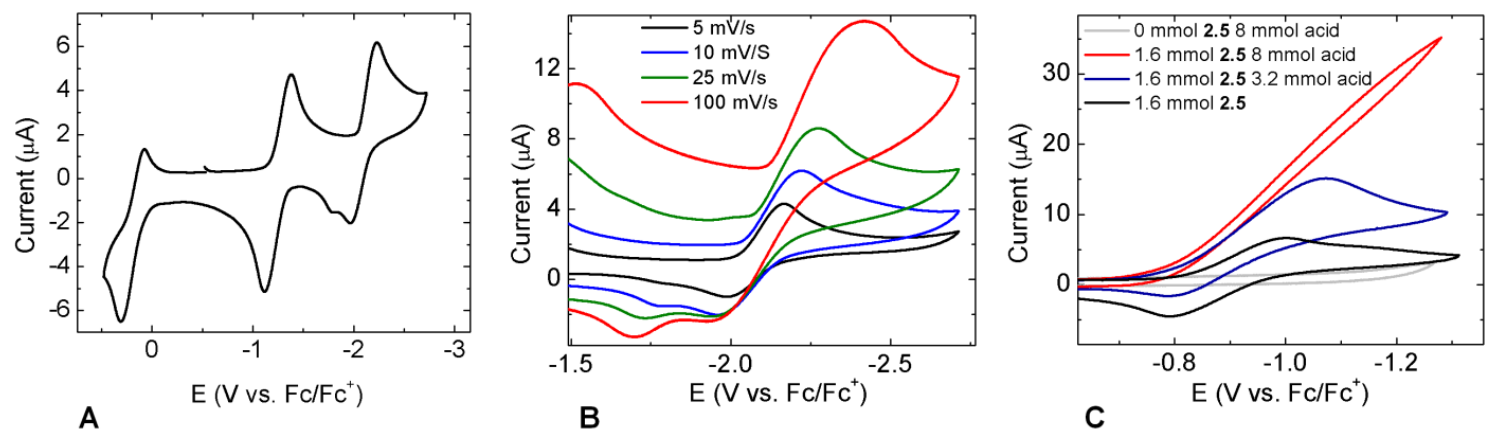

Figure 2.8. (A) CV of 2.5 at $10 \mathrm{mV} / \mathrm{s}$. (B) CV's of 2.5 at differing scan rates. (C) CV of 2.5 at $10 \mathrm{mV} / \mathrm{s}$ with the listed concentrations of $p$-toluenesulfonic acid. All scans were taken in THF with the following conditions: [TBA] $\left[\mathrm{PF}_{6}\right], \mathrm{THF}$, glassy carbon working, $\mathrm{Pt}$ auxiliary, $\mathrm{Ag} /[\mathrm{Ag}]\left[\mathrm{NO}_{3}\right]$ reference. 
Due to the resemblance of the ligand set of complex 2.5 with hydrogenase enzymes and the hydrogenase function of nitrogenase in the absence of $\mathrm{N}_{2}$, electrocatalytic reactivity towards acid was investigated (Figure 2.8C). Complex 2.5 shows no apparent reactivity with acid sources as gauged by proton NMR. Addition of p-toluenesulfonic acid to a $\mathrm{CV}$ of $\mathbf{2 . 5}$, however, results in an increase in reductive current at $\sim-0.8 \mathrm{~V}$ vs. $\mathrm{Fc} / \mathrm{Fc}^{+}$. The electrocatalytic peak onsets near the couple assigned as $\mathrm{Fe}(\mathrm{II}) \mathrm{Fe}(\mathrm{II}) / \mathrm{Fe}(\mathrm{II}) \mathrm{Fe}(\mathrm{I})$, indicating that these oxidation states may be involved in the catalytic cycle. An overpotential of $\sim 560 \mathrm{mV}$ can be estimated ${ }^{20}$ for the electrocatalytic reduction, which is in the typical range of 400 to $700 \mathrm{mV}$ observed in most hydrogenase mimics. $4^{\mathrm{d}}$ Bulk electrolyses of $\mathbf{2 . 5}$ in a standard two chamber cell show a Faradaic efficiency of $77 \%$, indicating that the majority of protons and electrons are used in producing $\mathrm{H}_{2}$.

\subsection{Conclusion}

Taken together, the Fe-S-Fe complexes presented in this chapter display rich redox, magnetic, spectroscopic, and catalytic features. The highly reduced complexes $\mathbf{2 . 2}$ and 2.3 illustrate that $S^{2-}$ can still be bound to low-valent Fe as could be necessary in nitrogenase for $\mathrm{N}_{2}$ binding. Furthermore, these reduced Fe centers adopt a low-spin state which could also prove beneficial for $\mathrm{N}_{2}$ binding. In addition to the reduced Fe-S-Fe complexes, 2.1 shows interesting reactivity with $\mathrm{N}_{2} \mathrm{H}_{4}$ and $\mathrm{CO}$, resulting in complex $\mathbf{2 . 5}$ which shows functionality as a hydrogen evolution catalyst. These studies begin to 
highlight some of the electronic features that might be critical for the function of biological enzymatic systems with Fe-S-Fe units.

\subsection{Experimental Section}

\subsubsection{General Considerations}

Unless otherwise noted, all compounds were prepared by literature procedures or purchased from commercial sources. Specifically, the starting material $\left(\mathrm{PhBP}_{3}\right) \mathrm{FeCl}$ was made according to its literature preparation. ${ }^{21}$ All manipulations were carried out under a dinitrogen atmosphere by utilizing standard glovebox or Schlenk techniques to exclude oxygen and water. Solvents were dried and de-oxygenated by an argon sparge followed by passage through an activated alumina column purchased from S.G. Waters Company. All solvents were tested with a standard sodium-benzophenone ketyl solution to ensure the absence of oxygen and water. NMR measurements were obtained on Varian 300 or $500 \mathrm{MHz}$ or Bruker $400 \mathrm{MHz}$ spectrometers. Deuterated solvents for these measurements were obtained from Cambridge Isotope Laboratories and were dried and degassed prior to use. All ${ }^{1} \mathrm{H}$ spectra were referenced to residual solvent peaks. IR spectra were obtained via KBr pellets on a Bio-Rad Excalibur FTS 3000 spectrometer using Varian Resolutions Pro software set at $4 \mathrm{~cm}^{-1}$ resolution. Near-IR spectra were obtained using a Nicolet FT-NIR spectrometer with quartz cuvettes sealed with a groundglass stopper 


\subsubsection{Electrochemical Measurements}

All experiments were conducted with a $\mathrm{CH}$ Instruments 630-C Electrochemical Analyzer and the CHI Version 8.09 software package. Both CV and bulk electrolysis experiments were conducted under an atmosphere of dinitrogen with $0.1 \mathrm{M}[\mathrm{TBA}]\left[\mathrm{PF}_{6}\right]$ in THF as the electrolyte. Cyclic voltammetry experiments were conducted in a single cell setup with a platinum wire as the auxiliary electrode, a $\mathrm{Ag} /[\mathrm{TBA}]\left[\mathrm{PF}_{6}\right] / \mathrm{THF}$ pseudoreference electrode separated from the solution by a Vycor frit (Bioanalytical Systems, Inc.), and a $0.078 \mathrm{~cm}^{2}$ glassy carbon electrode (Bioanalytical Systems, Inc.). Ferrocene was included in scans as an internal standard of potential.

Bulk Electrolyses were performed under identical conditions in a sealed 2chamber cell with the working and reference electrode in the first cell and the auxiliary electrode in the second cell. The two chambers were separated by a fine glass frit. While an identical reference electrode was used, the working electrode was a glassy carbon slab (Tokai Carbon USA) submerged such that roughly $64 \mathrm{~cm}^{2}$ was in the electrolyte solution and the auxiliary electrode was a $3.18 \mathrm{~mm}$ thick piece of carbon felt (Alfa Aesar) which was similarly submerged to the working electrode. Quantification of $\mathrm{H}_{2}$ was performed by extraction of an aliquot of the headspace and analysis with an Agilent 7890A gas chromatograph using a thermal conductivity detector.

\subsubsection{EPR Measurements}

EPR X-band spectrometry was obtained on a Bruker EMX spectrometer with the aid of Bruker Win-EPR software suite version 3.0. The spectrometer was equipped with a rectangular cavity which operated in the $\mathrm{TE}_{102}$ mode. Temperature control was 
achieved with the use of an Oxford continuous-flow helium cryostat (temperature range $3.6-300 \mathrm{~K})$. The microwave bridge came equipped with a frequency counter which enabled accurate measurement of the frequency values. The sample was prepared in a 9:1 THF:1-MeTHF solution in an EPR tube sealed with a Teflon stopcock.

\subsubsection{Magnetic Measurements}

Data was obtained using a Quantum Designs SQUID magnetometer running MPMSR2 software (Magnetic Property Measurement System Revision 2) at a field strength of $50000 \mathrm{G}$. Samples were inserted into the magnetometer in plastic straws sealed under nitrogen with polycarbonate capsules. Loaded samples were centered within the magnetometer using the DC centering scan at $35 \mathrm{~K}$ and 5000 gauss. Data were acquired at 2-20 K (one data point every $2 \mathrm{~K}$ ), and 20-310 K (one data point every $5 \mathrm{~K}$ ). The magnetic susceptibility was adjusted for diamagnetic contributions using the constitutive corrections of Pascal's constants, as well as a diamagnetic subtraction due to the holder diamagnetism. Data workup, including simulations, was performed in the JulX software package. ${ }^{22}$

\subsubsection{Mössbauer Spectroscopy}

Spectra were recorded on a spectrometer from SEE Co (Edina, MN) operating in the constant acceleration mode in a transmission-geometry. Spectra were recorded with the temperature of the sample maintained at $80 \mathrm{~K}$. The sample was kept in an SVT-400 dewar from Janis (Wilmington, MA) at zero field. Application of a magnetic field of 54 $\mathrm{mT}$ parallel to the $\gamma$-beam did not cause detectable changes in the spectra recorded at 80 
$\mathrm{K}$. The quoted isomer shifts are relative to the centroid of the spectrum of a metallic foil of $\alpha$-Fe at RT. Samples were prepared by grinding polycrystalline material into a fine powder and then mounted in a cup fitted with a screw-cap as a boron nitride pellet. Data analysis was performed using the program $\mathrm{WMOSS}^{23}$ and quadrupole doublets were fit to Lorentzian lineshapes.

\subsubsection{X-Ray Crystallography}

Data were obtained at low temperatures on a Siemens or Bruker Platform threecircle diffractometer coupled to a Bruker-AXS Smart Apex CCD detector with graphitemonochromated Mo or $\mathrm{Cu} \operatorname{K} \alpha$ radiation $(\lambda=0.71073$ or $1.54178 \AA$, respectively), performing $\varphi$-and $\omega$-scans. All structures were solved by standard direct or Patterson methods and refined against $\mathrm{F}^{2}$ using the SHELX program package. ${ }^{24,25,26}$ All atoms, with the exception of hydrogens, were anisotropically refined. All hydrogen atoms were calculated using a standard riding model.

Several disordered ligand and solvent molecules were refined with the use of standard restraints. It is noteworthy that in the structure of $\mathbf{2 . 1}$ additional electron density was found in the central core of the molecule. This was modeled as a small percentage of a disordered bis-thiolate. While the bond lengths in $\mathbf{1}$ seem longer than what would be expected for similar molecules, these models fit the data quite well and were left in. The structure of 2.2 suffers from a large amount of disorder in solvent and counterion molecules. This leads to poor, although still acceptable, overall statistics. Additionally, there is a small component of disorder present in the phosphine ligands of 2.2. This disorder may be a manifestation of localization of the inter-valence species. 


\subsubsection{Synthesis}

Synthesis of $((\mathbf{P h B P}) \mathbf{F e})_{2}(\boldsymbol{\mu}-\mathbf{S})$, 2.1. $\left(\mathrm{PhBP}_{3}\right) \mathrm{FeCl}(0.301 \mathrm{~g}, 0.39 \mathrm{mmol})$ and $\mathrm{NEt}_{3}(0.1$ $\mathrm{mL}, 0.72 \mathrm{mmol})$ were dissolved in benzene $(10 \mathrm{~mL})$ to form a bright yellow solution. To this, a suspension of [TBA] [SH] $(0.081 \mathrm{~g}, 0.29 \mathrm{mmol})$ in THF $(5 \mathrm{~mL})$ was added dropwise over 5 minutes. The solution rapidly turned dark brown with dark precipitate and was allowed to stir at RT for 2 hours. After this time, solvent was removed in vacuo and the remaining residue was extracted into benzene $(10 \mathrm{~mL})$ and filtered through a silica plug. The benzene solution was frozen and lyophilized to yield $\mathbf{2 . 1}$ as a dark brown powder $(0.150 \mathrm{~g}, 0.01 \mathrm{mmol}, 51 \%)$. X-ray quality crystals were grown from pentane diffusion into a concentrated benzene solution of 2.1. ${ }^{1} \mathrm{H}$ NMR $\left(\mathrm{C}_{6} \mathrm{D}_{6}, \delta\right): 28.29$ (s), 14.67 (s), 10.50 (t, J = 7 Hz), 9.75 (t, J = 7 Hz), 5.56 (s), 4.20 (t, J = 7 Hz), 2.76 (br s). UV-vis (THF) $\lambda_{\max }, \mathrm{nm}\left(\varepsilon, \mathrm{M}^{-1} \mathrm{~cm}^{-1}\right): 944$ (sh), 905 (5550), 637 (2140), 350 (13310), 301 (16580), 263 (sh). Anal. Calc. for $\mathrm{C}_{90} \mathrm{H}_{82} \mathrm{~B}_{2} \mathrm{Fe}_{2} \mathrm{P}_{6} \mathrm{~S}$ : C 71.36; H 5.46. Found: C 71.04; $\mathrm{H}$ 5.45 .

Synthesis of $\left[\left(\left(\mathrm{PhBP}_{3}\right) \mathbf{F e}\right)_{2}(\mu-\mathrm{S})\right][\mathrm{Na}(12-\mathrm{crown}-4) 2], 2.2$. A solution of $2.1(0.050 \mathrm{~g}$, $0.03 \mathrm{mmol})$ in THF $(5 \mathrm{~mL})$ was placed over a freshly prepared amalgam of sodium $(0.01$ $\mathrm{g}, 0.43 \mathrm{mmol})$ and mercury $(1 \mathrm{~g})$ with a stir bar. The amalgam was stirred for 15 minutes, over which time the solution turned dark green. The THF solution was then decanted from the amalgam and filtered through a celite plug before volatiles were removed. The resulting dark green solid was triturated and washed $3 \mathrm{x}$ with ether and benzene $(3 \mathrm{ml})$ before being taken up in a minimum of THF. 12-crown-4 $(0.1 \mathrm{~mL}, 0.6$ mmol) was then added before the solution was layered with pentane and cooled to $-35{ }^{\circ} \mathrm{C}$ 
to crystallize overnight. After 12 hours the mother liquor was removed and the dark crystals were washed $3 \mathrm{x}$ with benzene $(3 \mathrm{~mL})$ to provide 2.2 as a black solid $(0.047 \mathrm{~g}$, 0.025 mmol, 76\%). ${ }^{1} \mathrm{H}\left(\mathrm{THF}_{8}, \delta\right): 53.68$ (br s), 10.54 (s), 9.64 (s), 1.93 (s), 0.053 (br s). UV-vis (THF) $\lambda_{\max }, \mathrm{nm}\left(\varepsilon, \mathrm{M}^{-1} \mathrm{~cm}^{-1}\right): 944$ (sh), 905 (5550), 740 (sh), 638 (8463), 511 (sh), 346 (24420), 296 (28560). Elemental analysis was obtained on the bis-THF adduct obtained prior to 12-crown-4 addition, Anal. Calc. for $\mathrm{C}_{114} \mathrm{H}_{124} \mathrm{~B}_{2} \mathrm{Fe}_{2} \mathrm{NaO}_{6} \mathrm{P}_{6} \mathrm{~S}$ : C 69.70, H 6.36. Found: C 69.08, H 6.41.

Synthesis of $\left[\left(\left(\mathbf{P h B P}_{3}\right) \mathbf{F e}\right)_{2}(\boldsymbol{\mu}-\mathrm{S})\right]\left[\mathbf{N a}(12-\text { crown-4)2 })_{2}, 2.3\right.$. Naphthalene $(0.009 \mathrm{~g}, 0.07$ mmol) was mixed with sodium $(0.01 \mathrm{~g}, 0.43 \mathrm{mmol})$ and a stirbar in a $20 \mathrm{~mL}$ scintillation vial. THF ( $2 \mathrm{~mL})$ was added and the resulting mixture was vigorously stirred for 2 hours, over which time the liquid phase turned dark green. $2.1(0.050 \mathrm{~g}, 0.03 \mathrm{mmol})$ in THF (5 $\mathrm{mL}$ ) was cooled to $-35{ }^{\circ} \mathrm{C}$ for 30 minutes. After this time the solution of $\mathrm{NaC}_{10} \mathrm{H}_{8}$ was filtered through a glass fiber filter paper into the solution of 1 . The solution was allowed to stir at RT for 10 minutes, during which time the color of the solution darkened to black. The solution was then concentrated to half volume before 12-crown-4 (0.012 g, $0.06 \mathrm{mmol}$ ) was added. The solution was then layered with $3 \mathrm{~mL}$ of pentane before being cooled to $-35{ }^{\circ} \mathrm{C}$ overnight to yield a black crystalline material which was then washed $3 \mathrm{x}$ with benzene $(3 \mathrm{~mL})$ to yield $3(0.037 \mathrm{~g}, .015 \mathrm{mmol}, 49 \%)$. ${ }^{1} \mathrm{H}$ NMR $\left(\mathrm{THF}-\mathrm{d}_{8}, \delta\right): 10.36$ (br s), 8.63 (br s), 7.83 (s), 7.23 (br s), 7.04 (br s), 0.04 (br s), -1.75 (br s). Anal. Calc. for $\mathrm{C}_{122} \mathrm{H}_{146} \mathrm{~B}_{2} \mathrm{Fe}_{2} \mathrm{Na}_{2} \mathrm{O}_{16} \mathrm{P}_{6} \mathrm{~S}: \mathrm{C}$ 64.67, H 6.50. Found: C 63.98, H 6.85. The low solubility of the product precluded the acquisition of a UV-Vis spectrum.

\section{Synthesis of $((\mathrm{PhBP}) \mathrm{Fe})\left(\mu-\eta^{1}: \eta^{1}-\mathrm{N}_{2} \mathrm{H}_{4}\right)\left(\mu-\eta^{2}: \eta^{2}-\mathrm{N}_{2} \mathrm{H}_{2}\right)((\mathrm{PhBP} 2 \mathrm{PS}) \mathrm{Fe}), 2.4$. Complex}

$2.1(0.010 \mathrm{~g}, 0.007 \mathrm{mmol})$ was dissolved in benzene $(5 \mathrm{~mL})$ to form a dark brown 
solution. After the solution became homogenous, a solution of hydrazine in THF (106 $\mu \mathrm{L}, 0.312 \mathrm{M}, 0.033 \mathrm{mmol}$ ) was added at RT with stirring. The solution was allowed to stir for 20 minutes over which time the color of the solution changed from dark brown to deep red-orange. Volatiles were removed to provide 5 as a rust colored powder $(0.010 \mathrm{~g}$, 0.006 mmol, 96\%). ${ }^{1} \mathrm{H}$ NMR $\left(\mathrm{C}_{6} \mathrm{D}_{6}, \delta\right): 8.67$ (t, J = $\left.6 \mathrm{~Hz}, 3 \mathrm{H}\right), 8.30$ (br s, 3H), 8.17 (d, J = $6 \mathrm{~Hz}, 2 \mathrm{H}), 7.93(\mathrm{~d}, \mathrm{~J}=6 \mathrm{~Hz}, 2 \mathrm{H}), 7.67(\mathrm{t}, \mathrm{J}=6 \mathrm{~Hz}, 2 \mathrm{H}), 7.60(\mathrm{~m}, 4 \mathrm{H}), 7.32(\mathrm{~m}, 10 \mathrm{H})$, $7.10(\mathrm{~m}, 6 \mathrm{H}), 6.87(\mathrm{~m}, 7 \mathrm{H}), 6.83(\mathrm{t}, \mathrm{J}=6 \mathrm{~Hz}, 3 \mathrm{H}), 6.54(\mathrm{~d}, \mathrm{~J}=30 \mathrm{~Hz}, 10 \mathrm{H}), 2.91$ (br s, 2H), $2.42(\mathrm{t}, \mathrm{J}=10 \mathrm{~Hz}, 3 \mathrm{H}), 2.15(\mathrm{t}, \mathrm{J}=10 \mathrm{~Hz}, 3 \mathrm{H}), 1.74($ br m, 6H), $1.61(\mathrm{~d}, \mathrm{~J}=10 \mathrm{~Hz}$, 2H), 1.52 (br s, 2H), 0.49 (br s, 2H). ${ }^{31} \mathrm{P}\left\{{ }^{1} \mathrm{H}\right\} \operatorname{NMR}\left(\mathrm{C}_{6} \mathrm{D}_{6}, \delta\right): 68.74$ (s, 2P), 63.94 (s, 1P), $63.48(\mathrm{~s}, 1 \mathrm{P}), 59.33(\mathrm{~s}, 2 \mathrm{P})$. IR $\left(\mathrm{KBr}, \mathrm{cm}^{-1}\right): 3310,3225\left(v_{\mathrm{NH}}\right)$.

Synthesis of $((\mathbf{P h B P}) \mathbf{F e}(\mathbf{C O})) 2(\boldsymbol{\mu}-\mathrm{S}), 2.5$. A schlenk tube was charged with a dark brown solution of $1(0.072 \mathrm{~g}, 0.047 \mathrm{mmol})$ in THF $(6 \mathrm{~mL})$ and a stir bar. This solution was degassed via three freeze, pump, thaw cycles and was then exposed to 1 atm of CO. Upon addition of $\mathrm{CO}$, an immediate color change to dark reddish purple was observed. The reaction was allowed to stir under CO for 5 minutes before solvent was removed. The remaining purple residue was extracted back into THF and was layered with pentane. Upon standing for 24 hours, red crystals of 4 were obtained in two crops $(0.053 \mathrm{~g}, 0.034$ mmol, $72 \%$ ). X-ray quality crystals were grown from a pentane vapor diffusion into a concentrated THF solution of 4. ${ }^{1} \mathrm{H}$ NMR $\left(\mathrm{C}_{6} \mathrm{D}_{6}, \delta\right): 8.16(\mathrm{~d}, \mathrm{~J}=6 \mathrm{~Hz}, 3 \mathrm{H}), 7.93$ (br m, 5H), $7.68(\mathrm{t}, \mathrm{J}=6 \mathrm{~Hz}, 4 \mathrm{H}), 7.42(\mathrm{~m}, 16 \mathrm{H}), 6.88(\mathrm{~m}, 24 \mathrm{H}), 6.71(\mathrm{~m}, 16 \mathrm{H}), 6.45$ (br s, 4H). ${ }^{31} \mathrm{P}\left\{{ }^{1} \mathrm{H}\right\} \operatorname{NMR}\left(\mathrm{C}_{6} \mathrm{D}_{6}, \delta\right): 55.97(\mathrm{dd}, \mathrm{J}=84,60 \mathrm{~Hz}), 24.29(\mathrm{t}, \mathrm{J}=58 \mathrm{~Hz}) . \quad \mathrm{UV}$-vis (THF) $\lambda_{\max }, \mathrm{nm}\left(\varepsilon, \mathrm{M}^{-1} \mathrm{~cm}^{-1}\right): 944$ (sh), 905 (5550), 665 (sh), 506 (23680), 407 (sh). IR (KBr, 
cm-1): $1950(v[\mathrm{CO}])$. Anal. Calc. for $\mathrm{C}_{100} \mathrm{H}_{96} \mathrm{~B}_{2} \mathrm{Fe}_{2} \mathrm{O}_{4} \mathrm{P}_{6} \mathrm{~S}: \mathrm{C} 70.11 \mathrm{H}$ 5.65. Found: $\mathrm{C}$ 69.36 H 5.87. 


\section{References Cited}

1 (a) Beinert, H.; Holm, R. H.; Münck, E. Science 1997, 277, 653-659; (b) Johnson, D.

C.; Dean, D. R.; Smith, A. D.; Johnson, M. K. Annu. Rev. Biochem. 2005, 74, 247-281.

2 (a) Evans, D. J.; Pickett, C. J. Chem. Soc. Rev. 2003, 32, 268-275; (b) Fontecilla-

Camps, J. C.; Volbeda, A.; Cavazza, C.; Nicolet, Y. Chem. Rev. 2007, 107, 4273-4303

3 (a) Dos Santos, P. C.; Igarashi, R. Y.; Lee, H. I.; Hoffman, B. M.; Seefeldt, L. C.; Dean, D. R. Acc. Chem. Res. 2005, 38, 208-214; (b) Einsle, O.; Tezcan, F. A.; Andrade, S. L. A.; Schmid, B.; Yoshida, M.; Howard, J. B.; Rees, D. C. Science 2002, 297, 16961700; (c) Seefeldt, L. C.; Hoffman, B. M.; Dean, D. R. Annu. Rev. Biochem. 2009, 78, 701-722.

4 (a) Crossland, J. L.; Tyler, D. R. Coord. Chem. Rev. 2010, 254, 1883-1894; (b)

Gloaguen, F.; Rauchfuss, T. B. Chem. Soc. Rev. 2009, 38, 100-108; (c) Rao, P. V.; Holm, R. H. Chem. Rev. 2004, 104, 527-559; (d) Tard, C. d.; Pickett, C. J. Chem. Rev. 2009, 109, 2245-2274. (e) Holm, R. H.; Kennepohl, P.; Solomon, E. I. Chem. Rev. 1996, 96, 2239-2314;

5 (a) Chakrabarti, M.; Deng, L.; Holm, R. H.; Munck, E.; Bominaar, E. L. Inorg. Chem. 2009, 48, 2735-2747; (b) Deng, L.; Holm, R. H. J. Am. Chem. Soc. 2008, 130, 98789886.

6 (a) Vela, J.; Stoian, S.; Flaschenriem, C. J.; Münck, E.; Holland, P. L. J. Am. Chem. Soc. 2004, 126, 4522-4523; (b) Rodriguez, M. M.; Stubbert, B. D.; Scarborough, C. C.; Brennessel, W. W.; Bill, E.; Holland, P. L. Angew. Chem. Int. Ed. 2012, 51, 8247-8250. 
7 (a) Brown, S. D.; Betley, T. A.; Peters, J. C. J. Am. Chem. Soc. 2002, 125, 322-323; (b)

Brown, S. D.; Mehn, M. P.; Peters, J. C. J. Am. Chem. Soc. 2005, 127, 13146-13147;

(c) Brown, S. D.; Peters, J. C. J. Am. Chem. Soc. 2005, 127, 1913-1923.

8 Cambridge Structural Database, 2011 update: F. H. Allen, Acta Crystallogr. B 2002, B58, 380-388.

9 Salifoglou, A.; Simopoulos, A.; Kostikas, A.; Dunham, R. W.; Kanatzidis, M. G.;

Coucouvanis, D. Inorg. Chem. 1988, 27, 3394-3406.

10 (a) Greenhough, T. J.; Kolthammer, B. W. S.; Legzdins, P.; Trotter, J. Inorg. Chem. 1979, 18, 3543-3548; (b) Mautz, J.; Huttner, G. Eur. J. Inorg. Chem. 2008, 1423-1434;

(c) Mealli, C.; Midollini, S.; Sacconi, L. Inorg. Chem. 1978, 17, 632-637; (d)

Schiemann, J.; Hubener, P.; Weiss, E. Angew. Chem., Int. Ed. Engl. 1983, 22, 980-981.

11 Mukherjee, R. N.; Stack, T. D. P.; Holm, R. H. J. Am. Chem. Soc. 1988, 110, 18501861.

12 (a) Birkelbach, F.; Winter, M.; Floerke, U.; Haupt, H.-J.; Butzlaff, C.; Lengen, M.;

Bill, E.; Trautwein, A. X.; Wieghardt, K.; Chaudhuri, P. Inorg. Chem. 1994, 33, 39904001; (b) Escuer, A.; Goher, M. A. S.; Mautner, F. A.; Vicente, R. Inorg. Chem. 2000, 39, 2107-2112; (c) Kahn, O.; Sikorav, S.; Gouteron, J.; Jeannin, S.; Jeannin, Y. Inorg. Chem. 1983, 22, 2877-2883.

13 Brunschwig, B. S.; Creutz, C.; Sutin, N. Chem. Soc. Rev. 2002, 31, 168-184.

14 Schatz, P. In Inorganic Electronic Structure and Spectroscopy; Lever, A. B. P., Solomon, E. I., Eds.; John Wiley \& Sons: New York, 1999; Vol. II.

15 Hendrich, M. P.; Gunderson, W.; Behan, R. K.; Green, M. T.; Mehn, M. P.; Betley, T. A.; Lu, C. C.; Peters, J. C. Proc. Natl. Acad. Sci. 2006, 103, 17107-17112. 
16 Neese, F. Inorg. Chim. Acta 2002, 337, 181-192.

17 Dionne, G. F. Magnetic Oxides; Springer Science+Business Media, LLC, 2010; pp 107-149.

18 Saouma, C. T.; Müller, P.; Peters, J. C. J. Am. Chem. Soc. 2009, 131, 10358-10359.

19 Bottomley, L. A.; Kadish, K. M. Inorg. Chem. 1981, 20, 1348-1357.

20 (a) Ding, F.; Smith, J. M.; Wang, H. J. Org. Chem. 2009, 74, 2679-2691; (b) Felton,

G. A. N.; Glass, R. S.; Lichtenberger, D. L.; Evans, D. H. Inorg. Chem. 2006, 45, 9181-

9184; (c) Fourmond, V.; Jacques, P.-A.; Fontecave, M.; Artero, V. Inorg. Chem. 2010, 49, 10338-10347.

21 Brown, S. D.; Betley, T. A.; Peters, J. C. J. Am. Chem. Soc. 2002, 125, 322-323.

22 http://ewww.mpi-muelheim.mpg.de/bac/logins/bill/julX_en.php

23 www.wmoss.org

24 Sheldrick, G. M. Acta Cryst. 1990, A46, 467.

25 Sheldrick, G. M. Acta Cryst. 2004, A64, 112.

26 Müller, P. Crystallography Reviews 2009, 15, 57. 


\section{Chapter 3: Conversion of $\mathrm{FeNH}_{2}$ to $\mathrm{FeN}_{2}$ with Release of $\mathrm{NH}_{3}$}

Reproduced in part with permission from

Anderson, J. S.; Moret, M.-E.; Peters, J. C. J. Am. Chem. Soc. 2013, 135, 534-537. (C2013 American Chemical Society 


\subsection{Introduction}

The complexity of proposed mechanisms for $\mathrm{N}_{2}$ fixation by Fe motivates efforts to synthesize and study intermediates along these pathways, and substantial efforts have been made towards characterizing many of the different species that might be involved in a catalytic cycle. ${ }^{1,2}$ The tris-phosphine frameworks that have been employed by the Peters lab have been particularly useful in this context, stabilizing a wide variety of nitrogenous ligands on Fe centers supported by both the $\left(\mathrm{PhBP}_{3}\right)$ and $\left(\mathrm{SiP}_{3}\right)$ ligand scaffolds. $^{3,4}$ Despite the isolation of many examples of Fe complexes featuring nitrogenous ligands of interest, such as nitrides $(\mathrm{FeN}),{ }^{5} \mathrm{FeNH}_{2}$ species remain relatively poorly precedented, with only one example reported by Bergman and co-workers. ${ }^{6}$ This paucity of examples is even more striking when considering the fact that a terminal $\mathrm{FeNH}_{2}$ is one intermediate that is common to both "distal" and "alternating" mechanisms.

Despite the success of the (TPB) ligand scaffold towards the stabilization of substituted imides and the functionalization of $\mathrm{N}_{2},{ }^{7}$ little work had been done to install functionalities containing N-H bonds. Furthermore, in shifting from the $\left(\mathrm{SiP}_{3}\right)$ scaffold to the (TPB) scaffold, the cationic $\mathrm{N}_{\mathrm{x}} \mathrm{H}_{\mathrm{y}}$ adducts which were $S=1$ on $\left(\mathrm{SiP}_{3}\right) \mathrm{Fe}$ would be non-integer spin on (TPB)Fe, making them amenable to study by EPR spectroscopy. Finally, the noted ability of (TPB)Fe to stabilize $\pi$-basic ligands suggests that it may be able to accommodate a terminal $\mathrm{NH}_{2}^{-}$ligand. In this context, the synthesis of terminal (TPB)Fe complexes of $\mathrm{N}_{2} \mathrm{H}_{4}, \mathrm{NH}_{3}$, and $\mathrm{NH}_{2}{ }^{-}$are described. All of these complexes are formally $\mathrm{Fe}(\mathrm{I})$ and populate $S=3 / 2$ spin states. Furthermore, a reductive protonation sequence wherein $\mathrm{FeNH}_{2}$ is sequentially protonated to form $\mathrm{FeNH}_{3}$ and then reduced to release $\mathrm{NH}_{3}$ and form (TPB)Fe( $\left.\mathrm{N}_{2}\right)$ is shown. Such a sequence is novel for any Fe 
system and links together the final steps in either a "distal" or an "alternating" mechanism for $\mathrm{N}_{2}$ reduction catalysis.

\subsection{Results and Discussion}

\subsubsection{Formation of a Cationic Fe(I) Synthon.}

In order to install nitrogenous ligands of interest, a suitable synthon with a labile or vacant apical coordination site was sought. Specifically, protonation of a terminal Fe alkyl complex was pursued as a means to generate such a species. Access to such an alkyl complex is provided by the addition of methyllithium to (TPB)FeBr ${ }^{7}$, which affords the corresponding methyl complex (TPB)FeMe (3.1) in high yield (Scheme 3.1). Subsequently, protonation of 1 by $\mathrm{HBAr}_{4}{ }_{4} \cdot 2 \mathrm{Et}_{2} \mathrm{O}\left(\mathrm{BAr}_{4} \mathrm{~F}^{-}=\mathrm{B}\left(3,5-\mathrm{C}_{6} \mathrm{H}_{3}\left(\mathrm{CF}_{3}\right)_{2}\right)_{4}{ }^{-}\right)$in a cold ethereal solution releases methane to yield [(TPB)Fe][BAr $\left.{ }_{4}{ }_{4}\right](\mathbf{3 . 2})$, which serves as the desired synthon with a vacant coordination site.

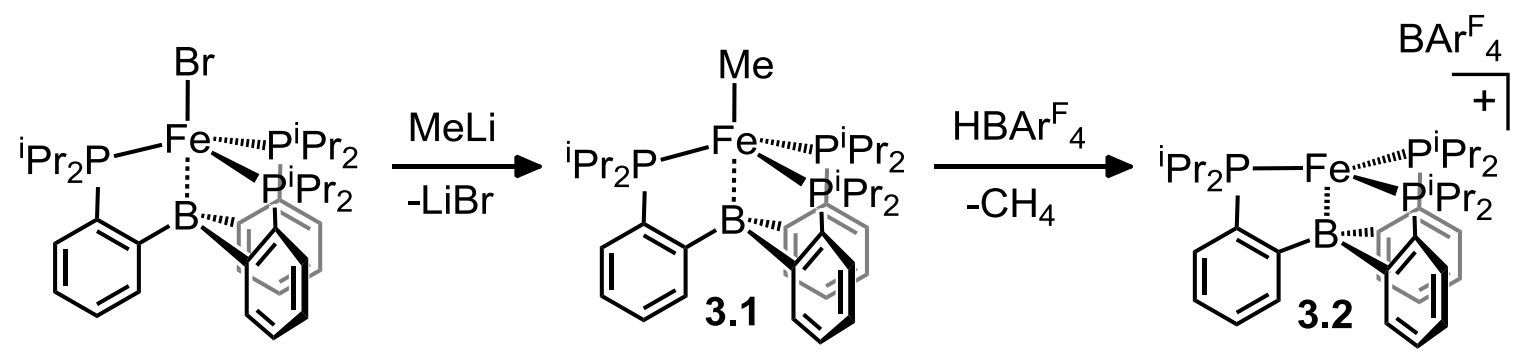

Scheme 3.1. Synthesis of complexes 3.1 and 3.2.

XRD data were obtained for $\mathbf{3 . 1}$ and $\mathbf{3 . 2}$ (Figure 3.1). The geometry of $\mathbf{1}$ is pseudo trigonal bipyramidal about Fe with an Fe-C bond length of 2.083(10) $\AA$ and a relatively long Fe-B bond length of 2.522(2) $\AA$. In the solid state 2 possesses a four-coordinate distorted trigonal pyramidal geometry with no close contacts in the apical site trans to 
boron, making this complex coordinatively unsaturated. Additionally, there is one wide $\mathrm{P}-\mathrm{Fe}-\mathrm{P}$ angle of $136^{\circ}$ indicating that the three phosphine ligands are distorting towards a $\mathrm{T}$-shaped geometry. The origin of this distortion is not clear, but a possible explanation is increased back-bonding from a relatively electron rich Fe center into the phosphine ligands that would arise from widening one P-Fe-P angle (see Appendix 2).
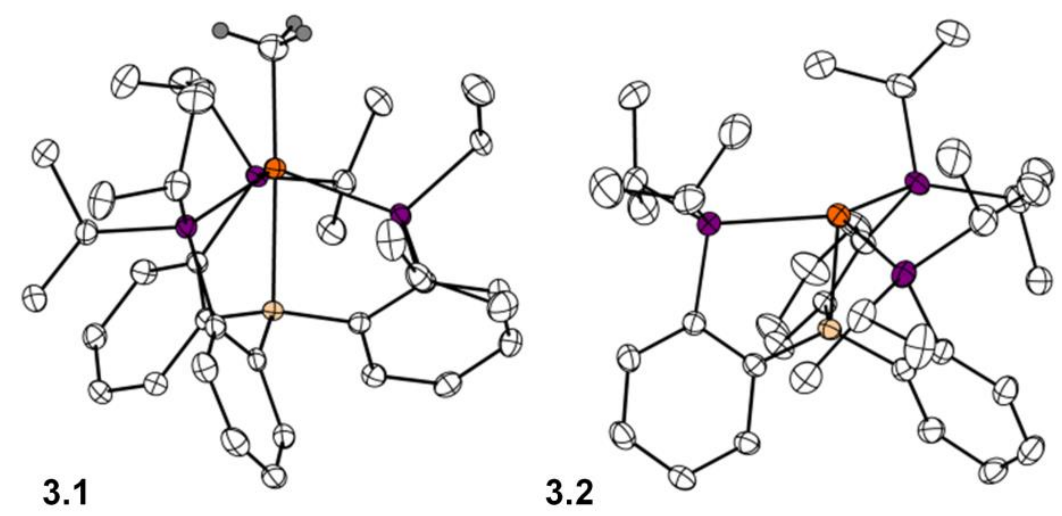

Figure 3.1. XRD structures of complexes 3.1 and 3.2 with ellipsoids at 50\%. Most hydrogens and counterions have been omitted for clarity. Fe atoms are shown in orange, $\mathrm{P}$ in purple, $\mathrm{B}$ in tan, $\mathrm{H}$ in gray, and $\mathrm{C}$ in white. Selected metrics can be found in Table 3.1.

The Fe-B distance in $3.2(2.217(2) \AA)$ is markedly shorter than that in (TPB)FeBr (2.459(5) $\AA$ ) and is the shortest Fe-B distance yet observed on any (TPB)Fe complex, shorter even than $\left[(\mathrm{TPB}) \mathrm{Fe}\left(\mathrm{N}_{2}\right)\right]\left[\mathrm{Na}(12 \text {-crown-4) })_{2}\right](2.292(3) \AA)$. This short distance is noteworthy because one might expect the formal loss of an anionic $\sigma$-donor ligand in going from (TPB)FeBr to 3.2 to reduce the Lewis basicity of the metal and thus weaken the Fe-B bond. For example, the Au-B distance in (TPB)AuCl (2.318 $\AA$ ) lengthens upon chloride abstraction to $2.448 \AA$ in [(TPB)Au] $]^{+} .{ }^{8}$ Despite the comparatively short Fe-B 
distance, it is noteworthy that the boron center in four-coordinate 3.2 is less pyramidalized $\left(\Sigma(\mathrm{C}-\mathrm{B}-\mathrm{C})=347.3^{\circ}\right)$ than that in five-coordinate $(\mathrm{TPB}) \mathrm{FeBr}(\Sigma(\mathrm{C}-\mathrm{B}-\mathrm{C})$ $=341.2^{\circ}$ ), pointing to a weak interaction despite the short distance. A short distance without a substantial Fe-B bonding interaction suggests that another factor may be involved in the observed geometry of 3.2. If one assumes a weak Fe-B interaction, the observed geometry about Fe might be best understood as derived from a planar threecoordinate $\mathrm{Fe}(\mathrm{I})$ center distorted towards a T-shaped geometry which has been observed in other $\mathrm{Fe}(\mathrm{I})$ complexes,${ }^{9}$ with the unusually short Fe-B distance being due largely to the constraints imposed by the ligand cage structure.
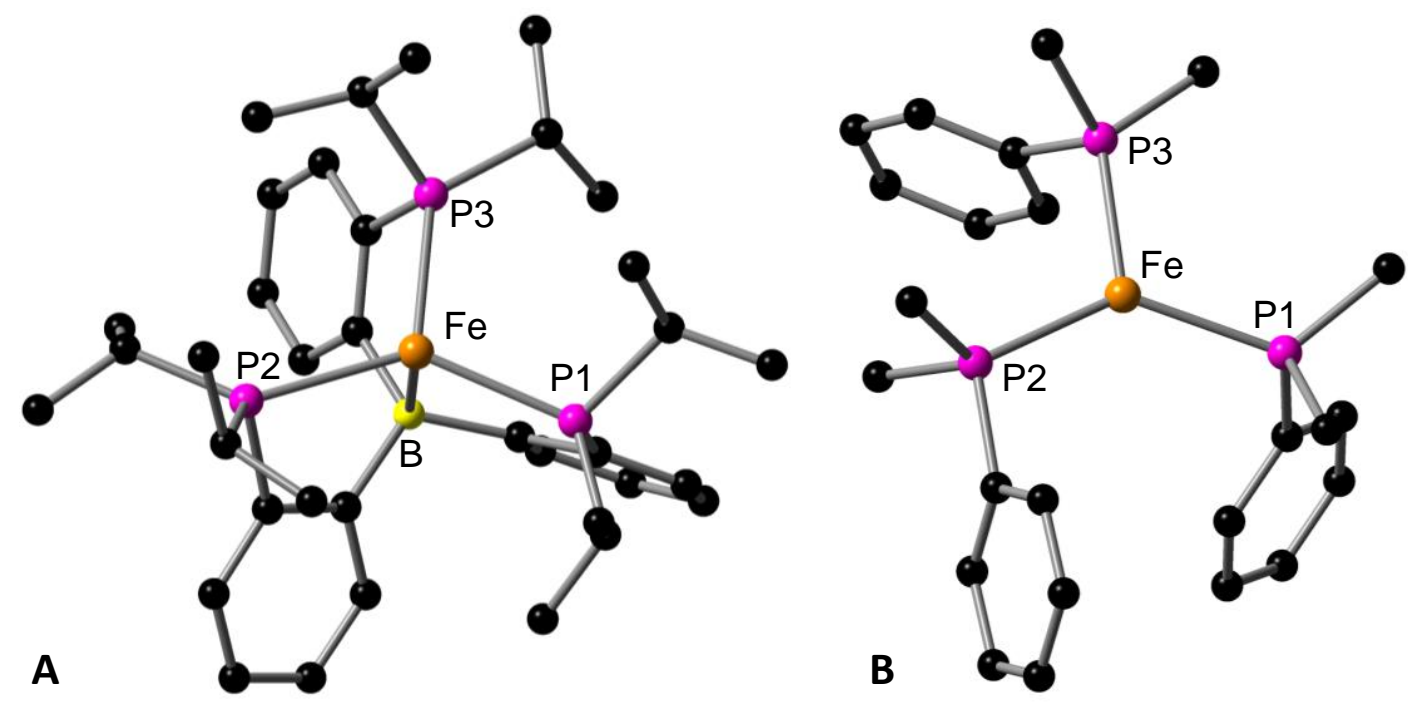

Figure 3.2. DFT optimized geometries at the B $3 \mathrm{LYP} / 6-31 \mathrm{G}(\mathrm{d})$ level of theory for (A) 3.2 and (B) $\left[\left(\mathrm{Me}_{2} \mathrm{PhP}\right)_{3} \mathrm{Fe}\right]^{+}$. Selected bond distances $[\AA]$ and angles [ $\left.{ }^{\circ}\right]:(\mathrm{A}): \mathrm{Fe}-\mathrm{P} 1$ 2.426, Fe-P2 2.481, Fe-P3 2.460, Fe-B 2.189, P1-Fe-P2 137.5, P1-Fe-P3 109.1, P2-Fe-P3 113.2; (B): Fe-P1 2.359, Fe-P2 2.328, Fe-P3 2.350, P1-Fe-P2 134.8, P1-Fe-P3 113.1, P2-Fe-P3 111.7. 
This interpretation is consistent with a computational model study wherein the DFT (B3LYP/6-31G(d)) optimized geometry of the hypothetical complex $\left[\left(\mathrm{Me}_{2} \mathrm{PhP}\right)_{3} \mathrm{Fe}\right]^{+}$(Figure 3.2) replicates the T-shaped distortion by exhibiting a planar geometry with P-Fe-P angles of $134.8^{\circ}, 113.1^{\circ}$, and $111.7^{\circ}$, very close to those measured for $[(\mathrm{TPB}) \mathrm{Fe}]^{+}\left(137.5^{\circ}, 113.2^{\circ}, 109.1^{\circ}\right)$. These computational studies combined with the aforementioned data raise interesting questions about the nature of the Fe-B interaction.

\begin{tabular}{cccccc}
\hline Complex & Fe-X $(\AA)$ & $\begin{array}{c}\text { Fe-B } \\
(\mathbf{\AA})\end{array}$ & $\begin{array}{c}\text { Avg. } \\
\text { Fe-P }(\AA)\end{array}$ & $\Sigma$ P-Fe-P & $\Sigma \mathbf{\Sigma}-\mathbf{A}-\mathbf{C}$ \\
\hline $\mathbf{3 . 1}$ & $2.083(10)$ & $2.523(2)$ & 2.40 & $339^{\circ}$ & $341^{\circ}$ \\
$\mathbf{3 . 2}$ & - & $2.217(2)$ & 2.38 & $359^{\circ}$ & $347^{\circ}$ \\
$\mathbf{3 . 3}$ & $2.205(2)$ & $2.392(2)$ & 2.44 & $350^{\circ}$ & $339^{\circ}$ \\
$\mathbf{3 . 4}$ & $2.280(3)$ & $2.433(3)$ & 2.44 & $349^{\circ}$ & $341^{\circ}$ \\
$\mathbf{3 . 5}$ & $1.918(3)$ & $2.449(4)$ & 2.39 & $343^{\circ}$ & $339^{\circ}$ \\
$\mathbf{3 . 6}$ & $1.8916(7)$ & $2.4438(9$ & 2.39 & $348^{\circ}$ & $337^{\circ}$ \\
\hline
\end{tabular}

Table 3.1. Selected metrics for complexes 3.1-3.6.

When considering the bonding of the $(\mathrm{Fe}-\mathrm{B})^{7}$ subunit of $\mathbf{3 . 2}$ in order to estimate the most appropriate oxidation state and valence assignment, two limiting scenarios present themselves: $\mathrm{Fe}(\mathrm{III}) / \mathrm{B}(\mathrm{I})$ and $\mathrm{Fe}(\mathrm{I}) / \mathrm{B}(\mathrm{III})$. The structural data and computations for 3.2 are suggestive of a weak Fe-B interaction and indicate that this species is better regarded as $\mathrm{Fe}(\mathrm{I}) / \mathrm{B}(\mathrm{III})$ rather than $\mathrm{Fe}(\mathrm{III}) / \mathrm{B}(\mathrm{I})$. Calculations indicate that a small amount of spin density resides on the B-atom of $\mathbf{3 . 2}$ (see Appendix 2) and suggest that some contribution from an $\mathrm{Fe}(\mathrm{II}) / \mathrm{B}$ (II) resonance form may also be relevant. The remainder of the complexes presented herein possess significantly longer, and therefore presumably weaker, Fe-B interactions (vide infra) and are hence also better classified as Fe(I) species. Additional spectroscopic studies (e.g., XAS and Mössbauer) may help to 
better map the strength of the Fe-B bonding interaction and its relation to variable Fe-B distances, and also as a function of the spin state of the overall complex. These studies would help to determine the value and limitation of classically derived oxidation/valence assignments for boratranes of these types. ${ }^{10}$

Regardless of the nature of the Fe-B interaction, the ability of $\mathbf{3 . 2}$ to bind neutral L-type donors in its vacant apical site was investigated to probe the utility of this complex as a synthon for installing nitrogenous ligands. One of the initial observations in this context was that solutions of $\mathbf{3 . 2}$ are orange in $\mathrm{Et}_{2} \mathrm{O}$ and pale yellow-green in THF, potentially suggestive of solvent coordination in the apical site. Titration of THF into an ethereal solution of $\mathbf{3 . 2}$ results in a distinct change in the UV-vis spectrum consistent with weak THF binding (see Appendix 2). The evidence that THF can bind in the vacant apical site of $\mathbf{3 . 2}$ suggests that binding of other L-type donors at this site should be feasible.

\subsection{2 [(TPB)Fe $]^{+}$Adducts of $\mathrm{N}_{2} \mathrm{H}_{4}$ and $\mathrm{NH}_{3}$}

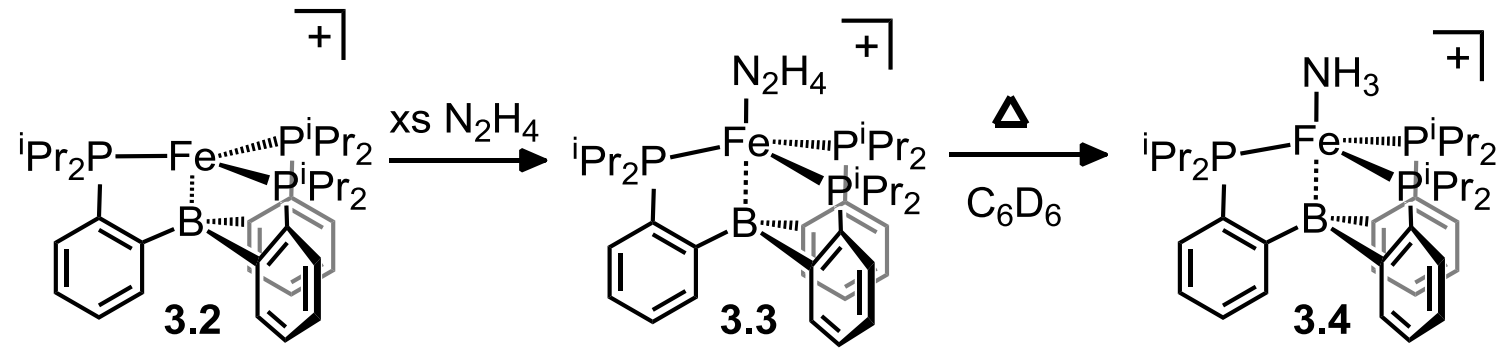

Scheme 3.2. Synthesis of complexes 3.3 and 3.4. Counterions are not depicted, but are $\mathrm{BAr}_{4}{ }^{-}$in all cases. 
Addition of an excess of $\mathrm{N}_{2} \mathrm{H}_{4}$ to an ethereal solution of $\mathbf{3 . 2}$ results in a slight lightening of the orange color of the solution to afford [(TPB)Fe( $\left.\left(\mathrm{N}_{2} \mathrm{H}_{4}\right)\right]\left[\mathrm{BAr}{ }_{4}{ }_{4}\right](3.3)$ in 89\% yield (Scheme 3.2). Complex 3.3 shows a paramagnetically shifted ${ }^{1} \mathrm{H}$ NMR spectrum indicative of an $S=3 / 2 \mathrm{Fe}$ center. The proposed high-spin state of the Fe center is corroborated by a RT solution magnetic moment of $\mu_{\mathrm{eff}}=3.5 \mu_{\mathrm{B}}$. Complex 3.3 is stable to vacuum, but solutions decompose cleanly at RT over hours to form the $S=3 / 2$ cationic ammonia complex $\left[(\mathrm{TPB}) \mathrm{Fe}\left(\mathrm{NH}_{3}\right)\right]\left[\mathrm{BAr}^{\mathrm{F}}{ }_{4}\right], \mathbf{3 . 4}$, which was assigned by comparison of its ${ }^{1} \mathrm{H}$ NMR spectrum with an independently prepared sample formed by the addition of $\mathrm{NH}_{3}$ to the cation 3.2.

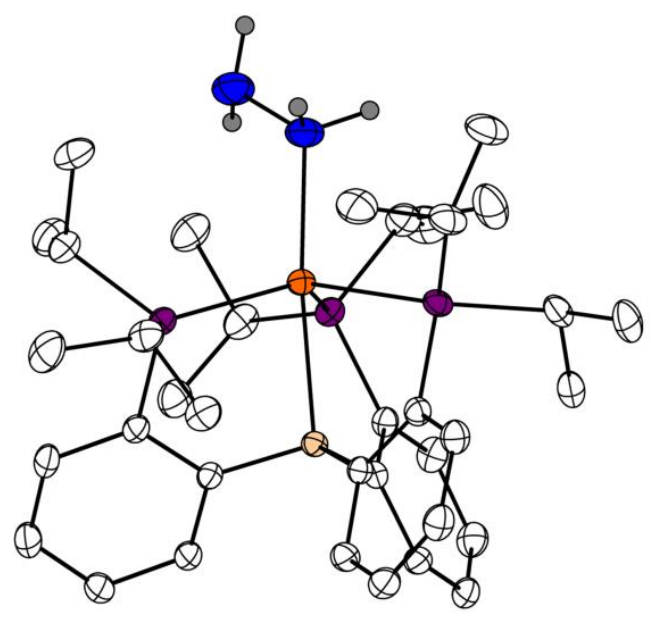

3.3

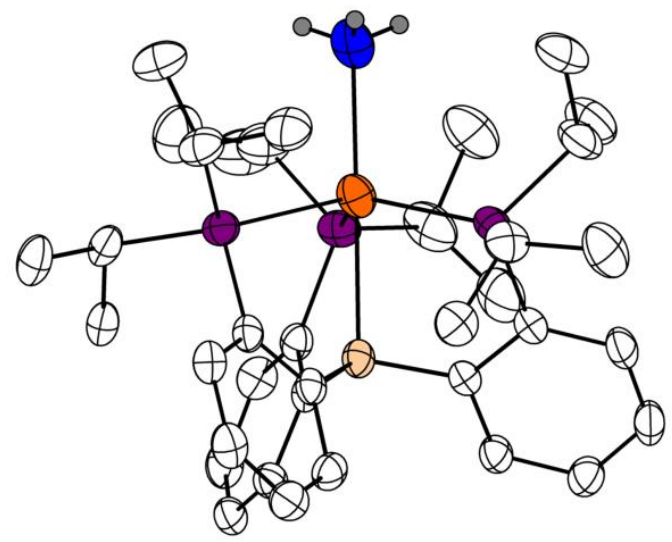

3.4

Figure 3.3. XRD structures of complexes 3.3 and 3.4 with $\mathrm{C}-\mathrm{H}$ hydrogens and counterions omitted for clarity. Fe atoms are shown in orange, $\mathrm{P}$ in purple, $\mathrm{N}$ in blue, $\mathrm{B}$ in tan, $\mathrm{H}$ in gray, and $\mathrm{C}$ in white. Selected metrics can be found in Table 3.1.

The identities of the nitrogenous ligands in $\mathbf{3 . 3}$ and $\mathbf{3 . 4}$ were confirmed by XRD data collected on these complexes (Figure 3.3). Both complexes possess a distorted 
trigonal bipyramidal geometry about Fe similar to $\mathbf{3 . 1}$ and the previously reported (TPB)FeBr. $7^{\text {a }}$ The Fe-N distances of 2.205(2) $\AA$ in 3.3 and 2.280(3) $\AA$ in $\mathbf{3 . 4}$ are unusually long ( $2.14 \AA$ is the average quaternary $\mathrm{N}$-Fe distance in the Cambridge Structural Database) ${ }^{11}$ reflecting the unusual quartet spin state in these complexes. Despite these long distances, $\mathbf{3 . 4}$, like $\mathbf{3 . 3}$, is stable to vacuum. The unpaired spins in these complexes similarly result in long average Fe-P distances of $2.44 \AA$. The complexes 3.2, 3.3, and 3.4 are unusual by virtue of their $S=3 / 2$ spin states and underscore the utility of local 3-fold symmetry with respect to stabilizing high spin states at iron, even in the presence of strong-field phosphine ligands. Finally, the Fe-B distances in $\mathbf{3 . 3}$ and $\mathbf{3 . 4}$ of 2.392(2) Å and 2.433(3) Å respectively likely indicate a minimal interaction between Fe and B and suggest that a formal oxidation state of $\mathrm{Fe}(\mathrm{I})$ is most appropriate in these complexes.
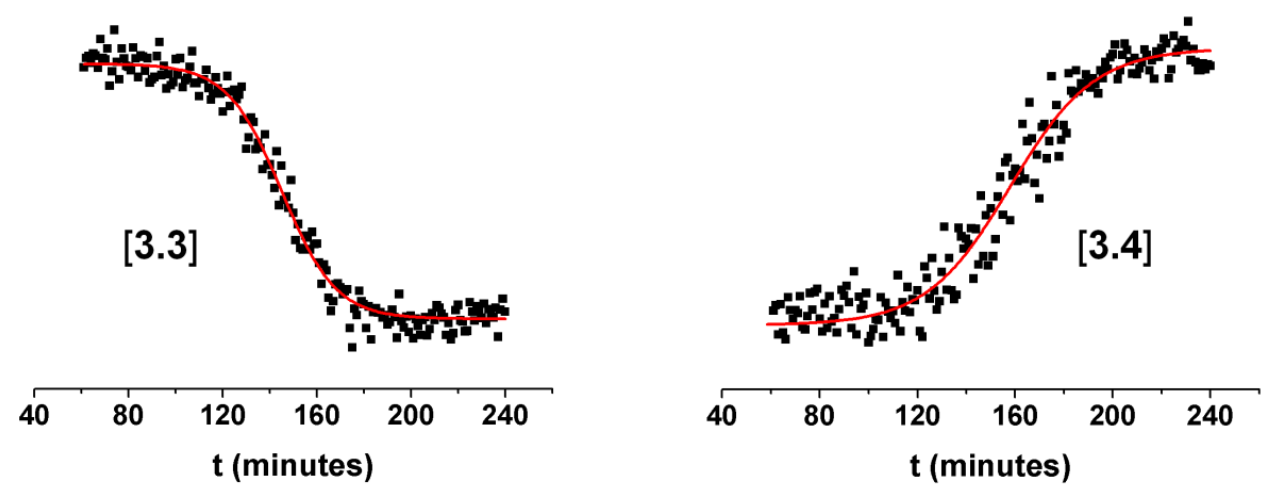

reaction: $A+B \longrightarrow 2 B \quad$ rate law: $[A] /\left([B]_{0}+[A]_{0}-[A]\right)=\left([A]_{0} /[B]_{0}\right) e^{-k t\left([A]_{0}+[B]_{0}\right)} \quad$ Fit: $y=a /\left(1+b^{*} \exp \left(-k^{*} x\right)\right)$ $a\left([A]_{0}\right)=0.038, b\left(\left[A_{0}\right] /\left[B_{0}\right]\right)=10000, k\left(k[A]_{0}\right)=0.058, R^{2}=0.965$

Figure 3.4. Reaction kinetics of the thermolysis of 3.3 to 3.4 at $60{ }^{\circ} \mathrm{C}$ in a $6: 1$ mixture of $\mathrm{C}_{6} \mathrm{D}_{6}: \mathrm{THF}-d_{8}$. 
The conversion of $\mathbf{3 . 3}$ to $\mathbf{3 . 4}$ deserves additional comment. As written in Scheme 3.2, the transformation is not balanced and so the reaction mixture was analyzed for the presence of additional degradation products. Two degradation pathways are likely accessible to the bound $\mathrm{N}_{2} \mathrm{H}_{4}$ molecule: degradation to $11 / 3$ equivalents of $\mathrm{NH}_{3}$ and $2 / 3$ equivalents of $\mathrm{N}_{2}$ or degradation to $\mathrm{N}_{2}$ and two equivalents of $\mathrm{H}_{2}$. The presence of $\mathrm{NH}_{3}$ in 3.4 suggests that the former process dominates and analysis of the additional degradation products shows the formation of 0.12 equivalents $\mathrm{NH}_{3}$ and only trace $\mathrm{H}_{2}$.

In a further attempt to probe the mechanism of this process, the conversion of $\mathbf{3 . 3}$ to 3.4 was monitored by ${ }^{1} \mathrm{H}$ NMR spectroscopy at $60{ }^{\circ} \mathrm{C}$, which showed a clean reaction with no discernible intermediates. The traces of the concentrations of $\mathbf{3 . 3}$ and $\mathbf{3 . 4}$ are shown in Figure 3.4. What is immediately obvious is the sigmoidal shape of the reactant and product curves suggestive of an auto-catalytic mechanism. The data can be fit to a crude auto-catalytic rate law with a reasonable agreement provided by the parameters shown in Figure 3.4. ${ }^{12}$ The identity of the auto-catalyst is unclear, as doping $\mathbf{3 . 4}$ into solutions of $\mathbf{3 . 3}$ does not eliminate the observed induction period. Despite the lack of evidence of $\mathrm{N}_{2} \mathrm{H}_{4}$ or $\mathrm{NH}_{3}$ dissociation from 3.3 or 3.4, it is possible that the vacant species 3.2 is acting as the auto-catalyst. Further insight into the mechanism of this decomposition beyond the identity of the auto-catalyst will likely prove challenging due to the relatively complicated mechanism. 


\subsubsection{Conversion of $\mathrm{FeNH}_{2}$ to $\mathrm{FeN}_{2}$ with release of $\mathrm{NH}_{3}$}

The paucity of terminal $\mathrm{FeNH}_{2}$ species prompted investigations into whether such a species could be isolated on the (TPB) framework. The previously reported capability of (TPB)Fe to support $\pi$-donor ligands suggested that an $\mathrm{FeNH}_{2}$ complex could be stabilized with this ligand. Addition of excess $\mathrm{NaNH}_{2}$ to the cation 3.2 affords the terminal amide, (TPB)FeNH $\mathrm{FH}_{2}(\mathbf{3 . 5})$ in ca. $85 \%$ non-isolated yield by ${ }^{1} \mathrm{H}$ NMR integration (Scheme 3.3). The XRD structure of $\mathbf{3 . 5}$ (Figure 3.5) shows an overall geometry similar to that observed in 3.1, 3.3, and 3.4. Of interest is the short Fe-N distance of 1.918(3) $\AA$ by comparison to $3.4(2.280(3) \AA)$. The amide hydrogens were located in the difference map and indicate a nearly planar geometry about $\mathrm{N}$ (with the sum of the angles around $\mathrm{N}$ being $355^{\circ}$ ).
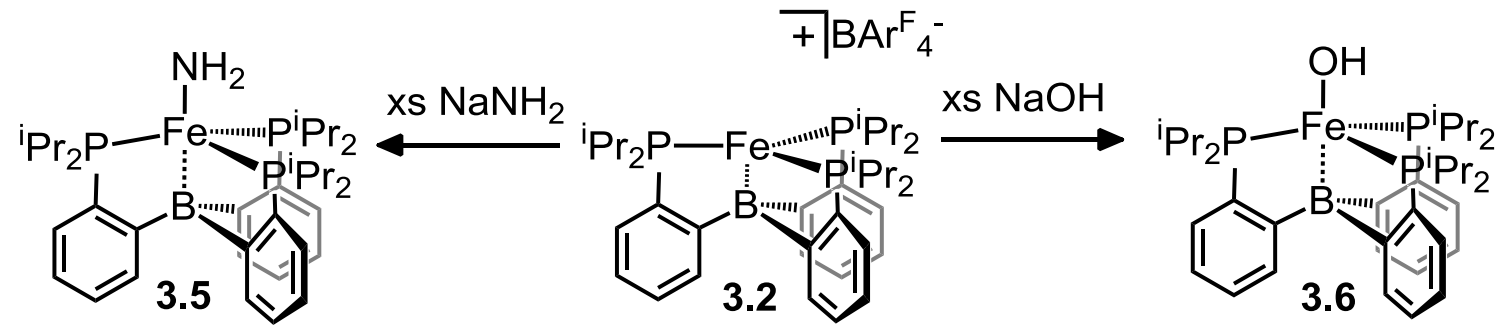

Scheme 3.3. Synthesis of complexes 3.5 and 3.6.

While the XRD data set of $\mathbf{3 . 5}$ is of high quality, concern about the difficulty in distinguishing an $\mathrm{FeNH}_{2}$ group from a potentially disordered $\mathrm{Fe}-\mathrm{OH}$ moiety remained. The hydroxo complex, (TPB)Fe-OH (3.6) (Scheme 2), was therefore independently synthesized and characterized similarly to $\mathbf{3 . 5}$ by the reaction of $\mathbf{3 . 2}$ with an excess of $\mathrm{NaOH}$. Complex 3.6 possesses a geometry similar to that observed in $\mathbf{3 . 5}$ with an Fe-B distance of 2.4438(9) $\AA$ and an Fe-O distance of 1.8916(7) $\AA$. Despite the structural 
similarity between 3.5 and 3.6, different spectral signatures in both their ${ }^{1} \mathrm{H}$ NMR and EPR (Figure 3.6) spectra allow for facile distinction between them.
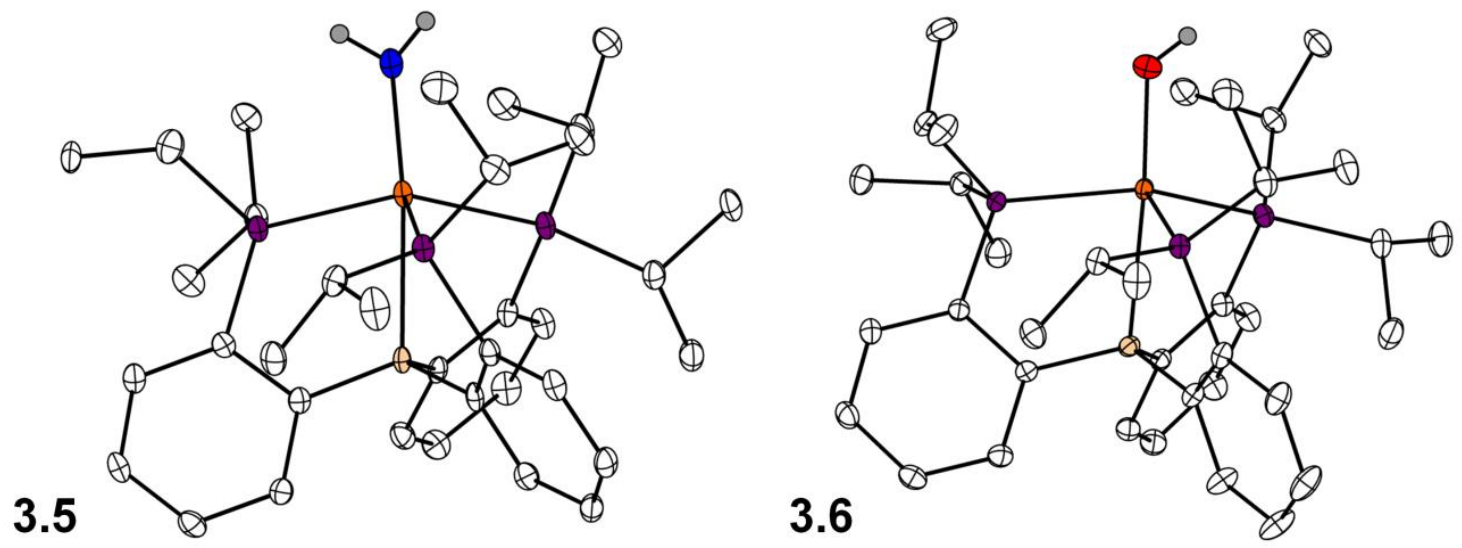

Figure 3.5. XRD structures of complexes 3.5 and 3.6 with $\mathrm{C}-\mathrm{H}$ hydrogens omitted for clarity. Fe atoms are shown in orange, $\mathrm{P}$ in purple, $\mathrm{N}$ in blue, $\mathrm{O}$ in red, $\mathrm{B}$ in tan, $\mathrm{H}$ in gray, and $\mathrm{C}$ in white. Selected metrics can be found in Table 3.1.

Parent amide complexes of first row transition metals are rare. ${ }^{13}$ Noteworthy precedent for related terminal $\mathrm{M}-\mathrm{NH}_{2}$ species includes three square planar nickel complexes ${ }^{13 c, e, f}$ and one octahedral and diamagnetic iron complex, $(\mathrm{dmpe})_{2} \mathrm{Fe}(\mathrm{H}) \mathrm{NH}_{2} .6 \mathrm{In}$ addition to their different coordination numbers, geometries, and spin-states, (dmpe $)_{2} \mathrm{Fe}(\mathrm{H})\left(\mathrm{NH}_{2}\right)$ and 3.5 show a distinct difference at the $\mathrm{FeNH}_{2}$ subunit. Sixcoordinate (dmpe) $)_{2} \mathrm{Fe}(\mathrm{H})\left(\mathrm{NH}_{2}\right)$ is an 18-electron species without $\pi$-donation from the amide ligand, which is pyramidalized as a result. By contrast, five-coordinate $\mathbf{3 . 5}$ accommodates $\pi$-bonding and allows donation from the lone pair on the amide ligand. This donation is further borne out in its much shorter Fe-N distance (1.918(3) $\AA$ for $\mathbf{3 . 5}$ 
versus $2.068 \AA$ for $\left.(\mathrm{dmpe})_{2} \mathrm{Fe}(\mathrm{H})\left(\mathrm{NH}_{2}\right)\right)$, and also its comparative planarity (the sum of the angles around $\mathrm{N}$ is $355^{\circ}$ for 3.5 versus $325^{\circ}$ for $\left.(\mathrm{dmpe})_{2} \mathrm{Fe}(\mathrm{H})\left(\mathrm{NH}_{2}\right)\right)$.
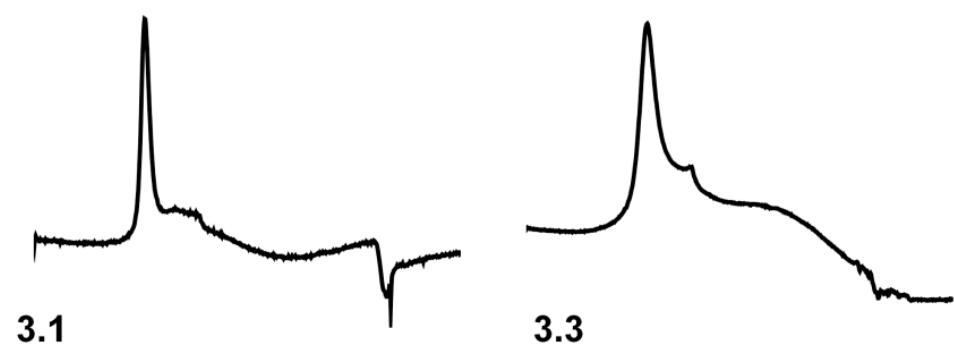

3.3
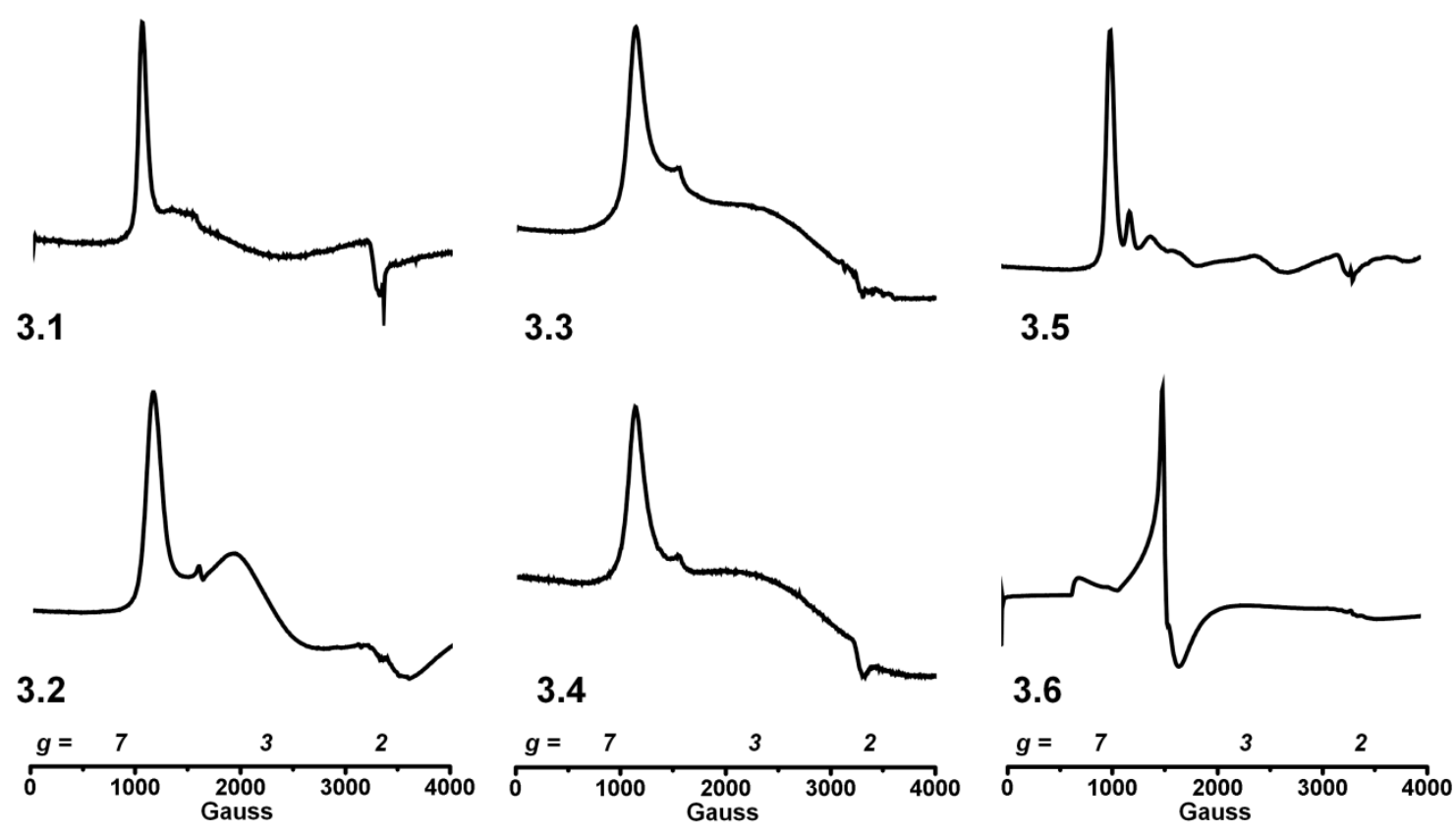

Figure 3.6. Low-temperature $X-B$ and EPR spectra for complexes 3.1-3.6. Conditions: 3.1: Toluene, 8 K; 3.2: 2:1 Toluene:Et ${ }_{2} \mathrm{O}, 10 \mathrm{~K}$ 3.3: 2-MeTHF, $10 \mathrm{~K}$; 3.4: 2-MeTHF, 10 K; 3.5: 2-MeTHF, $10 \mathrm{~K}$; 3.6: Toluene, $10 \mathrm{~K}$.

In order to further query the electronic structures of the complexes presented here, low-temperature EPR data and magnetic data have been acquired. X-Band EPR data at $10 \mathrm{~K}$ have been obtained on complexes 3.1-3.6 and are shown in Figure 3.6. All complexes show intense features shifted to large g-values: $\sim 5$ for 3.6, $\sim 6$ for 3.2-3.4, and close to 7 for 3.1 and 3.5. Such features are consistent with quartet Fe species, ${ }^{14}$ and this assignment is verified by the solution magnetic moments obtained for these complexes. Variable temperature solid-state SQUID magnetic data for complexes 3.2-3.5 (see 
Appendix 2) also establish quartet spin state assignments and display no evidence for spin-crossover phenomena. These data show a drop in magnetic moment in the range 50$70 \mathrm{~K}$ for all compounds studied. We propose that this effect is due to a large zero-field splitting in these species, which is consistent with Fe centers in related geometries. ${ }^{15}$ Simulations with zero-field splitting of $10-20 \mathrm{~cm}^{-1}$ provide reasonable fits to the data (see Appendix 2).

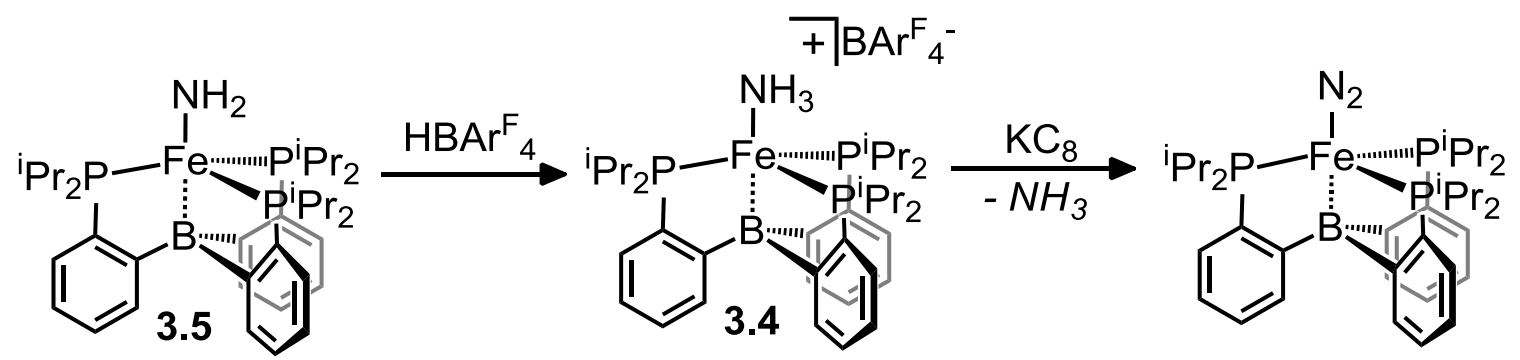

Scheme 3.4. Reductive protonation sequence to release $\mathrm{NH}_{3}$ and take up $\mathrm{N}_{2}$.

With the terminal amide $\mathbf{3 . 5}$ in hand, its suitability as a precursor to the previously reported $\mathrm{N}_{2}$ complex (TPB)Fe( $\left.\mathrm{N}_{2}\right)$ via release of $\mathrm{NH}_{3}$ was explored. Both reduction/protonation and protonation/reduction sequences were investigated as a means of effecting overall $\mathrm{H}$-atom transfer to the $\mathrm{FeNH}_{2}$ unit. Attempts to carry out the oneelectron reduction of $\mathbf{3 . 5}$ did not provide any tractable reactivity. For example, electrochemical studies of $\mathbf{3 . 5}$ in THF failed to show any reversible reduction waves, but the addition of harsh reductants (e.g., tBuLi) to $\mathbf{3 . 5}$ did show small amounts of $(\mathrm{TPB}) \mathrm{Fe}\left(\mathrm{N}_{2}\right)$ in the product profile, potentially via loss of $\mathrm{NH}_{2}{ }^{-}$. A more successful conversion sequence utilized protonation followed by chemical reduction. Thus, the addition of $\operatorname{HBAr}_{4} \mathrm{~F}_{4} \cdot 2 \mathrm{Et}_{2} \mathrm{O}$ to 3.5 at low temperature $\left(-35^{\circ} \mathrm{C}\right)$ rapidly generates the cationic ammonia adduct 3.4 (Scheme 3.4). The conversion is quantitative as determined 
by ${ }^{1} \mathrm{H}$ NMR spectroscopy, and $\mathbf{3 . 4}$ can be isolated in ca. 90\% yield from the solution. Subsequent exposure of $\mathbf{3 . 4}$ to one equiv of $\mathrm{KC}_{8}$ under an atmosphere of $\mathrm{N}_{2}$ releases $\mathrm{NH}_{3}$ and generates the (TPB)FeN $\mathrm{F}_{2}$ complex in similarly high yield.

While neither of these reactions is unexpected, the ability to link these complexes together in the reactions shown illustrates for the first time that Fe can mediate these steps on a single scaffold. The conversion of an $\mathrm{FeNH}_{2}$ species to an $\mathrm{FeNH}_{3}$ species and then terminally to an $\mathrm{FeN}_{2}$ species are steps common to both limiting "distal" and "alternating" mechanisms. Additionally, these processes represent the final steps of these mechanisms to regenerate an $\mathrm{FeN}_{2}$ species and re-enter a catalytic cycle. While the uptake of $\mathrm{N}_{2}$ via redox induced expulsion of $\mathrm{NH}_{3}$ had been previously reported $4^{\mathrm{b}}$ and the basicity of $\mathrm{FeNH}_{2}$ species has been documented,6 the fact that the (TPB) manifold can stabilize the requisite functionalities and transformations is noteworthy. Specifically, in

order to develop a catalyst for $\mathrm{N}_{2}$ reduction, Fe based systems capable of stabilizing and interconverting multiple nitrogenous species are required.

\subsection{Conclusion}

Protonation of the terminal alkyl complex $\mathbf{3 . 1}$ gives rise to the four-coordinate cationic complex 3.2, which possesses an unusually short Fe-B bond. Despite this bond distance, calculations suggest that the $\mathrm{Fe}-\mathrm{B}$ bonding interaction is relatively weak. Complex 3.2 serves as a synthon for the installation of $\mathrm{N}_{2} \mathrm{H}_{4}, \mathrm{NH}_{2}{ }^{-}$, and $\mathrm{OH}^{-}$groups to make complexes 3.3, 3.5, and 3.6 respectively. Furthermore, thermolysis of 3.3 results in the disproportionation of $\mathrm{N}_{2} \mathrm{H}_{4}$ to yield the cationic $\mathrm{NH}_{3}$ adduct 3.4 via an autocatalytic degradation. All of these complexes are unusual $S=3 / 2$ complexes and X-Band EPR and 
magnetic measurements support this spin state assignment. Finally, protonation of $\mathbf{3 . 5}$ results in formation of $\mathbf{3 . 4}$ which can then be reduced to yield (TPB) $\mathrm{Fe}\left(\mathrm{N}_{2}\right)$, demonstrating this reductive sequence for the first time on a single Fe scaffold. Collectively, these results suggest that the (TPB)Fe scaffold can support a number of potential intermediates or conversions that might be found in a $\mathrm{N}_{2}$ fixation pathway.

\subsection{Experimental Section}

\subsubsection{General Considerations}

Unless otherwise noted, all compounds were prepared by literature procedures or purchased from commercial sources. The complex (TPB)FeBr ${ }^{7 \mathrm{a}}$ and $\mathrm{HBAr}_{4} \mathrm{~F}_{4} \cdot 2 \mathrm{Et}_{2} \mathrm{O}^{22}$ were prepared according to reported literature procedures. All manipulations were carried out under a dinitrogen atmosphere by utilizing standard glovebox or schlenk techniques. Solvents were dried and de-oxygenated by an argon sparge followed by passage through an activated alumina column purchased from S.G. Waters Company. All non-halogenated solvents were tested with a standard sodium-benzophenone ketyl solution to ensure the absence of oxygen and water.

NMR measurements were obtained on Varian 300, 400, or $500 \mathrm{MHz}$ spectrometers. Deuterated solvents for these measurements were obtained from Cambridge Isotope Laboratories and were dried and degassed prior to use. All ${ }^{1} \mathrm{H}$ spectra were referenced to residual solvent peaks and all ${ }^{31} \mathrm{P}$ spectra were referenced to an external $\mathrm{H}_{3} \mathrm{PO}_{4}$ standard. 


\subsubsection{EPR Spectroscopy}

EPR X-band spectra were obtained on a Bruker EMX spectrometer with the aid of Bruker Win-EPR software suite version 3.0. The spectrometer was equipped with a rectangular cavity which operated in the $\mathrm{TE}_{102}$ mode. Temperature control was achieved with the use of an Oxford continuous-flow helium cryostat (temperature range 3.6 - 300 K). All spectra were recorded at $9.37 \mathrm{GHz}$ with a microwave power of $20 \mathrm{~mW}$, a modulation amplitude of $4 \mathrm{G}$, and a modulation frequency of $100 \mathrm{kHz}$.

\subsubsection{X-Ray Crystallography}

Data were obtained at low temperatures on a Siemens or Bruker Platform threecircle diffractometer coupled to a Bruker-AXS Smart Apex CCD detector with graphitemonochromated Mo K $\alpha$ radiation $(\lambda=0.71073)$, performing $\varphi$-and $\omega$-scans. Data for complex 5.4 were collected with synchrotron radiation at the Stanford Synchrotron Radiation Laboratory (SSRL) beam line 12-2 at $17 \mathrm{keV}$ using a single phi axis and recorded on a Dectris Pilatus $6 \mathrm{M}$. The images were processed using $\mathrm{XDS}^{16}$, and further workup of the data was analogous to the other datasets. All structures were solved by standard direct or Patterson methods and refined against $\mathrm{F}^{2}$ using the SHELX program package. ${ }^{17,18,19}$ All atoms, with the exception of hydrogens, have been anisotropically refined. The hydrogen atoms bonded to atoms of interest, namely $\mathrm{N}$ or $\mathrm{O}$, have been located in the difference map and refined semi-freely. All other hydrogen atoms were included via a standard riding model.

In the structure of complex 5.1 a minor component of $\mathrm{TPBFeCl}$ was found in the difference map and modeled as disorder. Additional disorder of the $\mathrm{BAr}^{\mathrm{F}}{ }_{4}$ counterion 
was found in complex 4. This disorder was modeled as a rotational disorder of the $\mathrm{CF}_{3}$ groups on one of the phenyl rings, but some of the resulting F ellipsoids still display significantly prolate shapes. We feel that the shape of these ellipsoids accurately describes the actual electron density due to the rotational disorder.

\subsubsection{Magnetic Measurements}

Data were obtained using a Quantum Designs SQUID magnetometer running MPMSR2 software (Magnetic Property Measurement System Revision 2) at a field strength of 50000 G. Complexes were massed and then suspended in eicosane wax. Samples were then inserted into the magnetometer in plastic straws sealed under nitrogen with gelatin capsules. Loaded samples were centered within the magnetometer using the DC centering scan at $35 \mathrm{~K}$. Data were acquired at 20-30 K (one data point every $2 \mathrm{~K}$ ), and $30-300 \mathrm{~K}$ (one data point every $10 \mathrm{~K}$ ). The magnetic susceptibility was adjusted for diamagnetic contributions using the constitutive corrections of Pascal's constants, as well as a diamagnetic correction for the eicosane and capsule. Data workup, including simulations, was performed in the JulX software package. ${ }^{20}$ Complex $\mathbf{5 . 5}$ displayed a lower than expected magnetic moment. NMR analysis of the sample indicated the presence of $\sim 15 \%$ 12-crown-4, present as a result of the protocol for generation of the complex, where it is used to aid for removal of $\mathrm{NaBAr}^{\mathrm{F}}$. Accounting for this impurity leads to a magnetic moment consistent with the other samples. 


\subsubsection{Computational Methods}

Geometry optimizations were performed using the Gaussian03 package. $^{21}$ The B3LYP exchange-correlation functional was employed with a 6-31G(d) basis set. The GDIIS algorithm was used. A full frequency calculation was performed on each structure to establish true minima. A model for the initial geometry of complex $\mathbf{5 . 2}$ used the crystallographically determined coordinates as a starting point for subsequent minimization. Atoms were then stripped away from this structure to reveal a $\mathrm{Fe}\left(\mathrm{PMe}_{2} \mathrm{Ph}\right)_{3}{ }^{+}$as the starting point to determine the theoretical structure of $\mathrm{Fe}\left(\mathrm{PMe}{ }_{2} \mathrm{Ph}\right)_{3}{ }^{+}$ by another minimization. Structural models and orbital/spin density pictures were generated from Gaussview 03.

\subsubsection{Synthesis}

Synthesis of (TPB)FeMe, 3.1. (TPB)FeBr $(0.400 \mathrm{~g}, 0.55 \mathrm{mmol})$ was dissolved in $\mathrm{Et}_{2} \mathrm{O}$ $(15 \mathrm{~mL})$ and cooled to $-35^{\circ} \mathrm{C}$. To this stirred solution was added a $1.6 \mathrm{M}$ solution of MeLi in $\mathrm{Et}_{2} \mathrm{O}(0.620 \mathrm{~mL}, 0.99 \mathrm{mmol})$. After addition the solution was allowed to warm to RT and was stirred for an additional hour, over which time the solution changed in color from a dark brown to a deep orange red. After this time, volatiles were removed and the remaining solids were extracted $3 x$ with benzene $(3 \mathrm{~mL})$. Lyophilization of benzene resulted in a dark orange powder which was washed with cold pentane $(5 \mathrm{~mL})$ to yield (TPB)FeMe (.352 g, 97\%). X-ray quality crystals were grown from slow evaporation of a concentrated pentane solution of 3.1. ${ }^{1} \mathrm{H}$ NMR $\left(\mathrm{C}_{6} \mathrm{D}_{6}, \delta\right)$ : 74.48 (br s), 33.25 (s), 22.52 (s), 9.31 (br s), 5.73 (s), 2.65 (s), -2.33 (br s), -2.80 (s), -7.49 (br s), 16.33 (s). UV-Vis (THF) $\lambda_{\max }, \mathrm{nm}\left(\varepsilon, \mathrm{M}^{-1} \mathrm{~cm}^{-1}\right): 840$ (120). Anal. Calc. for 
$\mathrm{C}_{37} \mathrm{H}_{57} \mathrm{BFeP}_{3}$ : C 67.19; H 8.69. Found: C 67.26; H 8.59. Solution magnetic moment $\left(\mathrm{C}_{6} \mathrm{D}_{6}\right): 3.9 \mu_{\mathrm{B}}$.

Synthesis of [(TPB)Fe][BAr $\left.{ }^{\mathbf{F}}\right]$, 3.2. A dark orange solution of $\mathbf{1}(0.037 \mathrm{~g}, 0.06 \mathrm{mmol})$ in $5 \mathrm{~mL}$ of $\mathrm{Et}_{2} \mathrm{O}$ was cooled to $-35^{\circ} \mathrm{C}$. Once cooled, the solution was stirred while a similarly cooled solution of $\mathrm{HBAr}_{4} \mathrm{~F}_{4} \cdot 2 \mathrm{Et}_{2} \mathrm{O}^{22}$ in $\mathrm{Et}_{2} \mathrm{O}(5 \mathrm{~mL})$ was added dropwise over 5 minutes. After the addition, the solution was stirred at RT for an additional hour before being concentrated down to $1 \mathrm{~mL}$. This solution was layered with pentane $(1 \mathrm{~mL})$ and cooled to $-35^{\circ} \mathrm{C}$ for 2 days, upon which time dark orange crystals of [(TPB)Fe][BAr $\left.{ }_{4}\right]$ had formed (0.082 g, 97\%). ${ }^{1} \mathrm{H}$ NMR $\left(\mathrm{C}_{6} \mathrm{D}_{6} / \mathrm{THF}-d_{8}, \delta\right): 32.15$ (br s), 25.78 (s), 23.99 (br s), 8.93 (br s), 8.27 (s, BAr $\left._{4}{ }_{4}\right), 4.55$ (br s), 1.84 (br s), -1.24 (br s), -28.05 (s). UV-Vis $\left(\mathrm{Et}_{2} \mathrm{O}\right) \lambda_{\max }, \mathrm{nm}\left(\varepsilon, \mathrm{M}^{-1} \mathrm{~cm}^{-1}\right): 475$ (1700), 765 (800). Anal. Calc. for $\mathrm{C}_{68} \mathrm{H}_{66} \mathrm{~B}_{2} \mathrm{~F}_{24} \mathrm{FeP}_{3}: \mathrm{C}$ 54.10; H 4.41. Found: C 53.93; H 4.53.

Synthesis of [(TPB)Fe( $\left.\left.\mathbf{N}_{2} \mathbf{H}_{4}\right)\right]\left[\mathrm{BAr}^{\mathrm{F}_{4}}\right]$, 3.3. $3.2(0.356 \mathrm{~g}, 0.24 \mathrm{mmol})$ was dissolved in $\mathrm{Et}_{2} \mathrm{O}(10 \mathrm{~mL})$ and stirred. To this was added $\mathrm{N}_{2} \mathrm{H}_{4}(0.076 \mathrm{~mL}, 2.36 \mathrm{mmol})$ in one portion. Upon addition, the solution lightened slightly in color to a brown-orange. The solution was allowed to stir for 15 minutes before the solution was concentrated to $5 \mathrm{~mL}$ and layered with pentane $(5 \mathrm{~mL})$. After 2 days at $-35^{\circ} \mathrm{C}$, dark orange crystals of $\left[(\mathrm{TPB}) \mathrm{Fe}\left(\mathrm{N}_{2} \mathrm{H}_{4}\right)\right]\left[\mathrm{BAr}{ }_{4}{ }_{4}\right]$ had formed $(0.324 \mathrm{~g}, 89 \%) .{ }^{1} \mathrm{H}$ NMR $\left(\mathrm{C}_{6} \mathrm{D}_{6} / \mathrm{THF}-d_{8}, \delta\right): 53.72$ (br s), 28.26 (s), 25.32 (s), 20.18 (br s), $8.28\left(\mathrm{~s}, \mathrm{BAr}_{4}\right) 7.67\left(\mathrm{~s}, \mathrm{BAr}^{\mathrm{F}}\right.$ ), 8.14 (br s), 7.96 (br s), 3.00 (br s), 2.67 (br s), 0.30 (br s), -26.06 (s). UV-Vis (THF) $\lambda_{\max }, \mathrm{nm}\left(\varepsilon, \mathrm{M}^{-1} \mathrm{~cm}^{-}\right.$ ${ }^{1}$ ): 800 (140). Anal. Calc. for $\mathrm{C}_{68} \mathrm{H}_{70} \mathrm{~B}_{2} \mathrm{~F}_{24} \mathrm{FeN}_{2} \mathrm{P}_{3}$ : C 52.98; H 4.58; N 1.82. Found: C 53.03; H 4.63; N 1.70. Solution magnetic moment (THF- $\left.d_{8}\right)$ : $3.46 \mu_{\mathrm{B}}$. 
Synthesis of [(TPB)Fe(NH3)][BAr $\left.{ }^{F_{4}}\right]$, 3.4. A solution of $\mathbf{3 . 3}(0.308 \mathrm{~g}, 0.20 \mathrm{mmol})$ in 1:6 THF:Benzene $(10 \mathrm{~mL})$ was rapidly stirred at RT for 12 hours. After this time, the volatiles were removed in vacuo and the residue was taken up in $\mathrm{Et}_{2} \mathrm{O}$, filtered, and layered with pentane before being cooled to $-35^{\circ}$. After 2 days, dark orange-red crystals of [(TPB)Fe( $\left.\left(\mathrm{NH}_{3}\right)\right]\left[\mathrm{BAr}^{\mathrm{F}}{ }_{4}\right]$ had formed $(0.264 \mathrm{~g}, 87 \%) .{ }^{1} \mathrm{H}$ NMR $\left(\mathrm{C}_{6} \mathrm{D}_{6} / \mathrm{THF}^{8} \mathrm{~d}^{8}, \delta\right)$ : $68.22\left(\right.$ br s), $28.55(\mathrm{~s}), 24.28(\mathrm{~s}), 17.81(\mathrm{br} \mathrm{s}), 8.34\left(\mathrm{~s}, \mathrm{BAr}^{\mathrm{F}}\right), 7.68\left(\mathrm{~s}, \mathrm{BAr}^{\mathrm{F}}{ }_{4}\right), 5.74(\mathrm{br} \mathrm{s})$, 3.53 (s), 2.15 (br s), 1.22 (br s), -25.48 (s). UV-Vis (THF) $\lambda_{\max }, \mathrm{nm}\left(\varepsilon, \mathrm{M}^{-1} \mathrm{~cm}^{-1}\right): 871$ (50). IR (KBr, cm-1): 3381 (v[NH]) Anal. Calc. for $\mathrm{C}_{68} \mathrm{H}_{69} \mathrm{~B}_{2} \mathrm{~F}_{24} \mathrm{FeNP}_{3}$ : C 54.24; $\mathrm{H}$ 4.55; N 0.92. Found: C 53.47; H 4.72; N 0.94. Solution magnetic moment (THF- $d_{8}$ ): $3.63 \mu_{\mathrm{B}}$

Synthesis of (TPB)FeNH2, 3.5. A solution of $3.2(0.300 \mathrm{~g}, 0.20 \mathrm{mmol})$ in $\mathrm{Et}_{2} \mathrm{O}(5 \mathrm{~mL})$ was stirred over $\mathrm{NaNH}_{2}(0.077 \mathrm{~g}, 1.99 \mathrm{mmol})$ which had been finely ground with a mortar and pestle. The resulting mixture was allowed to stir for 1.5 hours at RT and, over this time, the liquid phase darkened from orange to a dark brown. Volatiles were removed and the remaining residue was extracted with pentane $(40 \mathrm{~mL})$ to yield a pale orange solution. To this solution was added 12-crown-4 (0.070 g, $0.40 \mathrm{mmol})$ to aid in the removal of $\mathrm{NaBAr}_{4}$, and solids began to precipitate. The solution was allowed to stand for 1 hour before filtration. Removal of solvent for 3 hours at $70^{\circ} \mathrm{C}$ resulted in (TPB)FeNH 2 as a dark orange powder $(0.060 \mathrm{~g}, 0.09 \mathrm{mmol}, 46 \%)$. Crystals suitable for X-ray diffraction were grown from slow evaporation of a concentrated ethereal solution. Due to the presence of a small amount of 12-crown-4 that had similar solubility properties to the product, satisfactory combustion analysis was not obtained for 3.5. ${ }^{1} \mathrm{H}$ $\operatorname{NMR}\left(\mathrm{C}_{6} \mathrm{D}_{6}, \delta\right): 91.12$ (br s), 38.21 (s), 25.42 (s), 4.12 (br s), 1.55 (br s), 0.21 (br s), -3.04 
(br s), -5.93 (br s), -20.19(s). UV-Vis (THF) $\lambda_{\max }, \mathrm{nm}\left(\varepsilon, \mathrm{M}^{-1} \mathrm{~cm}^{-1}\right): 700(90), 930(80)$. Solution magnetic moment $\left(\mathrm{C}_{6} \mathrm{D}_{6}\right): 4.05 \mu_{\mathrm{B}}$. We also wish to note that trace amounts $(<3 \%)$ of the neutral complex $(\mathrm{TPB}) \mathrm{Fe}\left(\mathrm{N}_{2}\right)$ are typically observed as impurities detected by NMR spectroscopy in preparations of 3.5. (TPB)Fe( $\left.\mathrm{N}_{2}\right)$ and $\mathbf{3 . 5}$ also have similar solubility properties.

Synthesis of (TPB)FeOH, 3.6. Complex $3.2(0.80 \mathrm{~g}, 0.05 \mathrm{mmol})$ was dissolved in $\mathrm{Et}_{2} \mathrm{O}$ $(5 \mathrm{~mL})$ and stirred over $\mathrm{NaOH}(0.063 \mathrm{~g}, 1.6 \mathrm{mmol})$ at RT for 2 hours, during which the color of the solution darkened to a deep brown. Volatiles were removed from the solution and the resulting solids were extracted with pentane to yield the title compound $(0.027,77 \%)$ as a brown powder. Crystals suitable for X-Ray diffraction were grown by a slow evaporation of a concentrated $\mathrm{Et}_{2} \mathrm{O}$ solution. ${ }^{1} \mathrm{H} \mathrm{NMR}\left(\mathrm{C}_{6} \mathrm{D}_{6}, \delta\right): 89.55$ (br s), 39.07 (s), 24.70 (s), 6.71 (s), 4.08 (s), 1.55 (br s), -0.52 (br s), -6.00 (br s), -21.02 (s). UV-Vis (THF) $\lambda_{\max }, \mathrm{nm}\left(\varepsilon, \mathrm{M}^{-1} \mathrm{~cm}^{-1}\right): 870$ (230), 700 (218). Anal. Calc. for $\mathrm{C}_{36} \mathrm{H}_{55} \mathrm{BFeOP}_{3}$ : C 65.18; H 8.36; N 0. Found: C 65.15; H 8.28; N none found. Solution magnetic moment $\left(\mathrm{C}_{6} \mathrm{D}_{6}\right): 4.12 \mu_{\mathrm{B}}$.

Protonation of 3.5. A $20 \mathrm{~mL}$ scintillation vial was charged with $3.5(0.005 \mathrm{~g}, 0.007$ mmol $)$ and $\mathrm{HBAr}_{4} \mathrm{~F}_{4} \cdot 2 \mathrm{Et}_{2} \mathrm{O}(0.008 \mathrm{~g}, 0.007 \mathrm{mmol})$ and cooled to $-35^{\circ} \mathrm{C}$. Similarly cooled $\mathrm{Et}_{2} \mathrm{O}(2 \mathrm{~mL})$ was added to the mixture and the color of the solution lightened rapidly. The solution was allowed to warm to RT over 30 minutes before volatiles were removed to yield $3.4(0.010 \mathrm{~g}, 0.006 \mathrm{mmol}, 91 \%)$. The identity of the product was determined via ${ }^{1} \mathrm{H}$ NMR chemical shifts which were identical to those observed for $\mathbf{3 . 4}$.

Reduction of 3.4. A $20 \mathrm{~mL}$ scintillation vial was charged with $3.4(0.025 \mathrm{~g}, 0.016$ $\mathrm{mmol})$ and $\mathrm{KC}_{8}(0.0024 \mathrm{~g}, 0.018 \mathrm{mmol}) . \mathrm{Et}_{2} \mathrm{O}(2 \mathrm{~mL})$ was added and the resulting dark 
suspension was allowed to stir for 2 hours at RT. After this time, the solution was filtered and volatiles were removed to yield (TPB)Fe( $\left(\mathrm{N}_{2}\right)$ as a brown solid. The identity of the product was determined via ${ }^{1} \mathrm{H}$ NMR chemical shifts which were identical to the previously reported values for $(\mathrm{TPB}) \mathrm{Fe}\left(\mathrm{N}_{2}\right)$.

Monitored Conversion of 3.3 to 3.4. Complex 3.3 ( $0.020 \mathrm{~g}, 0.013 \mathrm{mmol})$ was dissolved in a 6:1 mixture of $\mathrm{C}_{6} \mathrm{D}_{6}$ :THF- $d_{8}(0.3 \mathrm{~mL})$. The resulting solution was transferred to a NMR tube equipped with a capillary containing a solution of (TPB)FeBr in a 6:1 mixture of $\mathrm{C}_{6} \mathrm{D}_{6}$ :THF- $d 8$ as an internal standard. This NMR tube was sealed with a J-Young valve and placed into a $500 \mathrm{MHz}$ spectrometer which had been preheated to $60^{\circ} \mathrm{C}$. The reaction was monitored via single scans every minute for 4 hours, during which time complete and clean conversion from 3.3 to 3.4 was observed. After the reaction was complete, an aliquot of the headspace was analyzed by $\mathrm{GC}$ for the presence of $\mathrm{H}_{2}$. After this, volatiles were vacuum transferred onto a solution of $\mathrm{HCl}$ in THF. Volatiles were then removed and the resulting solids were diluted with water to appropriate volumes to test for the presence of $\mathrm{NH}_{3}$ via the indophenol test, ${ }^{23}$ or $\mathrm{N}_{2} \mathrm{H}_{4}$ with $p$ dimethylaminobenzaldehyde. ${ }^{24}$ The relative amounts of products are compiled in Appendix 2. 


\section{References Cited}

1 (a) Vela, J.; Stoian, S.; Flaschenriem, C. J.; Münck, E.; Holland, P. L. J. Am. Chem. Soc. 2004, 126, 4522-4523; (b) Field, L. D.; Li, H. L.; Dalgarno, S. J.; Turner, P. Chem.

Commun. 2008, 1680-1682; (c) Crossland, J. L.; Tyler, D. R. Coord. Chem. Rev. 2010, 254, 1883-1894. (d) Hazari, N. Chem. Soc. Rev. 2010, 39, 4044-4056; (e) Crossland, J. L.; Balesdent, C. G.; Tyler, D. R. Inorg. Chem. 2011, 51, 439-445; (f) MacLeod, K. C.; Holland, P. L. Nat. Chem. 2013, 5, 559-565.

2 (a) Lukoyanov, D.; Dikanov, S. A.; Yang, Z.-Y.; Barney, B. M.; Samoilova, R. I.;

Narasimhulu, K. V.; Dean, D. R.; Seefeldt, L. C.; Hoffman, B. M. J. Am. Chem. Soc.

2011, 133, 11655-11664; (b) Seefeldt, L. C.; Hoffman, B. M.; Dean, D. R. Annu. Rev. Biochem. 2009, 78, 701-722.

3 (a) Betley, T. A.; Peters, J. C. J. Am. Chem. Soc. 2003, 125, 10782-10783; (b) Saouma, C. T.; Müller, P.; Peters, J. C. J. Am. Chem. Soc. 2009, 131, 10358-10359; (c) Saouma, C. T.; Kinney, R. A.; Hoffman, B. M.; Peters, J. C. Angew. Chem. Int. Ed. 2011, 50, 3446-3449; (d) Saouma, C. T.; Peters, J. C. Coord. Chem. Rev. 2011, 255, 920-937. 4 (a) Whited, M. T.; Mankad, N. P.; Lee, Y.; Oblad, P. F.; Peters, J. C. Inorg. Chem. 2009, 48, 2507-2517; (b) Lee, Y.; Mankad, N. P.; Peters, J. C. Nat Chem 2010, 2, 558565.

5 (a) Betley, T. A.; Peters, J. C. J. Am. Chem. Soc. 2004, 126, 6252-6254; (b) Scepaniak, J. J.; Fulton, M. D.; Bontchev, R. P.; Duesler, E. N.; Kirk, M. L.; Smith, J. M. J. Am. Chem. Soc. 2008, 130, 10515-10517; (c) Scepaniak, J. J.; Young, J. A.; Bontchev, R. P.; Smith, J. M. Angew. Chem., Int. Ed. 2009, 48, 3158-3160. (d) Scepaniak, J. J.; 
Vogel, C. S.; Khusniyarov, M. M.; Heinemann, F. W.; Meyer, K.; Smith, J. M.

Science 2011, 331, 1049-1052;

6 Fox, D. J.; Bergman, R. G. J. Am. Chem. Soc. 2003, 125, 8984-8985.

7 (a) Moret, M.-E.; Peters, J. C. Angew. Chem. Int. Ed. 2011, 50, 2063-2067; (b) Moret,

M.-E.; Peters, J. C. J. Am. Chem. Soc. 2011, 133, 18118-18121.

8 Sircoglou, M.; Bontemps, S.; Bouhadir, G.; Saffon, N.; Miqueu, K.; Gu, W.; Mercy,

M.; Chen, C.-H.; Foxman, B. M.; Maron, L.; Ozerov, O.V.; Bourissou, D. J. Am. Chem. Soc. 2008, 130, 16729-16738.

9 A stable T-shaped, three-coordinate Fe(I) is known: Ingleson, M. J.; Fullmer, B. C.;

Buschhorn, D. T.; Fan, H.; Pink, M.; Huffman, J. C.; Caulton, K. G. Inorg. Chem. 2008, 47, 407-409.

10 (a) Amgoune, A.; Bourissou, D. Chem. Comm. 2011, 47, 859-871; (b) Hill, A. F.;

Owen, G. R.; White, A. J. P.; Williams, D. J. Angew. Chem., Int. Ed. 1999, 38, 2759-

2761; (c) Pang, K.; Quan, S. M.; Parkin, G. Chem. Comm. 2006, 5015-5017.

11 Cambridge Structural Database, 2011 update: F. H. Allen, Acta Crystallogr. B 2002, B58, 380-388.

12 Espenson, J. Chemical Kinetics and Reaction Mechanisms; McGraw-Hill Education, 2002.

13(a) Redshaw, C.; Wilkinson, G.; Hussain-Bates, B.; Hursthouse, M. B. J. Chem. Soc. Dalton, 1992, 1803-1811; (b) Brady, E.; Telford, J. R.; Mitchell, G.; Lukens, W. Acta Cryst. C 1995, 51, 558-560; (c) Cámpora, J.; Palma, P.; del Río, D.; Conejo, M. M.; Álvarez, E. Organometallics 2004, 23, 5653-5655; (d) Sofield, C. D.; Walter, M. D.; Andersen, R. A. Acta Cryst. C 2004, 60, 465-466; (e) Huffman, J. C.; Meyer, K.; 
Mindiola, D. J. Inorg. Chem. 2008, 47, 10479-10490; (f) Gutsulyak, D. V.; Piers, W.

E.; Borau-Garcia, J.; Parvez, M. J. Am. Chem. Soc. 2013.

14 Stoian, S. A.; Yu, Y.; Smith, J. M.; Holland, P. L.; Bominaar, E. L.; Munck, E. Inorg.

Chem. 2005, 44, 4915-4922.

15 Harman, W. H.; Harris, T. D.; Freedman, D. E.; Fong, H.; Chang, A.; Rinehart, J. D.;

Ozarowski, A.; Sougrati, M. T.; Grandjean, F.; Long, G. J.; Long, J. R.; Chang, C. J. J.

Am. Chem. Soc. 2010, 132, 18115-18126.

16 W. Kabsch, J. Appl. Cryst. 1993, 26, 795.

17 Sheldrick, G. M. Acta Cryst. 1990, A46, 467.

18 Sheldrick, G. M. Acta Cryst. 2004, A64, 112.

19 Müller, P. Crystallography Reviews 2009, 15, 57.

20 http://ewww.mpi-muelheim.mpg.de/bac/logins/bill/julX_en.php

21 Gaussian 03, Revision E.01, Frisch, M. J.; Trucks, G. W.; Schlegel, H. B.; Scuseria,

G. E.; Robb, M. A.; Cheeseman, J. R.; Montgomery, Jr., J. A.; Vreven, T.; Kudin,

K. N.; Burant, J. C.; Millam, J. M.; Iyengar, S. S.; Tomasi, J.; Barone, V.; Mennucci,

B.; Cossi, M.; Scalmani, G.; Rega, N.; Petersson, G. A.; Nakatsuji, H.; Hada, M.;

Ehara, M.; Toyota, K.; Fukuda, R.; Hasegawa, J.; Ishida, M.; Nakajima, T.; Honda, Y.;

Kitao, O.; Nakai, H.; Klene, M.; Li, X.; Knox, J. E.; Hratchian, H. P.; Cross, J. B.;

Bakken, V.; Adamo, C.; Jaramillo, J.; Gomperts, R.; Stratmann, R. E.; Yazyev, O.;

Austin, A. J.; Cammi, R.; Pomelli, C.; Ochterski, J. W.; Ayala, P. Y.; Morokuma, K.;

Voth, G. A.; Salvador, P.; Dannenberg, J. J.; Zakrzewski, V. G.; Dapprich, S.; Daniels,

A. D.; Strain, M. C.; Farkas, O.; Malick, D. K.; Rabuck, A. D.; Raghavachari, K.;

Foresman, J. B.; Ortiz, J. V.; Cui, Q.; Baboul, A. G.; Clifford, S.; Cioslowski, J.; 
Stefanov, B. B.; Liu, G.; Liashenko, A.; Piskorz, P.; Komaromi, I.; Martin, R. L.; Fox, D. J.; Keith, T.; Al-Laham, M. A.; Peng, C. Y.; Nanayakkara, A.; Challacombe, M.; Gill, P. M. W.; Johnson, B.; Chen, W.; Wong, M. W.; Gonzalez, C.; and Pople, J. A.; Gaussian, Inc., Wallingford CT, 2004.

22 Brookhart, M.; Grant, B.; Volpe, A. F. Organometallics 1992, 11, 3920-3922. 23 Weatherburn, M.W. Anal. Chem. 1967, 39, 971-974.

24 Watt, G. W.; Chrisp, J. D. Anal. Chem. 1952, 24, 2006-2008. 


\section{Chapter 4: Catalytic Conversion of $\mathrm{N}_{2}$ to $\mathrm{NH}_{3}$ by an Fe Model Complex}

Reproduced in part with permission from

Anderson, J. S.; Rittle, J.; Peters, J. C. Nature, 2013 in press, DOI: 10.1038/nature12435. C2013 Nature Publishing Group 


\subsection{Introduction}

Although ill-defined and heterogeneous mixtures of transition metals competent for the catalytic reduction of $\mathrm{N}_{2}$ to $\mathrm{NH}_{3}$ have been known for some time, ${ }^{1}$ molecular systems where potential catalytic intermediates can be studied have only recently been developed. Early work on Mo complexes supported by phosphine co-ligands could bind $\mathrm{N}_{2}$ and facilitate its protonation to release $\mathrm{NH}_{3}$ in near quantitative yields. ${ }^{2}$ More recently, advancements have led to two examples of molecular $\mathrm{N}_{2}$ reduction catalysts, both featuring Mo complexes synthesized by the groups of Schrock and Nishibayashi. ${ }^{3}$ Although Nishibayashi's system is more recent and little about its mechanism is currently known, ${ }^{4}$ there has been extensive work on the Schrock system and numerous potential intermediates have been isolated that strongly imply a "distal" or Chatt-type mechanism for $\mathrm{N}_{2}$ reduction. ${ }^{5}$

Fe mediated $\mathrm{NH}_{3}$ formation from $\mathrm{N}_{2}$ has progressed much more slowly than in the Mo systems. While significant amounts of $\mathrm{NH}_{3}$ can be generated from the protonation of Fe nitride species, ${ }^{6} \mathrm{FeN}_{2}$ complexes typically provide only small amounts ( $\left.10 \mathrm{~mol} \%\right)$ of $\mathrm{NH}_{3}$ derived from $\mathrm{N}_{2}{ }^{7}$ Recently, Holland and co-workers have reported an Fe complex than can split $\mathrm{N}_{2}$ into two nitride units which can then be exposed to acid or hydrogen to yield nearly stoichiometric $\mathrm{NH}_{3}{ }^{8}$ Additionally, Nishibayashi and co-workers have shown the catalytic formation of $\mathrm{N}(\mathrm{TMS})_{3}$ from $\mathrm{N}_{2}, \mathrm{Na}$, and $\mathrm{TMSCl}$ in the presence of simple Fe catalysts. ${ }^{9}$ Despite these advances, the development of a molecular system for converting $\mathrm{N}_{2}$ into $\mathrm{NH}_{3}$ with protons and electrons has remained a substantial challenge. In the context of nitrogen fixation by nitrogenase enzymes, ${ }^{10}$ the lack of such a functional 
system has weighed against Fe being the binding site in FeMoco, despite spectroscopic evidence to the contrary. ${ }^{11}$

While previous efforts with the $\left(\mathrm{SiP}_{3}\right)$ ligand scaffold yielded only moderate amounts of $\mathrm{N}_{2} \mathrm{H}_{4},{ }^{12}$ the species synthesized in Chapter 3 and the silylation chemistry that had been previously reported motivated a closer examination of the (TPB)Fe scaffold in the context of $\mathrm{NH}_{3}$ formation. ${ }^{13,14}$ This chapter therefore discusses initial protonation studies of $\left[(\mathrm{TPB}) \mathrm{Fe}\left(\mathrm{N}_{2}\right)\right][\mathrm{Na}(12$-crown-4)2] which yielded the previously reported complex 3.4. This result led to the optimization of conditions that allowed for the catalytic reduction of $\mathrm{N}_{2}$ to $\mathrm{NH}_{3}$ with $\left[(\mathrm{TPB}) \mathrm{Fe}\left(\mathrm{N}_{2}\right)\right][\mathrm{Na}(12$-crown-4) 2$]$ as the precatalyst. Control experiments suggest that the catalysis, while occurring in a heterogeneous mixture, is mediated by a molecular catalyst. Furthermore, the speciation of the Fe containing complex after catalysis is studied, suggesting possible degradation pathways.

\subsection{Results and Discussion}

\subsubsection{Initial Protonation Studies}

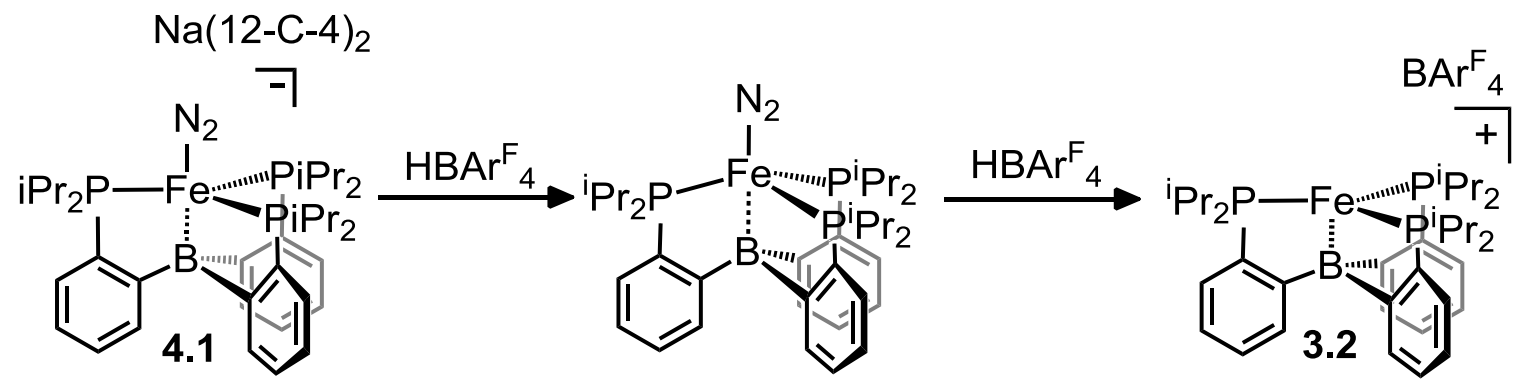

Scheme 4.1. Oxidation induced by acid addition on $\mathrm{N}_{2}$ adducts of (TPB)Fe. 
In order to investigate catalytic $\mathrm{NH}_{3}$ formation with protons and electrons, several significant challenges had to be addressed. Most notable of these was the propensity of reduced $\mathrm{Fe}$ phosphine systems to generate $\mathrm{H}_{2}$ more favorably than $\mathrm{N}-\mathrm{H}$ bonds when exposed to acids. This phenomenon had been observed with the (TPB) ligand scaffold and can be summarized in Scheme 1, where the addition of one equivalent of acid to the previously reported anionic $\left[(\mathrm{TPB}) \mathrm{Fe}\left(\mathrm{N}_{2}\right)\right]\left[\mathrm{Na}(12 \text {-crown-4) })_{2}\right](\mathbf{4 . 1})$ results in oxidation to (TPB)Fe( $\left.\mathrm{N}_{2}\right)$. Similarly, exposure of (TPB)Fe( $\left.\mathrm{N}_{2}\right)$ to acid also results in net oxidation and the generation of [(TPB)Fe][BAr$\left.{ }_{4}^{\mathrm{F}}\right]$ (3.2). In both reactions loss of $\mathrm{H}_{2}$ is likely, but the exact mechanism of oxidation is unclear. Any mechanistic insight into this process would be useful as a means to circumvent the oxidative pathway and lead to productive $\mathrm{N}_{2}$ functionalization.

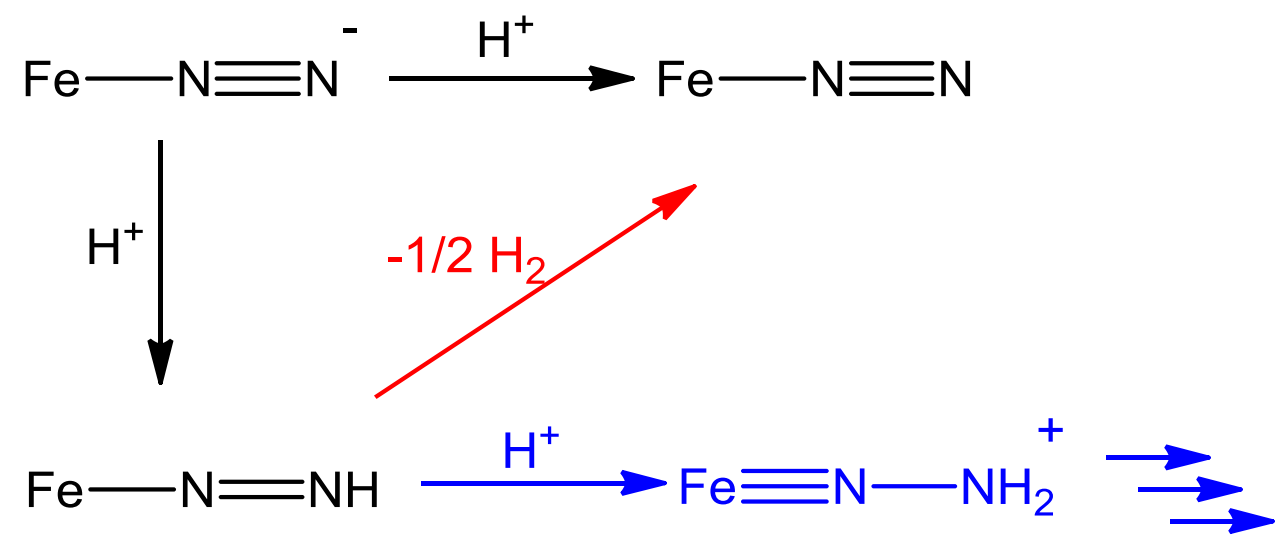

Scheme 4.2. Possible routes of protonation for an anionic $\mathrm{FeN}_{2}$ species. The reaction shown in red indicates undesired elimination of $\mathrm{H}_{2}$, while the reactions shown in blue indicate putative desirable protonations leading to further functionalization of $\mathrm{N}_{2}$.

Although the products of the reactions shown in Scheme 4.1 are net oxidation, an outer-sphere oxidation of the Fe center seemed unlikely, as the reduced product of such a 
reaction would be a highly reactive $\mathrm{H} \cdot$ radical. This supposition, combined with the observation that the $\beta \mathrm{N}$ of $\mathbf{4 . 1}$ is also nucleophilic enough to attack chlorosilanes, suggested that protonation at the $\beta \mathrm{N}$ of $\mathrm{N}_{2}$ might be reasonable, but that bi-metallic elimination of $\mathrm{H}_{2}$ from the formed diazenido (FeNNH) species might be facile and lead to the net observed oxidation (Scheme 4.2). Diazenido species are typically unstable, with the only crystallographically characterized example from the tri-amido amine system of Schrock and co-workers. ${ }^{15}$ Further protonation, however, has led to the characterization of more stable species, such as parent hydrazido(2-) complexes, which were some of the first ligands observed from protonating $\mathrm{N}_{2}$ on Mo. ${ }^{16}$

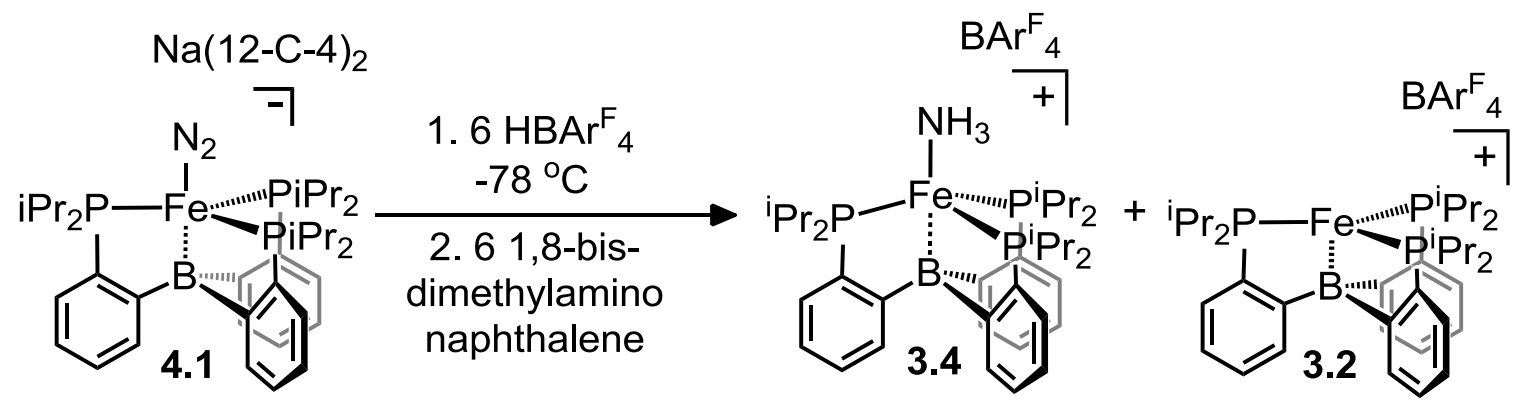

Scheme 4.3. Formation of complex 3.4 from complex 4.1 and acid.

Although stopping the loss of $\mathrm{H}_{2}$ from a putative diazenido species might prove challenging, a possible strategy to further functionalize the $\mathrm{N}_{2}$ species would be trapping the diazenido with excess protons before it can decompose (Scheme 4.2). With this strategy in mind, reaction of $\mathbf{4 . 1}$ with excess acid was investigated as a means to test whether $\mathrm{N}_{\mathrm{x}} \mathrm{H}_{\mathrm{y}}$ species could be detected in solution or bound to Fe. Reaction of 4.1 with 6 equivalents of $\mathrm{HBAr}_{4}{ }_{4} \cdot 2 \mathrm{Et}_{2} \mathrm{O}$ at $-78{ }^{\circ} \mathrm{C}$ results in a color change from the dark red of 4.1 to yellow. Although the excess acid present in the reaction mixture complicates ${ }^{1} \mathrm{H}$ proton analysis, addition of a base in the form of 1,8-bis-dimethylaminonaphthalene to 
bind the excess acid allowed for the identification of $\left[(\mathrm{TPB}) \mathrm{Fe}\left(\mathrm{NH}_{3}\right)\right]\left[\mathrm{BAr}^{\mathrm{F}}{ }_{4}\right]$ (3.4) as a major component of the reaction mixture (Scheme 4.3). Integration of the ${ }^{1} \mathrm{H} \mathrm{NMR}$ signals of 3.4 versus an internal integral standard provides a crude method to estimate the yield of the paramagnetic products and shows that the yield of the $\mathrm{NH}_{3}$ adduct 3.4 is $35 \%$ with the observation of complex 3.2 in $\sim 40 \%$ yield and other unidentified minor paramagnetic products. The observed yield of $\mathbf{3 . 4}$, although only an estimate, suggests that $\mathrm{NH}_{3}$ is being formed in unusually high yields in this reaction as compared with other phosphine complexes of Fe.7

The formation of $\mathrm{NH}_{3}$ in this reaction led to several important observations. Firstly, the lack of additional reductant in the solution indicates that the $\mathrm{NH}_{3}$ is being formed by some disproportionation pathway. Whether this pathway is through a disproportionation of $\mathrm{N}_{\mathrm{x}} \mathrm{H}_{\mathrm{y}}$ species, as was seen in chapter 3 with the disproportionation of $\left[(\mathrm{TPB}) \mathrm{Fe}\left(\mathrm{N}_{2} \mathrm{H}_{4}\right)\right]\left[\mathrm{BAr}_{4}{ }_{4}\right](\mathbf{3 . 3})$ to 3.4, or whether some portion of the initial complex 4.1 is protonated and then reduced by unreacted 4.1, is still unclear. Secondly, the observation of $\mathbf{3 . 4}$ and 3.2, as well as other putatively molecular species at the end of the reaction, suggests that a molecular process is responsible for the formation of $\mathrm{NH}_{3}$ in this transformation. Thirdly, the reductions of 3.4 to release $\mathrm{NH}_{3}$ and pick up $\mathrm{N}_{2}$ to form (TPB)Fe( $\left(\mathrm{N}_{2}\right)$ and the subsequent reduction of $(\mathrm{TPB}) \mathrm{Fe}\left(\mathrm{N}_{2}\right)$ to $\mathbf{4 . 1}$ are known. Complex 3.2 can similarly be reduced to 4.1. Indeed, the low-temperature reduction of a mixture similarly generated to that shown in Scheme 4.3 results in regeneration of $\mathbf{4 . 1}$ as determined by IR spectroscopy (Appendix 3). These combined transformations suggest that a synthetic cycle for the generation of $\mathrm{NH}_{3}$ from 4.1 should be plausible (Scheme 4.4). 


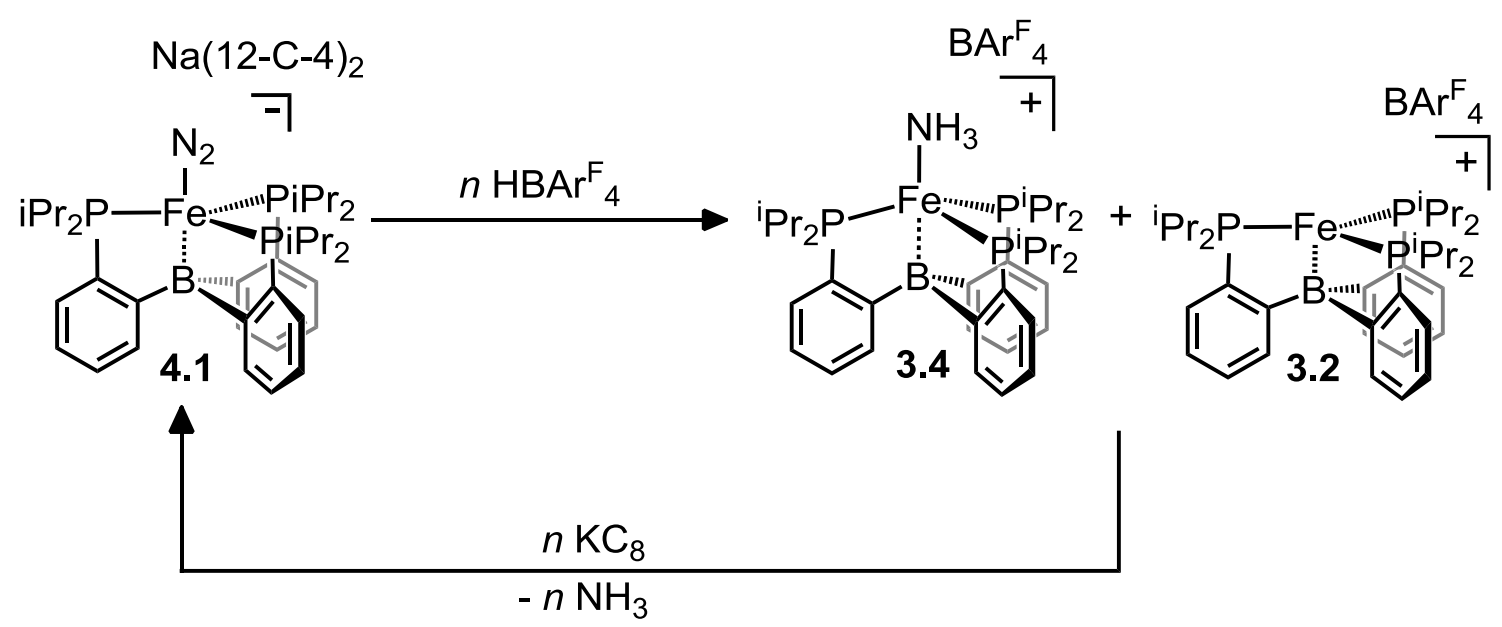

Scheme 4.4. A synthetic cycle for the formation of $\mathrm{NH}_{3}$ mediated by (TPB)Fe.

\subsubsection{Catalytic $\mathrm{N}_{2}$ Reduction to $\mathrm{NH}_{3}$}

In order to accurately quantify the amount of $\mathrm{NH}_{3}$ produced in any study, a reliable assay for $\mathrm{NH}_{3}$ formation was sought. Traditionally, UV-Visible spectroscopy of highly colored chromophores formed from $\mathrm{NH}_{4}{ }^{+}$salts have been employed for the detection of generated $\mathrm{NH}_{3}$. Specifically, generation of indophenol dyes from $\mathrm{NH}_{3}$, phenol, and hypochlorite is a technique that has been used by Schrock and Nishibayashi for the accurate quantification of $\mathrm{NH}_{3} .{ }^{17}$ A typical assay involves the vacuum transfer of the volatiles from a reaction mixture onto ethereal $\mathrm{HCl}$. The remaining reaction residues are then digested with $\mathrm{NaOtBu}$ to liberate any $\mathrm{NH}_{4}{ }^{+}$salts and then vacuum transferred again onto the same collection flask containing ethereal $\mathrm{HCl}$. The collection flask is then warmed and any $\mathrm{NH}_{3}$ is trapped as $\left[\mathrm{NH}_{4}\right][\mathrm{Cl}]$ which precipitates from solution. Upon removal of volatiles, the remaining $\left[\mathrm{NH}_{4}\right][\mathrm{Cl}]$ salts are re-dissolved in $\mathrm{H}_{2} \mathrm{O}$ and analyzed with solutions of phenol and hypochlorite to develop the blue color indicative of the indophenol chromophore (Figure 4.1). 
Studies with $\mathrm{HBAr}_{4}{ }_{4} \cdot 2 \mathrm{Et}_{2} \mathrm{O}$ and $\mathrm{KC}_{8}$ at $-78{ }^{\circ} \mathrm{C}$ showed unusually high yields of $\mathrm{NH}_{3}$, and the use of $\mathrm{Et}_{2} \mathrm{O}$ as solvent resulted in the formation of an average of $7.0 \pm 1$ equivalents of $\mathrm{NH}_{3}$ per Fe center, effectively demonstrating the efficacy of $\mathbf{4 . 1}$ as a precatalyst for $\mathrm{N}_{2}$ reduction to $\mathrm{NH}_{3}$ (Figure 4.1, Entry 1 Table 4.1). This reaction has been performed sixteen times, with some single runs producing as much as 8.5 equivalents of $\mathrm{NH}_{3}$ per Fe. In a typical reaction, complex 4.1 is suspended in $\mathrm{Et}_{2} \mathrm{O}$ at $-78{ }^{\circ} \mathrm{C}$ and 48 equivalents of $\mathrm{HBAr}_{4}{ }_{4} \cdot 2 \mathrm{Et}_{2} \mathrm{O}$ similarly dissolved in $\mathrm{Et}_{2} \mathrm{O}$ and cooled were added, resulting in a homogenous yellow solution. Addition of 48 equivalents of $\mathrm{KC}_{8}$ to the reaction vessel as a suspension in cold $\mathrm{Et}_{2} \mathrm{O}$ is then immediately followed by sealing of the reaction vessel. Quantification of $\mathrm{NH}_{3}$ was then performed as described above after allowing the reaction to stir for 40 minutes at $-78^{\circ} \mathrm{C}$.

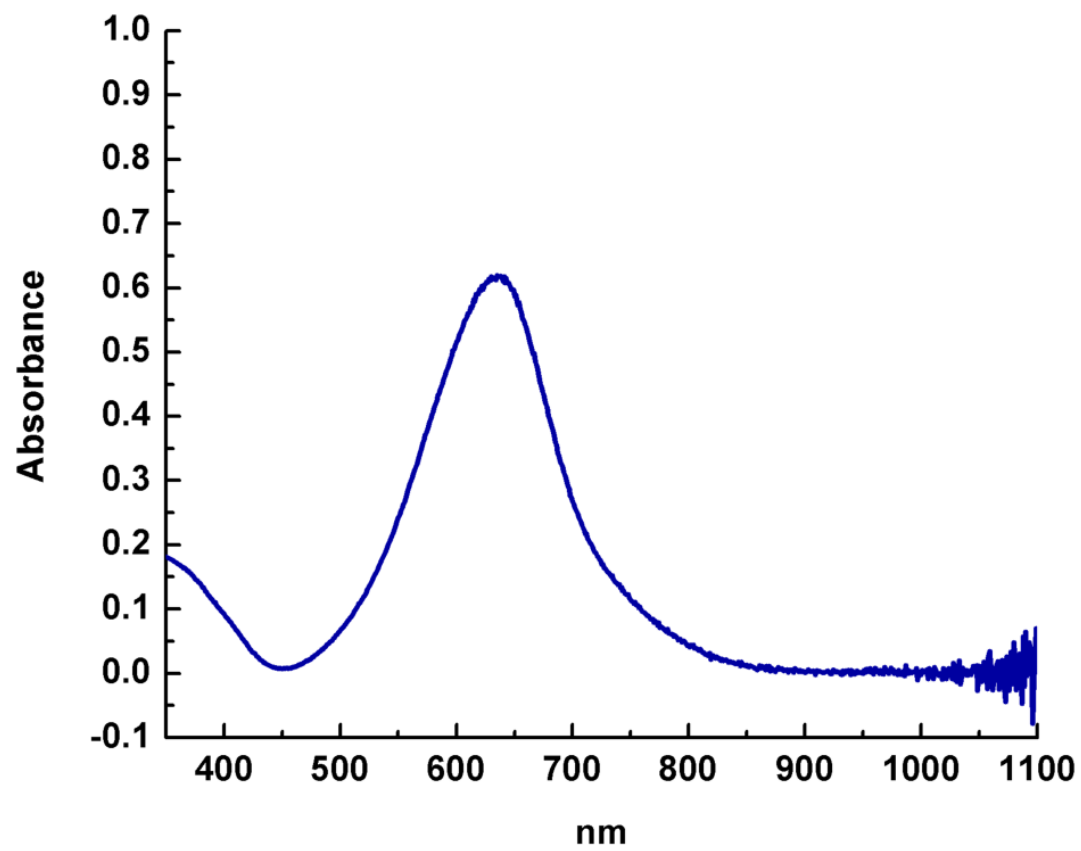

Figure 4.1. UV-Visible spectrum of the indophenol dye generated from $\mathrm{NH}_{3}$. This particular absorbance spectrum corresponds to 7.5 equivalents of $\mathrm{NH}_{3}$ generated per $\mathrm{Fe}$ center. 


\begin{tabular}{ccc}
\hline Entry & Fe precursor & $\mathrm{NH}_{3}$ equiv/Fe \\
\hline 1 & {$\left[(\mathrm{TPB}) \mathrm{Fe}\left(\mathrm{N}_{2}\right)\right]\left[\mathrm{Na}\left(12-\text { crown }^{-4}\right)_{2}\right]$} & $7.0 \pm 1$ \\
2 & {$[(\mathrm{TPB}) \mathrm{Fe}]\left[\mathrm{BAr} \mathrm{F}_{4}\right]$} & 6.2 \\
3 & {$\left[(\mathrm{TPB}) \mathrm{Fe}\left(\mathrm{NH}_{3}\right)\right]\left[\mathrm{BAr}_{4}\right]$} & 5.7 \\
4 & {$\left[(\mathrm{TPB}) \mathrm{Fe}\left(\mathrm{N}_{2} \mathrm{H}_{4}\right)\right]\left[\mathrm{BAr}_{4}\right]$} & 5.9 \\
5 & $(\mathrm{TPB}) \mathrm{Fe}\left(\mathrm{N}_{2}\right)$ & 2.0 \\
6 & $\mathrm{FeCl}_{2} \cdot 1.5 \mathrm{THF}$ & $<0.1$ \\
7 & $\mathrm{FeCl}_{3}$ & $<0.1$ \\
8 & $\mathrm{Cp}_{2} \mathrm{Fe}$ & $<0.2$ \\
9 & $\mathrm{Fe}(\mathrm{CO})_{5}$ & $<0.1$ \\
10 & none & $<0.1$ \\
\hline
\end{tabular}

Table 4.1. Catalytic runs using the standard conditions described in the text with any changes noted in the experimental section. All numbers shown are an average of a minimum of four runs. All individual runs can be found in Appendix 3.

In addition to complex 4.1, several other (TPB)Fe complexes have been tested (entries 2-5). In all cases, catalysis was observed with similar yields of $\mathrm{NH}_{3}$ as those observed when 4.1 was used as the pre-catalyst. Most notably, species that could be potential intermediates during the catalytic cycle, such as $\mathbf{3 . 2}$ (entry 2), $\mathbf{3 . 3}$ (entry 3), and 3.4 (entry 4), all function as capable pre-catalysts. The exception to these observations is (TPB)Fe( $\left.\mathrm{N}_{2}\right)$ (entry 5), which shows substantially decreased activity towards catalysis when compared with the other (TPB)Fe species studied. Reversal of the order of reagent addition, with reductant being added first followed by acid, resulted in an improved yield of 4.8 equivalents of $\mathrm{NH}_{3}$ per Fe center. Possible explanations for the lowered activity of (TPB)Fe( $\left.\mathrm{N}_{2}\right)$ under the standard conditions will be discussed below. As control 
experiments, several simple Fe(II) and Fe(III) salts were also tested as pre-catalysts, but did not show any catalytic activity. The absence of any Fe species in the catalytic mixture also did not produce significant quantities of $\mathrm{NH}_{3}$. Taken together, these results implicate the intermediacy of a molecular (TPB)Fe catalyst for $\mathrm{N}_{2}$ reduction, especially when considered alongside the NMR studies discussed in 4.2.1.

Although there are no exogenous $\mathrm{N}$ atoms in the (TPB)Fe scaffold, the acid, or the reductant employed, it was still valuable to verify that the $\mathrm{NH}_{3}$ being produced was coming from $\mathrm{N}_{2}$. In this context, the catalytic reaction was run under ${ }^{14} \mathrm{~N}_{2}$ or isotopically labeled ${ }^{15} \mathrm{~N}_{2}$ and the resulting solids were analyzed by ${ }^{1} \mathrm{H}$ NMR (Figure 4.2). Under ${ }^{14} \mathrm{~N}_{2}$ the triplet for $\left[\mathrm{NH}_{4}\right][\mathrm{Cl}]$ with ${ }^{1} J_{\mathrm{N}-\mathrm{H}}=51 \mathrm{~Hz}$ was clearly observed and this signal became a doublet with ${ }^{1} J_{\mathrm{N}-\mathrm{H}}=71 \mathrm{~Hz}$ typical of $\left[{ }^{15} \mathrm{NH}_{4}\right][\mathrm{Cl}]$ when ${ }^{15} \mathrm{~N}_{2}$ was used instead, with only trace $\left[{ }^{14} \mathrm{NH}_{4}\right][\mathrm{Cl}]$ being observed, likely arising from the residual ${ }^{14} \mathrm{~N}_{2}$ bound in $\mathbf{4 . 1}$. These results verify that gaseous $\mathrm{N}_{2}$ is the source of the resulting $\mathrm{NH}_{3}$.
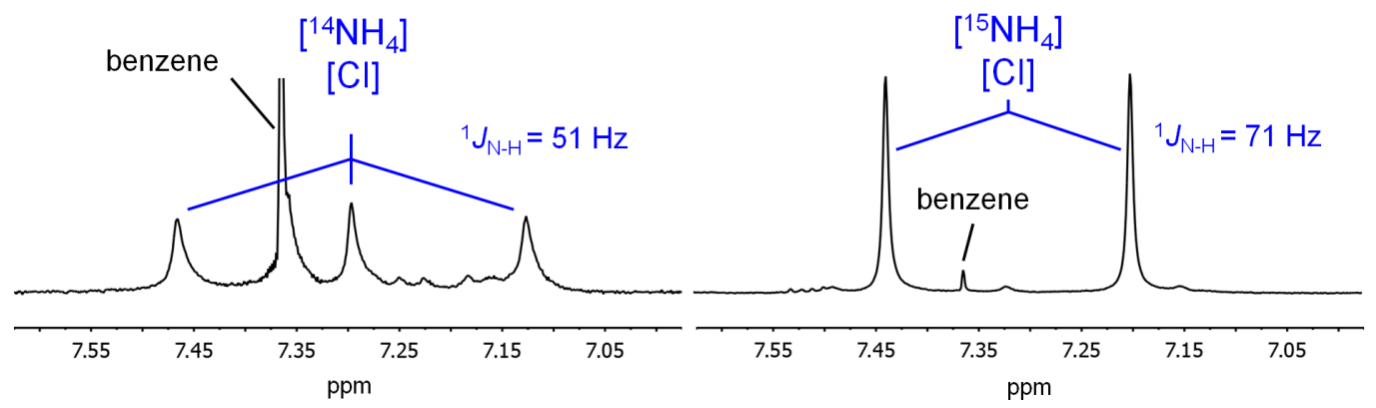

Figure 4.2. ${ }^{1} \mathrm{H}$ NMR spectra of $\left[{ }^{14} \mathrm{NH}_{4}\right][\mathrm{Cl}]$ and $\left[{ }^{15} \mathrm{NH}_{4}\right][\mathrm{Cl}]$ in DMSO- $d_{6}$ obtained from correspondingly labeled $\mathrm{N}_{2}$ gas via catalytic reduction with complex 4.1 using the standard catalytic protocol described in the text. 
It is somewhat noteworthy that the catalysis appears to be occurring at $-78{ }^{\circ} \mathrm{C}$. The disappearance of the bronze color of $\mathrm{KC}_{8}$ at $-78^{\circ} \mathrm{C}$ seems to suggest that consumption of reductant occurs at low temperature as opposed to only reacting upon warming to RT. Furthermore, the fact that N-H bond formation is occurs faster than $\mathrm{H}_{2}$ formation under these conditions is somewhat surprising, as $\mathrm{KC}_{8}$ and $\mathrm{HBAr}_{4}$ do react in the absence of any Fe complex under the reaction conditions to generate $>75 \%$ of the expected $\mathrm{H}_{2}$ within 40 minutes. Formation of $\mathrm{H}_{2}$ is nevertheless an issue, as $\sim 30 \%$ of the hydrogen atom equivalents on average, as determined by GC analysis of the reaction head space, end up as $\mathrm{H}_{2}$ during the course of catalytic runs (See Appendix 3). The formation of the $\mathrm{N}-\mathrm{H}$ bonds during catalysis is likely aided by the heterogeneity of the reaction conditions, slowing $\mathrm{H}_{2}$ formation enough to allow for effective delivery of hydrogen atom equivalents to $\mathrm{N}_{2}$.

It is not straightforward to compare this Fe-based system to the Mo-based systems of Shrock and Nishibayashi. The turnovers for Fe (7) are quite similar to those observed for Schrock (7.5) and Nishibayashi (12.2), but the Fe system benefits from a substantially stronger reductant. It is not yet clear whether the redox potential required to form $\mathbf{4 . 1}$ ($2.19 \mathrm{~V}$ vs. $\mathrm{Fc} / \mathrm{Fc}^{+}$) mandates a stronger reductant, or whether weaker reductants only capable of accessing species such as (TPB)Fe( $\left.\mathrm{N}_{2}\right)$ could participate in catalysis. While a stronger reductant is required at this point, the Fe system does appear to operate at substantially lower temperatures than the Mo systems, potentially highlighting higher reactivity at the Fe based system. 


\subsubsection{Catalyst Speciation}

With evidence of a molecular Fe-based catalyst for the fixation of $\mathrm{N}_{2}$ in hand, initial studies on the speciation of the (TPB)Fe complexes in solution and potential causes of termination of catalysis were undertaken. A previous study on the (TPB)Fe scaffold showed that exposure of (TPB)Fe( $\left.\mathrm{N}_{2}\right)$ to $\mathrm{H}_{2}$ resulted in formation of (TPB) $(\mu-$

$\mathrm{H}) \mathrm{Fe}(\mathrm{H})\left(\mathrm{N}_{2}\right) .{ }^{18}$ Because $\mathrm{H}_{2}$ was formed as a by-product of the reaction, it was suspected that $(\mathrm{TPB})(\mu-\mathrm{H}) \mathrm{Fe}(\mathrm{H})\left(\mathrm{N}_{2}\right)$ could be formed under the catalytic conditions. In this context, 4.1 was reacted with 10 equivalents of $\mathrm{HBAr}^{\mathrm{F}}{ }_{4} \cdot 2 \mathrm{Et}_{2} \mathrm{O}$ and 12 equivalents of $\mathrm{KC}_{8}$. The presence of $(\mathrm{TPB})(\mu-\mathrm{H}) \mathrm{Fe}(\mathrm{H})\left(\mathrm{N}_{2}\right)$ in a $~ 30 \%$ yield was confirmed by both ${ }^{31} \mathrm{P}$ NMR and IR spectroscopy, where the strong N-N stretching vibration can be observed at $v_{\mathrm{NN}}=2073 \mathrm{~cm}^{-1}$. These results indicate that formation of $(\mathrm{TPB})(\mu-\mathrm{H}) \mathrm{Fe}(\mathrm{H})\left(\mathrm{N}_{2}\right)$ under the catalytic conditions is likely. To test whether $(\mathrm{TPB})(\mu-\mathrm{H}) \mathrm{Fe}(\mathrm{H})\left(\mathrm{N}_{2}\right)$ would terminate a catalytic cycle, this complex was submitted to the standard catalytic conditions, and it was found that only 0.5 equivalents of $\mathrm{NH}_{3}$ were formed per Fe center. This result suggests that if $(\mathrm{TPB})(\mu-\mathrm{H}) \mathrm{Fe}(\mathrm{H})\left(\mathrm{N}_{2}\right)$ is formed under catalysis, it likely is unable to reenter the catalytic cycle. Further evidence supporting this conclusion comes from the observation that $(\mathrm{TPB})(\mu-\mathrm{H}) \mathrm{Fe}(\mathrm{H})\left(\mathrm{N}_{2}\right)$ does not show appreciable reactivity with either $\mathrm{HBAr}_{4}{ }_{4} \cdot 2 \mathrm{Et}_{2} \mathrm{O}$ or $\mathrm{KC}_{8}$ at $\mathrm{RT}$ in $\mathrm{Et}_{2} \mathrm{O}$.

When considering the comparably low yields of $\mathrm{NH}_{3}$ provided when (TPB) $\mathrm{Fe}\left(\mathrm{N}_{2}\right)$ (Table 1, entry 5) is used as a pre-catalyst the observation that $(\mathrm{TPB})(\mu-\mathrm{H}) \mathrm{Fe}(\mathrm{H})\left(\mathrm{N}_{2}\right)$ can be formed from reaction of (TPB)Fe( $\left(\mathrm{N}_{2}\right)$ with $\mathrm{H}_{2}$ suggests that starting with (TPB)Fe( $\left.\mathrm{N}_{2}\right)$ may allow for a greater percentage of the (TPB)Fe centers to be trapped as the catalytically inactive $(\mathrm{TPB})(\mu-\mathrm{H}) \mathrm{Fe}(\mathrm{H})\left(\mathrm{N}_{2}\right)$, thus decreasing catalysis. Alternately, a 
low-spin state such as that observed in (TPB) $\mathrm{Fe}(\mathrm{CO})^{13}$ could dominate in $(\mathrm{TPB}) \mathrm{Fe}\left(\mathrm{N}_{2}\right)$ at low temperature, significantly decreasing its catalytic activity. Avoidance of this oxidation state by adding $\mathrm{KC}_{8}$ initially to reduce all of the (TPB) $\mathrm{Fe}\left(\mathrm{N}_{2}\right)$ to $\left[(\mathrm{TPB}) \mathrm{Fe}\left(\mathrm{N}_{2}\right)\right]^{-}$matches with both of these hypotheses.

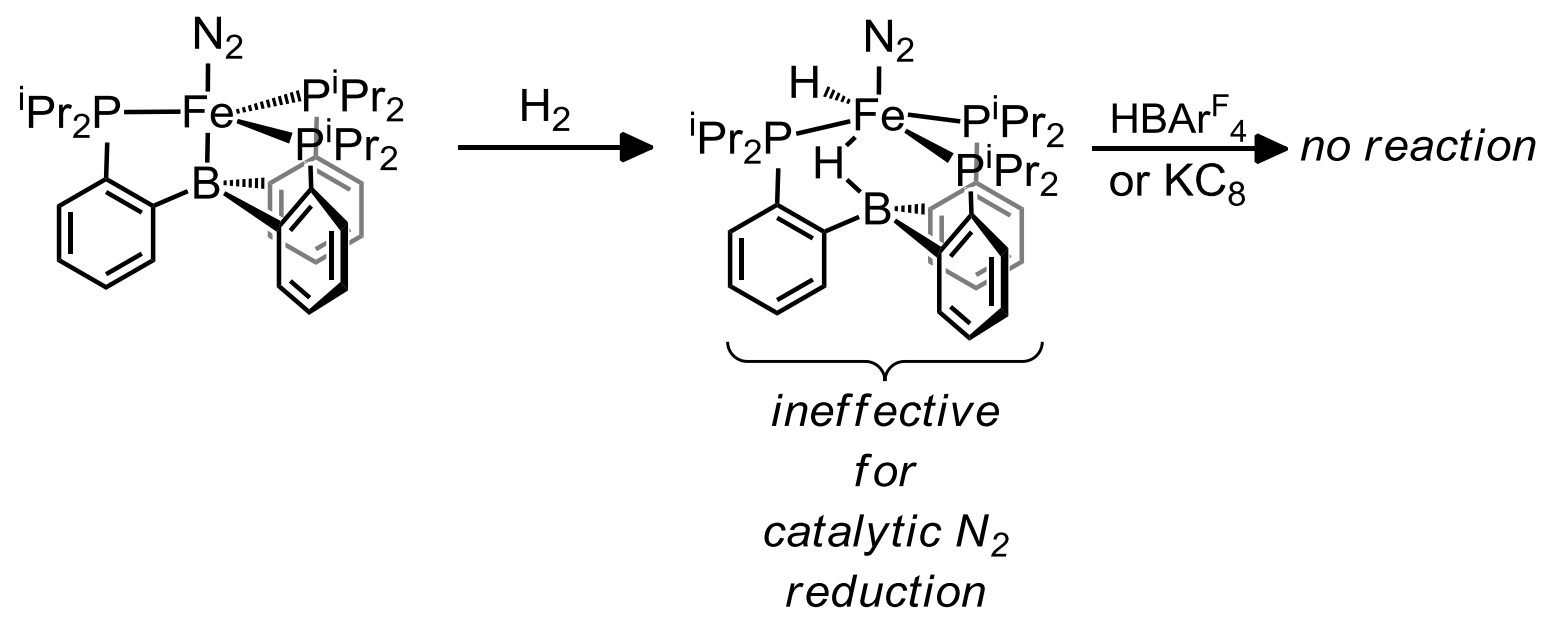

Scheme 4.5. Formation of $(\mathrm{TPB})(\mu-\mathrm{H}) \mathrm{Fe}(\mathrm{H})\left(\mathrm{N}_{2}\right)$ and its reactivity with acid and reductant indicating that it is not a competent pre-catalyst.

Another possible termination pathway arises from the presence of $\mathrm{Cl}^{-}$in the reaction mixture. Since $\mathrm{HBAr}_{4}{ }_{4} \cdot 2 \mathrm{Et}_{2} \mathrm{O}$ is made via loss of $\mathrm{NaCl}, \mathrm{Cl}^{-}$contamination is a reasonable possibility. The most conclusive test for the effect of $\mathrm{Cl}^{-}$is use of the $S=3 / 2$ complex (TPB) $\mathrm{FeCl}$, which was synthesized and crystallized in an analogous manner to the previously reported (TPB)FeBr. ${ }^{13 a}$ Catalytic runs using this pre-catalyst give, on average, 3.2 equivalents of $\mathrm{NH}_{3}$ per Fe center, suggesting that while $\mathrm{Cl}^{-}$does not terminate catalysis, it does hinder the reactivity of the (TPB)Fe species relative to using 4.1 as a pre-catalyst. Similarly, addition of exogenous $\mathrm{Cl}^{-}$in the form of excess $\mathrm{KCl}$ to the standard catalytic conditions with $\mathbf{4 . 1}$ also results in 3.0 equivalents of $\mathrm{NH}_{3}$ being 
formed. These result suggests that any residual $\mathrm{Cl}^{-}$may lower the yield of $\mathrm{NH}_{3}$, but should not terminate the catalytic cycle by formation of (TPB)FeCl.

In addition to termination processes, it was of great interest to determine whether $\mathrm{N}_{2} \mathrm{H}_{4}$ was involved in the catalytic cycle, as any presence of $\mathrm{N}_{2} \mathrm{H}_{4}$ would imply the involvement of an "alternating" type mechanism. A UV-Visible spectroscopic assay similar to the indophenol method for $\mathrm{NH}_{3}$ quantification was employed to detect the presence of $\mathrm{N}_{2} \mathrm{H}_{4}$ in reaction mixtures. ${ }^{19}$ No $\mathrm{N}_{2} \mathrm{H}_{4}$ was detected from any catalytic mixture. As an additional test, two equivalents of $\mathrm{N}_{2} \mathrm{H}_{4}$ were added to 4.1 before performing the standard catalytic protocol. In these runs, only trace $\mathrm{N}_{2} \mathrm{H}_{4}$ was observed, suggesting that if $\mathrm{N}_{2} \mathrm{H}_{4}$ is formed during catalysis, it would likely be consumed and should not be observed.

\subsection{Conclusion}

The anionic $\mathrm{N}_{2}$ complex 4.1 generates $\mathrm{NH}_{3}$ in the form of complex 4.4 upon exposure to excess acid, likely via some disproportionation pathway. Use of $\mathrm{HBAr}_{4} \cdot 2$ $\mathrm{Et}_{2} \mathrm{O}$ and $\mathrm{KC}_{8}$ in $\mathrm{Et}_{2} \mathrm{O}$ enables the catalytic reduction of $\mathrm{N}_{2}$ to $\mathrm{NH}_{3}$ with 7 equivalents of $\mathrm{NH}_{3}$ being generated per Fe center. Multiple other (TPB)Fe species also serve as precatalysts, but simple Fe salts and complexes do not, suggesting the agency of a molecular (TPB)Fe catalyst. Analysis of reaction mixtures indicates the formation of (TPB)( $\mu-$ $\mathrm{H}) \mathrm{Fe}(\mathrm{H})\left(\mathrm{N}_{2}\right)$ as a likely byproduct of catalysis. This complex is also not competent as a

pre-catalyst and hence its formation indicates a possible pathway for the termination of catalysis. The presence of chloride appears to inhibit, but not terminate, catalysis and (TPB)FeCl still serves as a competent pre-catalyst. Finally, no $\mathrm{N}_{2} \mathrm{H}_{4}$ is detected in 
catalytic reaction mixtures, but $\mathrm{N}_{2} \mathrm{H}_{4}$ is also consumed under catalysis, as determined by the addition of two equivalents of $\mathrm{N}_{2} \mathrm{H}_{4}$ to catalytic mixtures. This result suggests that if $\mathrm{N}_{2} \mathrm{H}_{4}$ were formed during catalysis it would likely not be detectable.

Due to the dearth of synthetic Fe species that can form appreciable quantities of $\mathrm{NH}_{3}$ from $\mathrm{N}_{2}$, Mo complexes have received a great deal of attention as the likely binding site of $\mathrm{N}_{2}$ in the FeMoco active site of nitrogenase. ${ }^{20}$ The results disclosed herein show for the first time that a molecular Fe species can also catalyze nitrogen fixation with protons and electrons in comparable yields to the Mo systems. This work validates the hypothesis that $\mathrm{N}_{2}$ binding and reduction may occur at a single Fe site in the FeMoco. ${ }^{21}$ Furthermore, the flexible nature of the Fe-B interaction in the (TPB)Fe scaffold further motivates the consideration of a similar hemi-labile role for the central $\mathrm{C}$ atom of the FeMoco. $^{22}$

\subsection{Experimental Section}

\subsubsection{General Considerations}

Unless otherwise noted, all compounds were purchased from commercial sources and used without further purification.[(TPB) $\left.\mathrm{Fe}\left(\mathrm{N}_{2}\right)\right]\left[\mathrm{Na}\left(12\right.\right.$-crown-4) $\left.{ }_{2}\right]{ }^{13}$ $[(\mathrm{TPB}) \mathrm{Fe}]\left[\mathrm{BAr}_{4}{ }_{4}\right],{ }^{14}(\mathrm{TPB})(\mu-\mathrm{H}) \mathrm{Fe}(\mathrm{H})\left(\mathrm{N}_{2}\right), 18 \mathrm{HBAr}^{\mathrm{F}} \cdot 2 \mathrm{Et}_{2} \mathrm{O},{ }^{23} \mathrm{FeCl}_{2} \cdot 1.5 \mathrm{THF}^{24}$ $\mathrm{KC}_{8},{ }^{25}\left[(\mathrm{TPB}) \mathrm{Fe}\left(\mathrm{NH}_{3}\right)\right]\left[\mathrm{BAr}{ }_{4}\right]^{14}$ and $\left[(\mathrm{TPB}) \mathrm{Fe}\left(\mathrm{N}_{2} \mathrm{H}_{4}\right)\right]\left[\mathrm{BAr}{ }_{4}\right]^{14}$ were prepared according to literature procedures $\left(\left[\mathrm{BAr}{ }^{\mathrm{F}}{ }_{4}\right]=\left[\mathrm{B}\left(3,5-\left(\mathrm{CF}_{3}\right)_{2}-\mathrm{C}_{6} \mathrm{H}_{3}\right)_{4} \mathrm{~B}\right]^{-}\right)$. All manipulations were carried out under a $\mathrm{N}_{2}$ atmosphere utilizing standard glovebox or Schlenk techniques. Solvents were dried and de-oxygenated by an argon sparge followed by passage through an activated alumina column purchased from S.G. Waters Company. 
Labeled ${ }^{15} \mathrm{~N}_{2}$ (98\% purity) was obtained from Cambridge Isotope Laboratories. Solvents for catalytic runs were additionally stirred for more than 2 hours over $\mathrm{Na} / \mathrm{K}$ alloy and then filtered prior to use.

IR spectra were obtained via KBr pellets on a Bio-Rad Excalibur FTS 3000 spectrometer using Varian Resolutions Pro software set at $4 \mathrm{~cm}^{-1}$ resolution. NMR measurements were obtained on Varian $300 \mathrm{MHz}$ or $500 \mathrm{MHz}$ spectrometers. Deuterated solvents for these measurements were obtained from Cambridge Isotope Laboratories and were dried and degassed prior to use. All ${ }^{1} \mathrm{H}$ NMR spectra were referenced to residual solvent peaks. UV-Visible spectra were taken on a Cary 50 spectrometer from $1100 \mathrm{~nm}$ to $200 \mathrm{~nm}$ in the fast scan mode. Samples were prepared in a $1 \mathrm{~cm}$ path length quartz cuvette. All samples had a blank sample background subtraction applied.

\subsubsection{Standard Catalytic Protocol}

$\left[(\mathrm{TPB}) \mathrm{Fe}\left(\mathrm{N}_{2}\right)\right]\left[\mathrm{Na}(12 \text {-crown-4) })_{2}(2 \mathrm{mg}, 0.002 \mathrm{mmol})\right.$ was suspended in $\mathrm{Et}_{2} \mathrm{O}(0.5$ $\mathrm{mL}$ ) in a $20 \mathrm{~mL}$ scintillation vial equipped with a stir bar. This suspension was vigorously stirred and cooled to $-78{ }^{\circ} \mathrm{C}$ in a cold well inside of the glove box. A similarly cooled solution of $\mathrm{HBAr}_{4} \cdot 2 \mathrm{Et}_{2} \mathrm{O}(93 \mathrm{mg}, 0.092 \mathrm{mmol})$ in $\mathrm{Et}_{2} \mathrm{O}(1.5 \mathrm{~mL})$ was added to the suspension in one portion with rapid stirring. Any remaining acid was dissolved in cold $\mathrm{Et}_{2} \mathrm{O}(0.25 \mathrm{~mL})$ and added subsequently. The reaction mixture turned light yellow-orange and homogeneous upon addition of acid and the resulting solution was allowed to stir for 5 minutes before being transferred into a pre-cooled Schlenk tube equipped with a stir bar. The original reaction vial was washed with cold $\mathrm{Et}_{2} \mathrm{O}(0.25 \mathrm{~mL})$ which was subsequently transferred to the Schlenk tube. Solid $\mathrm{KC}_{8}(15 \mathrm{mg}, 0.100 \mathrm{mmol})$ was 
suspended in cold $\mathrm{Et}_{2} \mathrm{O}(0.75 \mathrm{~mL})$ and added dropwise to the rapidly stirred solution in the Schlenk tube, which was then tightly sealed. The reaction was allowed to stir for 40 minutes at $-78{ }^{\circ} \mathrm{C}$ before being warmed to RT and stirred for 15 minutes.

\subsubsection{Ammonia Quantification}

A Schlenk tube was charged with $\mathrm{HCl}$ ( $3 \mathrm{~mL}$ of a $2.0 \mathrm{M}$ solution in $\mathrm{Et}_{2} \mathrm{O}, 6$ mmol). Reaction mixtures were vacuum transferred into this collection flask. Residual solid in the reaction vessel was treated with a solution of [ $\mathrm{Na}][\mathrm{OtBu}](40 \mathrm{mg}, 0.4 \mathrm{mmol})$ in 1,2-dimethoxyethane (1 mL) and sealed. The resulting suspension was allowed to stir for 10 minutes before all volatiles were again vacuum transferred into the collection flask. After completion of the vacuum transfer, the flask was sealed and warmed to RT. Solvent was removed in vacuo and the remaining residue was dissolved in $\mathrm{H}_{2} \mathrm{O}(1 \mathrm{~mL})$. An aliquot of this solution $(20$ or $40 \mu \mathrm{L})$ was then analyzed for the presence of $\mathrm{NH}_{3}$ (trapped as $\left[\mathrm{NH}_{4}\right][\mathrm{Cl}]$ ) via the indophenol method. ${ }^{17}$ Quantification was performed with UV-Visible spectroscopy by analyzing the absorbance at $635 \mathrm{~nm}$. The tables shown in Appendix 4 below list the raw data for the runs. Runs with small absorbance levels $(<$ 0.02 absorbance units) suffer from a large degree of error due to a small signal-to-noise ratio.

\subsubsection{Synthesis of (TPB)FeCl}

A mixture of $\mathrm{FeCl}_{2}(0.087 \mathrm{~g}, 0.69 \mathrm{mmol}), \mathrm{TPB}^{\mathrm{iPr}}(0.400 \mathrm{~g}, 0.69 \mathrm{mmol}), \mathrm{Fe}$ powder $(0.415 \mathrm{~g}, 7.40 \mathrm{mmol})$, and THF $(20 \mathrm{~mL})$ was heated to $90{ }^{\circ} \mathrm{C}$ in a sealed schlenk tube under vigorous stirring for 3 days, during which time the color of the liquid phase 
turned from pale yellow to brown. The solids were removed from the mixture by filtration, and the solvent was removed in vacuo. The brown residue was then triturated then extracted with pentane $(200 \mathrm{~mL})$ and filtered through celite to give a brown solution. Solvent evaporation in vacuo afforded the product as a greenish brown powder $(0.422 \mathrm{~g}$, $90 \%)$. An analytically pure sample was obtained by slow concentration of a saturated pentane solution. Crystals suitable for XRD analysis were obtained upon cooling a saturated solution of 5 in pentane to $-35{ }^{\circ} \mathrm{C} .{ }^{1} \mathrm{H}$ NMR $\left(\mathrm{C}_{6} \mathrm{D}_{6}, \delta\right): 96.9$ (br s), $35.0(\mathrm{~s})$, 23.6 (s), 9.8 (br s), $5.8(\mathrm{~s}), 1.9$ (br s), 1.7 (sh), -0.3 (s), -2.3 (br s), -22.4 (s) . UV-vis (THF, nm $\left.\left\{\mathrm{cm}^{-1} \mathrm{M}^{-1}\right\}\right): 280\left\{2.0 \cdot 10^{4}\right\}, 320\{\mathrm{sh}\}, 560\{\mathrm{sh}\}, 790\{150\}, 960\{190\} . \mu_{\text {eff }}$ $\left(\mathrm{C}_{6} \mathrm{D}_{6}\right.$, Evans method, $\left.20^{\circ} \mathrm{C}\right): 4.0 \mu_{\mathrm{B}}$. Anal. calcd. for $\mathrm{C}_{36} \mathrm{H}_{54} \mathrm{BClFeP}_{3}$ : C 63.41, H 7.98; found: C 63.16, H 7.72 .

\subsubsection{Catalytic Protocols}

Catalytic protocol under ${ }^{15} \mathrm{~N}_{2}$. [(TPB) $\left.\mathrm{Fe}\left(\mathrm{N}_{2}\right)\right]\left[\mathrm{Na}(12 \text {-crown-4) })_{2}\right](4 \mathrm{mg}, 0.004 \mathrm{mmol})$ was suspended in $\mathrm{Et}_{2} \mathrm{O}(3 \mathrm{~mL}$ ) in a $25 \mathrm{~mL}$ three neck flask (ground-glass, 14/20) equipped with a stir bar. The flask was then equipped with a stopcock adaptor in the central opening, a solid addition arm containing $\mathrm{HBAr}_{4} \mathrm{~F}_{4} \cdot 2 \mathrm{Et}_{2} \mathrm{O}(188 \mathrm{mg}, 0.186 \mathrm{mmol})$ in one of the side openings, and an additional solid addition arm containing $\mathrm{KC}_{8}(37 \mathrm{mg}$, $0.274 \mathrm{mmol}$ ) in the final opening. The apparatus was sealed, brought out of the glovebox, and connected to a high-vacuum manifold. The solution was degassed via four freezepump-thaw cycles and then allowed to thaw to $-78{ }^{\circ} \mathrm{C}$ with stirring. The flask was backfilled with $1 \mathrm{~atm}{ }^{15} \mathrm{~N}_{2}$. At this point the acid was added to the solution in one portion via the solid addition arm. The resulting solution was allowed to stir for 5 minutes before 
$\mathrm{KC}_{8}$ was added via the other solid addition arm resulting in a dark suspension. This suspension was allowed to stir for 40 minutes at $-78^{\circ} \mathrm{C}$ and then an additional 10 minutes at RT prior to the standard work-up. The presence of $\left[{ }^{15} \mathrm{NH}_{4}\right][\mathrm{Cl}]$ was verified by ${ }^{1} \mathrm{H}$ NMR spectroscopy (Figure 4 in the $\mathrm{SI}$ ). The yield of $\mathrm{NH}_{3}$ was 3.64 equiv $\mathrm{NH}_{3} / \mathrm{Fe}$ as measured using the indophenol method. $\mathrm{The}^{\mathrm{NH}_{3}}$ yield, while still showing catalysis, was lower than the average obtained by the standard protocol, presumably due to differences associated with adding the $\mathrm{HBAr}_{4} \cdot 2 \mathrm{Et}_{2} \mathrm{O}$ and $\mathrm{KC}_{8}$ solids via the solid addition arms. Runs with [(TPB)Fe] $\left[\mathbf{B A r}^{\mathbf{F}}{ }_{4}\right]$ as precursor. The procedure was identical to that of the standard catalytic protocol with the changes noted. The precursor used was [(TPB)Fe][BAr $\left.{ }_{4}{ }_{4}\right](2.3 \mathrm{mg}, 0.002 \mathrm{mmol})$, which is a dark orange solid. Note that [(TPB)Fe] $\left[\mathrm{BAr}_{4} \mathrm{~F}_{4}\right]$ was soluble in $\mathrm{Et}_{2} \mathrm{O}$ and formed a yellow solution. No substantial color change was observed upon addition of acid.

Runs with $(\mathrm{TPB})(\boldsymbol{\mu}-\mathrm{H}) \mathrm{Fe}(\mathrm{H})\left(\mathbf{N}_{2}\right)$ as precursor. The procedure was identical to that of the standard catalytic protocol with the changes noted. The precursor used was (TPB)( $\mu-$ $\mathrm{H}) \mathrm{Fe}(\mathrm{H})\left(\mathrm{N}_{2}\right)(1.3 \mathrm{mg}, 0.002 \mathrm{mmol})$, which is a yellow solid. Note that (TPB)( $\mu-$ $\mathrm{H}) \mathrm{Fe}(\mathrm{H})\left(\mathrm{N}_{2}\right)$ was insoluble in $\mathrm{Et}_{2} \mathrm{O}$ and did not dissolve upon addition of acid. As such, the resulting mixture was a suspension through the remaining manipulations.

Runs with $\mathrm{FeCl}_{2} \cdot 1.5 \mathrm{THF}$ as precursor. The procedure was identical to that of the standard catalytic protocol with the changes noted. The precursor used was $\mathrm{FeCl}_{2} \cdot 1.5$ THF (0.5 mg, $0.002 \mathrm{mmol})$, which is an off white powder. Note that $\mathrm{FeCl}_{2} \cdot 1.5 \mathrm{THF}$ did not dissolve upon addition of acid. As such, the resulting mixture was a suspension through the remaining manipulations. 
Runs with $\mathrm{FeCl}_{3}$ as precursor. The procedure was identical to that of the standard catalytic protocol with the changes noted. The precursor used was $\mathrm{FeCl}_{3}(0.3 \mathrm{mg}, 0.002$ mmol), which is a dark solid. Note that $\mathrm{FeCl}_{3}$ was soluble in $\mathrm{Et}_{2} \mathrm{O}$ and formed a yellow solution. No substantial color change was observed upon addition of acid.

Runs with $\mathrm{Fe}(\mathrm{CO})_{5}$ as precursor. The procedure was identical to that of the standard catalytic protocol with the changes noted. The precursor used was $\mathrm{Fe}(\mathrm{CO})_{5}(0.35 \mathrm{mg}$, $0.002 \mathrm{mmol})$, which is a pale yellow liquid. Note that $\mathrm{Fe}(\mathrm{CO})_{5}$ was soluble in $\mathrm{Et}_{2} \mathrm{O}$ and formed a colorless solution. No substantial color change was observed upon addition of acid.

Runs with FeCp2 as precursor. The procedure was identical to that of the standard catalytic protocol with the changes noted. The precursor used was $\mathrm{FeCp}_{2}(0.35 \mathrm{mg}, 0.002$ $\mathrm{mmol}$ ), which is an orange solid. Note that $\mathrm{FeCp}_{2}$ was soluble in $\mathrm{Et}_{2} \mathrm{O}$ and formed a yellow solution. No substantial color change was observed upon addition of acid.

Runs without an Fe precursor. The procedure was identical to that of the standard catalytic protocol with the changes noted. A $2 \mathrm{~mL} \mathrm{Et}_{2} \mathrm{O}$ solution of $\mathrm{HBAr}^{\mathrm{F}} \cdot 2 \mathrm{Et}_{2} \mathrm{O}(93$ mg, $0.092 \mathrm{mmol}$ ), was added directly into a Schlenk tube equipped with a stir bar and cooled to $-78{ }^{\circ} \mathrm{C}$. Addition of $\mathrm{KC}_{8}$ and subsequent work-up was identical to the standard catalytic protocol.

Runs with [(TPB)Fe $\left.\left(\mathbf{N H}_{3}\right)\right]\left[\mathrm{BAr}^{\mathrm{F}}\right.$ ] as precursor. The procedure was identical to that of the standard catalytic protocol with the changes noted. The precursor used was $\left[(\mathrm{TPB}) \mathrm{Fe}\left(\mathrm{NH}_{3}\right)\right]\left[\mathrm{BAr}^{\mathrm{F}}\right](2.9 \mathrm{mg}, 0.002 \mathrm{mmol})$, which is an orange solid . Note that the solution became homogeneous with no significant color change upon addition of acid. 
Runs with [(TPB)Fe( $\left.\left.\mathbf{N}_{2} \mathbf{H}_{4}\right)\right]\left[B A r^{F_{4}}\right]$ as precursor. The procedure was identical to that of the standard catalytic protocol with the changes noted. The precursor used was $\left[(\mathrm{TPB}) \mathrm{Fe}\left(\mathrm{N}_{2} \mathrm{H}_{4}\right)\right]\left[\mathrm{BAr}_{4}\right](2.9 \mathrm{mg}, 0.002 \mathrm{mmol})$, which is an orange solid. Note that the solution became homogeneous with no significant color change upon addition of acid. Runs with (TPB)FeCl as precursor. The procedure was identical to that of the standard catalytic protocol with the changes noted. The precursor used was (TPB)FeCl (1.3 mg, $0.002 \mathrm{mmol}$ ), which is a brown solid. Note that the solution became homogeneous with no significant color change upon addition of acid.

Inclusion of hydrazine in a catalytic run with $\left[(\mathrm{TPB}) \mathrm{Fe}\left(\mathrm{N}_{2}\right)\right][\mathrm{Na}(12-\mathrm{crown}-4) 2]$. The procedure was identical to that of the standard catalytic protocol with the following changes noted. Hydrazine $(0.12 \mu \mathrm{L}, 0.004 \mathrm{mmol})$ was added directly to the suspension of $\left[(\mathrm{TPB}) \mathrm{Fe}\left(\mathrm{N}_{2}\right)\right]\left[\mathrm{Na}(12 \text {-crown-4) })_{2}\right]$ prior to subjecting the mixture to the standard catalytic protocol. No color change was observed upon addition of $\mathrm{N}_{2} \mathrm{H}_{4}$. After workup the aqueous solution was analyzed for $\mathrm{NH}_{3}$ as described above, and also for $\mathrm{N}_{2} \mathrm{H}_{4}$ via a literature protocol. ${ }^{19}$ The results obtained show most all of the $\mathrm{N}_{2} \mathrm{H}_{4}$ had been consumed, indicating that if it is produced in some amount under the standard catalytic protocol it is unlikely to be detectable. As a control experiment it was shown that $\mathrm{N}_{2} \mathrm{H}_{4}$ was not degraded to $\mathrm{NH}_{3}$ under the standard catalytic conditions in the absence of $\left[(\mathrm{TPB}) \mathrm{Fe}\left(\mathrm{N}_{2}\right)\right][\mathrm{Na}(12-$ crown-4) $]$.

\subsubsection{Other Reaction Protocols}

\section{IR spectral analysis of addition of 2 equiv $\mathrm{HBAr}_{4} \cdot 2 \mathrm{Et}_{2} \mathrm{O}$ to $\left[(\mathrm{TPB}) \mathrm{Fe}\left(\mathrm{N}_{2}\right)\right][\mathrm{Na}(12-$} crown-4)2], followed by 3 equiv KC8. A $20 \mathrm{~mL}$ scintillation vial was charged with a stir 
bar and $\left[(\mathrm{TPB}) \mathrm{Fe}\left(\mathrm{N}_{2}\right)\right]\left[\mathrm{Na}(12-\mathrm{crown}-4)_{2}\right](8 \mathrm{mg}, 0.0074 \mathrm{mmol})$. In a separate vial, $\mathrm{HBAr}_{4} \cdot 2 \mathrm{Et}_{2} \mathrm{O}(15 \mathrm{mg}, 0.015 \mathrm{mmol})$ was dissolved in $\mathrm{Et}_{2} \mathrm{O}(1 \mathrm{~mL})$. Finally, a third vial was prepared containing a suspension of potassium graphite $(3 \mathrm{mg}, 0.023 \mathrm{mmol})$ in $\mathrm{Et}_{2} \mathrm{O}$ $(1 \mathrm{~mL})$. All three vials were chilled in the cold well to $-70+/-5^{\circ} \mathrm{C}$ for 30 minutes. The solution of $\mathrm{HBAr}_{4} \mathrm{~F}_{4} \cdot 2 \mathrm{Et}_{2} \mathrm{O}$ was quickly added to the stirring suspension of $\left[(\mathrm{TPB}) \mathrm{Fe}\left(\mathrm{N}_{2}\right)\right]\left[\mathrm{Na}(12 \text {-crown-4) })_{2}\right]$ with a glass pipette pre-cooled to $-70{ }^{\circ} \mathrm{C}$. Any residue of the acid was washed with pre-chilled $\mathrm{Et}_{2} \mathrm{O}(0.5 \mathrm{~mL})$ and transferred to the stirring solution. The resulting solution turned homogeneous. After stirring for 5 minutes, the suspension of $\mathrm{KC}_{8}$ was added rapidly to the stirring solution. Any additional $\mathrm{KC}_{8}$ was washed with pre-chilled $\mathrm{Et}_{2} \mathrm{O}(0.5 \mathrm{~mL})$ and the resulting suspension was transferred to the stirring mixture. After addition of $\mathrm{KC}_{8}$ the solution adopted a red color. This mixture was capped and stirred at $-70{ }^{\circ} \mathrm{C}$ for 40 minutes and then brought to RT and stirred for 10 minutes. The red color persisted upon thawing to RT. Graphite was removed by filtration through glass filter paper. To the red solution was added 12-crown-4 (13.1 mg, 74.3 $\mu \mathrm{mol})$ in $\mathrm{Et}_{2} \mathrm{O}(1 \mathrm{~mL})$ and the resulting solution was stirred for 10 minutes. The solution was then cooled to $-70{ }^{\circ} \mathrm{C}$ for 30 minutes and stirred vigorously, leading to a red precipitate. The precipitate was collected on a filter pad and the light orange filtrate was concentrated to dryness in vacuo. IR analysis of the precipitate ( $\mathrm{KBr}$ pellet) showed an intense band at $v_{\mathrm{NN}}=1904 \mathrm{~cm}^{-1}$, identical to that of authentic $\left[(\mathrm{TPB}) \mathrm{Fe}\left(\mathrm{N}_{2}\right)\right][\mathrm{Na}(12$ crown-4 $\left.)_{2}\right]\left(v_{\mathrm{NN}}=1905 \mathrm{~cm}^{-1}, \mathrm{KBr}\right.$ pellet $)$. No assignable $v_{\mathrm{NN}}$ IR bands were observed for the filtrate in the window of $1700-2300 \mathrm{~cm}^{-1}$. See Figure S6 of the SI.

\section{IR and ${ }^{31} \mathrm{P} \mathrm{NMR}$ spectral analysis of addition of 10 equiv $\mathrm{HBAr}^{\mathrm{F}}{ }_{4} \cdot 2 \mathrm{Et}_{2} \mathrm{O}$ to [(TPB)Fe(N2)][Na(12-crown-4)2], followed by 12 equiv KC8. A 20 mL scintillation}


vial was charged with a stir bar and $\left[(\mathrm{TPB}) \mathrm{Fe}\left(\mathrm{N}_{2}\right)\right]\left[\mathrm{Na}(12 \text {-crown-4) })_{2}\right](10.4 \mathrm{mg}, 10.2$ $\mu \mathrm{mol})$. In a separate vial, $\mathrm{HBAr}_{4} \cdot 2 \mathrm{Et}_{2} \mathrm{O}(103 \mathrm{mg}, 102 \mu \mathrm{mol})$ was dissolved in $\mathrm{Et}_{2} \mathrm{O}(1$ $\mathrm{mL}$ ). Finally, a third vial was prepared containing a suspension of potassium graphite $(16.5 \mathrm{mg}, 122 \mu \mathrm{mol})$ in $\mathrm{Et}_{2} \mathrm{O}(1 \mathrm{~mL})$. All three vials were chilled in the cold well to -70 $+/-5{ }^{\circ} \mathrm{C}$ for 30 minutes. The solution of $\mathrm{HBAr}_{4}{ }_{4} \cdot 2 \mathrm{Et}_{2} \mathrm{O}$ was quickly added to the stirring suspension of $\left[(\mathrm{TPB}) \mathrm{Fe}\left(\mathrm{N}_{2}\right)\right]\left[\mathrm{Na}(12 \text {-crown-4) })_{2}\right]$ with a glass pipette pre-cooled to $-70{ }^{\circ} \mathrm{C}$. Any residue of the acid was washed with pre-chilled $\mathrm{Et}_{2} \mathrm{O}(0.5 \mathrm{~mL})$ and transferred to the stirring solution. The resulting solution turned homogeneous. After stirring for 5 minutes, the suspension of $\mathrm{KC}_{8}$ was added rapidly to the stirring solution. Any additional $\mathrm{KC}_{8}$ was washed with pre-chilled $\mathrm{Et}_{2} \mathrm{O}(0.5 \mathrm{~mL})$ and the resulting suspension was transferred to the stirring mixture. The large amount of graphite present in the vial prevented the color of the resulting solution from being accurately discerned. This mixture was capped and stirred at $-70{ }^{\circ} \mathrm{C}$ for 40 minutes and then brought to RT and stirred for 10 minutes. Graphite was removed by filtration through glass filter paper. To the resulting orange solution was added 12-crown-4 $(60 \mathrm{mg}, 340 \mu \mathrm{mol})$ in $\mathrm{Et}_{2} \mathrm{O}(1 \mathrm{~mL})$ and ${ }^{31} \mathrm{P}$ NMR integration standard of triphenylphosphine (11.9 mg, $\left.45.4 \mu \mathrm{mol}\right)$ in toluene $(1 \mathrm{~mL})$ followed by stirring for 10 minutes. The solution was then cooled to $70^{\circ} \mathrm{C}$ for 30 minutes and stirred vigorously. No precipitate formed and volatiles were removed in vacuo. The orange powder was dissolved in THF and integration of ${ }^{31} \mathrm{P}$ NMR resonances suggest the formation of $(\mathrm{TPB})(\mu-\mathrm{H}) \mathrm{Fe}\left(\mathrm{N}_{2}\right)(\mathrm{H})(3.4 \mu \mathrm{mol})$ in $30 \%$ yield. Solid-state IR analysis of the orange solid (KBr pellet) showed a strong, sharp band at $v_{\mathrm{NN}}=2073 \mathrm{~cm}^{-1}(\mathrm{~s})$, identical to that of authentic $(\mathrm{TPB})(\mu-\mathrm{H}) \mathrm{Fe}\left(\mathrm{N}_{2}\right)(\mathrm{H})$. Additional broad, weak bands were observed at 1942, 1875, 1802, $1734 \mathrm{~cm}^{-1}$ that could not be 
assigned. ${ }^{31} \mathrm{P}\left\{{ }^{1} \mathrm{H}\right\}$ NMR (400 MHz, THF): 72.6, $63.1 \mathrm{ppm}$. See Figures S6 and $\mathrm{S} 7$ of the SI.

Reactivity of (TPB)( $\mu-\mathbf{H}) \mathbf{F e}(\mathbf{H})\left(\mathbf{N}_{2}\right)$ with $\mathbf{K C} 8$. A $20 \mathrm{~mL}$ scintillation vial was charged with a stir bar and $(\mathrm{TPB})(\mu-\mathrm{H}) \mathrm{Fe}(\mathrm{H})\left(\mathrm{N}_{2}\right)(11 \mathrm{mg}, 0.016 \mathrm{mmol})$ suspended in $\mathrm{Et}_{2} \mathrm{O}(2$ $\mathrm{mL}$ ). A separate vial was charged with $\mathrm{KC}_{8}(2.6 \mathrm{mg}, 0.019 \mathrm{mmol})$ suspended in $\mathrm{Et}_{2} \mathrm{O}$ (2 $\mathrm{mL}$ ). Both vials were cooled to $-70+/-5^{\circ} \mathrm{C}$ and the Fe-containing vial was stirred vigorously. The suspension of $\mathrm{KC}_{8}$ was quickly transferred to the vial containing $(\mathrm{TPB})(\mu-\mathrm{H}) \mathrm{Fe}(\mathrm{H})\left(\mathrm{N}_{2}\right)$ and stirred for 10 minutes at low temperature. The vial was then brought to $\mathrm{RT}$ and the brown color of $\mathrm{KC}_{8}$ slowly turned to black over 1 hour. Graphite was filtered through a glass filter pad and the orange filtrate was transferred to a vial containing 12-crown-4 (21.0 mg, $119.17 \mu \mathrm{mol}, 7.25$ equivalents) and stirred vigorously at $-70{ }^{\circ} \mathrm{C}$ for 10 minutes. No precipitate formed and the resulting orange solution was brought to RT and concentrated to dryness in vacuo. IR analysis of the residue $(\mathrm{KBr}$ pellet) showed a strong stretch at $v_{\mathrm{NN}}=2073 \mathrm{~cm}^{-1}$, consistent with authentic (TPB) $(\mu$ $\mathrm{H}) \mathrm{Fe}(\mathrm{H})\left(\mathrm{N}_{2}\right)\left(2073 \mathrm{~cm}^{-1}, \mathrm{KBr}\right.$ pellet). ${ }^{1} \mathrm{H}$ NMR analysis was consistent with the presence of predominately (TPB) $(\mu-\mathrm{H}) \mathrm{Fe}(\mathrm{H})\left(\mathrm{N}_{2}\right)$ and minor amounts of unidentified paramagnetic species.

Reactivity of $(\mathbf{T P B})(\boldsymbol{\mu}-\mathrm{H}) \mathrm{Fe}(\mathrm{H})\left(\mathbf{N}_{2}\right)$ with $\mathrm{HBAr}_{4} \cdot 2 \mathbf{E t}_{2} \mathrm{O}$. A $20 \mathrm{~mL}$ scintillation vial was charged with a stir bar and (TPB) $(\mu-\mathrm{H}) \mathrm{Fe}(\mathrm{H})\left(\mathrm{N}_{2}\right)(9 \mathrm{mg}, 0.014 \mathrm{mmol})$ suspended in $\mathrm{Et}_{2} \mathrm{O}(2 \mathrm{~mL})$. A separate vial was charged with $\mathrm{HBAr}_{4} \cdot 2 \mathrm{Et}_{2} \mathrm{O}(15 \mathrm{mg}, 0.015 \mathrm{mmol}$, 1.08) suspended in $\mathrm{Et}_{2} \mathrm{O}(2 \mathrm{~mL})$. Both vials were cooled to $-70+/-5^{\circ} \mathrm{C}$ and the $\mathrm{Fe}-$ containing vial was stirred vigorously. The solution of $\mathrm{HBAr}_{4} \cdot 2 \mathrm{Et}_{2} \mathrm{O}$ was quickly transferred to the vial containing (TPB) $(\mu-\mathrm{H}) \mathrm{Fe}(\mathrm{H})\left(\mathrm{N}_{2}\right)$ and stirred for 10 minutes at low 
temperature. The vial was then brought to RT and no noticeable color change was observed over 1 hour. The solution was concentrated to dryness in vacuo and the remaining residue was analyzed with IR spectroscopy (KBr pellet), which showed a strong stretch at $v_{\mathrm{NN}}=2073 \mathrm{~cm}^{-1}$, consistent with authentic $(\mathrm{TPB})(\mu-\mathrm{H}) \mathrm{Fe}(\mathrm{H})\left(\mathrm{N}_{2}\right)(2073$ $\mathrm{cm}^{-1}, \mathrm{KBr}$ pellet). The residue was then re-dissolved in $\mathrm{C}_{6} \mathrm{D}_{6}$ and analyzed by ${ }^{1} \mathrm{H} \mathrm{NMR}$ spectroscopy, which showed $(\mathrm{TPB})(\mu-\mathrm{H}) \mathrm{Fe}(\mathrm{H})\left(\mathrm{N}_{2}\right)$ with minor amounts of unidentified paramagnetic species and resonances from the $\mathrm{BAr}_{4}{ }_{4}$ anion. Complete consumption of $(\mathrm{TPB})(\mu-\mathrm{H}) \mathrm{Fe}(\mathrm{H})\left(\mathrm{N}_{2}\right)$ to unidentified paramagnetic species was observed after 12 hours at RT.

\section{Identification of $\left[(\mathrm{TPB}) \mathrm{Fe}\left(\mathrm{NH}_{3}\right)\right]\left[\mathrm{BAr}^{\mathrm{F}}{ }_{4}\right]$ from protonation of $\left[(\mathrm{TPB}) \mathrm{Fe}\left(\mathrm{N}_{2}\right)\right][\mathrm{Na}(12-$} crown-4)2]. [(TPB)Fe( $\left.\left.\mathrm{N}_{2}\right)\right][\mathrm{Na}(12$-crown-4)2] $(5 \mathrm{mg}, 0.005 \mathrm{mmol})$ was dissolved in 2 $\mathrm{mL}$ of THF and cooled to $-78{ }^{\circ} \mathrm{C}$. This dark red solution was added dropwise to a similarly cooled $2 \mathrm{~mL}$ THF solution of $\mathrm{HBAr}^{\mathrm{F}} \cdot 2 \mathrm{Et}_{2} \mathrm{O}(29 \mathrm{mg}, 0.029 \mathrm{mmol})$ with stirring. The resulting yellow-orange solution was allowed to stir for 10 minutes at low temperature before being warmed to RT and stirred for an additional 40 minutes. 1,8Bis(dimethylamino)naphthalene $(6 \mathrm{mg}, 0.029 \mathrm{mmol})$ was added and the solution was allowed to stir for 15 minutes with no noticeable color change. Volatiles were removed from the solution and the resulting yellow residue was taken up in THF- $d_{8}$. The presence

of $\left[(\mathrm{TPB}) \mathrm{Fe}\left(\mathrm{NH}_{3}\right)\right]\left[\mathrm{BAr}^{\mathrm{F}}{ }_{4}\right]$ was determined by comparison of the ${ }^{1} \mathrm{H}$ NMR spectrum with that of an authentic sample prepared as recently reported. ${ }^{14}$ Addtionally, a capillary insert of the previously reported (TPB)FeMe ${ }^{14}$ in THF- $d_{8}$ was added to the NMR sample, which allowed for crude measurements of the yield of $\left[(\mathrm{TPB}) \mathrm{Fe}\left(\mathrm{NH}_{3}\right)\right]\left[\mathrm{BAr}^{\mathrm{F}}\right.$ ] , a species tentatively assigned as [(TPB)Fe][BAr ${ }_{4}$ ], and the total amount of $S=3 / 2$ TPB species as 
roughly $30 \%, 50 \%$, and $100 \%$ respectively. Note that there is likely a significant degree of error on these measurements due to the broad paramagnetic peaks used for integration. See Figure S1of the SI.

Identification of $\mathrm{H}_{2}$ in standard catalytic runs. The catalytic runs were performed according to the standard procedure. Prior to the vacuum transfer of volatiles, the solutions inside of the Schlenk tubes were frozen. The ground glass joint of the Schlenk tube was then sealed with a rubber septum and the head space between the Teflon stopcock of the Schlenk tube and the septum was evacuated. This head space was left under static vacuum and the Teflon stopcock of the reaction vessel was opened after which a $10 \mathrm{~mL}$ aliquot of the headspace was sampled through the septa via a gas-tight syringe. This sample was then analyzed for hydrogen with an Agilent 7890A gas chromatograph using a thermal conductivity detector. After $\mathrm{H}_{2}$ analysis, the reaction vessel was sealed and subjected to the standard analysis for $\mathrm{NH}_{3}$. As some $\mathrm{H}_{2}$ leakage is unavoidable by the procedure used, these values represent lower limits of the $\mathrm{H}_{2}$ yield. The values for $\mathrm{NH}_{3}$ and $\mathrm{H}_{2}$ yield are included in Appendix 4

Identification of $\mathrm{H}_{2}$ in runs without an Fe precursor. A Schlenk tube was charged with a stir bar and a suspension of $\mathrm{KC}_{8}(14 \mathrm{mg}, 0.100 \mathrm{mmol})$ in $\mathrm{Et}_{2} \mathrm{O}(0.5 \mathrm{~mL})$. The Schlenk tube was then fitted with a Teflon stopcock, but not sealed. The ground glass joint on the Schlenk tube was sealed with a rubber septum. This reaction vessel was then cooled to $-78{ }^{\circ} \mathrm{C}$. A pre-cooled solution of $\mathrm{HBAr}_{4} \mathrm{~F}_{4} \cdot 2 \mathrm{Et}_{2} \mathrm{O}(92 \mathrm{mg}, 0.092 \mathrm{mmol})$ in $\mathrm{Et}_{2} \mathrm{O}$ $(2 \mathrm{~mL})$ was then syringed directly into the reaction vessel with stirring, after which the vessel was rapidly sealed with its Teflon stopcock. The reaction was allowed to stir for 40 minutes at low temperature before the headspace between the Teflon valve and the septa 
was evacuated. After evacuation, the Teflon stopcock was opened and a $10 \mathrm{~mL}$ aliquot of the headspace was sampled via a gas tight syringe. This sample was then analyzed for hydrogen with an Agilent 7890A gas chromatograph using a thermal conductivity detector. The yield of hydrogen observed, based on proton-equivalents was $66 \%$ and $88 \%$ for each of two runs, respectively. As some $\mathrm{H}_{2}$ leakage is unavoidable by the procedure used, these values represent lower limits of the $\mathrm{H}_{2}$ yield. 


\section{References Cited}

1 (a) Shilov, A.; Denisov, N.; Efimov, O.; Shuvalov, N.; Shuvalova, N.; Shilova, A. Nature 1971, 231, 460-461; (b) Bazhenova, T. A.; Shilov, A. E. Coord. Chem. Rev. 1995, 144, 69-145.

2 Chatt, J.; Dilworth, J. R.; Richards, R. L. Chem. Rev. 1978, 78, 589-625.

3 (a) Yandulov, D. V.; Schrock, R. R. Science 2003, 301, 76-78; (b) Arashiba, K.; Miyake, Y.; Nishibayashi, Y. Nature Chem. 2011, 3, 120-125.

4 Kinoshita, E.; Arashiba, K.; Kuriyama, S.; Miyake, Y.; Shimazaki, R.; Nakanishi, H.; Nishibayashi, Y. Organometallics 2012, 31, 8437-8443.

5 Schrock, R. R. Acc. Chem. Res. 2005, 38, 955-962.

6 (a) Betley, T. A.; Peters, J. C. J. Am. Chem. Soc. 2004, 126, 6252-6254; (b) Brown, S. D.; Peters, J. C. J. Am. Chem. Soc. 2005, 127, 1913-1923; (c) Scepaniak, J. J.; Young, J. A.; Bontchev, R. P.; Smith, J. M. Angew. Chem. Int. Ed. 2009, 48, 3158-3160.

7 (a) Leigh, G. J.; Jimenez-Tenorio, M. J. Am. Chem. Soc. 1991, 113, 5862-5863; (b) Leigh, G. J. Acc. Chem. Res. 1992, 25, 177-181; (c) Hills, A.; Hughes, D. L.; JimenezTenorio, M.; Leigh, G. J.; Rowley, A. T. J. Chem. Soc., Dalton 1993, 3041-3049;

(d) Crossland, J. L.; Tyler, D. R. Coord. Chem. Rev. 2010, 254, 1883-1894.

8 Rodriguez, M. M.; Bill, E.; Brennessel, W. W.; Holland, P. L. Science 2011, 334, 780783.

9 Yuki, M.; Tanaka, H.; Sasaki, K.; Miyake, Y.; Yoshizawa, K.; Nishibayashi, Y. Nature comm. 2012, 3, 1254-1254.

10 (a) Burgess, B. K.; Lowe, D. J. Chem. Rev. 1996, 96, 2983-3011; (b) Eady, R. R. Chem. Rev. 1996, 96, 3013-3030. 
11 (a) Dos Santos, P. C.; Igarashi, R. Y.; Lee, H. I.; Hoffman, B. M.; Seefeldt, L. C.; Dean, D. R. Acc. Chem. Res. 2005, 38, 208-214; (b) Hoffman, B. M.; Dean, D. R.; Seefeldt, L. C. Acc. Chem. Res. 2009, 42, 609-619; (c) Seefeldt, L. C.; Hoffman, B. M.; Dean, D. R. Annu. Rev. Biochem. 2009, 78, 701-722; (d) Doan, P. E.; Telser, J.;

Barney, B. M.; Igarashi, R. Y.; Dean, D. R.; Seefeldt, L. C.; Hoffman, B. M. J. Am. Chem. Soc. 2011, 133, 17329-17340.

12 Mankad, N. P.; Whited, M. T.; Peters, J. C. Angew. Chem. Int. Ed. 2007, 46, 57685771.

13 (a) Moret, M.-E.; Peters, J. C. Angew. Chem. Int. Ed. 2011, 50, 2063-2067; (b) Moret, M.-E.; Peters, J. C. J. Am. Chem. Soc. 2011, 133, 18118-18121.

14 Anderson, J. S.; Moret, M.-E.; Peters, J. C. J. Am. Chem. Soc. 2012, 135, 534-537. 15 Yandulov, D. V.; Schrock, R. R. Inorg. Chem. 2005, 44, 1103-1117.

16 (a) Chatt, J.; Heath, G. A.; Richards, R. L. J. Chem. Soc., Dalton 1974, 2074-2082; (b) Hidai, M.; Kodama, T.; Sato, M.; Harakawa, M.; Uchida, Y. Inorg. Chem. 1976, 15, 2694-2697; (c) Takahashi, T.; Mizobe, Y.; Sato, M.; Uchida, Y.; Hidai, M. J. Am. Chem. Soc. 1980, 102, 7461-7467.

17 Weatherburn, M. W. Anal. Chem. 1967, 39, 971-974.

18 Fong, H.; Moret, M.-E.; Lee, Y.; Peters, J. C. Organometallics 2013, 32, 3053-3062. 19 Watt, G. W.; Chrisp, J. D. Anal. Chem. 1952, 24, 2006-2008.

20 (a) Leigh, G. J. Science 2003, 301, 55-56; (b) Schrock, R. R. Nature Chem. 2011, 3, 95-96.

21 Hendrich, M. P.; Gunderson, W.; Behan, R. K.; Green, M. T.; Mehn, M. P.; Betley, T. A.; Lu, C. C.; Peters, J. C. Proc. Natl. Acad. Sci. U. S. A. 2006, 103, 17107-17112. 
22 (a) Lancaster, K. M.; Roemelt, M.; Ettenhuber, P.; Hu, Y. L.; Ribbe, M. W.; Neese, F.; Bergmann, U.; DeBeer, S. Science 2011, 334, 974-977; (b) Spatzal, T.; Aksoyoglu, M.; Zhang, L. M.; Andrade, S. L. A.; Schleicher, E.; Weber, S.; Rees, D. C.; Einsle, O. Science 2011, 334, 940-940.

23 Brookhart, M.; Grant, B.; Volpe, A. F. Organometallics 1992, 11, 3920-3922.

24 Kern, R. J. J. Inorg. Nucl. Chem. 1962, 24, 1105-1109.

25 Weitz, I. S.; Rabinovitz, M. J. Chem. Soc., Perkin 1993, 117-120. 
Chapter 5: The Effect of Ligand and Reaction Conditions on Fe Mediated $\mathrm{N}_{2}$ Fixation 


\subsection{Introduction}

Chapter 4 described the development of a catalytic system for the Fe mediated conversion of $\mathrm{N}_{2}$ to $\mathrm{NH}_{3}$ with protons and electrons. ${ }^{1}$ The fact that Mo centers have been known to catalyze this reaction for some time had been viewed as supporting evidence for Mo being the $\mathrm{N}_{2}$ binding site in FeMoco. ${ }^{2}$ The discovery of an Fe based system serves to illustrate that Fe mediated $\mathrm{N}_{2}$ reduction to $\mathrm{NH}_{3}$ is feasible and bolsters arguments that $\mathrm{Fe}$ is the site of $\mathrm{N}_{2}$ binding and reduction in nitrogenase enzymes. ${ }^{3}$ Despite this initial result, relatively little is known about what factors enable catalysis or about the mechanism of $\mathrm{N}_{2}$ reduction. Understanding of these factors could help to guide thought on the mechanism of $\mathrm{N}_{2}$ reduction by the FeMoco.

Motivated by these questions, this chapter describes the preparation of three new phosphine supported Fe complexes analogous to $\left[\left(\mathrm{TPB}^{\mathrm{iPr}}\right) \mathrm{Fe}\left(\mathrm{N}_{2}\right)\right]\left[\mathrm{Na}(12 \text {-crown-4) })_{2}\right]$ (4.1): $\left[\left(\mathrm{TPB}^{\mathrm{Cy}}\right) \mathrm{Fe}\left(\mathrm{N}_{2}\right)\right]\left[\mathrm{Na}(12-\text { crown-4) })_{2}\right](\mathbf{5 . 1})\left(\mathrm{TPB}^{\mathrm{Cy}}=\left(o-\mathrm{Cy}_{2} \mathrm{P}\left(\mathrm{C}_{6} \mathrm{H}_{4}\right)\right)_{3} \mathrm{~B}\right)$, $\left[\left(\mathrm{TPB}^{\mathrm{Ph}}\right) \mathrm{Fe}\left(\mathrm{N}_{2}\right)\right]\left[\mathrm{Na}(12-\text { crown-4) })_{2}\right]\left(\right.$ 5.2) $\left(\mathrm{TPB}^{\mathrm{Ph}}=\left(o-\mathrm{Ph}_{2} \mathrm{P}\left(\mathrm{C}_{6} \mathrm{H}_{4}\right)\right)_{3} \mathrm{~B}\right)$, and $\left[(\mathrm{DPB}) \mathrm{Fe}\left(\mathrm{N}_{2}\right)\right]\left[\mathrm{K}(\mathrm{Bz} 15-\text { crown-5 })_{2}\right]^{4}(\mathbf{5 . 3})\left(\mathrm{DPB}=\left(o-\mathrm{iPr} \mathrm{P}_{2}\left(\mathrm{C}_{6} \mathrm{H}_{4}\right)\right)_{2} \mathrm{BPh}\right) \quad($ Figure 5.1) The efficacy of these complexes as well as the previously reported complexes $\left[\left(\mathrm{SiP}^{i \mathrm{Pr}}{ }_{3}\right) \mathrm{Fe}\left(\mathrm{N}_{2}\right)\right]\left[\mathrm{Na}(12 \text {-crown-4) })_{2}\right](\mathbf{5 . 4}),{ }^{5}\left[\left(\mathrm{PhBP}^{\mathrm{iPr}}{ }_{3}\right) \mathrm{Fe}\left(\mathrm{N}_{2}\right)\right]\left[\mathrm{MgCl}(\mathrm{THF})_{2}\right](\mathbf{5 . 5}),{ }^{6}$ $\left(\mathrm{Cy}_{2} \mathrm{P}\left(\mathrm{C}_{2} \mathrm{H}_{4}\right)\right)_{3} \mathrm{PFe}\left(\mathrm{N}_{2}\right)($ 5.6)$){ }^{7}$ and (depe $)_{2} \mathrm{Fe}\left(\mathrm{N}_{2}\right)(\text { 5.7 })^{8}\left(\right.$ depe $\left.=1,2-\left(\mathrm{Et}_{2} \mathrm{P}\right)_{2} \mathrm{C}_{2} \mathrm{H}_{4}\right)$ has been tested for $\mathrm{N}_{2}$ reduction under the standard catalytic conditions used for $\mathbf{4 . 1}$ (Figure 5.1). Empirically, of the complexes studied, only species with flexible Fe-B interactions produce substantial quantities of $\mathrm{NH}_{3}$ with both $\left[\left(\mathrm{TPB}^{\mathrm{Cy}}\right) \mathrm{Fe}\left(\mathrm{N}_{2}\right)\right]\left[\mathrm{Na}(12 \text {-crown-4) })_{2}\right.$ and $\left[\left(\mathrm{TPB}^{\mathrm{Ph}}\right) \mathrm{Fe}\left(\mathrm{N}_{2}\right)\right][\mathrm{Na}(12$-crown-4) $]$ serving as pre-catalysts. While these systems are not as efficient as the parent complex 4.1, they nevertheless demonstrate that the ligand field supplied by the TPB ligands is beneficial for catalytic conversion of $\mathrm{N}_{2}$ to $\mathrm{NH}_{3}$. In 
addition to these studies, further variations of the catalytic conditions for $\mathbf{4 . 1}$ including solvent, reductant, acid, and temperature have been studied and suggest additional factors that may be crucial for turnover.

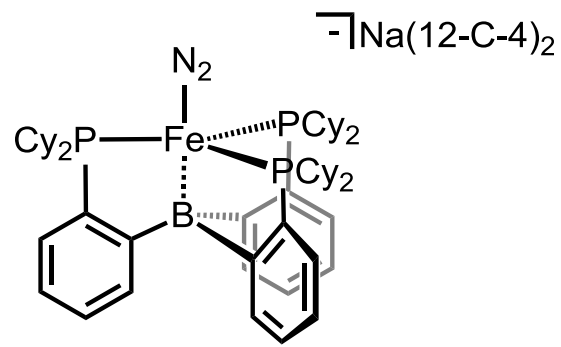

5.1

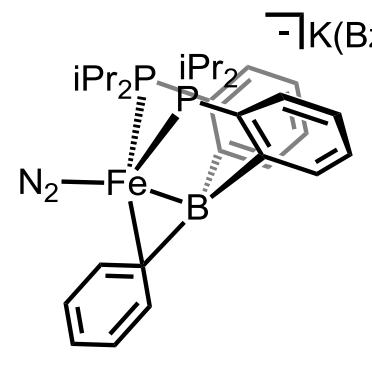

5.3

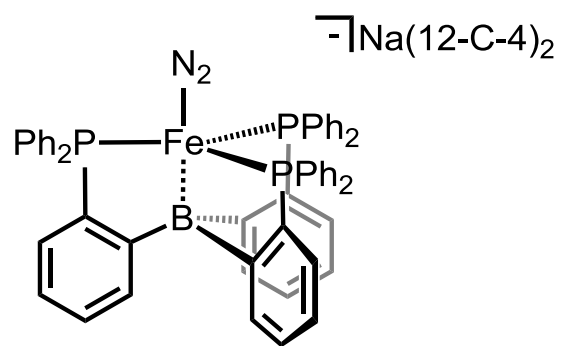

5.2

$$
7 \mathrm{Na}(12-\mathrm{C}-4)_{2} \quad \mathrm{~N}_{2}-7 \mathrm{MgCl}(\mathrm{THF})_{2}
$$

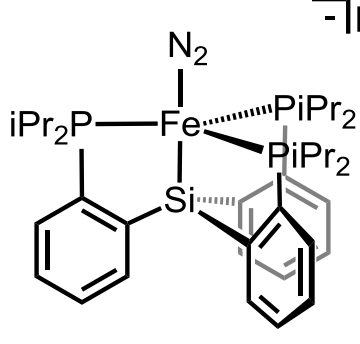

5.4

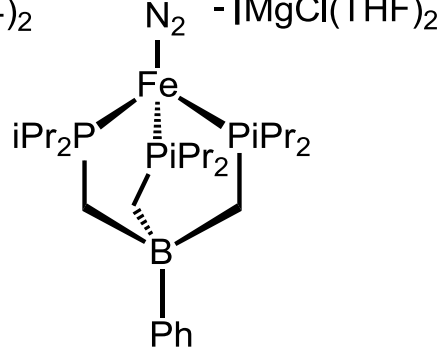

5.5

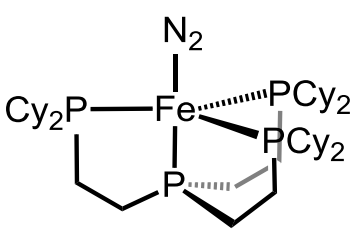

5.6<smiles>CCP1CCP2P(N)CCP1P2CC</smiles>

5.7

Figure 5.1. Complexes synthesized and studied towards $\mathrm{N}_{2}$ reduction. Note that complexes $\mathbf{5 . 4}, \mathbf{5 . 5}, \mathbf{5 . 6}$, and $\mathbf{5 . 7}$ have been previously reported in the literature (see references 5 (5.4), $3(\mathbf{5 . 5}), 4(\mathbf{5 . 6})$, and $8(\mathbf{5 . 5}))$.

\subsection{Results and Discussion}

\subsubsection{Ligand and Complex Synthesis}




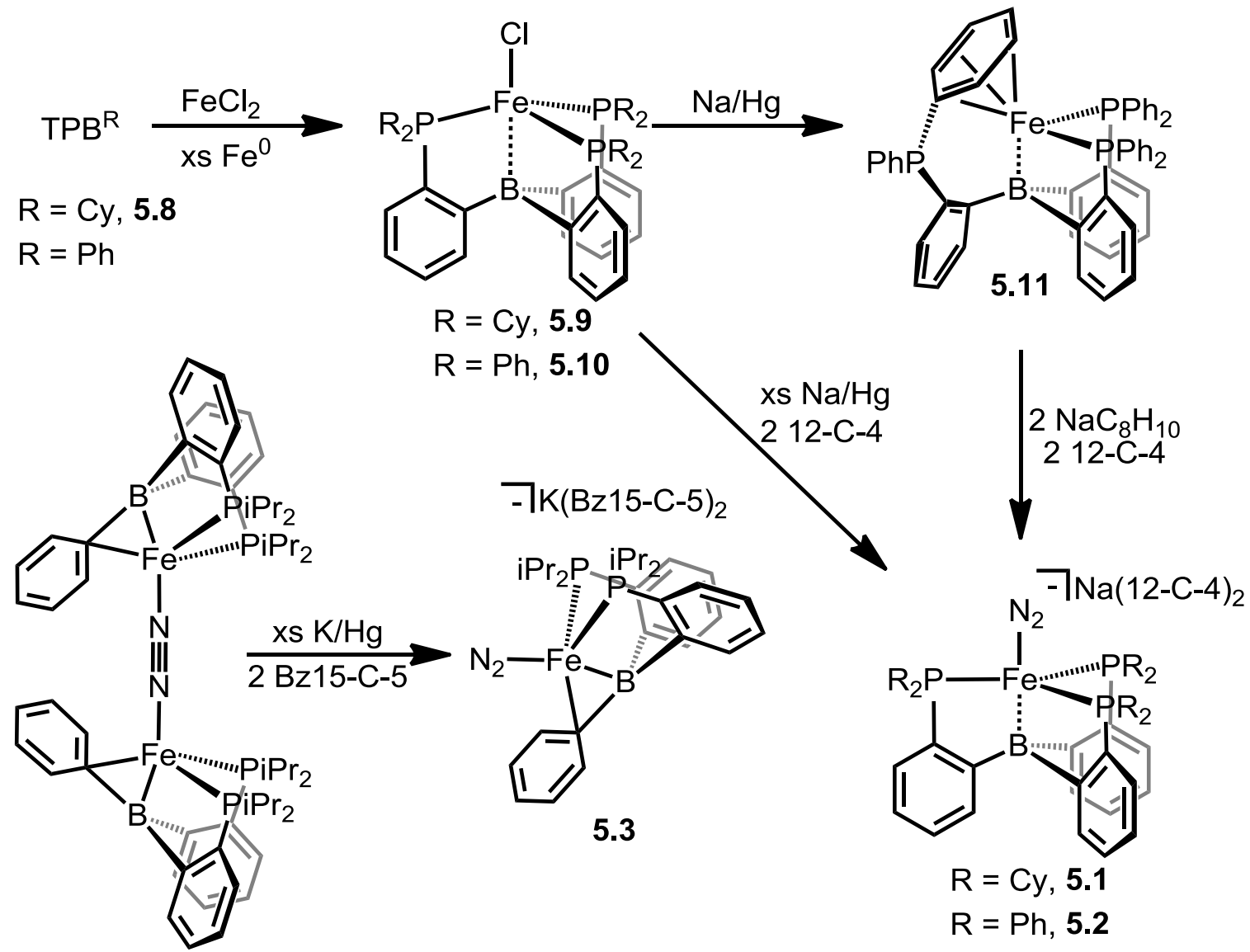

Scheme 5.1. Synthesis of complexes 5.1, 5.2, 5.3, 5.8, 5.9, 5.10, and 5.11.

With the desire of investigating the structural features that enable catalytic turnover, several variations on the TPB ligand scaffold were targeted. To probe the effect of a larger steric profile of the ligand scaffold, a cyclohexyl based TPB ${ }^{\mathrm{Cy}}$ scaffold was synthesized that would closely mimic the electronics of the TPB system while providing additional steric bulk. The previously reported ${ }^{9} \mathrm{TPB}^{\mathrm{Ph}}$ ligand also serves as an obvious variation on TPB to test the effect of weaker phosphine donors. ${ }^{10}$ Finally, the Peters lab recently reported the synthesis of Fe complexes of the previously reported $\mathrm{PhB}(o-$ ${ }_{i} \operatorname{Pr}_{2} \mathrm{P}\left(\mathrm{C}_{6} \mathrm{H}_{4}\right)_{2}$ (DPB) ligand. ${ }^{11,12}$ This DPB ligand ligates the Fe center through two 
phosphine donors and replaces one phosphine donor of TPB with an interaction through a $\mathrm{BPh}$ unit. The DPB scaffold hence provides a larger variation on the TPB scaffold than the simple change in phosphine substituent.

The preparation of $\mathrm{TPB}^{\mathrm{Ph}}$ has already been reported9 and the synthesis of $\mathrm{TPB}^{\mathrm{Cy}}$ (5.8) involves the lithiation of $o-\mathrm{Br}\left(\mathrm{C}_{6} \mathrm{H}_{4}\right) \mathrm{PCy}_{2}$ and subsequent reaction with $1 / 3$ of an equivalent of $\mathrm{BCl}_{3}$ analogously to the preparation of TPB. ${ }^{13}$ Metallation of these trisphosphine ligands also proceeds in an analogous manner to that reported for (TPB)FeBr ${ }^{17 \mathrm{a}}$ (Scheme 2) to yield the halides $\left(\mathrm{TPB}^{\mathrm{Cy}}\right) \mathrm{FeCl}^{14}(\mathbf{5 . 9})$ and $\left(\mathrm{TPB}^{\mathrm{Ph}}\right) \mathrm{FeCl}$ (5.10), which are brown solids and possess $S=3 / 2$ spin states as judged from their solution magnetic moments of $\mu_{\mathrm{eff}}=3.8$ and $4.0 \mu_{\mathrm{B}}$ respectively. Reduction of $\mathbf{5 . 9}$ with an excess of $\mathrm{Na} / \mathrm{Hg}$ amalgam followed by addition of 12 -crown-4 results in formation of 5.1 as a dark red $S=1 / 2$ complex with a N-N stretch at $1901 \mathrm{~cm}^{-1}$, very close to the reported value for $4.1\left(1905 \mathrm{~cm}^{-1}\right)$, suggesting that the $\mathrm{N}_{2}$ molecule is similarly activated in both of these complexes.

Reduction of $\mathbf{5 . 1 0}$ with one equivalent of $\mathrm{Na} / \mathrm{Hg}$ does not result in the uptake of $\mathrm{N}_{2}$ as is observed in the alkyl systems. Alternately, a diamagnetic species is obtained with ${ }^{1} \mathrm{H}$ NMR resonances shifted into the olefinic region. These shifted peaks suggest the possibility of an $\eta^{6}$ coordinated aryl ring, and XRD data (vide infra) confirm that one phosphine arm has dissociated and one of the phenyl groups attached to the phosphine is coordinated to the Fe center to give the bis-phosphino borane aryl complex $\left(\mathrm{TPB}^{\mathrm{Ph}}{ }^{\prime}\right) \mathrm{Fe}$ 5.11. ${ }^{14}$ Further reduction of $\mathbf{5 . 1 1}$ with $\mathrm{NaC}_{10} \mathrm{H}_{8}$ and addition of 12-crown-4 enables isolation of $\mathbf{5 . 2}$ as a red solid. Complex $\mathbf{5 . 2}$ similarly displays a strong N-N stretching vibration in the IR at $1988 \mathrm{~cm}^{-1}$ which occurs at substantially higher energy than that 
found in $\mathbf{5 . 1}$ or $\mathbf{4 . 1}$, reflecting the weaker donor ability of the tri-aryl phosphine donors consistent with similar shifts that have been observed in $\left(\mathrm{SiP}_{3}\right)$ examples from the Peters laboratory as well as in tetraphosphine $\mathrm{FeN}_{2}$ adducts. ${ }^{16 a, 15,8} 8$ Finally, reduction of the previously reported $[(\mathrm{DPB}) \mathrm{Fe}]_{2}\left(\mu-1,2-\mathrm{N}_{2}\right)$ with an excess of $\mathrm{K} / \mathrm{Hg}$ amalgam followed by addition of benzo-15-crown-5 results in dark red 5.3. The N-N stretch for complex $\mathbf{5 . 3}$ is observed at $1935 \mathrm{~cm}^{-1}$. This vibration suggests that the DPB scaffold still results in a strongly activated $\mathrm{N}_{2}$ despite the loss of one phosphine donor.

\subsubsection{Structural Characterization}

Complexes 5.1, 5.3, 5.9, 5.10, and $\mathbf{5 . 1 1}$ have been crystallographically characterized and their structures are depicted in Figure 2. The halide complexes $\mathbf{5 . 9}$ and 5.10 display relatively similar geometries about $\mathrm{Fe}$, with relatively long $\mathrm{Fe}-\mathrm{P}$ bonds consistent with other examples of formally $\mathrm{Fe}^{\mathrm{I}} S=3 / 2$ Fe centers from related complexes (Table 5.1). ${ }^{17 \mathrm{a}} \mathrm{A}$ trend in increasing Fe-P distances is observed upon moving from complex 5.10 to (TPB)FeCl to 5.9, potentially arising from the increasing steric demands from the substituents on phosphorus (Table 5.1). The Fe-B distance in these halide complexes is also quite long, likely indicating a minimal interaction between $\mathrm{Fe}$ and $\mathrm{B}$. The geometry about Fe, consistent with the long Fe-B distance, can best be described as pseudo-trigonal bipyramidal, with a strong distortion towards tetrahedral with $\tau_{4}$ values of $<0.5$ for all of the halide complexes. 

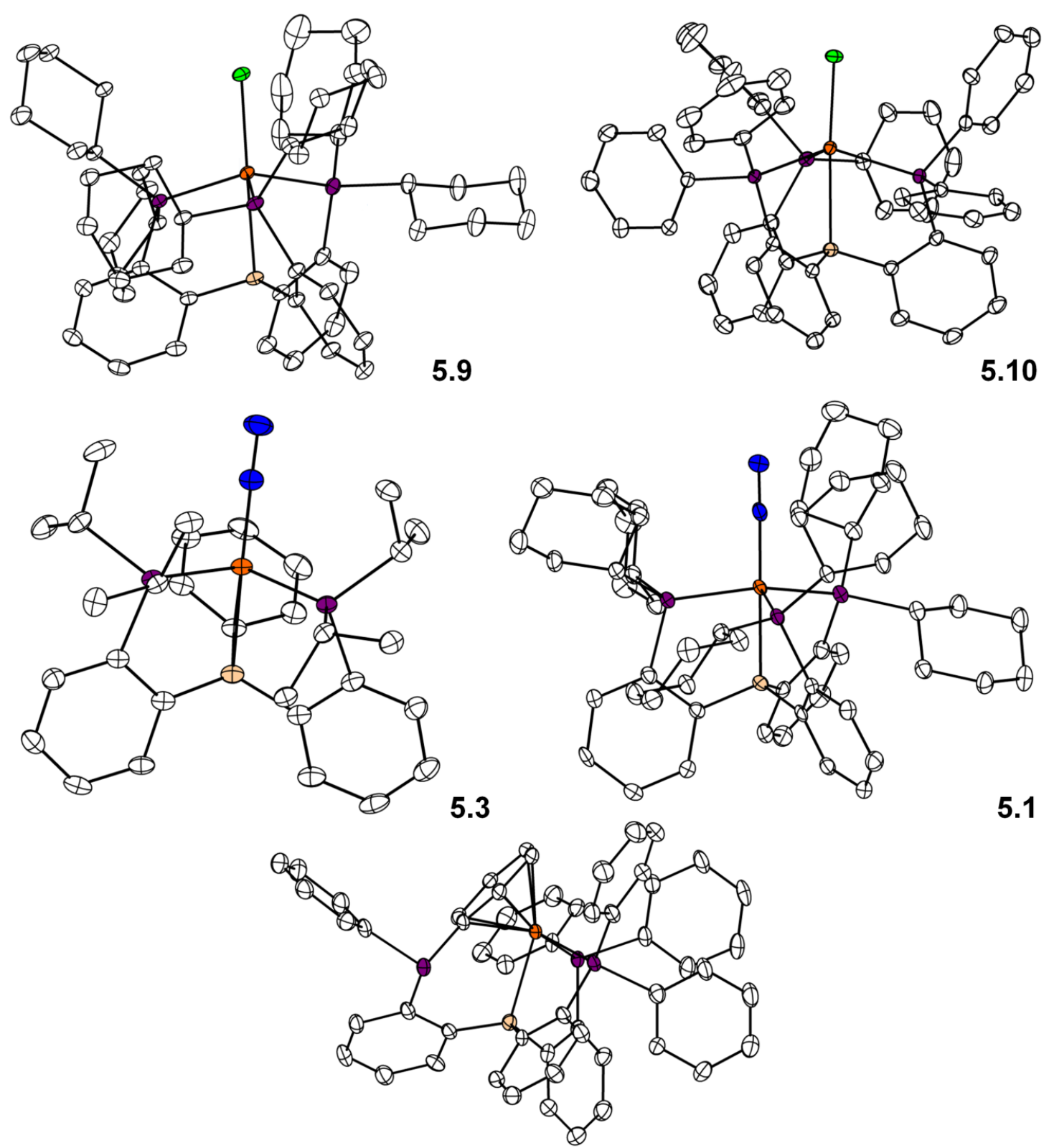

\subsection{1}

Figure 5.2. XRD structures of complexes 5.1, 5.3, 5.9, 5.10, and 5.11 with ellipsoids at $50 \%$ and hydrogens and counterions omitted for clarity. Fe atoms are shown in orange, $\mathrm{P}$ in purple, $\mathrm{B}$ in tan, $\mathrm{Cl}$ in green, and $\mathrm{N}$ in blue. See Table 5.1 for bonding metrics. 
The assignment of $\mathbf{5 . 1 1}$ as an $\eta^{6}$ aryl adduct was confirmed by its XRD structure, which shows the Fe interacting with a phenyl ring and one phosphine arm dissociated from $\mathrm{Fe}(\mathrm{Fe}-\mathrm{P}>3.5 \AA$ ). The $\mathrm{Fe}-\mathrm{C}$ distances range from 2.095(3) $\AA$ to 2.172(3) $\mathrm{A}$, with the ipso carbon having the shortest distance and an Fe-centroid distance of $1.595 \AA$. The other two Fe-P distances are substantially shorter than those observed in the halide complexes, reflecting the diamagnetism of $\mathbf{5 . 1 1}$ (Table 5.1). Despite the other short Fe ligand bonds, the Fe-B distance of 2.457(4) $\AA$ remains long. The $\Sigma \mathrm{C}-\mathrm{B}-\mathrm{C}$ in 5.11, however, shows a value of $334^{\circ}$ compared with an average of $341^{\circ}$ in complexes (TPB)FeCl, 5.9, and 5.10, indicating that the $\mathrm{B}$ is more pyramidalized in $\mathbf{1 0}$ and further suggesting that there is more donation to B in this complex than in the halide complexes.

\begin{tabular}{ccccccc}
\hline Complex & Fe-X & Fe-B & Fe-P1 & Fe-P2 & Fe-P3 & $\tau_{4}$ \\
\hline $\mathbf{5 . 1}$ & $1.792(3)$ & $2.292(3)$ & $2.3157(9)$ & $2.2228(9)$ & $2.2219(9)$ & 0.60 \\
$\mathbf{5 . 3}$ & $1.792(2)$ & $2.246(2)$ & $2.2265(7)$ & $2.2179(7)$ & - & - \\
$\mathbf{5 . 9}$ & 2.296 & 2.429 & 2.456 & 2.419 & 2.390 & 0.39 \\
$\mathbf{5 . 1 0}$ & $2.2712(4)$ & $2.5418(16)$ & $2.3622(4)$ & $2.3451(4)$ & $2.3325(4)$ & 0.33 \\
$\mathbf{5 . 1 1}$ & - & $2.457(4)$ & $2.2466(10)$ & $2.1846(9)$ & - & - \\
\hline
\end{tabular}

Table 5.1. Selected bond lengths $(\AA)$ and $\tau_{4}$ values for complexes $5.1,5.3,5.9,5.10$, and

5.11. Note that the values reported for 5.9 are the average of four molecules in the unit cell.

Although crystals of $\mathbf{5 . 2}$ suitable for XRD analysis could not be obtained, both complexes $\mathbf{5 . 1}$ and $\mathbf{5 . 3}$ were structurally characterized. Complex $\mathbf{5 . 3}$ shows a pseudo tetrahedral geometry about Fe, consistent with other DPB complexes, ${ }^{12}$ and displays a strong $\mathrm{Fe}-\mathrm{C}_{\mathrm{ipso}}$ interaction of 2.055(2) $\AA$. In addition to the short Fe- $\mathrm{C}_{\mathrm{ipso}}$ there is a moderately shortened Fe- $\mathrm{C}_{\text {ortho }}$ distance of 2.326(2) $\AA$. The Fe-B distance of 2.246(2) $\AA$ 5.3 is also short when compared with other DPB complexes of Fe. All of these bond 
metrics point to a strong interaction between the Fe center and the BCC unit in $\mathbf{5 . 3}$, and this conclusion is supported by bond alteration in the bound $\mathrm{Ph}$ ring with two short $\mathrm{C}-\mathrm{C}$ distances of $1.378(3) \AA$ and $1.385(3) \AA$ with the remainder of the $\mathrm{C}$-C distances $>1.408$ $\AA$. Finally, the Fe-N distance of 1.792(2) $\AA$ and the N-N distance of 1.135(3) $\AA$ are comparable to the analogous distances from 4.1 of 1.781(2) and 1.144(3) A, suggesting a slightly weaker degree of $\mathrm{N}_{2}$ activation consistent with the IR data for these complexes.

Complex 5.1 is similar to $\left[(\mathrm{TPB}) \mathrm{Fe}\left(\mathrm{N}_{2}\right)\right]\left[\mathrm{Na}(12 \text {-crown-4) })_{2}\right]$ in overall structure, as both complexes have pseudo-trigonal bipyramidal geometries with $\tau_{4}$ values of 0.60 and 0.61 respectively. Both complexes possess one large $\mathrm{P}-\mathrm{Fe}-\mathrm{P}$ angle which is $136.21(3)^{\circ}$ in 5.1 and $134.99(3)^{\circ}$ in $\left[(\mathrm{TPB}) \mathrm{Fe}\left(\mathrm{N}_{2}\right)\right]\left[\mathrm{Na}(12 \text {-crown-4) })_{2}\right]$. Unlike the corresponding halide complexes 5.9 and (TPB)FeCl, which show longer Fe-P distances on average with cyclohexyl substituents, $\mathbf{5 . 1}$ displays very similar average Fe-P distances to $\left[(\mathrm{TPB}) \mathrm{Fe}\left(\mathrm{N}_{2}\right)\right][\mathrm{Na}(12$-crown-4) 2$]$, with values of 2.254 and $2.251 \AA$ respectively. The Fe-B distance is also essentially identical in both $\mathbf{5 . 1}$ and $\left[(\mathrm{TPB}) \mathrm{Fe}\left(\mathrm{N}_{2}\right)\right][\mathrm{Na}(12$-crown4)2] with a value of 2.292(3) $\AA$ in both complexes. Finally, $\mathbf{5 . 1}$ has an Fe-N distance of $1.792(3) \AA$ and a N-N distance of $1.143(4) \AA$, very close to the values observed in $\left[(\mathrm{TPB}) \mathrm{Fe}\left(\mathrm{N}_{2}\right)\right]\left[\mathrm{Na}(12-\mathrm{crown}-4)_{2}\right]$ and consistent with their similar vibrational features.

\subsubsection{Comparison of Pre-Catalysts}

With the above-mentioned complexes isolated and characterized, comparative studies of their efficacy as pre-catalysts were conducted. Specifically targeted were complexes $\mathbf{5 . 1}, \mathbf{5 . 2}$, and $\mathbf{5 . 3}$ as well as the previously reported phosphine $\mathrm{N}_{2}$ complexes 5.4, 5.5, 5.6 and 5.7. The results from these studies are summarized in Table 5.2. While 
none of the investigated catalysts outperform the original system featuring 4.1 as a precatalyst ( 7 eq. $\mathrm{NH}_{3} / \mathrm{Fe}$ ), several trends relevant to catalysis become apparent. Most notably, the only complexes that are competent for catalytic turnover within this study, that is, complexes that can on average produce $>2$ eq. $\mathrm{NH}_{3} / \mathrm{Fe}$, bear a great deal of structural similarity to 4.1. Specifically, of the new complexes, 5.1 differs from 4.1 only in a slightly larger steric profile on the phosphine substituents and is otherwise very similar, which is manifested in the similar $v_{\mathrm{NN}}$ frequencies and bond metrics for these two species. While $\mathbf{5 . 1}$ is a competent pre-catalyst for $\mathrm{N}_{2}$ reduction, producing 3.2 equivalents of $\mathrm{NH}_{3}$ per $\mathrm{Fe}$ (Table 5.2, entry 1), it is less active than 4.1, suggesting a negative effect of the larger steric profile of the $\mathrm{TPB}^{\mathrm{Cy}}$ ligand.

Complex 5.2 also serves as a pre-catalyst for $\mathrm{N}_{2}$ reduction under these standard conditions, albeit only nominally. While the $\mathrm{Ph}$ substituted ligand scaffold has substantially different electronic properties that the iPr or Cy systems, the fact that it can still mediate catalysis suggests that the tris-phosphine borane ligand set common to all three catalysts is critical to enable catalytic turnover. Another potentially mechanistic observation arises from the $\mathrm{Ph}$ system. Because this scaffold preferentially binds an arene ring over $\mathrm{N}_{2}$ in its $\mathrm{Fe}(0)$ state, there is no evidence for an $\mathrm{Fe}(0) \mathrm{N}_{2}$ adduct with this system. The fact that catalysis is still observed might suggest that an $\mathrm{Fe}(0) \mathrm{N}_{2}$ adduct is not required for catalysis. This conclusion is further supported by the lower observed turnover number when $(\mathrm{TPB}) \mathrm{Fe}\left(\mathrm{N}_{2}\right)$ is utilized as a precatalyst (Chapter 4).

In contrast to the TPB based complexes, the DPB based $\mathbf{5 . 3}$ does not produce $>2$ eq. of $\mathrm{NH}_{3} / \mathrm{Fe}$ on average, although it does produce substantial quantities of $\mathrm{NH}_{3}$. Even though $\mathbf{5 . 3}$ activates $\mathrm{N}_{2}$ more strongly than $\mathbf{5 . 2}$, as evidenced by the IR spectra of these 
two complexes, the fact that $\mathbf{5 . 3}$ produces less $\mathrm{NH}_{3}$ again suggests the importance of the tris-phosphine borane scaffold. Additionally, the DPB scaffold might be expected to be more labile than the TPB scaffold due to the weaker coordinating ability of the BPh unit. If the catalysis is indeed mediated by a molecular species, this lability may compromise the stability of the species towards decomposition and explain the diminished capability of $\mathbf{5 . 3}$ for catalysis. Furthermore, the fact that $\mathbf{5 . 3}$ performs more poorly than $\mathbf{5 . 1}$ or $\mathbf{5 . 2}$ suggests that such a pathway is not beneficial for catalysis, circumstantially supporting the agency of a molecular species versus some heterogeneous species derived from decomposition.

\begin{tabular}{ccc}
\hline Entry & Complex & $\mathrm{NH}_{3}$ eq./Fe \\
\hline $\mathbf{5 . 1}$ & {$\left[\left(\mathrm{TPB}^{\mathrm{Cy}}\right) \mathrm{Fe}\left(\mathrm{N}_{2}\right)\right]\left[\mathrm{Na}(12 \text {-crown-4 })_{2}\right]$} & 3.2 \\
$\mathbf{5 . 2}$ & {$\left[\left(\mathrm{TPB}^{\mathrm{Ph}}\right) \mathrm{Fe}\left(\mathrm{N}_{2}\right)\right]\left[\mathrm{Na}(12 \text {-crown-4 })_{2}\right]$} & 2.2 \\
$\mathbf{5 . 3}$ & {$\left[(\mathrm{DPB}) \mathrm{Fe}\left(\mathrm{N}_{2}\right)\right]\left[\mathrm{K}(\mathrm{Bz} 15 \text {-crown-5 })_{2}\right]$} & 1.7 \\
$\mathbf{5 . 4}$ & {$\left[\left(\mathrm{SiP}^{\mathrm{iPr}}\right) \mathrm{Fe}\left(\mathrm{N}_{2}\right)\right]\left[\mathrm{Na}(12 \text {-crown-4 })_{2}\right]$} & 0.7 \\
$\mathbf{5 . 5}$ & {$\left[\left(\mathrm{PhBP}^{\mathrm{iPr}}{ }_{3}\right) \mathrm{Fe}\left(\mathrm{N}_{2}\right)\right]\left[\mathrm{MgCl}(\mathrm{THF})_{2}\right]$} & 1.2 \\
$\mathbf{5 . 6}$ & $\left(\mathrm{C}_{2} \mathrm{H}_{4} \mathrm{PCy}\right)_{3} \mathrm{PFe}\left(\mathrm{N}_{2}\right)$ & 0.7 \\
$\mathbf{5 . 7}$ & $\left(\right.$ depe $_{2} \mathrm{Fe}\left(\mathrm{N}_{2}\right)$ & 0.4 \\
\hline
\end{tabular}

Table 5.2. $\mathrm{N}_{2}$ reduction with phosphine Fe complexes. All data shown as an average of at least 3 runs (see Appendix 4) using the conditions described in the experimental section.

Complex 5.4 provides an interesting comparison to the original catalytic system with 4.1 in that the two complexes are isostructural, with the only difference being a substitution of a Si atom for the B atom of the TPB ligand. While there are certainly electronic differences to consider, one of the most striking differences between these two systems involves the flexibility of the Fe-Si or Fe-B bond. The Fe-Si bond in $\left(\mathrm{SiP}_{3}\right) \mathrm{Fe}$ complexes is quite rigid, with little variation in distance over a number of complexes.5,16 
This inflexibility strongly contrasts with the TPB system, where large variations in the $\mathrm{Fe}-\mathrm{B}$ distance take place to accommodate geometric and electronic changes at the $\mathrm{Fe}$ center. ${ }^{17}$ The fact that complex $\mathbf{5 . 4}$ is not a competent catalyst for $\mathrm{N}_{2}$ reduction while $\mathbf{4 . 1}$ is further implies that the flexible linkage in the TPB system may be important for catalysis.

Similarly, the tris-phosphino borate ligated complex $\mathbf{5 . 5}$ produces a substoichiometric amount of $\mathrm{NH}_{3}$, which is again consistent with the empirical observation of a need for a hemi-labile interaction between the Fe and the apical B. Interestingly, in the tetraphosphine complex $\mathbf{5 . 6}$ there exists, in principle, the possibility of a hemi-labile interaction with the apical $\mathrm{P}$ atom of the ligand scaffold. The low yields of $\mathrm{NH}_{3}$ for this system when compared with the other entries in Table 5.2 suggest that if any flexibility of the Fe-P bond exists, it does not enable catalysis in this system. Finally, complex $\mathbf{5 . 7}$ was subjected to the standard catalytic conditions to test a different tetra-phosphine complex but also did not exhibit catalytic $\mathrm{NH}_{3}$ formation. Similar Fe phosphine complexes had been tested for $\mathrm{NH}_{3}$ formation previously and had shown only $~ 10 \%$ of an equivalent of $\mathrm{NH}_{3}$ per Fe. ${ }^{18}$ While it is difficult to draw definite comparisons, the higher yields observed here may be reflective of the conditions used for catalysis in this study.

\subsubsection{Comparison of Catalytic Conditions}

In an effort to further explore the effect of variations on the standard catalytic conditions previously reported, several additional reaction variables were tested for catalysis. The first condition investigated was changing the solvent from $\mathrm{Et}_{2} \mathrm{O}$. As entries 1-5 in Table 5.3 illustrate, the solvent scope for catalysis is limited to relatively non-polar 
ethereal solvents. Unsurprisingly, $\operatorname{Pr}_{2} \mathrm{O}$ serves equally well as $\mathrm{Et}_{2} \mathrm{O}$ in the reaction, but moving to a more polar solvent in DME results in a drop in $\mathrm{NH}_{3}$ yield. Furthermore, the presence of some ethereal solvent is critical, likely due to solubility of the $\operatorname{HBAr}_{4} \cdot 2$ $\mathrm{Et}_{2} \mathrm{O}$ acid, as is evidenced by the low yields of $\mathrm{NH}_{3}$ in toluene (entry 4) compared with much higher yields when even a small amount of $\mathrm{Et}_{2} \mathrm{O}$ is included in the reaction mixture (entry 5). The lower yield of $\mathrm{NH}_{3}$ in $\mathrm{Bu}_{2} \mathrm{O}$ is likely similarly explained by lowered solubility of $\mathrm{HBAr}_{4}{ }_{4} \cdot 2 \mathrm{Et}_{2} \mathrm{O}$. The requirement for an ethereal solvent likely stems from the need for good solubility of the acid and any $\mathrm{BAr}_{4}^{-}$ions. Additionally, it is not clear whether $\mathrm{KC}_{8}$ will be thermodynamically or kinetically suitable to form 4.1 in less polar solvents such as toluene. Conversely, the lowered activities in more polar ethers likely result from accelerated $\mathrm{H}_{2}$ formation.

\begin{tabular}{ccc}
\hline Entry & Solvent & NH $_{\mathbf{3}}$ eq./Fe \\
\hline 1 & $\mathrm{iPr} 2$ & 6.53 \\
2 & $\mathrm{DME}_{2}$ & 3.37 \\
3 & $\mathrm{Bu}_{2} \mathrm{O}$ & 3.16 \\
4 & $\mathrm{Toluene}$ & 0.78 \\
5 & $1: 6 \mathrm{Et}_{2} \mathrm{O}:$ Toluene & 3.12 \\
\hline
\end{tabular}

Table 5.3. Effect of different solvents on the catalytic reduction of $\mathrm{N}_{2}$ to $\mathrm{NH}_{3}$ by complex

4.1. Note that all reported values are an average of at least 2 runs (See Appendix 4).

Aside from solvent, the reaction is quite sensitive to the choice of reductant (Table 5.4). The use of weaker reducing agents such as $\mathrm{Cp}_{2}{ }_{2} \mathrm{Co}$ or $\mathrm{Cp}_{2}{ }_{2} \mathrm{Cr}$ results in very low yields of $\mathrm{NH}_{3}$. It is unclear whether this is a reflection of the need for a reducing agent strong enough to generate $\left[(\mathrm{TPB}) \mathrm{Fe}\left(\mathrm{N}_{2}\right)\right]^{-}$or whether the potentially higher solubility of these reagents increases side reactions with the acid. The higher yields obtained with $\mathrm{NaC}_{10} \mathrm{H}_{8}$ (entry 3 ), which should be a strong and soluble reductant, suggest 
that the potentials of the reductants in entries 1 and 2 do hinder the reactivity. The use of $\mathrm{K}$ metal or $\mathrm{MgC}_{14} \mathrm{H}_{10}$ also leads to low yields of $\mathrm{NH}_{3}$. Finally, although other evidence supports the presence of a molecular catalyst, some sort of graphite bound complex as the catalytically active species cannot be ruled out. Entry 6 illustrates that $\mathrm{Na} / \mathrm{Hg}$ is also competent for catalysis, albeit only nominally, suggesting that graphite is not an essential component of the reaction mixture and further supporting the homogeneity of the catalyst.

\begin{tabular}{ccc}
\hline Entry & Reductant & NH3 eq./Fe \\
\hline 1 & $\mathrm{Cp}^{*}{ }_{2} \mathrm{Co}$ & 0.6 \\
2 & $\mathrm{Cp}^{*}{ }_{2} \mathrm{Cr}$ & $<0.2$ \\
3 & $\mathrm{NaC}_{10} \mathrm{H}_{8}$ & 1.0 \\
4 & $\mathrm{~K} \mathrm{metal}$ & 0.4 \\
5 & $\mathrm{MgC}_{14} \mathrm{H}_{10} \cdot 3 \mathrm{THF}$ & 0.3 \\
6 & $\mathrm{Na} / \mathrm{Hg}$ & 2.1 \\
\hline
\end{tabular}

Table 5.4. Effect of different reductants on the catalytic reduction of $\mathrm{N}_{2}$ to $\mathrm{NH}_{3}$ by complex 4.1. Note that all reported values are an average of at least 2 runs (See Appendix 4). Note that the $\mathrm{Na} / \mathrm{Hg}$ was $10 \% \mathrm{Na}$ by weight.

A number of different acids were tested in the catalysis with the results shown in Table 5.5. The use of $\mathrm{HBAr}_{4} \cdot 2 \mathrm{Et}_{2} \mathrm{O}$ in the standard catalytic runs was chosen due to its high acidity and the poor coordinating ability of the $\mathrm{BAr}^{\mathrm{F}_{4}^{-}}$counterion. Other strong acids, with potentially better coordinating counterions in HOTf and $\mathrm{HCl}$, showed very low yields of $\mathrm{NH}_{3}$ (entries 1 and 2). The use of a weaker acid in [Lutidinium][BAr ${ }_{4}$ ] also showed very low yields of $\mathrm{NH}_{3}$. Interestingly, the use of a slightly stronger acid in [2,6-dimethylanilinium][OTf] or [2,6-dimethylanilinium][BAr $\left.{ }_{4}\right]$ resulted in catalytic turnover. This result is somewhat surprising, as the $\mathrm{pK}_{\mathrm{a}}$ of [Lutidinium] is 6.77 versus 3.95 for [2,6-dimethylanilinium]. ${ }^{19,20}$ The cause for the disparity in activity between 
these two acids is unclear, but could potentially arise from different redox properties between anilinium and pyridinium acids. Alternately, the relatively narrow $\mathrm{pK}_{\mathrm{a}}$ range between these acids could bracket the acidity required for one of the catalytic steps. The last observation of note is that the two anilinium acids in entries 4 and 5 show similar activity despite having different counterions, which seems to suggest that the difference between $[\mathrm{OTf}]^{-}$and $\left[\mathrm{BAr}_{4}{ }_{4}\right]^{-}$is not significant for catalysis.

\begin{tabular}{ccc}
\hline Entry & Acid & NH3 eq./Fe \\
\hline 1 & HOTf & 0.4 \\
2 & $\mathrm{HCl}$ & $<0.1$ \\
3 & {$\left[\right.$ Lutidinium] $\left[\mathrm{BAr}^{\mathrm{F}}{ }_{4}\right]$} & $<0.1$ \\
4 & {$[2,6$-dimethylanilinium][OTf] } & 2.1 \\
5 & {$\left[2,6\right.$-dimethylanilinium] $\left[\mathrm{BAr}_{4}{ }_{4}\right]$} & 2.9 \\
\hline
\end{tabular}

Table 5.5. Effect of different acids on the catalytic reduction of $\mathrm{N}_{2}$ to $\mathrm{NH}_{3}$ by complex

4.1. Note that all reported values are an average of at least 2 runs (See Appendix 4). Note that $\left[2,6-\right.$ dimethylanilinium] $\left[\mathrm{BAr}^{\mathrm{F}}\right.$ ] was obtained as a $1.5 \mathrm{Et}_{2} \mathrm{O}$ adduct.

Finally, while the initial reaction screening was carried out at $-78^{\circ} \mathrm{C}$, it was desirable to determine whether low temperature was a prerequisite for $\mathrm{NH}_{3}$ formation, or whether higher temperatures could still be viable for $\mathrm{N}_{2}$ reduction. In this context, the catalysis was tested at -110 and $25^{\circ} \mathrm{C}$. The reduced yield of 1.33 equivalents of $\mathrm{NH}_{3}$ per Fe at RT illustrates that $\mathrm{NH}_{3}$ yields are drastically reduced at higher temperatures and that cooling of the reaction is necessary. Interestingly, the catalysis is still viable at temperatures as low as $-110{ }^{\circ} \mathrm{C}$ with a yield of 5.40 equivalents of $\mathrm{NH}_{3}$ per Fe. Although it will be difficult to exclude the possibility that reaction only occurs upon warming the solution, the conversion of the bronze color of $\mathrm{KC}_{8}$ to black graphite in the cold reaction mixture suggests reaction at these temperatures may be occurring. Furthermore, attempts 
to quench the catalysis at low temperature with either $[\mathrm{TBA}][\mathrm{CN}]$ or with $t$-BuNC have resulted in diminished, but still substantial yields of $\mathrm{NH}_{3}$, suggesting that catalysis is occurring at low temperature.

\subsection{Conclusions}

These combined studies varying both the pre-catalyst and the reaction conditions for the Fe-mediated reduction of $\mathrm{N}_{2}$ to $\mathrm{NH}_{3}$ provide several key insights on the catalysis. Firstly, all evidence still supports the agency of a molecular species. While a heterogeneous process will be difficult to completely exclude, the narrow range of viable pre-catalysts and the observation that other reduced Fe phosphine complexes are not competent for catalysis suggest that decomposition to a heterogeneous catalyst is unlikely. Furthermore, the catalysis is sensitive to even small variations in the substituents on the phosphine arms, suggesting the possibility of finding substituents that would improve catalysis. Such an observation is not completely surprising, as a similar dependence has been observed in both the of the previously reported Mo systems. ${ }^{21,22}$ Finally, the flexible Fe-B linkage in the TPB scaffold is empirically required for catalysis, at least among the complexes studied herein. Although recent results suggest that other ligand scaffolds with a carbon atom in the axial position are viable for catalysis, it is unclear in this system whether a flexible interaction is operative in this system and further studies will need to be performed to determine the role of the carbon atom. ${ }^{23}$ The apparent requirement for a flexible Fe-B interaction in the systems studied here parallels the hypothesis that a flexible $\mathrm{Fe}-\mathrm{C}$ interaction in nitrogenase is involved in catalysis. 
Furthermore, the catalysis is also strongly dependent on the catalytic conditions employed. While all of the conditions surveyed showed a decrease in catalytic activity relative to the original results with 4.1, several variations on the reaction conditions did preserve catalytic activity, suggesting some features required for catalysis. For example, only relatively non-polar ethereal solvents appear to be compatible with catalysis, likely due to the respective solubility of the acid and insolubility of the reductant in these solvents. It was also shown that catalysis is still viable with $\mathrm{Na} / \mathrm{Hg}$ as the reductant, suggesting that a graphite adsorbed complex is not crucial for the catalytic turnover. Anilinium acids are also compatible with catalysis while lutidinium acids are not. This observation raises interesting questions on what difference between these two acids leads to activity. Finally, the catalysis must be performed at low temperature and also seems to be active at temperatures as low as $-110{ }^{\circ} \mathrm{C}$, suggesting unusually high activity for this system. Taken together, the studies presented here begin to delineate the conditions and structures that are required for catalysis.

\subsection{Experimental Section}

\subsubsection{General Considerations}

Unless otherwise noted, all compounds were purchased from commercial sources and used without further purification. Complexes $5.4,5$ 5.5,6 5.6,7 and 5.78 as well as $\left[(\mathrm{TPB}) \mathrm{Fe}\left(\mathrm{N}_{2}\right)\right]\left[\mathrm{Na}(12 \text {-crown-4) })_{2}\right]{ }^{17}[(\mathrm{DPB}) \mathrm{Fe}]_{2}\left(\mu-1,2-\mathrm{N}_{2}\right),{ }^{12} \mathrm{MgC}_{14} \mathrm{H}_{10},{ }^{24} \mathrm{TPB}^{\mathrm{Ph}},{ }^{13} 2-$ $\mathrm{Cy}_{2} \mathrm{PC}_{6} \mathrm{H}_{4} \mathrm{Br},{ }^{25}$ and $\mathrm{HBAr}_{4} \mathrm{~F}_{4} \cdot 2 \mathrm{Et}_{2} \mathrm{O}^{26}$ were prepared according to literature procedures. All manipulations were carried out under a $\mathrm{N}_{2}$ atmosphere utilizing standard glovebox or Schlenk techniques. Solvents were dried and de-oxygenated by an argon sparge, followed 
by passage through an activated alumina column purchased from S.G. Waters Company. Solvents for catalytic runs were additionally stirred for more than 2 hours over $\mathrm{Na} / \mathrm{K}$ alloy and then filtered prior to use.

IR spectra were obtained via $\mathrm{KBr}$ pellets on a Bio-Rad Excalibur FTS 3000 spectrometer using Varian Resolutions Pro software set at $4 \mathrm{~cm}^{-1}$ resolution. Alternately, IR spectra were obtained on a Bruker Alpha Diamond ATR spectrometer on solid samples. NMR measurements were obtained on Varian $300 \mathrm{MHz}$ or $500 \mathrm{MHz}$ spectrometers. Deuterated solvents for these measurements were obtained from Cambridge Isotope Laboratories and were dried and degassed prior to use. All ${ }^{1} \mathrm{H}$ NMR spectra were referenced to residual solvent peaks, while ${ }^{31} \mathrm{P}$ NMR measurements were referenced to an external standard of $\mathrm{H}_{3} \mathrm{PO}_{4}$ and ${ }^{11} \mathrm{~B}$ NMR spectra were referenced to an external standard of $\mathrm{Et}_{2} \mathrm{O} \cdot \mathrm{BF}_{3}$. UV-Visible spectra were taken on a Cary 50 spectrometer from $1100 \mathrm{~nm}$ to $200 \mathrm{~nm}$ in the fast scan mode. Samples were prepared in a $1 \mathrm{~cm}$ path length quartz cuvette in the solvent indicated below. All samples had a blank sample background subtraction applied.

XRD data were obtained at low temperatures on a Siemens or Bruker Platform three-circle diffractometer coupled to a Bruker-AXS Smart Apex CCD detector with graphite-monochromated Mo K $\alpha$ radiation $(\lambda=0.71073)$, performing $\varphi$-and $\omega$-scans. All structures were solved by standard direct or Patterson methods and refined against $\mathrm{F}^{2}$ using the SHELX program package. ${ }^{27,28,29}$ All atoms, with the exception of hydrogens, were anisotropically refined. All hydrogen atoms were included via a standard riding model. 


\subsubsection{Synthesis}

Synthesis of TPB ${ }^{\mathrm{Cy}}$, 5.8. A schlenk tube with a stir bar was filled with a solution of 2dicyclohexylphosphinebromobenzene $(1.000 \mathrm{~g}, 2.830 \mathrm{mmol})$ in toluene $(10 \mathrm{~mL})$ and sealed. The schlenk tube was then hooked up to a schlenk line under a stream of $\mathrm{N}_{2}$ and the Teflon stopper of the schlenk tube was replaced with a rubber septum. The reaction vessel was then cooled to $-78{ }^{\circ} \mathrm{C}$. A $1.6 \mathrm{M}$ solution of $\mathrm{n}-\mathrm{BuLi}$ in hexane $(1.77 \mathrm{~mL}, 2.830$ mmol) was then slowly added via syringe. The resulting solution turned slightly orange while stirring for $15 \mathrm{~min}$ at $-78^{\circ} \mathrm{C}$. The solution was then warmed to ambient temperature and stirred for an additional hour before being cooled back to $-78{ }^{\circ} \mathrm{C}$. At this time a $1 \mathrm{M}$ solution of $\mathrm{BCl}_{3}$ in heptane $(0.92 \mathrm{~mL}, 0.920 \mathrm{mmol})$ was added to the stirring reaction vessel. The pale orange color of the solution lightened slightly upon addition of the $\mathrm{BCl}_{3}$. The septa was exchanged with a Teflon stopcock and the solution was allowed to stir at $-78^{\circ} \mathrm{C}$ for 1 hour before being warmed to RT and stirred for an additional 2 hours, during which time a brown color developed in the solution. The mixture was then heated to $90{ }^{\circ} \mathrm{C}$ for 16 hours, during which time the brown color lightened to orange and solids precipitated. Solvent was removed in vacuo and the remaining waxy solid was extracted $3 \mathrm{x}$ with $\mathrm{Et}_{2} \mathrm{O}(10 \mathrm{~mL})$ and filtered. The remaining pale orange solution was concentrated to half volume and cooled to $-35^{\circ} \mathrm{C}$ for 16 hours, which resulted in the formation of white crystals of the title compound $(0.426 \mathrm{~g}, 0.513 \mathrm{mmol}, 55 \%) .{ }^{1} \mathrm{H} \mathrm{NMR}$ $\left(\mathrm{C}_{6} \mathrm{D}_{6}, \delta\right): 8.30$ (br s, 4H), 7.46 (br s, 4H), 7.24 (br s, 2H), 7.18 (m, 2H), 1.93 (br m, 12H), 1.71 (br m, 12H), 1.63 (br s, 12H), 1.36 (br s, 8H), 1.17 (br m, 22H). ${ }^{31} \mathrm{P}\left\{{ }^{1} \mathrm{H}\right\} \mathrm{NMR}$ $\left(\mathrm{C}_{6} \mathrm{D}_{6}, \delta\right):-2.54$ (br s). ${ }^{11} \mathrm{~B}\left\{{ }^{1} \mathrm{H}\right\} \operatorname{NMR}\left(\mathrm{C}_{6} \mathrm{D}_{6}, \delta\right): 25.1$ (vbr s). ${ }^{13} \mathrm{C}\left\{{ }^{1} \mathrm{H}\right\} \operatorname{NMR}\left(\mathrm{C}_{6} \mathrm{D}_{6}, \delta\right)$ : 
159.69 (br s), 136.12 (br s), 131.97 (s), 127.30 (s), 35.83 (s), 31.29 (br s), 30.27 (s), 27.86 (d, $J=20 \mathrm{~Hz}), 27.01(\mathrm{~s})$.

Synthesis of (TPB $\left.{ }^{\mathrm{Cy}}\right) \mathbf{F e C l}$, 5.9. A mixture of $\mathrm{FeCl}_{2}(0.076 \mathrm{~g}, 0.60 \mathrm{mmol}), 7(0.500 \mathrm{~g}$, $0.60 \mathrm{mmol})$, Fe powder $(0.333 \mathrm{~g}, 6.02 \mathrm{mmol})$, and $\mathrm{THF}(10 \mathrm{~mL})$ was heated to $90{ }^{\circ} \mathrm{C}$ in a sealed schlenk tube under vigorous stirring for 3 days, during which time the color of the liquid phase turned from pale yellow to brown. The solids were removed from the mixture by filtration, and the solvent was removed in vacuo. The brown residue was then triturated, extracted with pentane $(200 \mathrm{~mL})$, and filtered through celite to give a brown solution. Solvent evaporation in vacuo afforded the product as a greenish brown powder $(0.460 \mathrm{~g}, 83 \%)$. An analytically pure sample and crystals suitable for XRD analysis were obtained by slow concentration of a saturated pentane solution. ${ }^{1} \mathrm{H}$ NMR $\left(\mathrm{C}_{6} \mathrm{D}_{6}, \delta\right): 81.73$ (br s), 36.11 (s), 25.66 (s), 17.64 (br s), 5.01 (s), 3.77 (br s), 1.84 (s), 1.57 (br s), 0.13 (s), $-0.13(\mathrm{~s}),-0.58(\mathrm{~s}),-0.75(\mathrm{sh}),-1.54$ (s), -1.98 (br s), -3.87 (br s), -5.91 (br s), -7.12 (br s), -23.01 (s). UV-vis (THF, nm $\left.\left\{\mathrm{cm}^{-1} \mathrm{M}^{-1}\right\}\right): 560\{130\}, 750\{100\}, 950\{150\} . \mu_{\text {eff }}\left(\mathrm{C}_{6} \mathrm{D}_{6}\right.$, Evans method, $20{ }^{\circ} \mathrm{C}$ ): $3.8 \mu$ в. Anal. calcd. for $\mathrm{C}_{54} \mathrm{H}_{78} \mathrm{BClFeP}_{3}$ : C 70.33 , H 8.52; found: C 70.45, H 8.49.

Synthesis of $\left(\mathbf{T P B}^{\mathrm{Ph}}\right) \mathbf{F e C l}, \mathbf{5 . 1 0}$. A Schlenk tube was charged with $\mathrm{TPB}^{\mathrm{Ph}}(0.923 \mathrm{~g}$, $1.240 \mathrm{mmol}), \mathrm{FeCl}_{2}(0.198 \mathrm{~g}, 1.560 \mathrm{mmol}), \mathrm{Fe}$ powder (0.176 g, $\left.3.160 \mathrm{mmol}\right)$, and THF $(50 \mathrm{~mL})$. The reaction was stirred vigorously for 3 days at $70{ }^{\circ} \mathrm{C}$, during which time the slurry turned dark brown. The mixture was filtered through celite to remove the excess iron powder and the volatiles removed in vacuo. The residual solids were triturated with toluene, slurried in $\mathrm{CH}_{2} \mathrm{Cl}_{2}$, and filtered to collect a dark brown powder $(0.841 \mathrm{~g}, 76 \%)$. Crystals suitable for $\mathrm{X}$-ray analysis were grown by slow concentration of a $\mathrm{C}_{6} \mathrm{H}_{6}$ solution. 
${ }^{1}$ H NMR $\left(d_{8}\right.$-THF, $\left.\delta\right): 34.23,23.91,9.89,7.30,4.73,2.31,-23.84 . \mu_{\text {eff }}\left(d_{8}\right.$-THF, Evans method, $25^{\circ} \mathrm{C}$ ): $4.0 \mu_{\mathrm{B}}$. We were unable to obtain satisfactory elemental analysis. Synthesis of (TPB $\left.{ }^{\mathbf{P h}}\right) \mathbf{F e}$, 5.11. Sodium $(0.003 \mathrm{~g}, 0.148 \mathrm{mmol})$ and mercury $(0.500 \mathrm{~g})$ were stirred vigorously with $\mathrm{C}_{6} \mathrm{H}_{6}(1 \mathrm{~mL})$. A slurry of $\left(\mathrm{TPB}^{\mathrm{Ph}}\right) \mathrm{FeCl}(0.095 \mathrm{~g}, 0.107$ mmol) in $\mathrm{C}_{6} \mathrm{H}_{6}(10 \mathrm{~mL})$ was added and the reaction mixture stirred for 6 hours at RT. The resulting dark red mixture was filtered and lyophilized $(0.080 \mathrm{~g}, 88 \%)$. Crystals suitable for X-ray analysis were grown by vapor diffusion of diethyl ether into a concentrated THF solution at $-35{ }^{\circ} \mathrm{C} .{ }^{1} \mathrm{H}$ NMR $\left(\mathrm{C}_{6} \mathrm{D}_{6}, \delta\right): 8.38(\mathrm{t}, J=8.4 \mathrm{~Hz}, 2 \mathrm{H}), 7.94(\mathrm{~d}, J=7.4 \mathrm{~Hz}$, $1 \mathrm{H}), 7.85(\mathrm{t}, J=7.3 \mathrm{~Hz}, 2 \mathrm{H}), 7.59$ (ddt, $J=9.6,7.3,3.1 \mathrm{~Hz}, 4 \mathrm{H}), 7.41(\mathrm{~d}, J=7.5 \mathrm{~Hz}$, 1H), 7.31-7.17 (m, 6H), 7.09-6.79 (m, 12H), $6.73(\mathrm{dd}, J=4.4,2.6 \mathrm{~Hz}, 3 \mathrm{H}), 6.60(\mathrm{t}, J=$ $8.6 \mathrm{~Hz}, 2 \mathrm{H}), 6.54-6.42(\mathrm{~m}, 2 \mathrm{H}), 6.33-6.15(\mathrm{~m}, 2 \mathrm{H}), 6.04(\mathrm{t}, J=5.9 \mathrm{~Hz}, 1 \mathrm{H}), 4.42(\mathrm{q}, J=$ $6.7 \mathrm{~Hz}, 1 \mathrm{H}), 4.16(\mathrm{q}, J=5.6 \mathrm{~Hz}, 1 \mathrm{H}), 3.89(\mathrm{~d}, J=6.1 \mathrm{~Hz}, 1 \mathrm{H}), 3.62(\mathrm{q}, J=6.6 \mathrm{~Hz}, 1 \mathrm{H})$. ${ }^{13} \mathrm{C}\left\{{ }^{1} \mathrm{H}\right\}$ NMR $\left(\mathrm{C}_{6} \mathrm{D}_{6}, \delta\right): 160.5(\mathrm{~s}), 145.7(\mathrm{~d}, J=7.0 \mathrm{~Hz}), 144.1(\mathrm{~s}), 143.8(\mathrm{~s}), 142.9(\mathrm{~s})$, $142.5(\mathrm{~s}), 141.9(\mathrm{~s}), 141.5(\mathrm{~s}), 140.9(\mathrm{~s}), 140.6(\mathrm{~s}), 139.8(\mathrm{~s}), 139.7(\mathrm{~s}), 137.7(\mathrm{~s}), 137.4$ (s), $136.0(\mathrm{~d}, J=10.8 \mathrm{~Hz}), 135.6(\mathrm{~s}), 135.2(\mathrm{~m}), 134.8(\mathrm{~s}), 134.6(\mathrm{~s}), 132.9(\mathrm{~m}), 132.3(\mathrm{~d}$, $J=8.7 \mathrm{~Hz}), 132.0(\mathrm{~d}, J=7.3 \mathrm{~Hz}), 130.9(\mathrm{~m}), 129.2(\mathrm{~s}), 129.0(\mathrm{~s}), 128.7(\mathrm{~s}), 126.9(\mathrm{~m})$, $126.3(\mathrm{~d}, J=8.7 \mathrm{~Hz}), 125.9$ (s), 124.3 (s), 123.8 (d, $J=6.6 \mathrm{~Hz}), 123.6$ (d, $J=6.5 \mathrm{~Hz})$, $109.2(\mathrm{~d}, J=15.7 \mathrm{~Hz}), 94.0(\mathrm{~d}, J=14.3 \mathrm{~Hz}), 88.6(\mathrm{~s}), 87.0(\mathrm{~s}), 85.8(\mathrm{~s}), 85.5(\mathrm{~m})$. ${ }^{31} \mathrm{P}\left\{{ }^{1} \mathrm{H}\right\}$ NMR $\left(\mathrm{C}_{6} \mathrm{D}_{6}, \delta\right): 86.1(\mathrm{~d}, J=81.8 \mathrm{~Hz}), 69.8(\mathrm{~d}, J=82.2 \mathrm{~Hz}),-12.1(\mathrm{~s}) .{ }^{11} \mathrm{~B}\left\{{ }^{1} \mathrm{H}\right\}$ $\left(\mathrm{C}_{6} \mathrm{D}_{6}, \delta\right):$ 15.9. Anal. calcd. for $\mathrm{C}_{54} \mathrm{H}_{42} \mathrm{BFeP}_{3}$ : C, 76.26; H, 4.98. Found: $\mathrm{C}, 76.69 ; \mathrm{H}$, 5.59 .

Synthesis of $\left[\left(\mathbf{T P B}^{\mathrm{Cy}}\right) \mathbf{F e}\left(\mathbf{N}_{2}\right)\right]\left[\mathbf{N a}(\mathbf{1 2} \text {-crown-4) })_{2}\right]$, 5.1. Sodium $(0.030 \mathrm{~g}, 1.304 \mathrm{mmol})$ and mercury $(1.0 \mathrm{~g})$ were mixed in a vial with a stir bar. Complex $8(0.137 \mathrm{~g}, 0.150$ 
mmol) was dissolved in THF (10 mL) and added to the freshly prepared $\mathrm{Na} / \mathrm{Hg}$ amalgam. The resulting mixture was vigorously stirred for 1 hour during which time the color of the solution changed from dark brown to a deep red. The solution was then filtered through celite and volatiles were removed in vacuo to yield a red residue. This residue was taken up in $\mathrm{Et}_{2} \mathrm{O}(10 \mathrm{~mL})$ and again filtered through celite to provide a dark red solution. 12crown-4 (0.052 g, $0.297 \mathrm{mmol})$ was added and the resulting solution was allowed to sit, over which time the product precipitated as red crystals. ${ }^{1} \mathrm{H}$ NMR $\left(\mathrm{THF}-\mathrm{d}_{8}, \delta\right): 18.83$ (vbr s), 12.50 (br s), 10.02 (s), 8.01 (vbr s), 7.88 (br s), 5.92 (br s), 5.51 (br s), 4.25 (br s), 3.80 (s, [Na(12-crown-4)2]), 2.15 (br s), 1.66 (br s), 1.51 (br s), 0.97 (vbr s), 0.58 (br s), 0.31 (br s), 0.07 (br s), -1.11 (sh), -3.66 (vbr s). IR (ATR, solid): $v_{\mathrm{NN}}=1905 \mathrm{~cm}^{-1}$. UV-vis (THF, nm $\left.\left\{\mathrm{cm}^{-1} \mathrm{M}^{-1}\right\}\right): 500\{\mathrm{sh}\}, 850\{40\} . \mu_{\mathrm{eff}}\left(\mathrm{THF}-\mathrm{d}_{8}\right.$, Evans method, $\left.20^{\circ} \mathrm{C}\right): 1.6 \mu_{\mathrm{B}}$. Anal. calcd. for $\mathrm{C}_{70} \mathrm{H}_{110} \mathrm{BFeN}_{2} \mathrm{NaO}_{8} \mathrm{P}_{3}$ : C 65.16, $\mathrm{H} 8.59, \mathrm{~N} 2.17$; found: $\mathrm{C} 64.89, \mathrm{H}$ 8.57, N 2.21 .

Synthesis of $\left[\left(\mathbf{T P B}^{\mathrm{Ph}}\right) \mathbf{F e}\left(\mathbf{N}_{2}\right)\right][\mathrm{Na}(\mathbf{1 2}$-crown-4)2], 5.2. Naphthalene $(0.005 \mathrm{~g}, 0.039$ mmol) was weighed into a vial with $\mathrm{Na}(0.01 \mathrm{~g}, 0.435 \mathrm{mmol})$, THF $(2 \mathrm{~mL})$ and a stir bar. The resulting mixture was then vigorously stirred for 2 hours over which time the liquid phase became dark green. The resulting solution of $\mathrm{NaC}_{10} \mathrm{H}_{8}$ was then filtered through a glass fiber filter paper into a $-35^{\circ} \mathrm{C}$ solution of $\mathbf{1 0}(0.030 \mathrm{~g}, 0.035 \mathrm{mmol})$ in THF $(2 \mathrm{~mL})$, which rapidly changed color from orange to dark red. The resulting solution was stirred for an additional 10 minutes before volatiles were removed. The dark red residue was washed $3 \mathrm{x}$ with pentane $(2 \mathrm{~mL})$ and then extracted into $\mathrm{Et}_{2} \mathrm{O}(10 \mathrm{~mL})$ and filtered through celite. The resulting red solution was then treated with 12-crown-4 (0.013 g, $0.074 \mathrm{mmol}$ ) and a fine red powder immediately precipitated. The mixture was allowed 
to stand for 1 hour before the supernatant was decanted and the resulting red solids were washed $3 \mathrm{x}$ with $\mathrm{Et}_{2} \mathrm{O}(2 \mathrm{~mL})$ to yield the title compound as a red powder $(0.029 \mathrm{~g}, 66 \%)$. ${ }^{1} \mathrm{H}$ NMR (THF-d $8, \delta$ ): 11.63 (br s), 9.77 (br s), 8.67 (s), 6.97 (vbr s), 6.04 (sh), 3.67 (s, [Na(12-crown-4) 2$]), 0.35$ (vbr s), $-0.06(\mathrm{~s}),-0.81$ (vbr s). IR (ATR, solid): $v_{\mathrm{NN}}=1988 \mathrm{~cm}^{-}$

1. UV-vis (THF, $\left.\mathrm{nm}\left\{\mathrm{cm}^{-1} \mathrm{M}^{-1}\right\}\right): 500\{\mathrm{sh}\} . \mu_{\mathrm{eff}}$ (THF-d 8 , Evans method, $\left.20{ }^{\circ} \mathrm{C}\right): 1.7 \mu_{\mathrm{B}}$. Complex 2 is unstable to prolonged vacuum which precluded satisfactory combustion analysis.

Synthesis of $\left[(\mathrm{DPB}) \mathrm{Fe}\left(\mathbf{N}_{2}\right)\right]\left[\mathrm{K}(\text { benzo-15-crown-5 })_{2}\right]$, 5.3. A solution of $[(\mathrm{DPB}) \mathrm{Fe}]_{2}(\mu-$ $\left.1,2-\mathrm{N}_{2}\right)(0.025 \mathrm{~g}, 0.023 \mathrm{mmol})$ and $\mathrm{K} / \mathrm{Hg}$ amalgam $(1 \mathrm{~g}, 1 \% \mathrm{~K}$ by weight $)$ in $\mathrm{THF}(1 \mathrm{~mL})$ was stirred at RT for $4 \mathrm{hr}$. The dark red solution was decanted and filtered through glass fiber filter paper onto solid benzo-15-crown-5 (0.026 g, $0.098 \mathrm{mmol})$. Solvent was removed in vacuo and the resulting solids were washed $3 \mathrm{x}$ with $\mathrm{Et}_{2} \mathrm{O}(1 \mathrm{~mL})$ and $\mathrm{C}_{6} \mathrm{H}_{6}(3$ x $1 \mathrm{~mL})$ to give dark solids of $3(0.048 \mathrm{~g}, 0.042 \mathrm{mmol}, 90 \%)$. Single crystals were grown by layering a THF solution with $\mathrm{Et}_{2} \mathrm{O}$ and pentane. ${ }^{1} \mathrm{H}$ NMR $\left(\mathrm{THF}-d_{8}, \delta\right)$ 14.50, 12.05, 6.86 (crown), 6.73 (crown), 3.85 (crown), 3.72 (crown), 2.80, 1.01, -2.72, -4.78. IR (ATR, thin film): $v_{\mathrm{NN}}=1935 \mathrm{~cm}^{-1}$. Anal. calcd. for $\mathrm{C}_{58} \mathrm{H}_{81} \mathrm{BFeKN}_{2} \mathrm{O}_{10} \mathrm{P}_{2}: \mathrm{C} 61.43, \mathrm{H}$ 7.20, N 2.47; found: C 60.09, H 7.33, N 1.71.

Synthesis of [2,6-dimethylanilinium][OTf]. 2,6-dimethylaniline (0.500 g, $4.1 \mathrm{mmol})$ was dissolved in pentane $(10 \mathrm{~mL})$. This solution was then cooled to $-35^{\circ} \mathrm{C}$ before $\mathrm{HOTf}$ (0.619 g, $4.1 \mathrm{mmol})$ was added to the solution with stirring. Upon addition of HOTf, white precipitate formed, and the resulting suspension was allowed to warm to RT and was stirred for 1 hour. After this time, the solids were allowed to settle before the supernatant was decanted off. The solids were then dried under vacuum and 
subsequently washed $3 \mathrm{x}$ with pentane $(5 \mathrm{~mL})$ and $3 \mathrm{x}$ with $\mathrm{Et}_{2} \mathrm{O}(5 \mathrm{~mL})$ to yield the title compound as a white powder $(0.894 \mathrm{~g}, 3.30 \mathrm{mmol}, 80 \%) .{ }^{1} \mathrm{H} \mathrm{NMR}\left(10: 1 \mathrm{CDCl}_{3}\right.$ :DMSO$\left.d_{6}, \delta\right) 7.06$ (vbr s), $6.84(\mathrm{~m}, 3 \mathrm{H}), 2.14(\mathrm{~s}, 6 \mathrm{H})$.

Synthesis of [2,6-dimethylanilinium $]\left[\mathrm{BAr}^{\mathrm{F}_{4}}\right] \cdot \mathbf{1 . 5} \mathbf{E t}_{2} \mathrm{O} .2,6$-dimethylaniline $(0.036 \mathrm{~g}$, $0.296 \mathrm{mmol})$ was dissolved in $\mathrm{Et}_{2} \mathrm{O}(3 \mathrm{~mL})$. To this was added a solution of $\mathrm{HBAr}_{4} \cdot 2$ $\mathrm{Et}_{2} \mathrm{O}(0.300 \mathrm{~g}, 0.296 \mathrm{mmol})$ in $\mathrm{Et}_{2} \mathrm{O}(3 \mathrm{~mL})$ and the resulting clear solution was allowed to stir for 1 hour. After this time, the solution was concentrated to $3 \mathrm{~mL}$ and layered with pentane $(3 \mathrm{~mL})$ and cooled to $-35{ }^{\circ} \mathrm{C}$ for 3 days, over which time white crystals of the product formed $(0.200 \mathrm{~g}, 0.182 \mathrm{mmol}, 62 \%) .{ }^{1} \mathrm{H}$ NMR $\left(\mathrm{C}_{6} \mathrm{D}_{6}, \delta\right) 8.60$ (br s, 3H), 8.24 (s, $8 \mathrm{H}), 7.64(\mathrm{~s}, 4 \mathrm{H}), 6.88(\mathrm{~m}, 1 \mathrm{H}), 6.75(\mathrm{~m}, 2 \mathrm{H}), 3.26(\mathrm{q}, J=7 \mathrm{~Hz}, 6 \mathrm{H}), 1.91(\mathrm{~s}, 6 \mathrm{H}), 1.09$ (t, $J=7 \mathrm{~Hz}, 8 \mathrm{H})$.

\subsubsection{Catalytic Protocols}

Variations on the standard catalytic conditions were performed with the procedures described below. The protocol for the standard catalytic runs can be found in chapter 4. Ammonia collection and quantification was also performed as previously described in chapter $4 .{ }^{30}$ All data for individual runs can be found in Appendix 4. Runs with $\left[\left(\mathrm{TPB}^{\mathrm{Cy}}\right) \mathrm{Fe}\left(\mathrm{N}_{2}\right)\right]\left[\mathrm{Na}\left(12-\right.\right.$ crown-4) $\left._{2}\right]($ 5.1) as precursor. The procedure was identical to that of the standard catalytic protocol with the changes noted. The precursor used was $\left[\left(\mathrm{TPB}^{\mathrm{Cy}}\right) \mathrm{Fe}\left(\mathrm{N}_{2}\right)\right]\left[\mathrm{Na}(12-\mathrm{crown}-4)_{2}\right](2.5 \mathrm{mg}, 0.002 \mathrm{mmol})$, which is a dark red solid.

Runs with $\left[\left(\mathrm{TPB}^{\mathrm{Ph}}\right) \mathrm{Fe}\left(\mathrm{N}_{2}\right)\right]\left[\mathrm{Na}\left(12-\right.\right.$ crown-4$\left._{2}\right]$ (5.2) as precursor. The procedure was identical to that of the standard catalytic protocol with the changes noted. The precursor 
used was $\left[\left(\mathrm{TPB}^{\mathrm{Ph}}\right) \mathrm{Fe}\left(\mathrm{N}_{2}\right)\right]\left[\mathrm{Na}(12-\text { crown-4) })_{2}\right](2.5 \mathrm{mg}, 0.002 \mathrm{mmol})$, which is a dark red solid.

Runs with [(DPB)Fe(N2)][K(Bz15-crown-5)2] (5.3) as precursor. The procedure was identical to that of the standard catalytic protocol with the changes noted. The precursor used was $\left[\left(\mathrm{TPB}^{\mathrm{Ph}}\right) \mathrm{Fe}\left(\mathrm{N}_{2}\right)\right]\left[\mathrm{Na}(12-\text { crown-4) })_{2}\right](2.3 \mathrm{mg}, 0.002 \mathrm{mmol})$, which is a dark red solid.

Runs with $\left[\left(\mathrm{SiPiPr}_{3}\right) \mathrm{Fe}\left(\mathrm{N}_{2}\right)\right][\mathrm{Na}(12-$-crown-4)2 $]$ (5.4) as precursor. The procedure was identical to that of the standard catalytic protocol with the changes noted. The precursor used was $\left[\left(\mathrm{SiP}_{3}^{\mathrm{iPr}}\right) \mathrm{Fe}\left(\mathrm{N}_{2}\right)\right]\left[\mathrm{Na}(12 \text {-crown-4) })_{2}\right](2 \mathrm{mg}, 0.002 \mathrm{mmol})$, which is a dark purple solid.

Runs with $\left[\left(\mathrm{PhBP}^{\mathrm{iPr}}{ }_{3}\right) \mathrm{Fe}\left(\mathbf{N}_{2}\right)\right]\left[\mathrm{MgCl}(\mathrm{THF})_{2}\right]$ (5.5) as precursor. The procedure was identical to that of the standard catalytic protocol with the changes noted. The precursor used was $\left[\left(\mathrm{PhBP}^{\mathrm{iPr}}{ }_{3}\right) \mathrm{Fe}\left(\mathrm{N}_{2}\right)\right]\left[\mathrm{MgCl}(\mathrm{THF})_{2}\right](1.4 \mathrm{mg}, 0.002 \mathrm{mmol})$, which is a brown solid. Note that the solution became homogeneous with no substantial color change upon addition of acid.

Runs with $\left(\mathrm{C}_{2} \mathrm{H}_{4} \mathrm{PCy}\right)_{3} \mathrm{PFe}\left(\mathbf{N}_{2}\right)$ (5.6) as precursor. The procedure was identical to that of the standard catalytic protocol with the changes noted. The precursor used was $\left(\mathrm{C}_{2} \mathrm{H}_{4} \mathrm{PCy}\right)_{3} \mathrm{PFe}\left(\mathrm{N}_{2}\right)(2.4 \mathrm{mg}, 0.003 \mathrm{mmol})$, which is an orange solid. Note that the solution became homogeneous with no substantial color change upon addition of acid. Runs with (depe) ${ }_{2} \mathrm{Fe}\left(\mathbf{N}_{2}\right)$ as precursor. The procedure was identical to that of the standard catalytic protocol with the changes noted. The precursor used was (depe) ${ }_{2} \mathrm{Fe}\left(\mathrm{N}_{2}\right)$ ( $1 \mathrm{mg}, 0.002 \mathrm{mmol})$, which is a dark red solid. Note that the solution became homogeneous with no significant color change upon addition of acid. 
Runs with $\mathrm{iPr}_{2} \mathrm{O}$ as solvent. The procedure was identical to that of the standard catalytic protocol with the changes noted. The solvent used was $\operatorname{iPr}_{2} \mathrm{O}$. The solubility of the reagents was similar to that observed in $\mathrm{Et}_{2} \mathrm{O}$.

Runs with DME as solvent. The procedure was identical to that of the standard catalytic protocol with the changes noted. The solvent used was DME. Complex 4.1 dissolved in the DME to form a red solution which turned yellow upon addition of the acid.

Runs with $\mathrm{Bu}_{2} \mathrm{O}$ as solvent. The procedure was identical to that of the standard catalytic protocol with the changes noted. The solvent used was $\mathrm{Bu}_{2} \mathrm{O}$. While complex 4.1 and $\mathrm{KC}_{8}$ were similarly insoluble in $\mathrm{Bu}_{2} \mathrm{O}$ as in $\mathrm{Et}_{2} \mathrm{O}, \mathrm{HBAr}^{\mathrm{F}} \cdot 2 \mathrm{Et}_{2} \mathrm{O}$ was only sparingly soluble in $\mathrm{Bu}_{2} \mathrm{O}$ and was added as a suspension.

Runs with toluene as solvent. The procedure was identical to that of the standard catalytic protocol with the changes noted. The solvent used was toluene. While complex 4.1 and $\mathrm{KC}_{8}$ were similarly insoluble in toluene as in $\mathrm{Et}_{2} \mathrm{O}, \mathrm{HBAr}_{4} \cdot 2 \mathrm{Et}_{2} \mathrm{O}$ was also insoluble and was added as a suspension. Notably, the bronze color associated with $\mathrm{KC}_{8}$ persisted for much longer during these runs.

Runs with 1:6 Et2O:Toluene as solvent. The procedure was identical to that of the standard catalytic protocol with the changes noted. The solvent used was a 1:6 mixture of $\mathrm{Et}_{2} \mathrm{O}$ :toluene. While complex 4.1 and $\mathrm{KC}_{8}$ were similarly insoluble in $\mathrm{Bu}_{2} \mathrm{O}$ as in $\mathrm{Et}_{2} \mathrm{O}$, $\mathrm{HBAr}_{4}{ }_{4} \cdot 2 \mathrm{Et}_{2} \mathrm{O}$ was only sparingly soluble in $\mathrm{Bu}_{2} \mathrm{O}$ and was added as a suspension. Runs with $\mathrm{CoCp}_{2}{ }_{2}$ as reductant. The procedure was identical to that of the standard catalytic protocol with the changes noted. The reductant used was decamethylcobaltocene, $\mathrm{CoCp}^{*}{ }_{2},(19 \mathrm{mg}, 0.058 \mathrm{mmol})$, which was added as a solid. A 
heterogeneous mixture resulted at $-78{ }^{\circ} \mathrm{C}$ that homogenized at $\mathrm{RT}$, producing a yellow solution.

Runs with $\mathrm{CrCp}_{2}{ }_{2}$ as reductant. The procedure was identical to that of the standard catalytic protocol with the changes noted. The reductant used was

decamethylchromocene, $\mathrm{CrCp}_{2}{ }_{2},(20 \mathrm{mg}, 0.062 \mathrm{mmol})$, which was added as a solid. The resulting suspension darkened before gradually returning to a yellow color.

Runs with $\mathrm{NaC}_{10} \mathrm{H}_{8}$ as reductant. The procedure was identical to that of the standard catalytic protocol with the changes noted. The reductant used was a freshly prepared solution of $\mathrm{NaC}_{10} \mathrm{H}_{8}$, which was made by stirring a solution of naphthalene (13 mg, $0.101 \mathrm{mmol})$ in THF $(1 \mathrm{~mL})$ over $\mathrm{Na}(10 \mathrm{mg}, 0.435 \mathrm{mmol})$ for two hours. This solution was then filtered through a glass fiber filter paper directly into the catalytic mixture which turned red upon addition of the reductant before gradually fading to yellow. Runs with $\mathbf{K}$ as reductant. The procedure was identical to that of the standard catalytic protocol with the changes noted. The reductant used was $\mathrm{K}$ metal $(4 \mathrm{mg}, 0.1 \mathrm{mmol})$, which was added as a solid. The reaction mixture was allowed to stir at $-78{ }^{\circ} \mathrm{C}$ for 40 minutes and was then warmed slowly to RT overnight. After this time, a pale red-orange solution was present. Longer reaction times were employed to ameliorate the effect of the small surface area of the $\mathrm{K}$ metal.

Runs with $\mathrm{MgC}_{14} \mathrm{H}_{10} \cdot 3 \mathrm{THF}$ as reductant. The procedure was identical to that of the standard catalytic protocol with the changes noted. The reductant used was $\mathrm{MgC}_{14} \mathrm{H}_{10} \cdot 3$ THF (20 mg, $0.048 \mathrm{mmol}$ ), which is a yellow-orange solid. The reductant is insoluble in $\mathrm{Et}_{2} \mathrm{O}$ and was added as a suspension. The solution gradually became more homogeneous over the 40 minute reaction time. 
Runs with $10 \% \mathrm{Na}$ by weight $\mathrm{Na} / \mathrm{Hg}$ as reductant. The procedure was identical to that of the standard catalytic protocol with the changes noted. The reductant used was $\mathrm{Na} / \mathrm{Hg}$ (10\% Na by weight) $\left(280 \mathrm{mg}, 1.217 \mathrm{mmol}\right.$ ), a dark grey solid which is insoluble in $\mathrm{Et}_{2} \mathrm{O}$ and was added as a solid. The solution stayed heterogeneous and no noticeable color change was observed over the course of the reaction. The larger excess of $\mathrm{Na} / \mathrm{Hg}$ was employed to help ameliorate the low surface area of the reductant.

Runs with trifluoromethanesulfonic acid as acid. The procedure was identical to that of the standard catalytic protocol with the changes noted. The acid used was trifluoromethanesulfonic acid $\left(131 \mu \mathrm{L}\right.$ of a $0.7 \mathrm{M}$ solution in $\left.\mathrm{Et}_{2} \mathrm{O}, 0.092 \mathrm{mmol}\right)$, which was added without further dilution. The red suspension turned light yellow-green and homogenized upon addition of acid.

Runs with HCl as acid. The procedure was identical to that of the standard catalytic protocol with the changes noted. The acid used was anhydrous $\mathrm{HCl}(46 \mu \mathrm{L}$ of a $2.0 \mathrm{M}$ solution in $\mathrm{Et}_{2} \mathrm{O}, 0.092 \mathrm{mmol}$ ), which was added without further dilution. The red suspension turned light yellow upon addition of acid, and subsequently precipitated a fine yellow solid. All subsequent manipulations were carried out with this suspension. Runs with [Lutidinium][BAr ${ }^{\left.\mathbf{F}_{4}\right]}$ as acid. The procedure was identical to that of the standard catalytic protocol with the changes noted. The acid used was [Lutidinium][BAr ${ }_{4}^{\mathrm{F}}$ ] $(90 \mathrm{mg}, 0.092 \mathrm{mmol})$.

Runs with [2,6-dimethylanilinium] $\left[\mathrm{BAr}^{\mathrm{F}}{ }_{4}\right] \cdot 1.5 \mathrm{Et}_{2} \mathrm{O}$ as acid. The procedure was identical to that of the standard catalytic protocol with the changes noted. The acid used was [2,6-dimethylanilinium] $\left[\mathrm{BAr}^{\mathrm{F}}{ }_{4}\right] \cdot 1.5 \mathrm{Et}_{2} \mathrm{O}(100 \mathrm{mg}, 0.092 \mathrm{mmol})$. 
Runs with [2,6-dimethylanilinium][OTf] as acid. The procedure was identical to that of the standard catalytic protocol with the changes noted. The acid used was [2,6dimethylanilinium][OTf] (25 mg, $0.092 \mathrm{mmol})$. The acid was only sparingly soluble in $\mathrm{Et}_{2} \mathrm{O}$ and was added as a suspension. Upon addition, complex $\mathbf{4 . 1}$ dissolved and the solution color became yellow.

Runs at RT. The procedure was identical to that of the standard catalytic protocol with the changes noted. All manipulations were performed analogously to the standard conditions at RT.

Runs at $-110{ }^{\circ} \mathbf{C}$. The procedure was identical to that of the standard catalytic protocol with the changes noted. All manipulations were performed analogously to the standard conditions at $-110{ }^{\circ} \mathrm{C}$. Temperature control was achieved with a liquid $\mathrm{N}_{2} / \mathrm{EtOH}$ cold bath cooling the cold well of a glove box. The temperature was monitored with a thermocouple inside the cold well.

Run with $[$ TBA $][$ CN] added. The procedure was identical to that of the standard catalytic protocol with the changes noted. [TBA] [CN] $(0.01 \mathrm{~g}, 0.037 \mathrm{mmol})$ was added immediately after addition of $\mathrm{KC}_{8}$ and the solution was then allowed to warm to room temperature before being worked up via the standard protocol. Absorbance: 0.294, Equiv $\mathrm{NH}_{3} / \mathrm{Fe}: 3.50, \%$ Yield: 21.9.

Run with $\boldsymbol{t}$-BuNC added. The procedure was identical to that of the standard catalytic protocol with the changes noted. $t$-BuNC $(0.01 \mathrm{~g}, 0.12 \mathrm{mmol})$ was added immediately after addition of $\mathrm{KC}_{8}$ and the solution was then allowed to warm to room temperature before being worked up via the standard protocol. Absorbance: 0.140, Equiv $\mathrm{NH}_{3} / \mathrm{Fe}$ : 1.67, \% Yield: 10.4 


\section{References Cited}

1 Anderson, J. S.; Rittle, J.; Peters, J. C. Nature 2013, in press, DOI:

10.1038/nature12435.

2 (a) Yandulov, D. V.; Schrock, R. R. Science 2003, 301, 76-78; (b) Arashiba, K.;

Miyake, Y.; Nishibayashi, Y. Nature Chem. 2011, 3, 120-125; (c) Schrock, R. R.

Nature Chem. 2011, 3, 95-96.

3 (a) Dos Santos, P. C.; Igarashi, R. Y.; Lee, H. I.; Hoffman, B. M.; Seefeldt, L. C.; Dean,

D. R. Acc. Chem. Res. 2005, 38, 208-214; (b) Hoffman, B. M.; Dean, D. R.; Seefeldt,

L. C. Acc. Chem. Res. 2009, 42, 609-619; (c) Seefeldt, L. C.; Hoffman, B. M.; Dean, D.

R. Annu. Rev. Biochem. 2009, 78, 701-722; (d) Doan, P. E.; Telser, J.; Barney, B. M.;

Igarashi, R. Y.; Dean, D. R.; Seefeldt, L. C.; Hoffman, B. M. J. Am. Chem. Soc. 2011, 133, 17329-17340.

4 Suess, D.L.M. Dissertation, California Institute of Technology, Pasadena 2013.

5 Lee, Y.; Mankad, N. P.; Peters, J. C. Nat Chem 2010, 2, 558-565.

6 Betley, T. A.; Peters, J. C. J. Am. Chem. Soc. 2003, 125, 10782-10783.

7 Gilbert-Wilson, R.; Field, L. D.; Colbran, S. B.; Bhadbhade, M. M. Inorg. Chem. 2013, $52,3043-3053$.

8 Komiya, S.; Akita, M.; Yoza, A.; Kasuga, N.; Fukuoka, A.; Kai, Y. Chem. Comm. 1993, 787-788.

9 Kameo, H; Hashimoto, Y.; Nakazawa, H. Organometallics 2012, 31, 3155-3162

10 Tolman, C. A. Chem. Rev. 1977, 77, 313-348.

11 Bontemps, S.; Gornitzka, H.; Bouhadir, G.; Miqueu, K.; Bourissou, D. Angew. Chem. Int. Ed. 2006, 45, 1611-1614. 
12 Suess, D. L. M.; Peters, J. C. J. Am. Chem. Soc. 2013, 135, 4938-4941.

13 Bontemps, S.; Bouhadir, G.; Dyer, P. W.; Miqueu, K.; Bourissou, D. Inorg. Chem. 2007, 46, 5149-5151.

14 MacMillan, S.N. Dissertation, California Institute of Technology, Pasadena 2013.

15 Cable, R. A.; Green, M.; Mackenzie, R. E.; Timms, P. L.; Turney, T. W. J. Chem. Soc., Chem. Commun. 1976, 270b-271.

16 (a) Mankad, N. P.; Whited, M. T.; Peters, J. C. Angew. Chem. Int. Ed. 2007, 46, 57685771; (b) Whited, M. T.; Mankad, N. P.; Lee, Y.; Oblad, P. F.; Peters, J. C. Inorg. Chem. 2009, 48, 2507-2517; (c) Mankad, N. P.; Müller, P.; Peters, J. C. J. Am. Chem. Soc. 2010, 132, 4083-4085.

17 (a) Moret, M.-E.; Peters, J. C. Angew. Chem. Int. Ed. 2011, 50, 2063-2067; (b) Moret, M.-E.; Peters, J. C. J. Am. Chem. Soc. 2011, 133, 18118-18121.

18 Leigh, G. J.; Jimenez-Tenorio, M. J. Am. Chem. Soc. 1991, 113, 5862-5863; (b)

Leigh, G. J. Acc. Chem. Res. 1992, 25, 177-181; (c) Hills, A.; Hughes, D. L.; Jimenez-

Tenorio, M.; Leigh, G. J.; Rowley, A. T. J. Chem. Soc., Dalton 1993, 3041-3049; (d)

Crossland, J. L.; Tyler, D. R. Coord. Chem. Rev. 2010, 254, 1883-1894.

19 Chrystiuk, E.; Williams, A. J. Am. Chem. Soc. 1987, 109, 3040-3046.

20 Beale, R. N. J. Chem. Soc. 1954, 4494-4499.

21 Ritleng, V.; Yandulov, D. V.; Weare, W. W.; Schrock, R. R.; Hock, A. S.; Davis, W. M. J. Am. Chem. Soc. 2004, 126, 6150-6163.

22 Kinoshita, E.; Arashiba, K.; Kuriyama, S.; Miyake, Y.; Shimazaki, R.; Nakanishi, H.;

Nishibayashi, Y. Organometallics 2012, 31, 8437-8443.

23 Creutz S.E.; Peters, J.C. J. Am. Chem. Soc. 2013. 
24 Freeman, P. K.; Hutchinson, L. L. The Journal of Organic Chemistry 1983, 48, 879881.

25 Murata, M.; Buchwald, S. L. Tetrahedron 2004, 60, 7397-7403.

26 Brookhart, M.; Grant, B.; Volpe, A. F. Organometallics 1992, 11, 3920-3922.

27 Sheldrick, G. M. Acta Cryst. 1990, A46, 467.

28 Sheldrick, G. M. Acta Cryst. 2004, A64, 112.

29 Müller, P. Crystallography Reviews 2009, 15, 57.

30 Weatherburn, M. W. Anal. Chem. 1967, 39, 971-974. 
Chapter 6: Spectroscopic Characterization of the Putative Catalytic Intermediate $\left[(\mathrm{TPB}) \mathrm{Fe} \equiv \mathrm{N}-\mathrm{NH}_{2}\right]\left[\mathrm{BAr}^{\mathrm{F}}\right]$ 


\subsection{Introduction}

A primary goal of using synthetic model complexes as a tool to study biological $\mathrm{N}_{2}$ fixation is to gain insight into feasible mechanisms or intermediates en route to $\mathrm{NH}_{3}$ formation. While information gained in a molecular system can be difficult to extrapolate to an enzyme, general trends in reactivity can be established. In order to draw any comparisons, however, studies on the mechanism of model systems must be performed. Very little is known about the mechanism of the catalytic system described in chapters 4 and $5,{ }^{1}$ and there is a great deal of interest in elucidating potential intermediates and pathways in this process. Previous synthetic work on Mo has outlined a "distal" mechanism, wherein protons are sequentially added to one nitrogen atom along with electrons to release $\mathrm{NH}_{3}$ and form a metal nitride which is then protonated and reduced to release $\mathrm{NH}_{3} .{ }^{2}$ Alternately, some of the spectroscopic and enzymatic studies on nitrogenase that have implicated $\mathrm{Fe}$ as the binding site of $\mathrm{N}_{2}$ have also supported a different "alternating" mechanism wherein protons are alternately added to the $\beta$ and the $\alpha$ nitrogens. $^{3}$

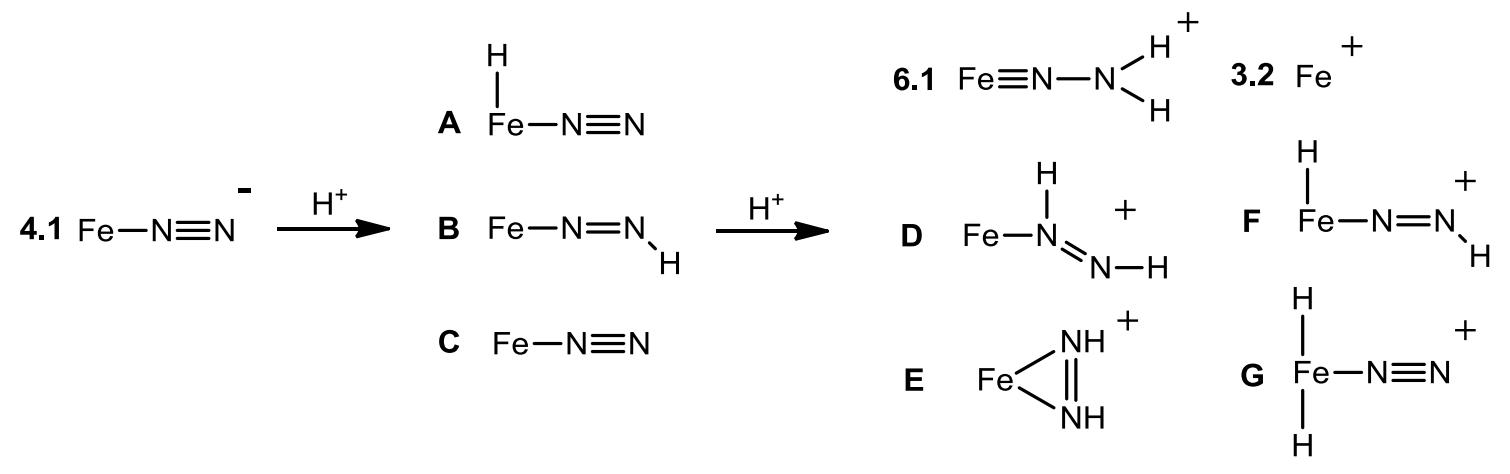

Scheme 6.1. Considered (TPB)Fe protonation products on from the reaction of 4.1 with acid. 
Although synthetic examples of Fe complexes and their reactivity supporting both "distal" and "alternating" mechanisms have been reported, ${ }^{4,5}$ none of these examples have come from a system that actually catalyzes $\mathrm{N}_{2}$ reduction. Presented here are initial studies directed towards the identification of a thermally unstable potential intermediate that is generated by the addition of excess acid to the pre-catalyst $\left[(\mathrm{TPB}) \mathrm{Fe}\left(\mathrm{N}_{2}\right)\right][\mathrm{Na}(12-$ crown-4) $)_{2}$ (4.1) at low temperatures. There are a number of reasonable products of protonation (Scheme 6.1), but combined EPR, ENDOR, XAS, and computational studies suggest that this species is likely the doubly protonated hydrazido(2-) complex $\left.\left[(\mathrm{TPB}) \mathrm{Fe} \equiv \mathrm{N}-\mathrm{NH}_{2}\right)\right]\left[\mathrm{BAr}_{4}{ }_{4}\right](\mathbf{6 . 1})$. While this intermediate has not been observed under turnover, the conditions for its generation map closely with the catalytic conditions and it can be observed in mixtures prior to the addition of reductant for catalysis. Taken together, these combined observations suggest that this doubly protonated species is likely an intermediate en route to $\mathrm{NH}_{3}$ formation.

\subsection{Results and Discussion}

\subsubsection{EPR Studies}

As mentioned in chapter 3, (TPB)Fe complexes are shifted by one electron from their $\left(\mathrm{SiP}_{3}\right)$ congeners, which in many cases makes them EPR active. For example, complex [(TPB)Fe( $\left.\left.\mathrm{N}_{2}\right)\right][\mathrm{Na}(12$-crown-4) 2$](4.1)$ is $S=1 / 2$ and displays an apparent axial spectrum in its 77K EPR spectrum (Figure 6.1A). Furthermore, silylation of the $\beta \mathrm{N}$ of 4.1 results in the formation of (TPB) $\mathrm{FeN}_{2} \mathrm{SiMe}_{3}$, which also displays an apparent axial signal in its 20K EPR spectrum (Figure 6.1B) which is substantially different that that observed for 4.1. These complexes contrast with the species characterized in Chapter 3 
which were high spin and displayed very different EPR signatures. These combined results indicate EPR spectroscopy should be an attractive method for monitoring whether successful protonation is occurring at $\mathbf{4 . 1}$ as opposed to effective oxidation of the metal, which would result in an EPR silent species.
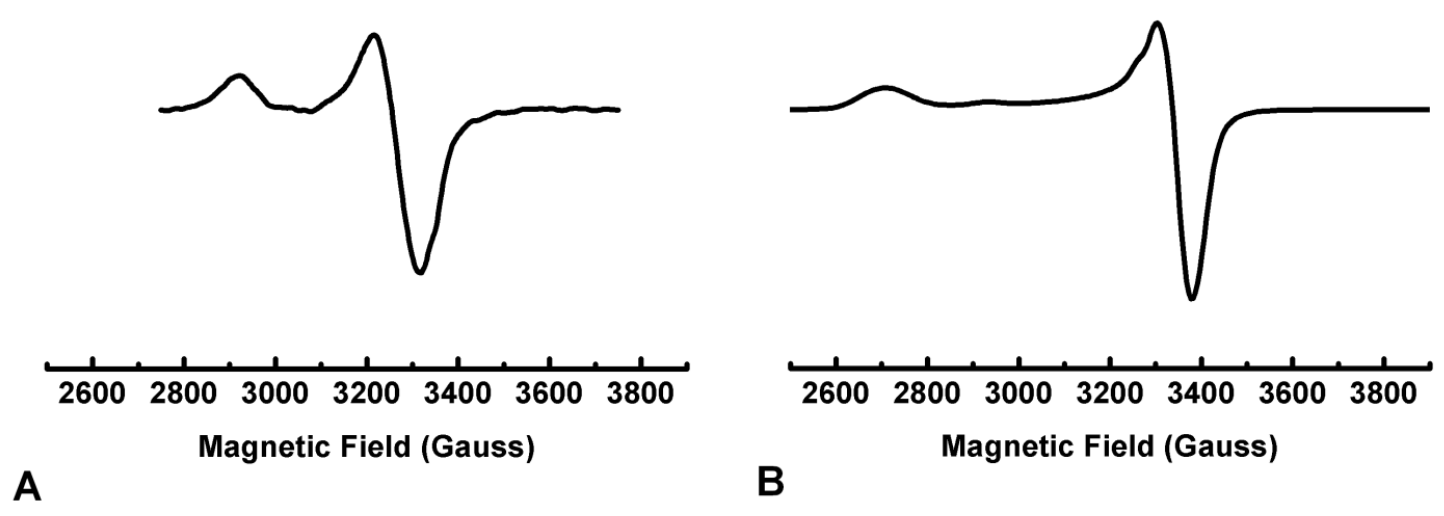

Figure 6.1. X-Band EPR spectra of: (A) Complex 4.1 and (B) (TPB)FeN $\mathrm{F}_{2} \mathrm{SiMe}_{3}$. Conditions for (A) $77 \mathrm{~K}, 2-\mathrm{MeTHF}, 9.39 \mathrm{GHz}$. Conditions for (B) $20 \mathrm{~K}$, toluene, 9.38 GHz.

Mixing of 4.1 and 10 equivalents of $\mathrm{HBAr}^{\mathrm{F}}{ }_{4} \cdot 2 \mathrm{Et}_{2} \mathrm{O}$ in thawing 2-MeTHF solutions at $-140{ }^{\circ} \mathrm{C}$ resulted in the disappearance of the dark red color characteristic of 4.1 and the formation of a brown-yellow solution. Analysis by X-band EPR indicates complete consumption of $\mathbf{4 . 1}$ and formation of a new distinctly rhombic $S=1 / 2$ signal (Figure 6.2A) at $77 \mathrm{~K}$ that was assigned as a new species (6.1). This signal can be generated with as little as 2 equivalents of acid, however, the use of 1 equivalent of acid results in no formation of $\mathbf{6 . 1}$ as judged by EPR spectroscopy (Appendix 5). A wider scan at $10 \mathrm{~K}$ reveals no significant amount of higher spin products being formed (6.2B). A simulation of the spectrum (6.2A) reveals $g$ values of $g_{1}=2.221, g_{2}=2.090, g_{3}=2.006$ 
and poorly resolved hyperfine coupling that has been simulated as coupling to two independent $\mathrm{H}$ atoms with coupling constants of 56 and $38 \mathrm{MHz}$. Interestingly, the spectrum of 6.1 is shows distinctly enhanced rhombicity when compared with $\mathbf{4 . 1}$ and (TPB)FeN $\mathrm{SiMe}_{3}$. The fact that (TPB)FeN $\mathrm{SiMe}_{3}$ displays a much more axial spectrum than 6.1 suggests that these two species are electronically different and that the rhombic spectrum may not belong to a diazenido (Scheme 6.1B) species.

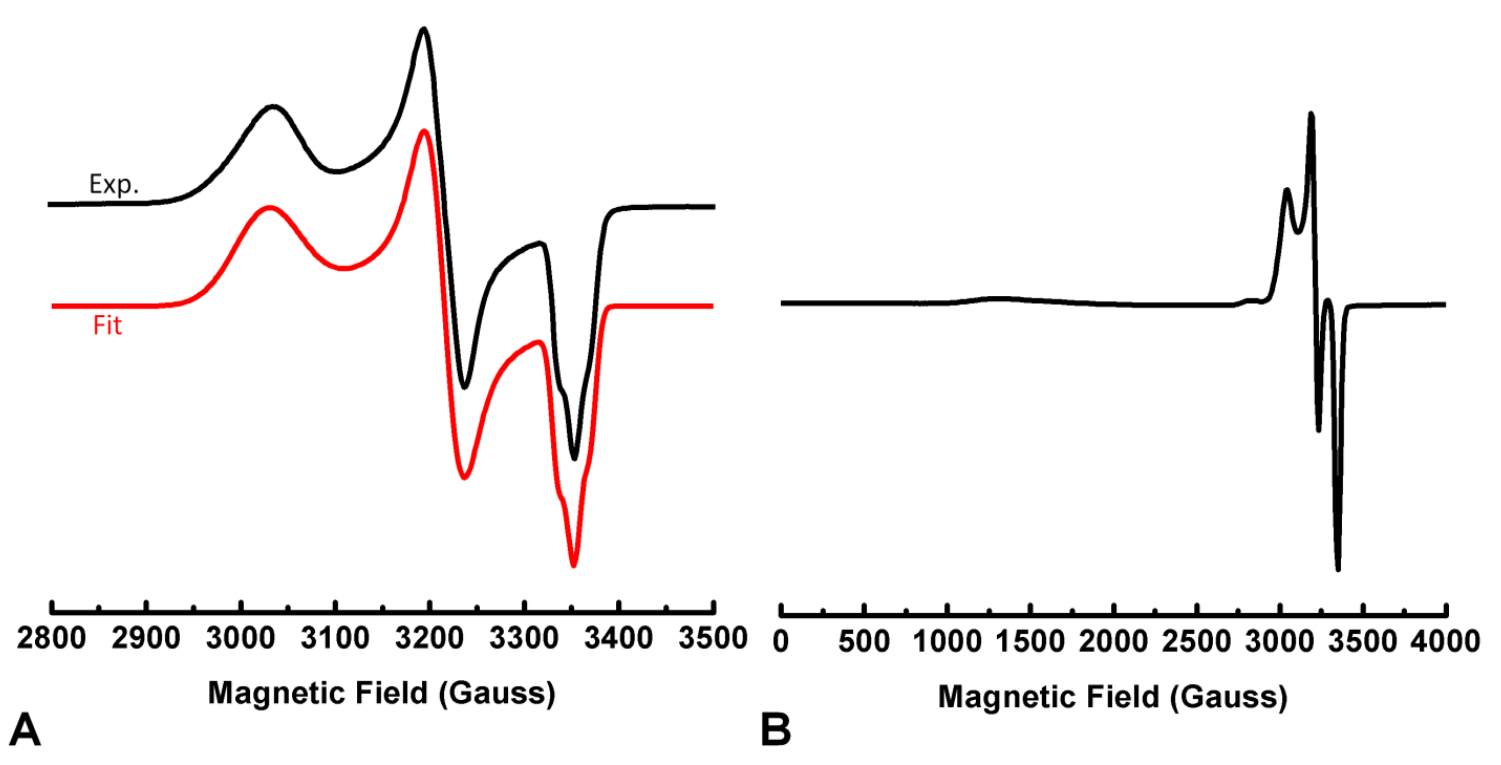

Figure 6.2. X-Band EPR spectra of the species generated from adding excess $\mathrm{HBAr}_{4} \mathrm{~F}_{4} 2$ $\mathrm{Et}_{2} \mathrm{O}$ to 4.1. (A) Scan from 2800 to 2500 gauss (B) Scan from 0 to $4000 \mathrm{G}$. Conditions: (A) $77 \mathrm{~K}$ (B) $10 \mathrm{~K}, 2-\mathrm{MeTHF}, 9.38 \mathrm{GHz}$. Fit parameters: $g_{1}=2.221, g_{2}=2.090, g_{3}=$ 2.006, $\mathrm{A}^{\mathrm{H} 1}=56 \mathrm{MHz}, \mathrm{A}^{\mathrm{H} 2}=38 \mathrm{MHz}$.

If 6.1 is not a diazenido complex, then a few alternate scenarios are feasible. Single oxidation of $\mathbf{4 . 1}$ and concomitant formation of $\mathrm{H}_{2}$ would lead to the known integer spin species (TPB)Fe( $\left.\mathrm{N}_{2}\right)$ (Scheme 6.1C) while net $2 \mathrm{e}^{-}$oxidation would lead to the known cation $[(\mathrm{TPB}) \mathrm{Fe}]\left[\mathrm{BAr}_{4}{ }_{4}\right]($ Scheme $6.1,3.2)$ which is $S=3 / 2$ and displays a distinctly different EPR spectrum from that observed for 6.1. These observations 
eliminate these simple oxidation products and suggest that protonated products should be considered. In one scenario, protonation at the metal could be occurring to generate an Fe-H, potentially with $\mathrm{N}_{2}$ bound (Scheme 6.1A). Some examples of (TPB)Fe hydrides have already been explored, and no evidence for any EPR active hydride species was observed in this work. ${ }^{6}$ Regardless, protonation at the metal center is possible and cannot be excluded on the basis of the EPR data alone. Another possibility is that two protons have been transferred to the $\mathrm{N}_{2}$ ligand, either with both protons at the $\beta \mathrm{N}$ or with one proton on each of the $\mathrm{N}$ atoms. Precedence for double protonation at the $\beta \mathrm{N}$ was demonstrated early in Mo $\mathrm{N}_{2}$ complexes, ${ }^{7}$ and so this initial hypothesis was targeted as a starting point for further investigations.

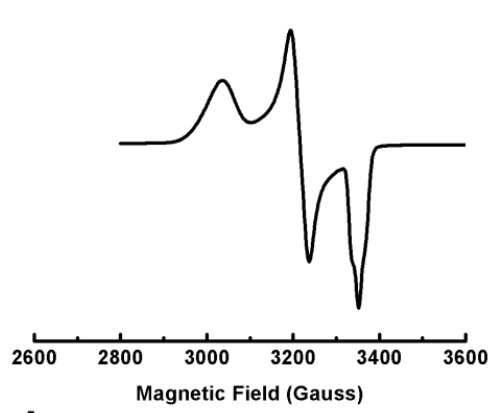

A Magnetic Field (Gauss)

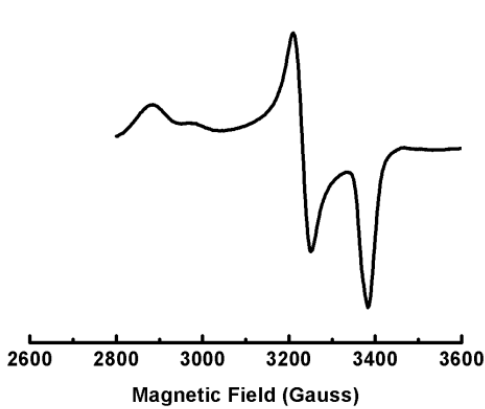

B

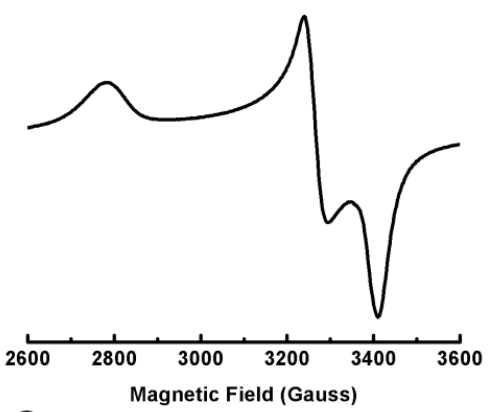

C

Figure 6.3. $X-B$ and EPR spectra of (A) 6.1, (B) $\left[(\mathrm{TPB}) \mathrm{Fe} \equiv \mathrm{N}\left(\mathrm{C}_{6} \mathrm{H}_{4} \mathrm{OMe}\right)\right]^{+}$, and $(\mathrm{C})$ [(TPB)Fe $\equiv \mathrm{NAd}]\left[\mathrm{BAr}^{\mathrm{F}}\right.$ ] . Conditions for all: $77 \mathrm{~K}, 2-\mathrm{MeTHF},(\mathrm{A}) 9.38 \mathrm{GHz},(\mathrm{B}) 9.40$ $\mathrm{GHz},(\mathrm{C}) 9.42 \mathrm{GHz}$.

Such a putative hydrazido(2-) structure for $\mathbf{6 . 1}$ should possess a multiply bonded Fe- $\mathrm{N}$ interaction, similar to that observed in related silylated $\mathrm{N}_{2}$ complexes on (TPB)Fe. $4^{\mathrm{d}}$ As such, it seemed that $\mathbf{6 . 1}$ should electronically resemble formally Fe(III) 
imide species. In order to test this hypothesis, EPR spectra of complexes with related electronic structures were obtained (Figure 6.3). Initially, the known imide complex $(\mathrm{TPB}) \mathrm{Fe} \equiv \mathrm{N}\left(\mathrm{C}_{6} \mathrm{H}_{4} \mathrm{OMe}\right)$ was oxidized with $[\mathrm{Fc}]\left[\mathrm{BAr}^{\mathrm{F}}{ }_{4}\right]$ in situ to generate a rhombic signal very similar to that observed in 6.1. More recently, the stable cationic imide $[(\mathrm{TPB}) \mathrm{Fe} \equiv \mathrm{NAd}]\left[\mathrm{BAr}_{4}^{\mathrm{F}}\right]$ has been isolated and also displays an EPR signal that is very similar to that observed in 6.1. Furthermore, spin quantitation of the signal from 6.1 against samples of both $[(\mathrm{TPB}) \mathrm{Fe} \equiv \mathrm{NAd}]\left[\mathrm{BAr}_{4}{ }_{4}\right]$ and 4.1 indicates that the new rhombic signal is formed in a $\sim 80 \%$ yield, suggesting a relatively high conversion to this new species. Qualitatively, these EPR spectra support the structural assignment of $\mathbf{6 . 1}$ as $\left[(\mathrm{TPB}) \mathrm{Fe} \equiv \mathrm{N}-\mathrm{NH}_{2}\right]\left[\mathrm{BAr}{ }_{4}{ }_{4}\right]$, but additional experiments were needed to validate the presence of a hydrazido(2-) structural unit.

\subsubsection{ENDOR Studies}

ENDOR spectroscopy has been a technique that has been used effectively to discern information about some paramagnetic species observed in the FeMoco as well as in model complexes. ${ }^{8}$ This technique involves a 2-D correlation between EPR and NMR spectroscopies, where an EPR transition is saturated and the coupling of this transition to

nearby NMR active nuclei, such as ${ }^{1} \mathrm{H}$ or ${ }^{15} \mathrm{~N}$, is observed. As such, this technique allows for greater structural information than would be provided by EPR alone. Specifically, this technique will allow for the observation of the nuclei corresponding to a nitrogenous ligand on Fe. Through a collaboration with the Hoffman lab at Northwestern University, multi-nuclear ENDOR data have been collected on 4.1 and 6.1 and some of their isotopically labeled congeners. 

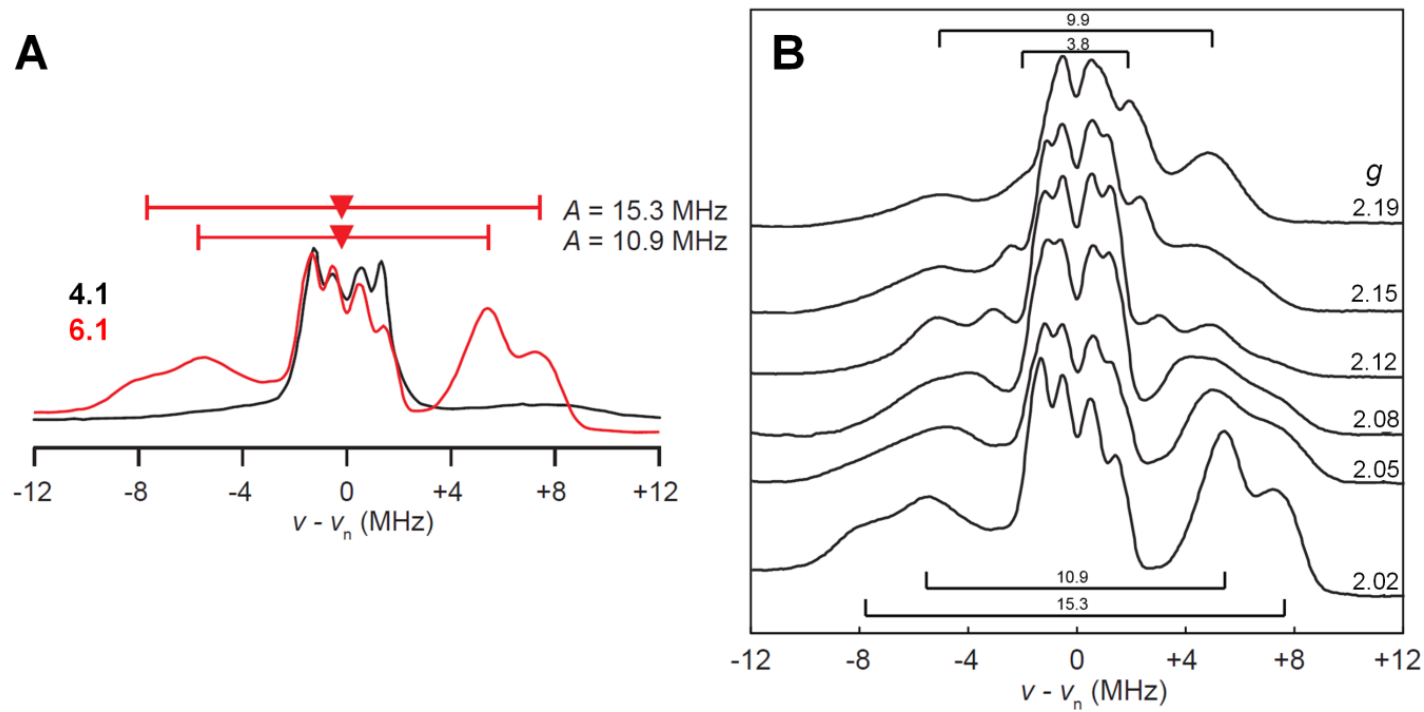

Figure 6.4. (A) Proton CW-ENDOR at $12.4 \mathrm{kG}$ and $35.24 \mathrm{GHz}$ of 4.1 (black) and 6.1 (red). (B) $35.01 \mathrm{GHz}$ CW-ENDOR of $\mathbf{6 . 1}$ at the variable fields shown.

${ }^{1} \mathrm{H}$ ENDOR spectroscopy should be especially useful in identifying any protonation intermediates, as this technique allows for the direct observation of ${ }^{1} \mathrm{H}$ nuclei coupling with the unpaired spin. As such, this data was obtained on both 4.1 and $\mathbf{6 . 1}$ (Figure 6.4A). The spectrum of $\mathbf{4 . 1}$ shows only very weak couplings of $<3 \mathrm{MHz}$, which likely arise from ${ }^{1} \mathrm{H}$ associated with the TPB ligand scaffold. Upon reaction with acid to form 6.1, however, two strong features appear with moderate couplings of 15.3 and 10.9 MHz. When adjusted for the differing magnetic fields, these coupling values agree well with the values obtained from the simulation of the X-band EPR spectrum of 6.1. Furthermore, these couplings vary with $g$-value as shown in Figure 6.4B, achieving their highest values near $g_{3}$ and decreasing to lower values of 9.9 and $3.8 \mathrm{MHz}$ near $g_{1}$. The observation of two new and independent signals in the ${ }^{1} \mathrm{H}$ ENDOR spectrum requires that there be at least two different types of protons and is consistent with the hypothesis of $\mathbf{6 . 1}$ 
being a doubly protonated species. Furthermore, the fact that the couplings do not show a large dependence on $g$-value suggests that they are likely located far from the nucleus, making protonation at an $\alpha \mathrm{N}$ less likely than at a $\beta \mathrm{N}$. Furthermore, this result suggests that protonation at the metal is highly unlikely. Distinguishing between protonation on $\mathrm{Fe}$ or $\mathrm{N}_{2}$ is difficult to determine from the coupling constants alone as the magnitude of the coupling constant associated with hydrogenated Fe species as well as a bridging $\mathrm{Fe}_{2}(\mu-$ $\mathrm{NH})$ complex have been known to vary from $17 \mathrm{MHz}$ to $56 \mathrm{MHz} .{ }^{9}$ It should be noted, however, that the observed coupling constant is at the very low end of this range species and further suggests that protonation at Fe is unlikely.
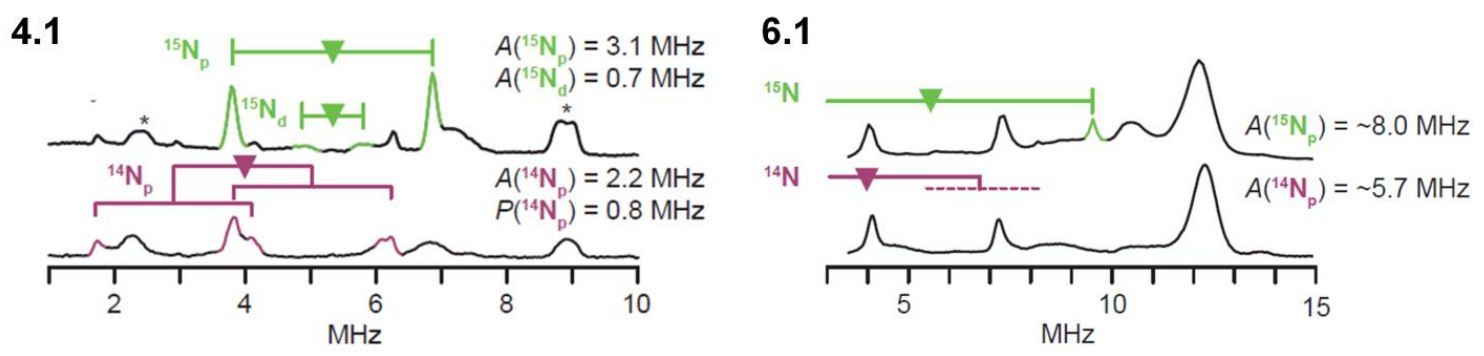

Figure 6.5. $35.0 \mathrm{GHz}$ Davies ${ }^{14} \mathrm{~N}$ and ${ }^{15} \mathrm{~N}$ ENDOR spectra from 4.1 and 6.1 acquired at $g=2.005$. Note that the additional signals are either overtones from ${ }^{11} \mathrm{~B}$ or ${ }^{31} \mathrm{P}$ or artifacts.

Further information can be gleaned from the ${ }^{14} \mathrm{~N}$ and ${ }^{15} \mathrm{~N}$ ENDOR signals (Figure 6.5). Probing near $g=2.005$, Complex 4.1 shows two resolvable couplings of approximately 3.1 and $0.7 \mathrm{MHz}$ in the ${ }^{15} \mathrm{~N}$ ENDOR spectrum which are assigned as the $\alpha \mathrm{N}$ and $\beta \mathrm{N}$ of the bound $\mathrm{N}_{2}$, respectively. Upon protonation to $\mathbf{6 . 1}$ only one coupling constant of approximately $8 \mathrm{MHz}$ in the ${ }^{15} \mathrm{~N}$ ENDOR spectrum is observed. These signals validate the presence of a nitrogenous ligand on $\mathrm{Fe}$ and hence eliminate any 
structures for $\mathbf{6 . 1}$ that include loss of $\mathrm{N}_{2}$ such as 3.2. The observation of only one signal in the ${ }^{15} \mathrm{~N}$ ENDOR spectrum of $\mathbf{6 . 1}$ furthermore preclude an $\eta^{2}$-diazene adduct of Fe (Scheme 6.1E) as the presence of two inequivalent ${ }^{1} \mathrm{H}$ signals in such a molecule would similarly require two inequivalent ${ }^{15} \mathrm{~N}$ signals.

The ${ }^{15} \mathrm{~N}$ ENDOR spectrum is consistent with the assignment of a hydrazido(2-) species with an Fe-N triple bond. Such a species would be expected to have a stronger coupling to the $\alpha \mathrm{N}$ as is observed. While the two protons on such a complex could be in fast rotation at RT, rotation is likely hindered at low temperature, giving rise to the two independent proton signals. Alternately, a canting of the $\mathrm{NNH}_{2}$ unit could also yield two inequivalent proton signals. In addition to the ${ }^{1} \mathrm{H}$ data, the ${ }^{11} \mathrm{~B}$ ENDOR spectrum of $\mathbf{6 . 1}$ also shows a decrease in coupling constant from $19.5 \mathrm{MHz}$ in 4.1 to $9.0 \mathrm{MHz}$ in $\mathbf{6 . 1}$, which is also consistent with an elongation of the Fe-B distance that would likely accompany the formation of an Fe-N triple bond as has been observed with other $(\mathrm{TPB}) \mathrm{Fe} \equiv \mathrm{NR}$ complexes. ${ }^{10}$ Although all of this data is consistent with a hydrazido(2-) structure for 6.1, direct and unique evidence of this functionality is not completely demonstrated by the ENDOR studies.

\subsubsection{Fe K-Edge X-ray Absorption Spectroscopy Measurements}

Although crystallization of $\mathbf{6 . 1}$ at low temperature was unsuccessful, structural data can be obtained via Fe K-edge X-ray absorption spectroscopy (XAS), and specifically Extended X-ray absorption fine structure (EXAFS) data has been collected on a frozen solution of $\mathbf{6 . 1}$ (Figure 6.6). The data show the presence of three primary peaks which can be fit with a first order approximation using the parameters shown in 
Table 6.1. The fit suggests a short light atom scatter at 1.639(7) $\AA$ and two sets of heavier scatterers observed at 2.279(5) and 2.422(3) $\AA$, respectively, which are best fit in a 1:2 ratio. These parameters provide a reasonable fit to the data and are consistent with the assignment of a short Fe-N bond and two inequivalent sets of Fe-P distances. The regions where the fit is poorest, specifically between 3 and $4 \AA$, arise from longer range interactions with light scatterers that have not been included in the fit. Finally, the observation that the Debye-Waller factor for the Fe-N bond is larger than for the Fe-P may potentially be explained by either some percentage of a species with a different $\mathrm{Fe}-\mathrm{N}$ distance or some vibrational contribution.
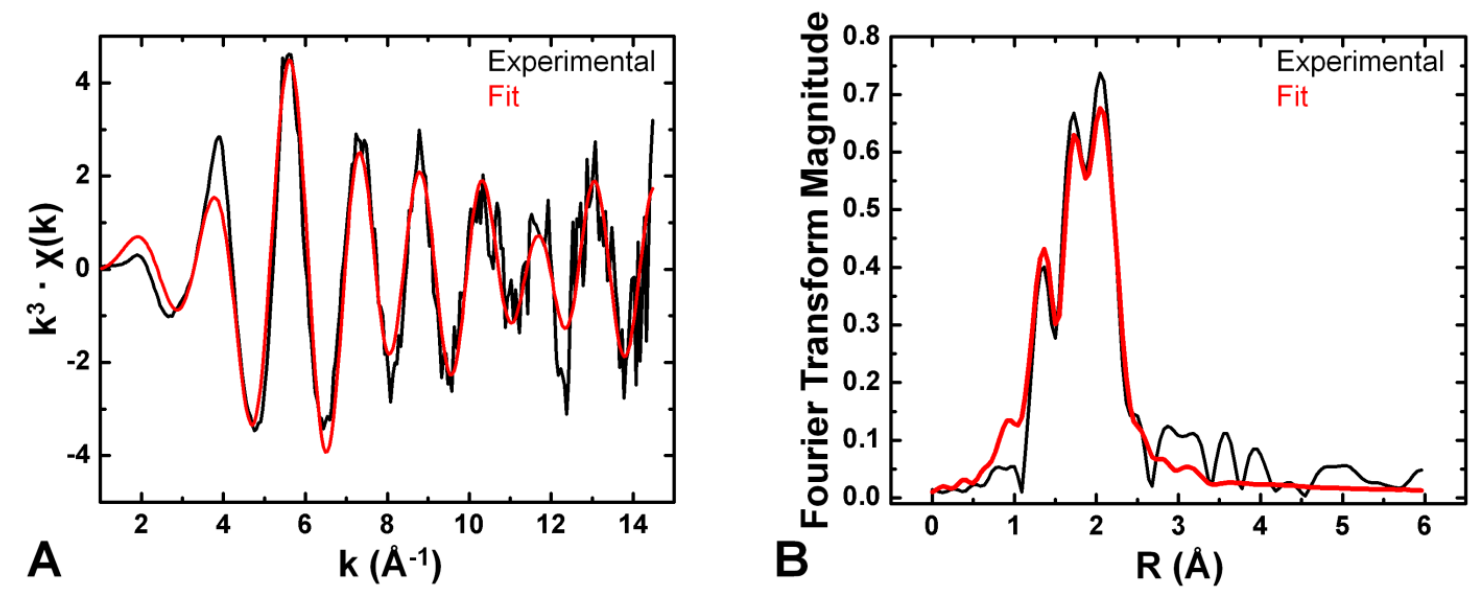

Figure 6.6. (A) EXAFS data. (B) Fourier transform of the EXAFS data. Fit parameters from those listed in Table 6.1.

When comparing these observed distances with those found in the known compound $[(\mathrm{TPB}) \mathrm{Fe} \equiv \mathrm{NAd}]\left[\mathrm{BAr}_{4}{ }_{4}\right]$ several similarities become apparent. The similar Fe$\mathrm{N}$ distances of 1.64 and $1.66 \AA$ in $\mathbf{6 . 1}$ and $[(\mathrm{TPB}) \mathrm{Fe} \equiv \mathrm{NAd}]\left[\mathrm{BAr}_{4}{ }_{4}\right]$ respectively are quite similar and both complexes display the pattern of two long and one short Fe-P bonds. 
These observations further support a hydrazido(2-) structural assignment for $\mathbf{6 . 1}$

Notably, while shortened bonds of $\sim 1.8 \AA$ might be expected with other complexes under consideration, no complex in Scheme 6.1 should display a Fe-N distance under $\sim 1.70 \AA$ aside from the hydrazido(2-) structure for 6.1. Iron nitrogen bonds of this length are typically only observed with Fe-N multiple bonds, such as those seen in $[(\mathrm{TPB}) \mathrm{Fe} \equiv \mathrm{NAd}]\left[\mathrm{BAr}^{\mathrm{F}}{ }_{4}\right]$ and other neutral Fe imides or hydrazido(2-) complexes supported by TPB. $4^{\mathrm{d}, 10}$

\begin{tabular}{ccccc}
\hline & $\boldsymbol{N}$ & $\boldsymbol{R}(\AA)$ & $\boldsymbol{\sigma}^{2}\left(\AA^{2}\right)$ & $\boldsymbol{F}$-factor \\
\hline Fe-P & 1 & $2.279(5)$ & $0.0021(2)$ & 0.377 \\
Fe-P & 2 & $2.422(3)$ & $0.0021(2)$ & \\
Fe-N & 1 & $1.639(7)$ & $0.0085(2)$ & \\
Fe-B & 1 & $2.674(12)$ & $0.0085(17)$ &
\end{tabular}

Table 6.1. Extended X-ray absorption fine structure (EXAFS) curve-fitting results. N, Coordination numbers, $\mathrm{R}$, interatomic distances, $\sigma^{2}$, Debye-Waller factors (the meansquare deviations in interatomic distance). The values in parentheses are the estimated standard deviations. The fit-error function $\mathrm{F}=\sqrt{\sum \mathrm{k}^{6}\left(\chi(\mathrm{k})_{\mathrm{calcd}}-\chi(\mathrm{k})_{\exp }\right)^{2} / \sum \chi(\mathrm{k})_{\exp }^{2}}$ where $\mathrm{k}$ is the photo-electron wave number.

\subsubsection{Computational Studies}

In addition to the spectroscopic studies already mentioned, computational studies offer an additional means to evaluate the proposed structure for $\mathbf{6 . 1}$, especially in comparison to other structural isomers that could be formed in the reaction mixture. DFT 
calculations have therefore been carried out with two levels of theory. Both the postulated hydrazido(2-) complex and a terminal diazene complex (Scheme 6.1D) were considered in their $S=1 / 2$ spin states. The geometries of these complexes were effectively minimized and frequency calculations showed no imaginary vibrations, indicating that the optimized structures represent global minima.

A

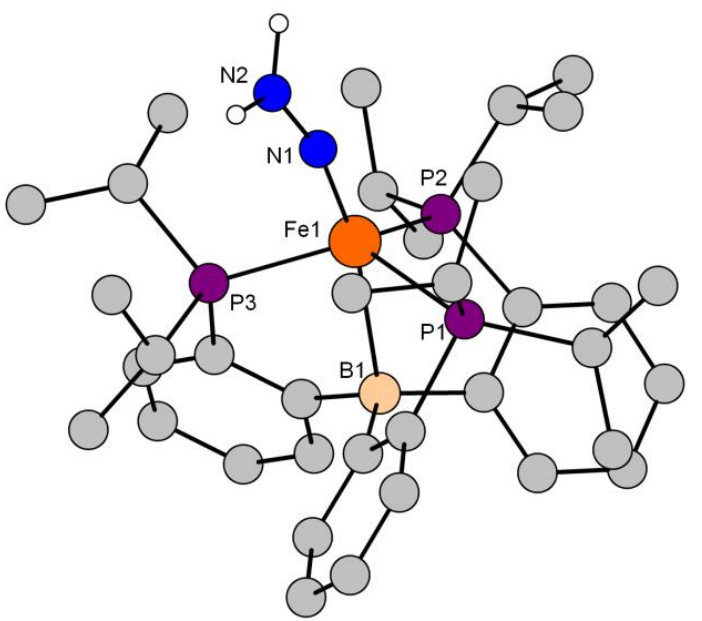

B

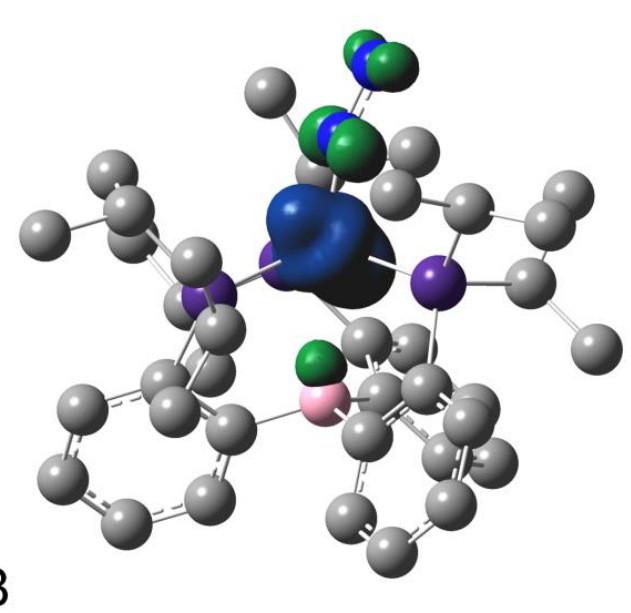

Figure 6.7. (A) Computed geometry for $\left[(\mathrm{TPB}) \mathrm{Fe} \equiv \mathrm{N}-\mathrm{NH}_{2}\right]^{+}$and (B) spin density plot for $\left[(\mathrm{TPB}) \mathrm{Fe} \equiv \mathrm{N}-\mathrm{NH}_{2}\right]^{+}$.

Of particular interest is the optimized geometry of the proposed structure of $\mathbf{6 . 1}$ (Figure 6.7A) using the M06L functional. The predicted Fe-N and Fe-P bond lengths of $1.70 \AA$ and $2.29,2.31$, and $2.36 \AA$ respectively agree well with the observed distances from the EXAFS data for 6.1. Additionally, a relatively long Fe-B distance of $2.56 \AA$ is predicted, $0.3 \AA$ longer than that observed in $\mathbf{4 . 1}$ and consistent with the weaker coupling observed in the ${ }^{11} \mathrm{~B}$ ENDOR spectrum of 6.1 versus 4.1. Analysis of the spin density in this computed structure (Figure 6.7B) indicates that while the majority of the spin is 
centered on $\mathrm{Fe}$, appreciable spin is also present on $\mathrm{B}$ and on the $\alpha \mathrm{N}$, which is consistent with the coupling observed in the ${ }^{11} \mathrm{~B}$ and ${ }^{15} \mathrm{~N}$ ENDOR spectra.

In addition to the minimized doublet hydrazido(2-) structure, the structure of the doublet diazene adduct (Scheme 6.1D) has also been computed (Appendix 5). The hydrazido(2-) structure $\mathrm{A}$ is lower than the diazene structure by 8 or $17 \mathrm{kcal} / \mathrm{mol}$ in energy depending on the level of theory used, suggesting that the proposed structure is preferred. Additionally, while the spin density in the doublet diazene structure is similarly primarily centered on Fe, there is virtually no spin density on boron, which is inconsistent with the observed coupling in the ${ }^{11} \mathrm{~B}$ ENDOR spectrum. Again, these calculations are consistent with the observed data and suggest that the proposed hydrazido(2-) structure is more reasonable.

As a final set of calculations, high spin $S=3 / 2$ calculations of both the hydrazido(2-) and diazene adducts have been considered. Interestingly, when using the M06L functional with TZVP, SVP, and 6-31G basis sets, the $S=3 / 2$ spin state of the both the hydrazido(2-) and the diazene adduct (Scheme 6.1D) are lower in energy than the $S=1 / 2$ hydrazido(2-) complex. While these spin states cannot correspond to the EPR or ENDOR data collected on 6.1, the calculations do suggest that $S=3 / 2$ states could be stable and perhaps accessible under the reaction conditions employed for catalysis. As will be discussed shortly, it seems plausible that thermal conversion to quartet spin states could occur in solutions of $\mathbf{6 . 1}$. 


\subsubsection{Decomposition Studies}

As was mentioned, $\mathbf{6 . 1}$ is thermally unstable and its decomposition was of interest in order to determine its relevance to the catalysis mediated by 4.1. Additionally, while 6.1 is formed from conditions very similar to those used in catalysis, it was desirable to determine whether $\mathbf{6 . 1}$ is formed in catalytic mixtures. Towards this end, further EPR studies on warmed samples were undertaken. The first test was to determine whether the signal associated with $\mathbf{6 . 1}$ is formed when acid is added to $\mathbf{4 . 1}$ analogously to the first step in the catalytic protocol at $-78{ }^{\circ} \mathrm{C}$. When $\mathbf{4 . 1}$ is exposed to 10 equivalents of $\mathrm{HBAr}_{4}$ - $2 \mathrm{Et}_{2} \mathrm{O}$ under these conditions the rhombic signal associated with $\mathbf{6 . 1}$ is observed, along with a substantial amount of new $S=3 / 2$ signals similar to those observed for the complexes reported in chapter 3 (Figure 6.8 , left). ${ }^{11}$ It is likely that the new quartet features are a result of decomposition of 6.1 as solutions of 6.1 made at low temperature decompose at $-40{ }^{\circ} \mathrm{C}$ to give the same quartet signals observed in the reaction at $-78{ }^{\circ} \mathrm{C}$ (Figure 6.8, middle). Further warming of the solution to RT results in further decay of 6.1 and further evolution of the quartet features (Figure 6.8, right). Notably, however, there appears to be no difference in the behavior of the solutions as a result of their preparations at $-140{ }^{\circ} \mathrm{C}$ or $-78^{\circ} \mathrm{C}$, suggesting that 6.1 is likely formed in the initial catalytic mixture prior to reductant addition.

Finally, if acid is added at $-78^{\circ} \mathrm{C}$ and then an excess of $\mathrm{KC}_{8}$ is added, also at -78 ${ }^{\circ} \mathrm{C}$, and an EPR spectrum is then taken, the signal associated with $\mathbf{6 . 1}$ as well as the $S=$ 3/2 signals disappear and a new roughly axial signal, similar to that observed for $\mathbf{4 . 1}$, results (Appendix 5). Taken together, these EPR studies suggest that some $S=3 / 2$ species are thermally accessible upon warming, which is consistent with the calculations. 
Furthermore, the intermediate generated by addition of acid to 4.1 is likely present in the catalytic mixture. Finally, this mixture, when exposed to reductant, regenerates what appears to be a species similar to $\mathbf{4 . 1}$, consistent with the stoichiometric reactions reported in Chapter 4.

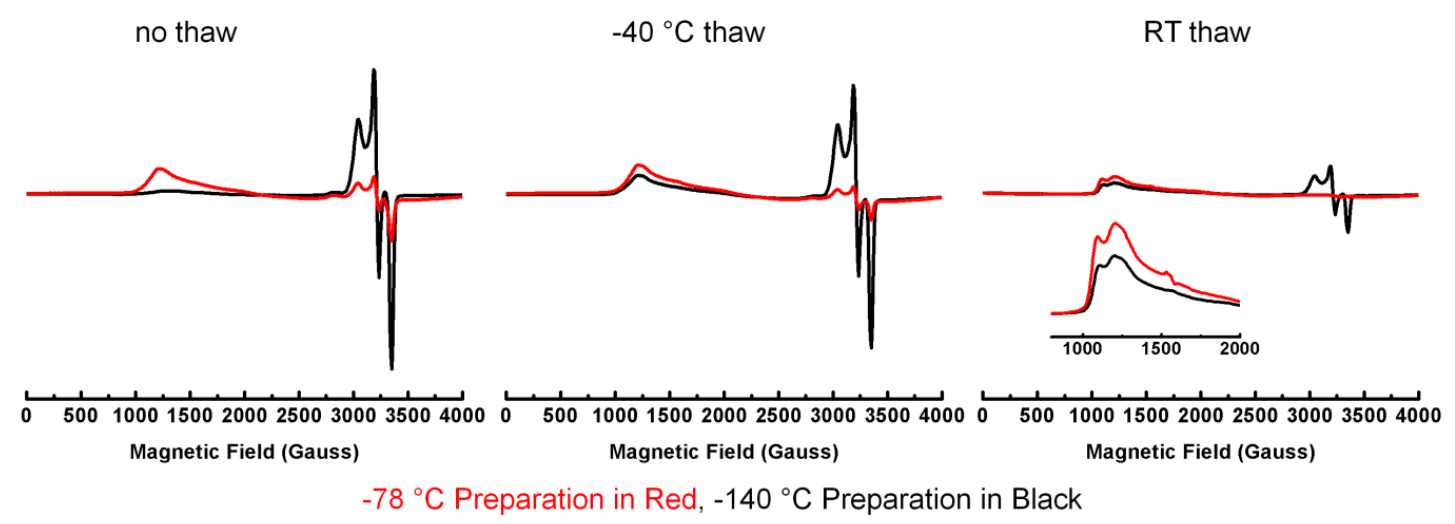

Figure 6.8. $77 \mathrm{~K}$ X-Band EPR spectrum comparing the addition of acid to 4.1 at different temperatures and the effect of thawing this sample to different temperatures. Conditions: 2-MeTHF, 9.4 GHz.

\subsection{Conclusions}

Addition of excess acid to $\mathbf{4 . 1}$ at low temperatures results in the formation of a new $S=1 / 2$ species 6.1 in good yield. EPR spectroscopy on this complex suggests that it is not a diazenido species and that its electronic structure resembles other cationic imide species of $(\mathrm{TPB}) \mathrm{Fe}$ such as $[(\mathrm{TPB}) \mathrm{Fe} \equiv \mathrm{NAd}]\left[\mathrm{BAr}^{\mathrm{F}}{ }_{4}\right]$. ENDOR studies confirm the presence of a nitrogenous ligand with two independent but similar protons. Furthermore, the dependence of the ${ }^{1} \mathrm{H}$ proton signal on $g$-value suggests that these protons are relatively far away from the Fe center. EXAFS spectroscopy confirms the presence of a 
short Fe-N scatterer, which should only be observed in a species with Fe-N multiple bonds. Finally, computations suggest that a hydrazido(2-) complex is the most favorable isomer for this species.

Taken together, these studies offer convincing evidence for the assignment of 6.1. Although parent hydrazido(2-) species were some of the first species identified from the protonation of $\mathrm{N}_{2}$ on Mo and $\mathrm{W},{ }^{12} \mathbf{6 . 1}$ represents the first example of such a species on $\mathrm{Fe}$ and also is likely the first example of a species en-route to $\mathrm{NH}_{3}$ formation. Indeed, structurally characterized examples of $\mathrm{M}-\mathrm{N}-\mathrm{NR}_{2}$ linkages on first row metals later than $\mathrm{V}$ are quite rare. ${ }^{13}$ This is somewhat remarkable, as other species such as nitrides and diazene adducts have been detected or isolated for some time. ${ }^{14,15}$ The rarity of species arising from the protonation of $\mathrm{N}_{2}$ on Fe speaks to the instability of these complexes and the difficulties associated with their characterization.

The potential role of this complex in a catalytic cycle is less clear at this point. Complex 6.1 is present in pre-catalytic mixtures prior to the addition of reductant and does appear to convert to other $S=3 / 2$ species upon warming even to $-78^{\circ} \mathrm{C}$. It should be noted that these same mixtures have been shown, upon warming, to produce $\left[(\mathrm{TPB}) \mathrm{Fe}\left(\mathrm{NH}_{3}\right)\right]\left[\mathrm{BAr}_{4}^{\mathrm{F}}\right]$. The fact that $\mathbf{6 . 1}$ has $\mathrm{N}-\mathrm{H}$ bonds already formed strongly implies the intermediacy of this species in the formation of $\mathrm{NH}_{3}$. While this certainly suggests that successive protonation at the $\beta \mathrm{N}$ of $\mathrm{N}_{2}$ is feasible under the catalytic conditions, the subsequent steps resulting in $\mathrm{NH}_{3}$ formation are still unclear. It is certainly still reasonable to think that a diazene species could be accessed subsequent to diprotonation of the $\beta \mathrm{N}$. The observed $S=3 / 2$ species being formed in the reaction mixture do not correspond to the reported complexes from chapter 3, although it is 
unclear whether this is a result of the convolution of multiple species, or the presence of a new quartet signal. This still leaves the mechanism of further steps in the catalytic cycle up for debate. Although reasonable arguments can be made for both distal and alternating mechanisms, another intriguing possibility is a disproportionation pathway from 6.1 to generate diazene, hydrazine, and finally $\mathrm{NH}_{3}$. The disproportionation chemistry shown in Chapter 3 offers further support for the feasibility of such a mechanism. Nevertheless, the identification of further species en route to $\mathrm{NH}_{3}$ formation will be of great interest in future studies and will be required to further elucidate the mechanism of $\mathrm{NH}_{3}$ formation.

\subsection{Experimental Section}

\subsubsection{General Considerations}

Unless otherwise noted, all compounds were purchased from commercial sources and used without further purification. [(TPB) $\left.\mathrm{Fe}\left(\mathrm{N}_{2}\right)\right]\left[\mathrm{Na}(12 \text {-crown-4) })_{2},{ }^{10}\right.$ (TPB)Fe( $\left(\mathrm{N}_{2}\right),{ }^{10} \mathrm{HBAr}^{\mathrm{F}}{ }_{4} \cdot 2 \mathrm{Et}_{2} \mathrm{O},{ }^{16}\left[\mathrm{Cp}_{2} \mathrm{Fe}\right]\left[\mathrm{BAr}_{4}{ }_{4}\right],{ }^{17}$ and $\mathrm{KC}_{8},{ }^{18}$ were prepared according to literature procedures $\left(\left[\mathrm{BAr}_{4}^{\mathrm{F}}\right]=\left[\mathrm{B}\left(3,5-\left(\mathrm{CF}_{3}\right)_{2}-\mathrm{C}_{6} \mathrm{H}_{3}\right)_{4} \mathrm{~B}\right]^{-}\right)$. All manipulations were carried out under a $\mathrm{N}_{2}$ atmosphere utilizing standard glovebox or Schlenk techniques. Solvents were dried and de-oxygenated by an argon sparge followed by passage through an activated alumina column purchased from S.G. Waters Company. Labeled ${ }^{15} \mathrm{~N}_{2}$ (98\% purity) was obtained from Cambridge Isotope Laboratories. 


\subsubsection{EPR Spectroscopy}

EPR X-band spectra were obtained on a Bruker EMX spectrometer with the aid of Bruker Win-EPR software suite version 3.0. The spectrometer was equipped with a rectangular cavity which operated in the $\mathrm{TE}_{102}$ mode. Temperature control was achieved with the use of an Oxford continuous-flow helium cryostat (temperature range 3.6 - 300 K). All spectra were recorded at $9.37 \mathrm{GHz}$ with a microwave power of $20 \mathrm{~mW}$, a modulation amplitude of $4 \mathrm{G}$, and a modulation frequency of $100 \mathrm{kHz}$. Simulations were performed with the Easyspin software suite. ${ }^{19} \mathrm{EPR}$ samples were thawed to $-40{ }^{\circ} \mathrm{C}$ with a dry ice/acetonitrile slush bath for a time period of 5 minutes or alternately thawed to RT for a time period of 5 minutes.

\subsubsection{ENDOR Spectroscopy}

Both pulse and continuous wave (CW) EPR and ENDOR spectroscopic data were collected at $35 \mathrm{GHz}$ on home-built spectrometers, which have been described previously. ${ }^{20}$ Temperature control was achieved with liquid He immersion dewars for measurements at $2 \mathrm{~K}$. A field modulation of $100 \mathrm{kHz}$ and dispersion mode detection under rapid passage conditions were employed in the $\mathrm{CW}$. In order to improve signal-tonoise, RF broadening of $100 \mathrm{kHz}$ was employed in the ${ }^{1} \mathrm{H} \mathrm{CW}$ ENDOR spectra. ${ }^{21}$ The stochastic-field modulation detected ENDOR sequence was used on ${ }^{1} \mathrm{H} \mathrm{CW}$ ENDOR spectra to improve ENDOR lineshapes. ${ }^{22}$ Data acquisition for all pulse experiments utilized the SpecMan software package (http://specman4epr.com) in conjunction with a Spin-Core PulseBlaster ESR_PRO $400 \mathrm{MHz}$ word generator and an Agilent Technologies Acquiris DP235 500MS/s digitizer. 


\subsubsection{XAS Measurements}

XAS measurements were conducted at the Stanford Synchrotron Radiation Laboratory (SSRL) with the SPEAR 3 storage ring containing $500 \mathrm{~mA}$ at $3.0 \mathrm{GeV}$. Fe Kedge data were collected on the beamline 9-3 operating with a wiggler field of $2 \mathrm{~T}$ and employing a $\operatorname{Si}(220)$ double-crystal monochromator. Beamline 9-3 is equipped with a rhodium-coated vertical collimating mirror upstream of the monochromator and a bentcylindrical focusing mirror (also rhodium-coated) downstream of the monochromator. Harmonic rejection was accomplished by setting the energy cutoff angle of the mirrors to $10 \mathrm{keV}$. The incident and transmitted X-ray intensities were monitored using Nitrogenfilled ionization chambers, and X-ray absorption was measured as the Fe Ka fluorescence excitation spectrum using an array of 100 Canberra germanium detectors. During data collection, samples were maintained at a temperature of approximately $10 \mathrm{~K}$ using an Oxford instruments liquid helium flow cryostat. The energy was calibrated by reference to the absorption of a standard iron metal foil measured simultaneously with each scan, assuming a lowest energy inflection point of the iron foil to be $7111.2 \mathrm{eV}$.

The extended $\mathrm{x}$-ray absorption fine structure (EXAFS) oscillations $\chi(k)$ were quantitatively analyzed by curve-fitting using the EXAFSPAK suite of computer programs. ${ }^{23} \mathrm{Ab}$-initio theoretical phase and amplitude functions were calculated using the program FEFF version $8 .{ }^{24}$ No smoothing, filtering, or related operations were performed on the data. 


\subsubsection{Computational Methods}

Geometry optimizations were performed using the Gaussian03 or the Gaussian09 packages. ${ }^{25,26}$ The BP86 exchange-correlation functional was employed with a 6-31G(d) basis set on $\mathrm{Fe}, \mathrm{P}, \mathrm{N}$, and $\mathrm{B}$ and the 6-31G basis set on $\mathrm{C}$ and $\mathrm{H}$ for the Gaussian03 calculations. Alternately, the M06L functional with the TZVP basis set on Fe, the SVP basis set on $\mathrm{P}, \mathrm{B}$, and $\mathrm{N}$, and the $6-31 \mathrm{G}$ basis set on $\mathrm{C}$ and $\mathrm{H}$. A full frequency calculation was performed on each structure to establish true minima. The initial geometries used for the calculations were the XRD coordinates for $[(\mathrm{TPB}) \mathrm{Fe} \equiv \mathrm{NAd}]\left[\mathrm{BAr}_{4}{ }_{4}\right]$, which was modified to feature the correct nitrogenous ligands. Computed energies were corrected for thermal energy. Structural models were generated as .mol files and plotted in Diamond 3.2 and orbital/spin density pictures were generated from Gaussview 03.

\subsubsection{Synthesis}

Synthesis of $\left[(\mathbf{T P B}) \mathbf{F e} \equiv \mathbf{N}-\mathrm{NH}_{2}\right]\left[\mathrm{BAr}^{\mathbf{F}}\right.$ ], 6.1. Complex $4.1(4 \mathrm{mg}, 0.004 \mathrm{mmol})$ was dissolved in 2-MeTHF $(0.25 \mathrm{~mL})$ and added into a quartz EPR tube. This solution was then frozen in a liquid $\mathrm{N}_{2}$ cooled cold well. A thawing solution of $\mathrm{HBAr}^{\mathrm{F}}{ }_{4} \cdot 2 \mathrm{Et}_{2} \mathrm{O}(38$ $\mathrm{mg}, 0.037 \mathrm{mmol})$ in 2-MeTHF $(0.25 \mathrm{~mL})$ was then added to the EPR tube and frozen before reaching the bottom of the tube. A long needle, which was also cooled to $77 \mathrm{~K}$, was then inserted into the tube and used to mechanically mix the solutions over 10 minutes. The tube was also raised slightly out of the cold well to slightly thaw the solutions and aid in mixing. After mixing was complete, the dark red color of $\mathbf{4 . 1}$ had 
disappeared and a brown yellow solution was obtained. This frozen tube solution was then brought out of the glovebox and subjected to EPR analysis.

Synthesis of $\left[(T P B) F e \equiv N\left(C_{6} H_{4} O M e\right)\right]\left[B A r^{F_{4}}\right]$. An EPR sample of this complex was generated by dissolving (TPB)Fe $\equiv \mathrm{N}\left(p-\mathrm{C}_{6} \mathrm{H}_{4} \mathrm{OMe}\right)(3 \mathrm{mg}, 0.004 \mathrm{mmol})$ in 2-MeTHF $(0.25 \mathrm{~mL})$. This solution was then cooled to $-78^{\circ} \mathrm{C}$ and then mixed with a similarly cooled solution of $[\mathrm{Fc}]\left[\mathrm{BAr}_{4}{ }_{4}\right](\mathrm{Fc}=$ ferrocenium $)(4 \mathrm{mg}, 0.004 \mathrm{mmol})$ in 2-MeTHF $(0.25 \mathrm{~mL})$ with rapid stirring. Upon mixing the dark blue color of $[\mathrm{Fc}]\left[\mathrm{BAr}{ }_{4}\right]$ disappeared and the dark green color of (TPB) $\mathrm{Fe} \equiv \mathrm{N}\left(p-\mathrm{C}_{6} \mathrm{H}_{4} \mathrm{OMe}\right)$ lightened slightly to green-yellow. The solution was allowed to stir for an additional 10 minutes and then transferred to a quartz EPR tube and frozen. Note that there is a small signal resulting from an unknown $S=1 / 2$ component in the product mixture.

Synthesis of $(\mathbf{T P B}) \mathbf{F e} \equiv \mathbf{N A d}$. Under an atmosphere of nitrogen, a $0.1 \mathrm{M}$ solution of adamantyl azide in benzene $(1.27 \mathrm{~mL}, 0.127 \mathrm{mmol})$ was added to a solution of (TPB)FeN $2(86 \mathrm{mg}, 0.127 \mathrm{mmol})$ in benzene $(5 \mathrm{~mL})$ and stirred, giving a deep red solution. The solution was transferred to a sealed Schlenk tube and stirred overnight at $80^{\circ} \mathrm{C}$, resulting in a deep green solution. Lyophilization yielded a green powder which was washed twice in THF, leaving a bright green powder $((\mathrm{TPB}) \mathrm{Fe} \equiv \mathrm{NAd})$. The product was suspended in benzene and lyophilized in preparation for elemental analysis. Elemental analysis yielded the following results: Calculated: C 69.44, H 8.74, N 1.76; Experimental: C 69.29, H 8.47, N 1.67. NMR analysis was not obtained due to the poor solubility properties of the product.

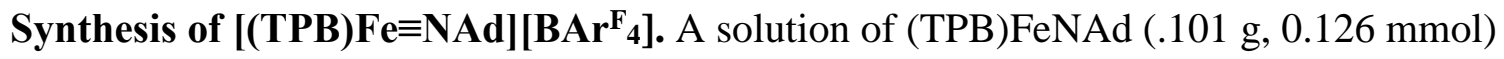
in THF (3 mL) was added to a solution of $\left[\mathrm{FeCp}_{2}\right]\left[\mathrm{BAr}_{4}{ }_{4}\right](.133 \mathrm{~g}, 0.126 \mathrm{mmol})$ in THF 
$(2 \mathrm{~mL})$, giving a dark green solution which was stirred for 15 minutes. The solvent was removed, leaving a dark green sludgy solid $[(\mathrm{TPB}) \mathrm{Fe} \equiv \mathrm{NAd}]\left[\mathrm{BAr}_{4}^{\mathrm{F}}\right]$ which was washed $3 \mathrm{x}$ with pentane $(3 \mathrm{~mL})$. Crystals for XRD were obtained by vapor diffusion of pentane into a solution of $[(\mathrm{TPB}) \mathrm{Fe} \equiv \mathrm{NAd}]\left[\mathrm{BAr}^{\mathrm{F}}{ }_{4}\right]$ in diethyl ether. ${ }^{1} \mathrm{H}$ NMR $\left(\mathrm{THF}-d_{8}, \delta\right): 26.56$ (vbr s), 10.66 (br s), 7.77 (s, $\left.\mathrm{BAr}_{4}{ }^{-}\right), 7.69$ (br s), $7.56\left(\mathrm{~s}, \mathrm{BAr}_{4}{ }^{-}\right), 6.67$ (vbr s), 6.48 (br s), 5.44 (br s), 4.96 (br s), 3.16 (br s), $-2,85$ (vbr s), -5.96 (br s), -6.53 (br s), -8.23 (vbr s), 13.96 (br s). Anal. calcd. for $\mathrm{C}_{78} \mathrm{H}_{81} \mathrm{~B}_{2} \mathrm{~F}_{24} \mathrm{FeNP}_{3}$ : C 56.48 , $\mathrm{H}$ 4.92, $\mathrm{N}$ 0.84; found: $\mathrm{C}$ 56.24, H 4.83, N 0.80.

Preparation of ENDOR samples. Samples of 4.1 were prepared by dissolving the complex $(1.2 \mathrm{mg}, 0.001 \mathrm{mmol})$ in 2-MeTHF $(0.5 \mathrm{~mL})$ and transferring this solution to an ENDOR before freezing the solution prior to shipping. Samples of $\mathbf{6 . 1}$ were prepared analogously as described above with $4.1(1 \mathrm{mg}, 0.0009 \mathrm{mmol})$ and $\mathrm{HBAr}_{4} \cdot 2 \mathrm{Et}_{2} \mathrm{O}(10$ $\mathrm{mg}, 0.0099 \mathrm{mmol}$ ) in 2-MeTHF (total volume of $0.5 \mathrm{~mL}$ ). The only deviation from the above described procedure was that $\mathbf{6 . 1}$ was initially prepared in a $5 \mathrm{~mL}$ scintillation vial before being slightly thawed and transferred into the ENDOR tube while cold. The samples were then frozen and packaged for shipment. They were shipped to Northwestern University under liquid $\mathrm{N}_{2}$.

Preparation of ${ }^{15} \mathbf{N}$ labeled ENDOR samples. Two stock solutions of 4.1 (5 mg, 0.0048 $\mathrm{mmol})$ and $\mathrm{HBAr}_{4} \cdot 2 \mathrm{Et}_{2} \mathrm{O}(50 \mathrm{mg}, 0.049 \mathrm{mmol})$ in 2-MeTHF (0.5 mL each) and 2MeTHF (1 mL) were each placed into three short test tubes. These test tubes and the ENDOR tubes were placed into a round-bottom schlenk flask with a glass stopcock sidearm. The flask was then sealed with a rubber septum and brought out of the glovebox. The solution was freeze-pump-thawed $3 x$ before backfilling with an atmosphere of ${ }^{15} \mathrm{~N}_{2}$. 
The solutions were then sparged with ${ }^{15} \mathrm{~N}_{2}$ from the headspace of the flask with the use of a long needled syringe through the rubber septum. The syringe was rinsed with the 2MeTHF from the third test tube to avoid cross contamination. The solution of $\mathbf{4 . 1}$ was then distributed to the ENDOR tubes with the use of the syringe. To generate 6.1, the apparatus was cooled to $77 \mathrm{~K}$ with liquid nitrogen. The solutions were then briefly thawed and the solution of $\mathrm{HBAr}_{4}{ }_{4} \cdot 2 \mathrm{Et}_{2} \mathrm{O}$ was layered on top of the solutions of $\mathbf{4 . 1}$ in the ENDOR tubes. The solutions were then mechanically mixed with the syringe as described above. After mixing was complete, the solutions were frozen, and the septum was removed, after which the samples were quickly dumped into liquid $\mathrm{N}_{2}$ before being sealed for shipment. The samples were shipped to Northwestern University under liquid $\mathrm{N}_{2}$.

Preparation of XAS samples. The sample of 6.1 for XAS analysis was prepared analogously to that reported earlier with $4.1(10 \mathrm{mg}, 0.0095 \mathrm{mmol})$ and $\mathrm{HBAr}_{4} \cdot 2 \mathrm{Et}_{2} \mathrm{O}$ (100 mg, $0.099 \mathrm{mmol})$ in 2-MeTHF (0.5 mL total volume). The solution was prepared in a $5 \mathrm{~mL}$ scintillation vial before being slightly thawed and transferred into the XAS sample holder with a syringe. The sample was then re-frozen before being packaged for shipping to SSRL. The sample was shipped under liquid $\mathrm{N}_{2}$.

Preparation and EPR analysis of 6.1 at $-78{ }^{\circ} \mathbf{C}$. Complex $4.1(8 \mathrm{mg}, 0.0076 \mathrm{mmol})$ was suspended in $\mathrm{Et}_{2} \mathrm{O}(0.25 \mathrm{~mL})$ and cooled to $-78^{\circ} \mathrm{C}$ in a $5 \mathrm{~mL}$ scintillation vial. $\mathrm{HBAr}_{4}{ }_{4} \cdot 2 \mathrm{Et}_{2} \mathrm{O}(80 \mathrm{mg}, 0.079 \mathrm{mmol})$ was dissolved in $\mathrm{Et}_{2} \mathrm{O}(0.25 \mathrm{~mL})$ in a $20 \mathrm{~mL}$ scintillation vial equipped with a stir bar and cooled to $-78^{\circ} \mathrm{C}$ as well. Once cooled, the suspension of 4.1 was added to the $\mathrm{HBAr}_{4}{ }_{4} \cdot 2 \mathrm{Et}_{2} \mathrm{O}$ with stirring. The resulting solution was dark yellow-brown and homogeneous and was allowed to stir at $-78{ }^{\circ} \mathrm{C}$ for 10 
minutes. To this solution was then added 2-MeTHF $(0.5 \mathrm{~mL})$ which had been similarly cooled to $-78{ }^{\circ} \mathrm{C}$. The resulting solution was then transferred into an EPR tube and frozen with liquid $\mathrm{N}_{2}$ before analysis.

EPR analysis of the reaction of complex 4.1 with one equivalent of $\mathrm{HBAr}^{\mathrm{F}}{ }_{4} \cdot 2 \mathrm{Et}_{2} \mathrm{O}$. The procedure employed was identical to that used for the generation of 6.1 with the exception that a only one equivalent of $\mathrm{HBAr}_{4} \cdot 2 \mathrm{Et}_{2} \mathrm{O}(3.8 \mathrm{mg}, 0.0038 \mathrm{mmol})$ was used.

Preparation and EPR analysis of 6.1 after reduction at $-\mathbf{7 8}{ }^{\circ} \mathrm{C}$. Complex $4.1(8 \mathrm{mg}$, $0.0076 \mathrm{mmol})$ was suspended in $\mathrm{Et}_{2} \mathrm{O}(0.25 \mathrm{~mL})$ and cooled to $-78{ }^{\circ} \mathrm{C}$ in a $5 \mathrm{~mL}$ scintillation vial. $\mathrm{HBAr}_{4}{ }_{4} \cdot 2 \mathrm{Et}_{2} \mathrm{O}(80 \mathrm{mg}, 0.079 \mathrm{mmol})$ was dissolved in $\mathrm{Et}_{2} \mathrm{O}(0.25 \mathrm{~mL})$ in a $20 \mathrm{~mL}$ scintillation vial equipped with a stir bar and cooled to $-78^{\circ} \mathrm{C}$ as well. Once cooled, the suspension of $\mathbf{4 . 1}$ was added to the $\mathrm{HBAr}_{4} \cdot 2 \mathrm{Et}_{2} \mathrm{O}$ with stirring. The resulting solution was dark yellow-brown and homogeneous and was allowed to stir at $78{ }^{\circ} \mathrm{C}$ for 10 minutes. After this time $\mathrm{KC}_{8}(20 \mathrm{mg}, 0.15 \mathrm{mmol})$ was added as a solid. The resulting suspension was allowed to stir for 30 minutes at $-78{ }^{\circ} \mathrm{C}$ before it was filtered through a glass fiber filter paper. Pre-cooled 2-MeTHF $(0.5 \mathrm{~mL})$ was then added to the resulting dark red-brown solution, which was then transferred to an EPR tube and frozen with liquid $\mathrm{N}_{2}$ before analysis. 


\section{References Cited}

1 Anderson, J. S.; Rittle, J.; Peters, J. C. Nature in press, DOI: 10.1038/nature12435.

2 (a) Chatt, J.; Dilworth, J. R.; Richards, R. L. Chem. Rev. 1978, 78, 589-625; (b) Hidai, M.; Mizobe, Y. Chem. Rev. 1995, 95, 1115-1133; (c) Schrock, R. R. Acc. Chem. Res. 2005, 38, 955-962.

3 (a) Dos Santos, P. C.; Igarashi, R. Y.; Lee, H. I.; Hoffman, B. M.; Seefeldt, L. C.; Dean, D. R. Acc. Chem. Res. 2005, 38, 208-214; (b) Hoffman, B. M.; Dean, D. R.; Seefeldt, L. C. Acc. Chem. Res. 2009, 42, 609-619; (c) Seefeldt, L. C.; Hoffman, B. M.; Dean, D. R. Annu. Rev. Biochem. 2009, 78, 701-722; (d) Lukoyanov, D.; Dikanov, S. A.; Yang, Z.-Y.; Barney, B. M.; Samoilova, R. I.; Narasimhulu, K. V.; Dean, D. R.; Seefeldt, L. C.; Hoffman, B. M. J. Am. Chem. Soc. 2011, 133, 11655-11664.

4 For recent examples see: (a) Betley, T. A.; Peters, J. C. J. Am. Chem. Soc. 2004, 126, 6252-6254; (b) Scepaniak, J. J.; Fulton, M. D.; Bontchev, R. P.; Duesler, E. N.; Kirk, M. L.; Smith, J. M. J. Am. Chem. Soc. 2008, 130, 10515-10517; (c) Scepaniak, J. J.; Young, J. A.; Bontchev, R. P.; Smith, J. M. Angew. Chem., Int. Ed. 2009, 48, 31583160; (d) Moret, M.-E.; Peters, J. C. J. Am. Chem. Soc. 2011, 133, 18118-18121. (e) Scepaniak, J. J.; Vogel, C. S.; Khusniyarov, M. M.; Heinemann, F. W.; Meyer, K.; Smith, J. M. Science 2011, 331, 1049-1052.

5 For recent examples see: (a) Field, L. D.; Li, H. L.; Dalgarno, S. J.; Turner, P. Chem. Comm. 2008, 1680-1682; (b) Field, L. D.; Li, H. L.; Magill, A. M. Inorg. Chem. 2008, 48, 5-7; (c) Saouma, C. T.; Müller, P.; Peters, J. C. J. Am. Chem. Soc. 2009, 131, 10358-10359. (d) Crossland, J. L.; Balesdent, C. G.; Tyler, D. R. Inorg. Chem. 2011, 
51, 439-445. (e) Saouma, C. T.; Kinney, R. A.; Hoffman, B. M.; Peters, J. C. Angew. Chem. Int. Ed. 2011, 50, 3446-3449.

6 Fong, H.; Moret, M.-E.; Lee, Y.; Peters, J. C. Organometallics 2013, 32, 3053-3062.

7 (a) Chatt, J.; Heath, G. A.; Richards, R. L. J. Chem. Soc., Dalton 1974, 2074-2082; (b)

Hidai, M.; Kodama, T.; Sato, M.; Harakawa, M.; Uchida, Y. Inorg. Chem. 1976, 15, 2694-2697; (c) Takahashi, T.; Mizobe, Y.; Sato, M.; Uchida, Y.; Hidai, M. J. Am.

Chem. Soc. 1980, 102, 7461-7467.

8 Hoffman, B. M.; Dean, D. R.; Seefeldt, L. C. Acc. Chem. Res. 2009, 42, 609-619.

9 (a) Lee, Y.; Kinney, R. A.; Hoffman, B. M.; Peters, J. C. J. Am. Chem. Soc. 2011, 133, 16366-16369; (b) Chiang, K. P.; Scarborough, C. C.; Horitani, M.; Lees, N. S.; Ding, K.; Dugan, T. R.; Brennessel, W. W.; Bill, E.; Hoffman, B. M.; Holland, P. L. Angew. Chem. Int. Ed. 2012, 51, 3658-3662; (c) Kinney, R. A.; Saouma, C. T.; Peters, J. C.; Hoffman, B. M. J. Am. Chem. Soc. 2012, 134, 12637-12647.

10 Moret, M.-E.; Peters, J. C. Angew. Chem. Int. Ed. 2011, 50, 2063-2067.

11 Anderson, J. S.; Moret, M.-E.; Peters, J. C. J. Am. Chem. Soc. 2012, 135, 534-537.

12 (a) Chatt, J.; Heath, G. A.; Richards, R. L. J. Chem. Soc., Dalton 1974, 2074-2082; (b)

Hidai, M.; Kodama, T.; Sato, M.; Harakawa, M.; Uchida, Y. Inorg. Chem. 1976, 15, 2694-2697; (c) Takahashi, T.; Mizobe, Y.; Sato, M.; Uchida, Y.; Hidai, M. J. Am. Chem. Soc. 1980, 102, 7461-7467.

13 (a) Mahy, J. P.; Battioni, P.; Mansuy, D.; Fisher, J.; Weiss, R.; Mispelter, J.; Morgenstern-Badarau, I.; Gans, P. J. Am. Chem. Soc. 1984, 106, 1699-1706; (b) Körner, V.; Huttner, G.; Vogel, S.; Barth, A.; Zsolnai, L. Chem. Ber. 1997, 130, 489- 
492; (c) Paulat, F.; Lehnert, N.; Ishikawa, Y.; Okamoto, K.-I.; Fujisawa, K. Inorg. Chim. Acta 2008, 361, 901-915.

14 (a) Grapperhaus, C. A.; Mienert, B.; Bill, E.; Weyhermüller, T.; Wieghardt, K. Inorg. Chem. 2000, 39, 5306-5317; (b) Brown, S. D.; Peters, J. C. J. Am. Chem. Soc. 2005, 127, 1913-1923; (c) Vogel, C.; Heinemann, F. W.; Sutter, J.; Anthon, C.; Meyer, K. Angew. Chem. Int. Ed. 2008, 47, 2681-2684; (d) Scepaniak, J. J.; Young, J. A.; Bontchev, R. P.; Smith, J. M. Angew. Chem. Int. Ed. 2009, 48, 3158-3160.

15 (a) Sellmann, D.; Soglowek, W.; Knoch, F.; Moll, M. Angew. Chem. Int. Ed. 1989, 28, 1271-1272; (b) Field, L. D.; Li, H. L.; Dalgarno, S. J.; Turner, P. Chem. Comm. 2008, 1680-1682; (c) Field, L. D.; Li, H. L.; Magill, A. M. Inorg. Chem. 2008, 48, 5-7; (e) Crossland, J. L.; Balesdent, C. G.; Tyler, D. R. Inorg. Chem. 2011, 51, 439-445. 16 Brookhart, M.; Grant, B.; Volpe, A. F. Organometallics 1992, 11, 3920-3922. 17 Chávez, I.; Alvarez-Carena, A.; Molis, E.; Roig, A.; Maniukiewicz, W.; Arancibia, A.; Arancibia, V.; Brand, H.; Manríquez, J. M. J. Organomet. Chem. 2000, 601, 126-132. 18 Weitz, I. S.; Rabinovitz, M. J. Chem. Soc. Perkin 1993, 117-120.

19 Stoll, S.; Schweiger, A. J. Magn. Reson. 2006, 178, 42-55.

20 (a) Werst, M. M.; Davoust, C. E.; Hoffman, B. M. J. Am. Chem. Soc. 1991, 113, 1533; (b) Davoust, C. E.; Doan, P. E.; Hoffman, B. M. J. Magn. Reson. 1996, 119, 38; (c) Zipse, H.; Artin, E.; Wnuk, S.; Lohman, G. J. S.; Martino, D.; Griffin, R. G.; Kacprzak, S.; Kaupp, M.; Hoffman, B.; Bennati, M.; Stubbe, J.; Lees, N. J. Am. Chem. Soc. 2009, $131,200$.

21 Hoffman, B. M.; DeRose, V. J.; Ong, J. L.; Davoust, C. E. J. Magn. Reson. 1994, 110, 52. 
22 Lee, H.-I.; Igarashi, R. Y.; Laryukhin, M.; Doan, P. E.; Dos Santos, P. C.; Dean, D.

R.; Seefeldt, L. C.; Hoffman, B. M. J. Am. Chem. Soc. 2004, 126, 9563.

23 George, G.N., http://ssrl.slac.stanford.edu/exafspak.html.

24 Ankudinov, A. L.; Ravel, B.; Rehr, J. J.; Conradson, S. D. Physical Review B 1998, $58,7565-7576$.

25 Gaussian 03, Revision C.02, Frisch, M. J.; Trucks, G. W.; Schlegel, H. B.; Scuseria,

G. E.; Robb, M. A.; Cheeseman, J. R.; Montgomery, Jr., J. A.; Vreven, T.; Kudin, K.

N.; Burant, J. C.; Millam, J. M.; Iyengar, S. S.; Tomasi, J.; Barone, V.; Mennucci, B.;

Cossi, M.; Scalmani, G.; Rega, N.; Petersson, G. A.; Nakatsuji, H.; Hada, M.; $\quad$ Ehara,

M.; Toyota, K.; Fukuda, R.; Hasegawa, J.; Ishida, M.; Nakajima, T.; Honda, Y.; Kitao,

O.; Nakai, H.; Klene, M.; Li, X.; Knox, J. E.; Hratchian, H. P.; Cross, J. B.; Bakken, V.;

Adamo, C.; Jaramillo, J.; Gomperts, R.; Stratmann, R. E.; Yazyev, O.; Austin, A. J.;

Cammi, R.; Pomelli, C.; Ochterski, J. W.; Ayala, P. Y.; Morokuma, K.; Voth, G. A.;

Salvador, P.; Dannenberg, J. J.; Zakrzewski, V. G.; $\quad$ Dapprich, S.; Daniels, A. D.;

Strain, M. C.; Farkas, O.; Malick, D. K.; Rabuck, A. D.; Raghavachari, K.; Foresman,

J. B.; Ortiz, J. V.; Cui, Q.; Baboul, A. G.; Clifford, S.; Cioslowski, J.; Stefanov, B. B.;

Liu, G.; Liashenko, A.; Piskorz, P.; Komaromi, I.; Martin, R. L.; Fox, D. J.; Keith, T.;

Al-Laham, M. A.; Peng, C. Y.; Nanayakkara, A.; Challacombe, M.; Gill, P. M. W.;

Johnson, B.; Chen, W.; Wong, M. W.; Gonzalez, C.; and Pople, J. A.; Gaussian, Inc.,

Wallingford CT, 2004.

26 Gaussian 09, Revision A.1, Frisch, M. J.; Trucks, G. W.; Schlegel, H. B.; Scuseria, G.

E.; Robb, M. A.; Cheeseman, J. R.; Scalmani, G.; Barone, V.; Mennucci, B.; Petersson,

G. A.; Nakatsuji, H.; Caricato, M.; Li, X.; Hratchian, H. P.; Izmaylov, A. F.; Bloino, J.; 
Zheng, G.; Sonnenberg, J. L.; Hada, M.; Ehara, M.; Toyota, K.; Fukuda, R.; Hasegawa, J.; Ishida, M.; Nakajima, T.; Honda, Y.; Kitao, O.; Nakai, H.; Vreven, T.; Montgomery, Jr., J. A.; Peralta, J. E.; Ogliaro, F.; Bearpark, M.; Heyd, J. J.; Brothers, E.; Kudin, K. N.; Staroverov, V. N.; Kobayashi, R.; Normand, J.; Raghavachari, K.; Rendell, A.;

Burant, J. C.; Iyengar, S. S.; Tomasi, J.; Cossi, M.; Rega, N.; Millam, J. M.; Klene, M.;

Knox, J. E.; Cross, J. B.; Bakken, V.; Adamo, C.; Jaramillo, J.; Gomperts, R.;

Stratmann, R. E.; Yazyev, O.; Austin, A. J.; Cammi, R.; Pomelli, C.; Ochterski, J. W.;

Martin, R. L.; Morokuma, K.; Zakrzewski, V. G.; Voth, G. A.; Salvador, P.;

Dannenberg, J. J.; Dapprich, S.; Daniels, A. D.; Farkas, Ö.; Foresman, J. B.; Ortiz, J. V.; Cioslowski, J.; Fox, D. J. Gaussian, Inc., Wallingford CT, 2009. 
Appendix 1: Supplementary Data for Chapter 2 
Table A1.1. Crystal data and structure refinement for $\left(\left(\mathrm{PhBP}_{3}\right) \mathrm{Fe}\right)_{2}(\mu-\mathrm{S})(\mathbf{2 . 1})$.

Identification code

Empirical formula

Formula weight

Temperature

Wavelength

Crystal system

Space group

Unit cell dimensions

Volume

$\mathrm{Z}$

Density (calculated)

Absorption coefficient

$\mathrm{F}(000)$

Crystal size

Theta range for data collection

Index ranges

Reflections collected

Independent reflections

Completeness to theta $=31.44^{\circ}$

Absorption correction

Max. and min. transmission

Refinement method

Data / restraints / parameters

Goodness-of-fit on $\mathrm{F}^{2}$

Final $\mathrm{R}$ indices [I $>2 \operatorname{sigma}(\mathrm{I})]$

$\mathrm{R}$ indices (all data)

Largest diff. peak and hole temp

C90 H82 B2 Fe2 P6 S1.11

1518.28

100(2) K

$0.71073 \AA$

Monoclinic

$\mathrm{P} 2(1) / \mathrm{n}$

$\mathrm{a}=12.9215(13) \AA \quad \alpha=90^{\circ}$.

$\mathrm{b}=13.3515(14) \AA \quad \beta=92.191(2)^{\circ}$.

$\mathrm{c}=22.126(2) \AA \quad \gamma=90^{\circ}$. 3814.4(7) $\AA^{3}$

2

$1.322 \mathrm{Mg} / \mathrm{m}^{3}$

$0.584 \mathrm{~mm}^{-1}$

1584

$0.30 \times 0.20 \times 0.05 \mathrm{~mm}^{3}$

1.78 to $31.44^{\circ}$.

$-18<=\mathrm{h}<=18,-19<=\mathrm{k}<=18,-31<=\mathrm{l}<=31$

66507

$11930[\mathrm{R}(\mathrm{int})=0.1232]$

$94.5 \%$

Semi-empirical from equivalents

0.9714 and 0.8444

Full-matrix least-squares on $\mathrm{F}^{2}$

11930 / 15 / 467

1.010

$\mathrm{R} 1=0.0702, \mathrm{wR} 2=0.1559$

$\mathrm{R} 1=0.1644, \mathrm{wR} 2=0.1971$

1.222 and -0.566 e. $\AA^{-3}$ 
Table A1.2. Crystal data and structure refinement for $\left[\left(\left(\mathrm{PhBP}_{3}\right) \mathrm{Fe}\right)_{2}(\mu-\mathrm{S})\right][\mathrm{Na}(12$-crown4) 2 ] (2.2).

Identification code

Empirical formula

P0.38 S0.06

Formula weight

Temperature

Wavelength

Crystal system

Space group

Unit cell dimensions

Volume

Z

Density (calculated)

Absorption coefficient

$\mathrm{F}(000)$

Crystal size

Theta range for data collection

Index ranges

Reflections collected

Independent reflections

Completeness to theta $=26.43^{\circ}$

Refinement method

Data / restraints / parameters

Goodness-of-fit on $\mathrm{F}^{2}$

Final $\mathrm{R}$ indices [I $>2 \operatorname{sigma}(\mathrm{I})]$

$\mathrm{R}$ indices (all data)

Largest diff. peak and hole jsa01_0m

C6.62 H7.12 B0.12 Fe0.12 Na0.06 O0.50

118.14

296(2) K

$0.71073 \AA$

Monoclinic

$\mathrm{C} 2 / \mathrm{C}$

$\mathrm{a}=25.1189(12) \AA \quad \alpha=90^{\circ}$.

$\mathrm{b}=13.2882(6) \AA \quad \beta=94.365(2)^{\circ}$.

$\mathrm{c}=28.3900(13) \AA \quad \gamma=90^{\circ}$.

9448.7(8) $\AA^{3}$

64

$1.329 \mathrm{Mg} / \mathrm{m}^{3}$

$0.493 \mathrm{~mm}^{-1}$

3972

$0.57 \times 0.34 \times 0.26 \mathrm{~mm}^{3}$

1.73 to $26.43^{\circ}$.

$-31<=\mathrm{h}<=31,-16<=\mathrm{k}<=16,-35<=\mathrm{l}<=35$

74372

$9722[\mathrm{R}(\mathrm{int})=0.0624]$

$99.8 \%$

Full-matrix least-squares on $\mathrm{F}^{2}$

9722 / 4000 / 1059

1.035

$\mathrm{R} 1=0.0472, w R 2=0.1148$

$\mathrm{R} 1=0.0751, \mathrm{wR} 2=0.1329$

1.020 and -0.341 e. $\AA^{-3}$ 
Table A1.3. Crystal data and structure refinement for $\left[\left(\left(\mathrm{PhBP}_{3}\right) \mathrm{Fe}\right)_{2}(\mu-\mathrm{S})\right][\mathrm{Na}(12$-crown-

$\left.4)_{2}\right]_{2}(\mathbf{2 . 3})$.

Identification code

Empirical formula

Formula weight

Temperature

Wavelength

Crystal system

Space group

Unit cell dimensions

Volume

$\mathrm{Z}$

Density (calculated)

Absorption coefficient

$\mathrm{F}(000)$

Crystal size

Theta range for data collection

Index ranges

Reflections collected

Independent reflections

Completeness to theta $=24.71^{\circ}$

Absorption correction

Max. and min. transmission

Refinement method

Data / restraints / parameters

Goodness-of-fit on $\mathrm{F}^{2}$

Final $\mathrm{R}$ indices [I $>2 \operatorname{sigma}(\mathrm{I})]$

$\mathrm{R}$ indices (all data)

Largest diff. peak and hole jsa42_0m

C138 H178 B2 Fe2 Na2 O20 P6 S

2553.98

100(2) K

$0.71073 \AA$

Triclinic

P-1

$\mathrm{a}=12.5634(6) \AA \quad \alpha=82.174(3)^{\circ}$.

$\mathrm{b}=18.2367(10) \AA \quad \beta=79.885(3)^{\circ}$.

$\mathrm{c}=29.0547(17) \AA \quad \gamma=88.640(2)^{\circ}$.

6492.4(6) $\AA^{3}$

2

$1.306 \mathrm{Mg} / \mathrm{m}^{3}$

$0.387 \mathrm{~mm}^{-1}$

2712

$0.5 \times 0.2 \times 0.1 \mathrm{~mm}^{3}$

1.42 to $24.71^{\circ}$.

$-14<=\mathrm{h}<=14,-21<=\mathrm{k}<=21,-34<=\mathrm{l}<=34$

113949

$21981[\mathrm{R}(\mathrm{int})=0.1035]$

$99.3 \%$

Semi-empirical from equivalents

0.7456 and 0.6813

Full-matrix least-squares on $\mathrm{F}^{2}$

21981 / 1697 / 1544

1.011

$\mathrm{R} 1=0.0623, \mathrm{wR} 2=0.1286$

$\mathrm{R} 1=0.1182, \mathrm{wR} 2=0.1507$

0.919 and -0.767 e. $\AA^{-3}$ 
Table A1.4. Crystal data and structure refinement for $\left(\left(\mathrm{PhBP}_{3}\right) \mathrm{Fe}\right)\left(\mu-\eta^{1}: \eta^{1}-\mathrm{N}_{2} \mathrm{H}_{4}\right)(\mu-$ $\left.\eta^{2}: \eta^{2}-\mathrm{N}_{2} \mathrm{H}_{2}\right)\left(\left(\mathrm{PhBP}_{2} \mathrm{PS}\right) \mathrm{Fe}\right)(\mathbf{2 . 4})$.

Identification code

Empirical formula

Formula weight

Temperature

Wavelength

Crystal system

Space group

Unit cell dimensions

Volume

Z

Density (calculated)

Absorption coefficient

$\mathrm{F}(000)$

Crystal size

Theta range for data collection Index ranges

Reflections collected

Independent reflections

Completeness to theta $=25.23^{\circ}$

Refinement method

Data / restraints / parameters

Goodness-of-fit on $\mathrm{F}^{2}$

Final $\mathrm{R}$ indices [I $>2 \operatorname{sigma}(\mathrm{I})]$

$\mathrm{R}$ indices (all data)

Largest diff. peak and hole jsa218

C90 H88 B2 Fe2 N4 O P6 S

1592.84

293(2) K

$0.71073 \AA$

Monoclinic

P-1

$\mathrm{a}=12.575(3) \AA$ $\alpha=85.92(3)^{\circ}$.

$\mathrm{b}=15.871(3) \AA$ $\beta=75.18(3)^{\circ}$.

$\mathrm{c}=22.750(5) \AA$ $\gamma=76.30(3)^{\circ}$. 4264.2(15) $\AA^{3}$

2

$1.241 \mathrm{Mg} / \mathrm{m}^{3}$

$0.525 \mathrm{~mm}^{-1}$

1664

0.93 to $25.23^{\circ}$.

$-15<=\mathrm{h}<=15,-18<=\mathrm{k}<=18,-27<=\mathrm{l}<=27$

47144

$12523[\mathrm{R}($ int $)=0.0466]$

$81.3 \%$

Full-matrix least-squares on $\mathrm{F}^{2}$

12523 / 4582 / 1243

1.056

$\mathrm{R} 1=0.0570, \mathrm{wR} 2=0.1738$

$\mathrm{R} 1=0.0612, \mathrm{wR} 2=0.1777$

0.518 and -0.777 e. $\AA^{-3}$ 
Figure A1.1. XRD Structure of $\left(\left(\mathrm{PhBP}_{3}\right) \mathrm{Fe}\right)\left(\mu-\eta^{1}: \eta^{1}-\mathrm{N}_{2} \mathrm{H}_{4}\right)\left(\mu-\eta^{2}: \eta^{2}-\right.$

$\left.\mathrm{N}_{2} \mathrm{H}_{2}\right)\left(\left(\mathrm{PhBP}_{2} \mathrm{PS}\right) \mathrm{Fe}\right)(\mathbf{2 . 4})$ with ellipsoids at $50 \%$ and $\mathrm{C}-\mathrm{H}$ hydrogens and solvents removed for clarity.

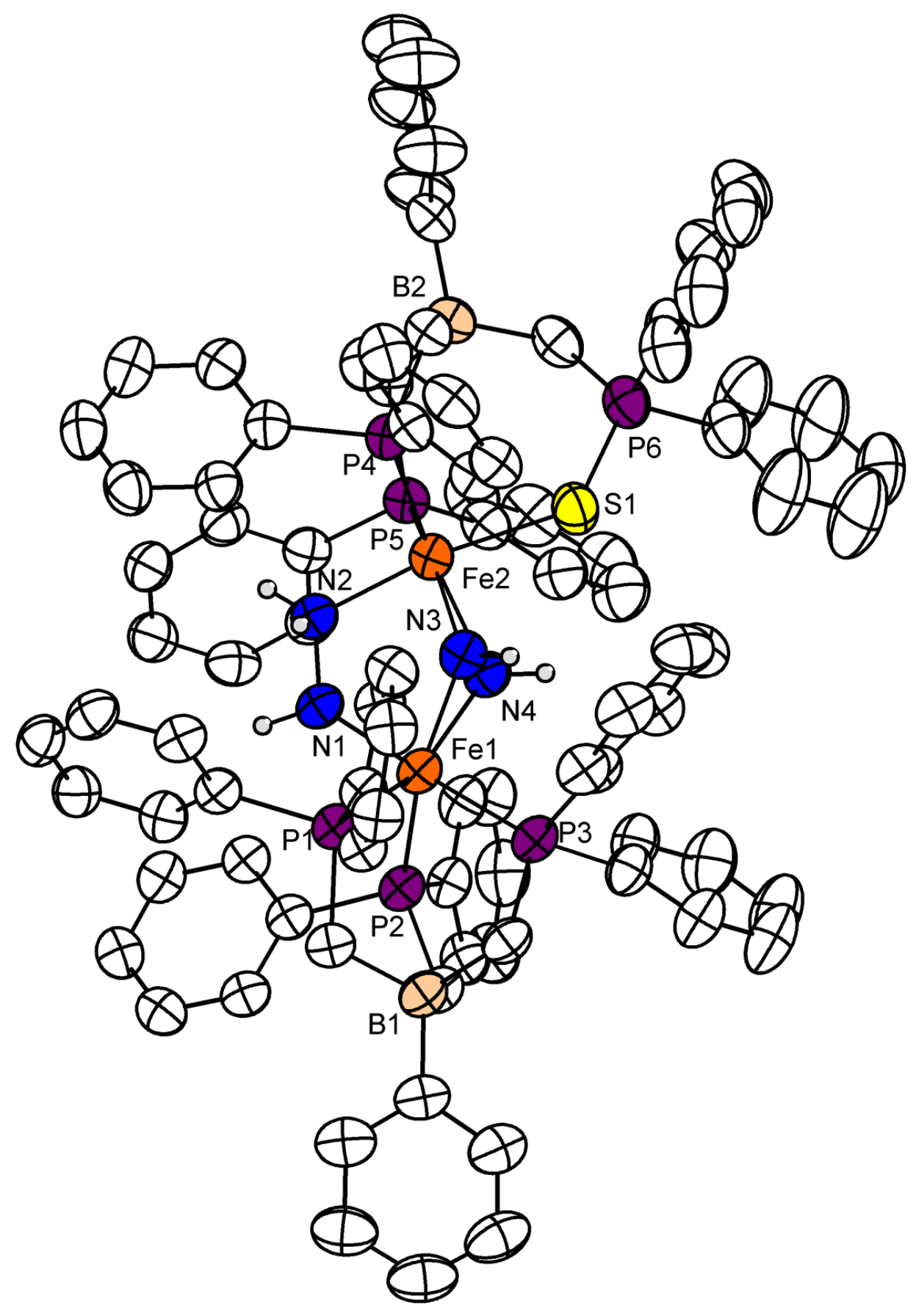


Table A1.5. Crystal data and structure refinement for $\left(\left(\mathrm{PhBP}_{3}\right) \mathrm{Fe}(\mathrm{CO})\right)_{2}(\mu-\mathrm{S})(\mathbf{2 . 5})$.

Identification code

Empirical formula

Formula weight

Temperature

Wavelength

Crystal system

Space group

Unit cell dimensions

Volume

$\mathrm{Z}$

Density (calculated)

Absorption coefficient

$\mathrm{F}(000)$

Crystal size

Theta range for data collection

Index ranges

Reflections collected

Independent reflections

Completeness to theta $=29.14^{\circ}$

Refinement method

Data / restraints / parameters

Goodness-of-fit on $\mathrm{F}^{2}$

Final $\mathrm{R}$ indices [I $>2 \operatorname{sigma}(\mathrm{I})]$

$\mathrm{R}$ indices (all data)

Largest diff. peak and hole jsa05_0m

C100 H98 B2 Fe2 O4 P6 S

1714.98

296(2) K

$0.71073 \AA$

Monoclinic

$\mathrm{P} 2(1) / \mathrm{m}$

$\mathrm{a}=23.8929(7) \AA \quad \alpha=90^{\circ}$.

$\mathrm{b}=13.1133(4) \AA$ $\beta=91.443(2)^{\circ}$.

$\mathrm{c}=26.9690(8) \AA$ $\gamma=90^{\circ}$.

$$
\text { 8447.1(4) } \AA^{3}
$$

4

$1.349 \mathrm{Mg} / \mathrm{m}^{3}$

$0.536 \mathrm{~mm}^{-1}$

3592

$0.23 \times 0.19 \times 0.13 \mathrm{~mm}^{3}$

1.77 to $29.14^{\circ}$.

$-32<=\mathrm{h}<=32,-17<=\mathrm{k}<=17,-36<=\mathrm{l}<=36$

164026

22722 [R(int) $=0.0829]$

$99.9 \%$

Full-matrix least-squares on $\mathrm{F}^{2}$

22722 / 2460 / 1235

1.077

$\mathrm{R} 1=0.0518, \mathrm{wR} 2=0.1452$

$\mathrm{R} 1=0.0873, \mathrm{wR} 2=0.1683$

0.970 and -0.781 e. $\AA^{-3}$ 
Figure A1.2. XRD Structure of $\left(\left(\mathrm{PhBP}_{3}\right) \mathrm{Fe}(\mathrm{CO})\right)_{2}(\mu-\mathrm{S})(\mathbf{2 . 5})$ with ellipsoids at $50 \%$ and hydrogens and solvents removed for clarity.

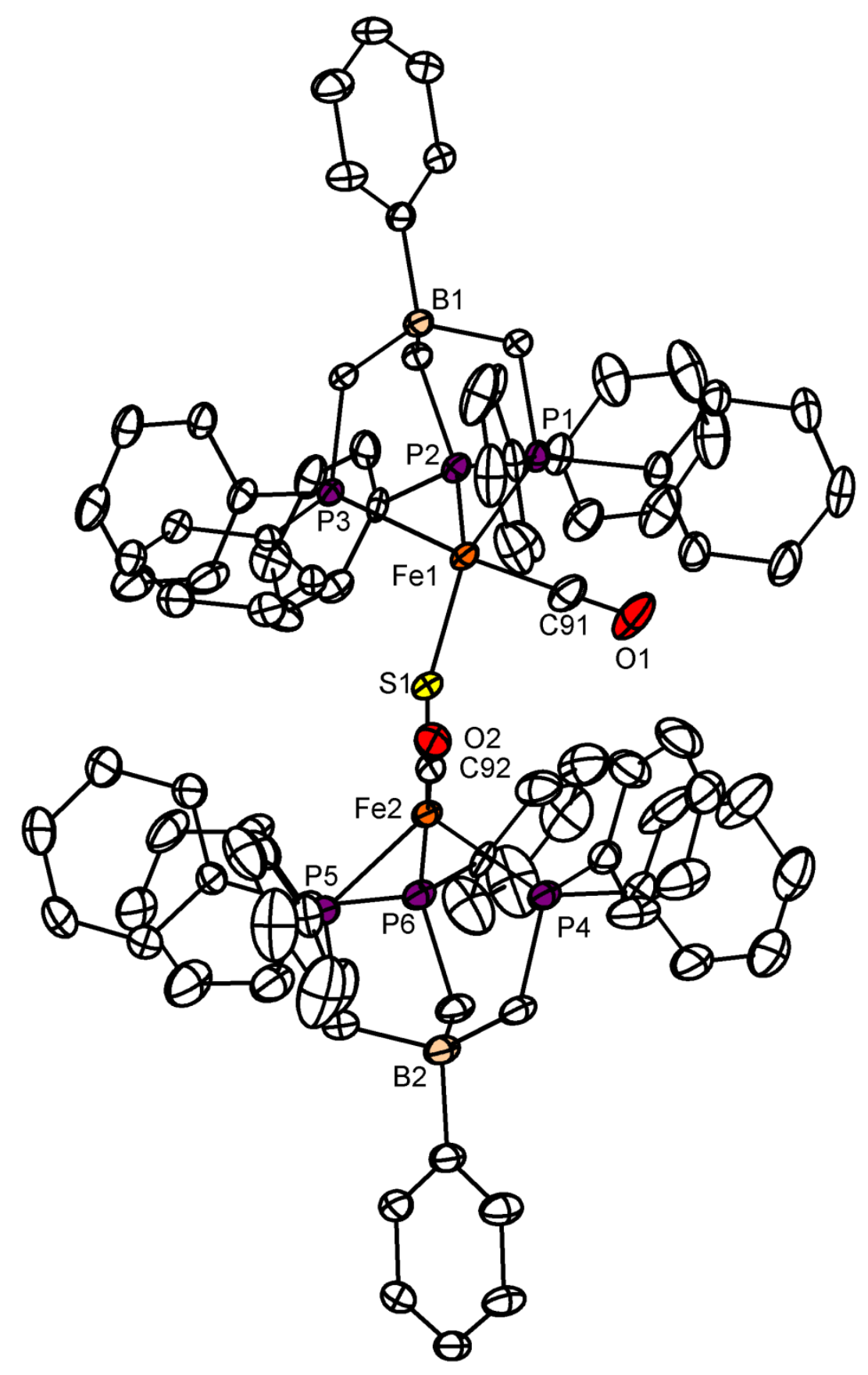


Figure A1.3. Comparison of Variable Temperature Magnetic Fits of $\left[\left(\left(\mathrm{PhBP}_{3}\right) \mathrm{Fe}\right)_{2}(\mu-\right.$ $\mathrm{S})][\mathrm{Na}(12$-crown-4) 2$](\mathbf{2 . 2})$

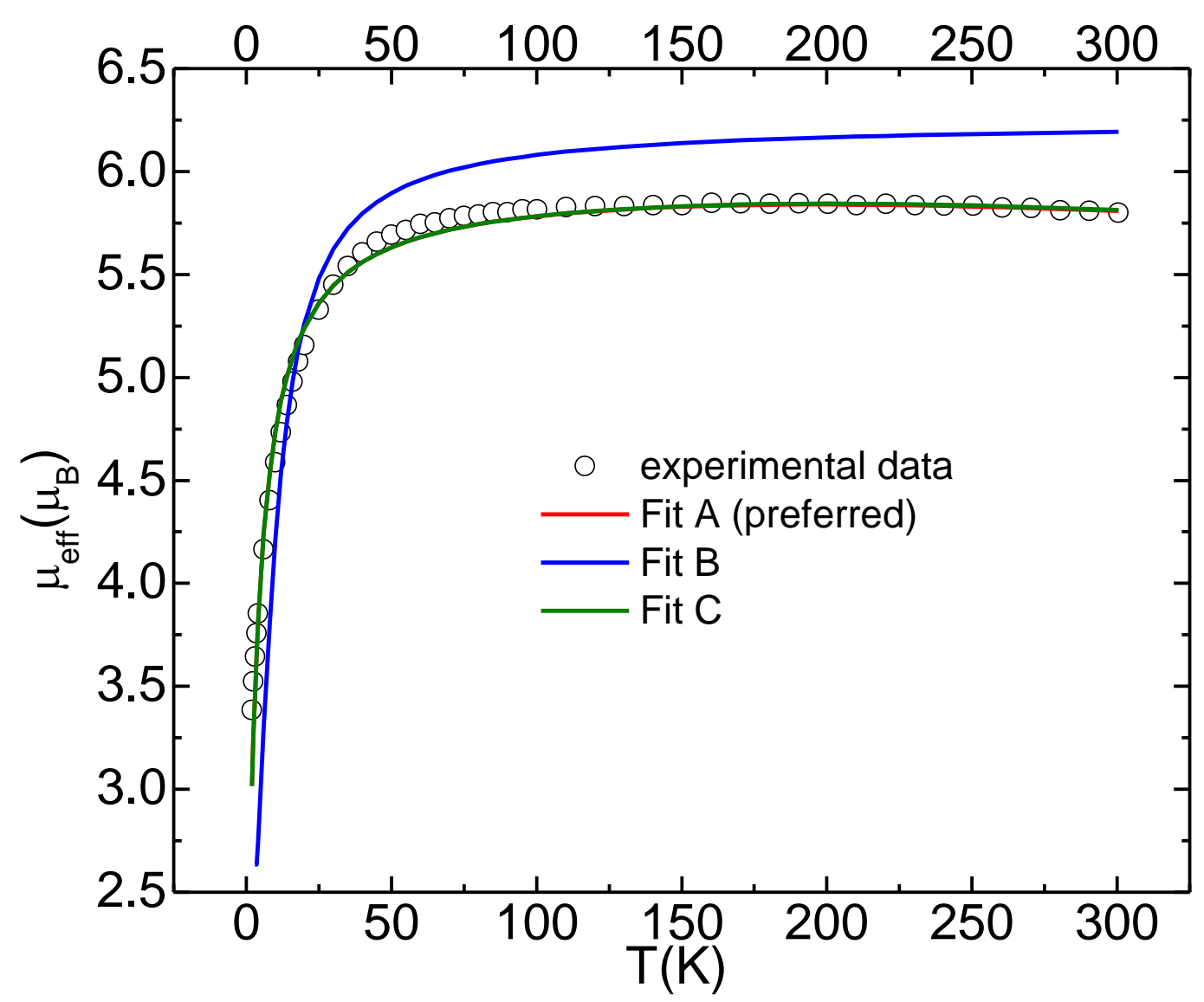

\begin{tabular}{cccc}
\hline Fit Parameters & A & B & C \\
\hline$g$ & 2.01 & 2.00 & 2.01 \\
$S_{1}$ & 2 & 2 & 1 \\
$S_{2}$ & 0.5 & 1.5 & 1.5 \\
$J_{12}\left(\mathrm{~cm}^{-1)}\right.$ & 110 & -1.5 & 118 \\
$\Theta(\mathrm{K})$ & -5.7 & 1.6 & -5.7 \\
\hline
\end{tabular}


Appendix 2: Supplementary Data for Chapter 3 
Table A2.1. Crystal data and structure refinement for (TPB)FeMe (3.1).

Identification code

Empirical formula

Formula weight

Temperature

Wavelength

Crystal system

Space group

Unit cell dimensions

Volume

Z

Density (calculated)

Absorption coefficient

$\mathrm{F}(000)$

Crystal size

Theta range for data collection

Index ranges

Reflections collected

Independent reflections

Completeness to theta $=27.10^{\circ}$

Refinement method

Data / restraints / parameters

Goodness-of-fit on $\mathrm{F}^{2}$

Final $\mathrm{R}$ indices [I $>2 \operatorname{sigma}(\mathrm{I})]$

$\mathrm{R}$ indices (all data)

Largest diff. peak and hole jsa200m

C37 H57 B Cl Fe P3

696.85

293(2) K

$0.71073 \AA$

Triclinic

P-1

$\mathrm{a}=10.9554(3) \AA \quad \alpha=91.4010(10)^{\circ}$.

$\mathrm{b}=11.5075(3) \AA \quad \beta=95.4060(10)^{\circ}$.

$\mathrm{c}=15.9312(4) \AA \quad \gamma=117.8130(10)^{\circ}$.

$1763.16(8) \AA^{3}$

2

$1.313 \mathrm{Mg} / \mathrm{m}^{3}$

$0.665 \mathrm{~mm}^{-1}$

744

$.456 \times .304 \times .209 \mathrm{~mm}^{3}$

1.29 to $27.10^{\circ}$.

$-14<=\mathrm{h}<=14,-14<=\mathrm{k}<=14,-20<=\mathrm{l}<=20$

36496

$7758[\mathrm{R}($ int $)=0.0311]$

$99.8 \%$

Full-matrix least-squares on $\mathrm{F}^{2}$

7758 / 338 / 402

1.086

$\mathrm{R} 1=0.0321, \mathrm{wR} 2=0.0813$

$\mathrm{R} 1=0.0371, \mathrm{wR} 2=0.0860$

0.890 and -0.305 e. $\AA^{-3}$ 
Table A2.2. Crystal data and structure refinement for $[(\mathrm{TPB}) \mathrm{Fe}]\left[\mathrm{BAr} \mathrm{F}_{4}\right](3.2)$.

Identification code

Empirical formula

Formula weight

Temperature

Wavelength

Crystal system

Space group

Unit cell dimensions

Volume

Z

Density (calculated)

Absorption coefficient

$\mathrm{F}(000)$

Crystal size

Theta range for data collection

Index ranges

Reflections collected

Independent reflections

Completeness to theta $=33.73^{\circ}$

Absorption correction

Max. and min. transmission

Refinement method

Data / restraints / parameters

Goodness-of-fit on $\mathrm{F}^{2}$

Final $\mathrm{R}$ indices [I $>2 \operatorname{sigma}(\mathrm{I})]$

$\mathrm{R}$ indices (all data)

Largest diff. peak and hole mem130

C68 H66 B2 F24 Fe N0 P3 Si0

1509.59

100(2) K

$0.71073 \AA$

Orthorhombic

Pbca

$a=26.4056(9) \AA \quad \alpha=90^{\circ}$.

$\mathrm{b}=19.7833(7) \AA \quad \beta=90^{\circ}$.

$\mathrm{c}=26.4402(9) \AA \quad \gamma=90^{\circ}$.

13812.1(8) $\AA^{3}$

8

$1.452 \mathrm{Mg} / \mathrm{m}^{3}$

$0.393 \mathrm{~mm}^{-1}$

6168

$0.32 \times 0.30 \times 0.26 \mathrm{~mm}^{3}$

1.85 to $33.73^{\circ}$.

$-35<=\mathrm{h}<=41,-30<=\mathrm{k}<=30,-41<=\mathrm{l}<=41$

379408

$27590[\mathrm{R}(\mathrm{int})=0.0500]$

$100.0 \%$

Semi-empirical from equivalents

0.9046 and 0.8844

Full-matrix least-squares on $\mathrm{F}^{2}$

27590 / 18 / 951

1.062

$\mathrm{R} 1=0.0496, \mathrm{wR} 2=0.1239$

$\mathrm{R} 1=0.0744, \mathrm{wR} 2=0.1400$

0.740 and -0.532 e. $\AA^{-3}$ 
Table A2.3. Crystal data and structure refinement for $\left[(\mathrm{TPB}) \mathrm{Fe}\left(\mathrm{N}_{2} \mathrm{H}_{4}\right)\right]\left[\mathrm{BAr}{ }^{\mathrm{F}}{ }_{4}\right](3.3)$.

\begin{tabular}{|c|c|c|}
\hline Identification code & \multicolumn{2}{|l|}{ jsa19_0m } \\
\hline Empirical formula & \multicolumn{2}{|c|}{ C78 H68 B2 F24 Fe N2 P3 } \\
\hline Formula weight & \multicolumn{2}{|l|}{1659.72} \\
\hline Temperature & \multicolumn{2}{|l|}{$296(2) \mathrm{K}$} \\
\hline Wavelength & \multicolumn{2}{|l|}{$0.71073 \AA$} \\
\hline Crystal system & \multicolumn{2}{|l|}{ Orthorhombic } \\
\hline Space group & \multicolumn{2}{|l|}{ Pbca } \\
\hline \multirow[t]{3}{*}{ Unit cell dimensions } & $a=20.0031(7) \AA$ & $\alpha=90^{\circ}$ \\
\hline & $\mathrm{b}=25.7862(8) \AA$ & $\beta=90^{\circ}$ \\
\hline & $c=26.6970(8) \AA$ & $\gamma=90^{\circ}$ \\
\hline Volume & \multicolumn{2}{|l|}{$13770.4(8) \AA^{3}$} \\
\hline $\mathrm{Z}$ & \multicolumn{2}{|l|}{8} \\
\hline Density (calculated) & \multicolumn{2}{|l|}{$1.601 \mathrm{Mg} / \mathrm{m}^{3}$} \\
\hline Absorption coefficient & \multicolumn{2}{|l|}{$0.404 \mathrm{~mm}^{-1}$} \\
\hline $\mathrm{F}(000)$ & \multicolumn{2}{|l|}{6776} \\
\hline Crystal size & \multicolumn{2}{|c|}{$0.46 \times 0.26 \times 0.15 \mathrm{~mm}^{3}$} \\
\hline Theta range for data collection & \multicolumn{2}{|l|}{2.00 to $32.59^{\circ}$. } \\
\hline Index ranges & \multicolumn{2}{|c|}{$-30<=\mathrm{h}<=30,-39<=\mathrm{k}<=39,-40<=\mathrm{l}<=40$} \\
\hline Reflections collected & \multicolumn{2}{|l|}{347031} \\
\hline Independent reflections & \multicolumn{2}{|c|}{$25087[\mathrm{R}(\mathrm{int})=0.0696]$} \\
\hline Completeness to theta $=32.59^{\circ}$ & \multicolumn{2}{|l|}{$99.9 \%$} \\
\hline Max. and min. transmission & \multicolumn{2}{|l|}{0.9419 and 0.8361} \\
\hline Refinement method & \multicolumn{2}{|c|}{ Full-matrix least-squares on $\mathrm{F}^{2}$} \\
\hline Data / restraints / parameters & \multicolumn{2}{|l|}{25087 / 971 / 981} \\
\hline Goodness-of-fit on $\mathrm{F}^{2}$ & \multicolumn{2}{|l|}{0.937} \\
\hline Final $R$ indices $[\mathrm{I}>2 \operatorname{sigma}(\mathrm{I})]$ & \multicolumn{2}{|c|}{$\mathrm{R} 1=0.0531, \mathrm{wR} 2=0.1373$} \\
\hline $\mathrm{R}$ indices (all data) & \multicolumn{2}{|c|}{$\mathrm{R} 1=0.0872, \mathrm{wR} 2=0.1681$} \\
\hline Largest diff. peak and hole & \multicolumn{2}{|c|}{1.295 and $-0.755 \mathrm{e} . \AA^{-3}$} \\
\hline
\end{tabular}


Table A2.4. Crystal data and structure refinement for $\left[(\mathrm{TPB}) \mathrm{Fe}\left(\mathrm{NH}_{3}\right)\right]\left[\mathrm{BAr} \mathrm{F}_{4}\right](\mathbf{3 . 4})$.

Identification code

Empirical formula

Formula weight

Temperature

Wavelength

Crystal system

Space group

Unit cell dimensions

Volume

Z

Density (calculated)

Absorption coefficient

$\mathrm{F}(000)$

Crystal size

Theta range for data collection

Index ranges

Reflections collected

Independent reflections

Completeness to theta $=25.18^{\circ}$

Refinement method

Data / restraints / parameters

Goodness-of-fit on $\mathrm{F}^{2}$

Final $\mathrm{R}$ indices [I $>2 \operatorname{sigma}(\mathrm{I})]$

$\mathrm{R}$ indices (all data)

Largest diff. peak and hole xds_ascii

C68 H80 B4 F24 Fe N2 O2 P3

1605.34

293(2) K

$0.71073 \AA$

Orthorhombic

Pbca

$\begin{array}{ll}\mathrm{a}=19.846(4) \AA & \alpha=90^{\circ} . \\ \mathrm{b}=25.821(5) \AA & \beta=90^{\circ} . \\ \mathrm{c}=26.862(5) \AA & \gamma=90^{\circ} .\end{array}$

$13765(5) \AA^{3}$

8

$1.549 \mathrm{Mg} / \mathrm{m}^{3}$

$0.402 \mathrm{~mm}^{-1}$

6600

$.25 \times .15 \times .15 \mathrm{~mm}^{3}$

1.50 to $25.18^{\circ}$.

$-23<=\mathrm{h}<=23,-30<=\mathrm{k}<=30,-32<=\mathrm{l}<=32$

155016

$12232[\mathrm{R}($ int $)=0.0175]$

$99.0 \%$

Full-matrix least-squares on $\mathrm{F}^{2}$

12232 / 972 / 961

1.041

$\mathrm{R} 1=0.0606, \mathrm{wR} 2=0.1680$

$\mathrm{R} 1=0.0620, \mathrm{wR} 2=0.1692$

1.741 and -1.346 e. $\AA^{-3}$ 
Table A2.5. Crystal data and structure refinement for (TPB)FeNH $2(3.5)$.

Identification code
Empirical formula
Formula weight
Temperature
Wavelength
Crystal system
Space group
Unit cell dimensions

Volume

$\mathrm{Z}$

Density (calculated)

Absorption coefficient

$\mathrm{F}(000)$

Crystal size

Theta range for data collection

Index ranges

Reflections collected

Independent reflections

Completeness to theta $=28.28^{\circ}$

Max. and min. transmission

Refinement method

Data / restraints / parameters

Goodness-of-fit on $\mathrm{F}^{2}$

Final $\mathrm{R}$ indices [I $>2 \operatorname{sigma}(\mathrm{I})]$

$\mathrm{R}$ indices (all data)

Largest diff. peak and hole jsa23_0m

C36 H56 B Fe N P3

662.39

100(2) K

$0.71073 \AA$

Triclinic

P-1

$\mathrm{a}=10.9229(9) \AA \quad \alpha=77.268(7)^{\circ}$.

$\mathrm{b}=11.2493(13) \AA \quad \beta=84.862(5)^{\circ}$.

$\mathrm{c}=16.5084(15) \AA \quad \gamma=61.117(4)^{\circ}$.

1732.1(3) $\AA^{3}$

2

$1.483 \mathrm{Mg} / \mathrm{m}^{3}$

$0.615 \mathrm{~mm}^{-1}$

812

$0.23 \times 0.15 \times 0.15 \mathrm{~mm}^{3}$

2.11 to $28.28^{\circ}$.

$-14<=\mathrm{h}<=14,-14<=\mathrm{k}<=14,-22<=\mathrm{l}<=22$

52847

$8561[\mathrm{R}(\mathrm{int})=0.0706]$

$99.7 \%$

0.9134 and 0.8715

Full-matrix least-squares on $\mathrm{F}^{2}$

8561 / 2 / 397

1.120

$\mathrm{R} 1=0.0545, \mathrm{wR} 2=0.1236$

$\mathrm{R} 1=0.0810, \mathrm{wR} 2=0.1324$

1.541 and -0.646 e. $\AA^{-3}$ 
Table A2.6. Crystal data and structure refinement for (TPB)FeOH (3.6).

Identification code

Empirical formula

Formula weight

Temperature

Wavelength

Crystal system

Space group

Unit cell dimensions

Volume

$\mathrm{Z}$

Density (calculated)

Absorption coefficient

$\mathrm{F}(000)$

Crystal size

Theta range for data collection

Index ranges

Reflections collected

Independent reflections

Completeness to theta $=37.78^{\circ}$

Max. and min. transmission

Refinement method

Data / restraints / parameters

Goodness-of-fit on $\mathrm{F}^{2}$

Final $\mathrm{R}$ indices [I $>2 \operatorname{sigma}(\mathrm{I})]$

$\mathrm{R}$ indices (all data)

Largest diff. peak and hole jsa21_0m

C36 H56 B Fe N O P3

678.39

100(2) K

$0.71073 \AA$

Triclinic

P-1

$\mathrm{a}=10.9554(4) \AA \quad \alpha=77.466(2)^{\circ}$.

$\mathrm{b}=11.3311(4) \AA \quad \beta=78.105(2)^{\circ}$.

$\mathrm{c}=16.6454(7) \AA \quad \gamma=61.338(2)^{\circ}$.

1757.30(12) $\AA^{3}$

2

$1.282 \mathrm{Mg} / \mathrm{m}^{3}$

$0.595 \mathrm{~mm}^{-1}$

726

$10.00 \times 0.29 \times 0.17 \mathrm{~mm}^{3}$

2.07 to $37.78^{\circ}$.

$-18<=\mathrm{h}<=17,-19<=\mathrm{k}<=19,-28<=\mathrm{l}<=28$

142106

$18846[\mathrm{R}(\mathrm{int})=0.0433]$

$100.0 \%$

0.9056 and 0.0661

Full-matrix least-squares on $\mathrm{F}^{2}$

18846 / 1 / 382

1.024

$\mathrm{R} 1=0.0316, \mathrm{wR} 2=0.0745$

$\mathrm{R} 1=0.0477, \mathrm{wR} 2=0.0810$

0.810 and -0.493 e. $\AA^{-3}$ 
Figure A2.1. Crystal Structure for (TPB)FeOH (3.6) with ellipsoids at 50\% and $\mathrm{C}-\mathrm{H}$ hydrogens omitted for clarity.

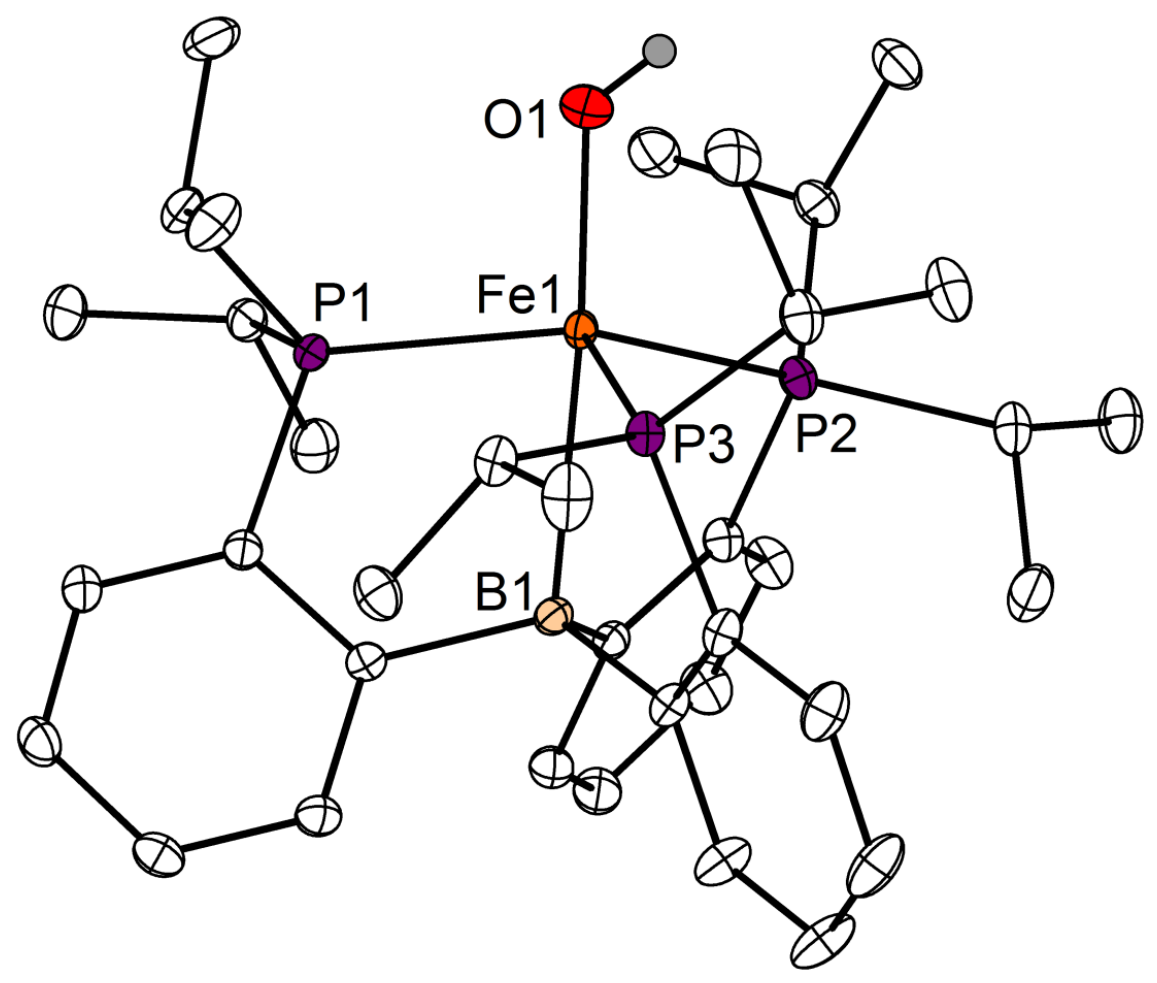


Figure A2.2. NMR traces of the monitored decomposition of 3.3 to 3.4.

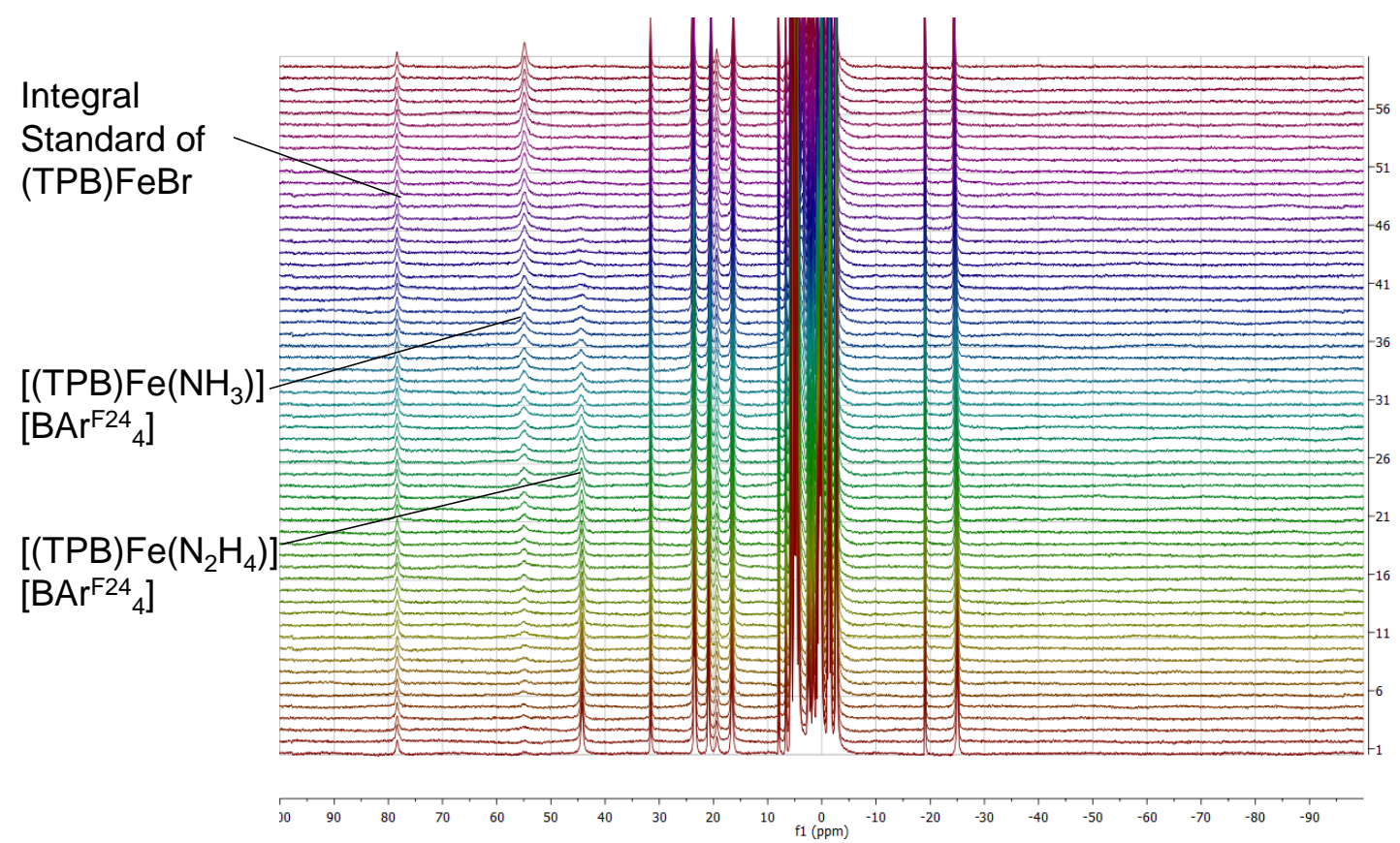

Conditions: $0.037 \mathrm{M}, \mathrm{C}_{6} \mathrm{D}_{6} / \mathrm{THF}-\mathrm{d}^{8}, 60^{\circ} \mathrm{C}$, Total time $=4 \mathrm{~h}$. Only $2^{\text {nd }}$ hour is shown.

Table A2.7. Product quantification for the decomposition of $\mathbf{3 . 3}$ to $\mathbf{3 . 4}$.

\begin{tabular}{cccc}
\hline Run & Equiv $\mathbf{H}_{2}$ & Equiv $\mathbf{N}_{\mathbf{2}} \mathbf{H}_{\mathbf{4}}$ & Equiv $\mathbf{N H}_{\mathbf{3}}$ \\
\hline 1 & 0.01 & None det. & 0.09 \\
2 & 0.009 & None det. & 0.12 \\
3 & None det. & None det. & 0.14 \\
\hline
\end{tabular}


Figure A2.3. Titration of THF into a $4 \mathrm{~mL}$ ethereal solution of 3.2.

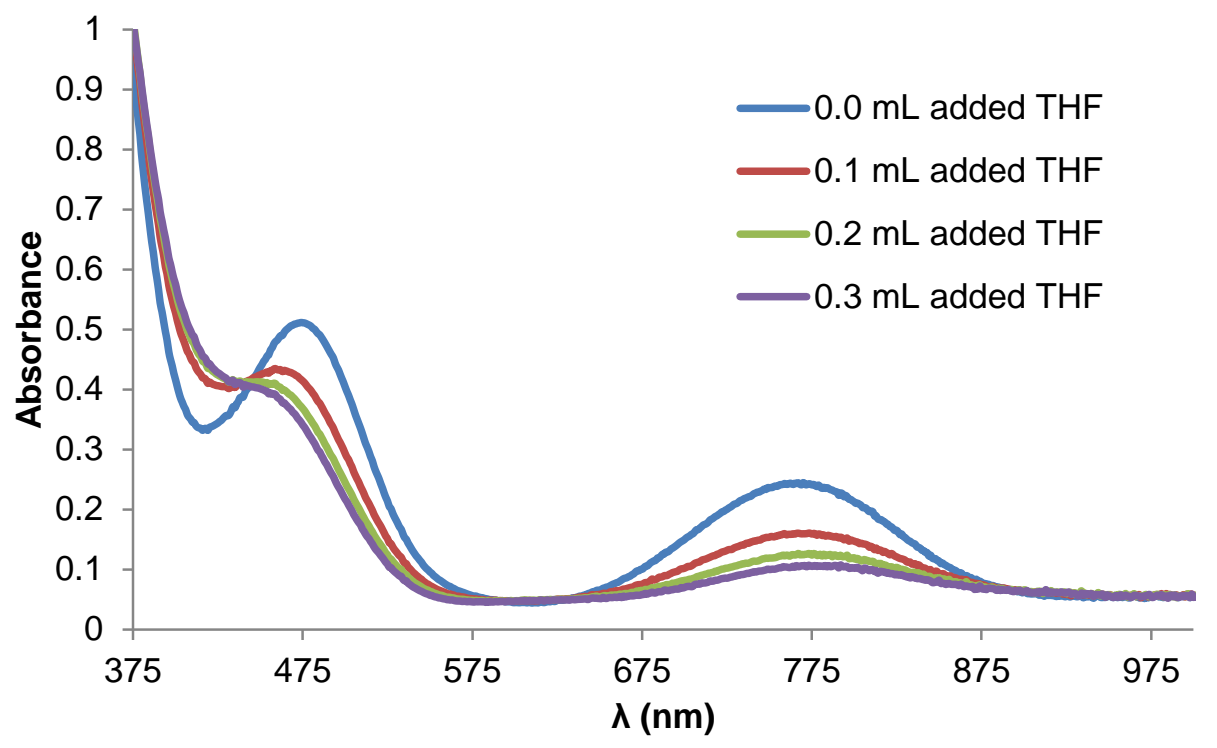


Figure A2.4. $\mathrm{MO}$ and spin density diagram of $[(\mathrm{TPB}) \mathrm{Fe}]^{+}($3.2) optimized at the B3LYP/6-31G(d) level.
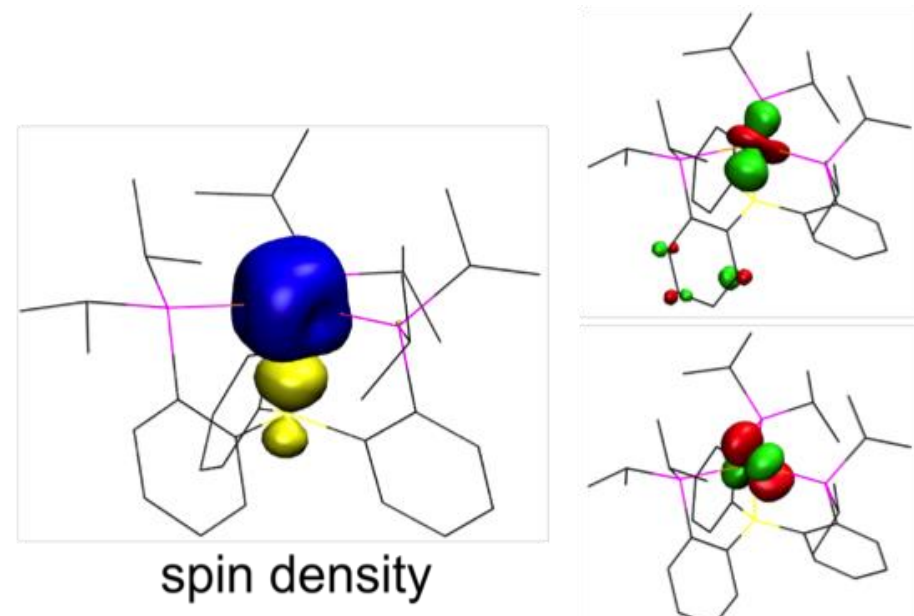

$-0.135$

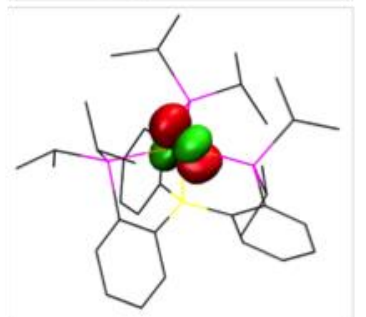

$-0.143$

$-0.151$
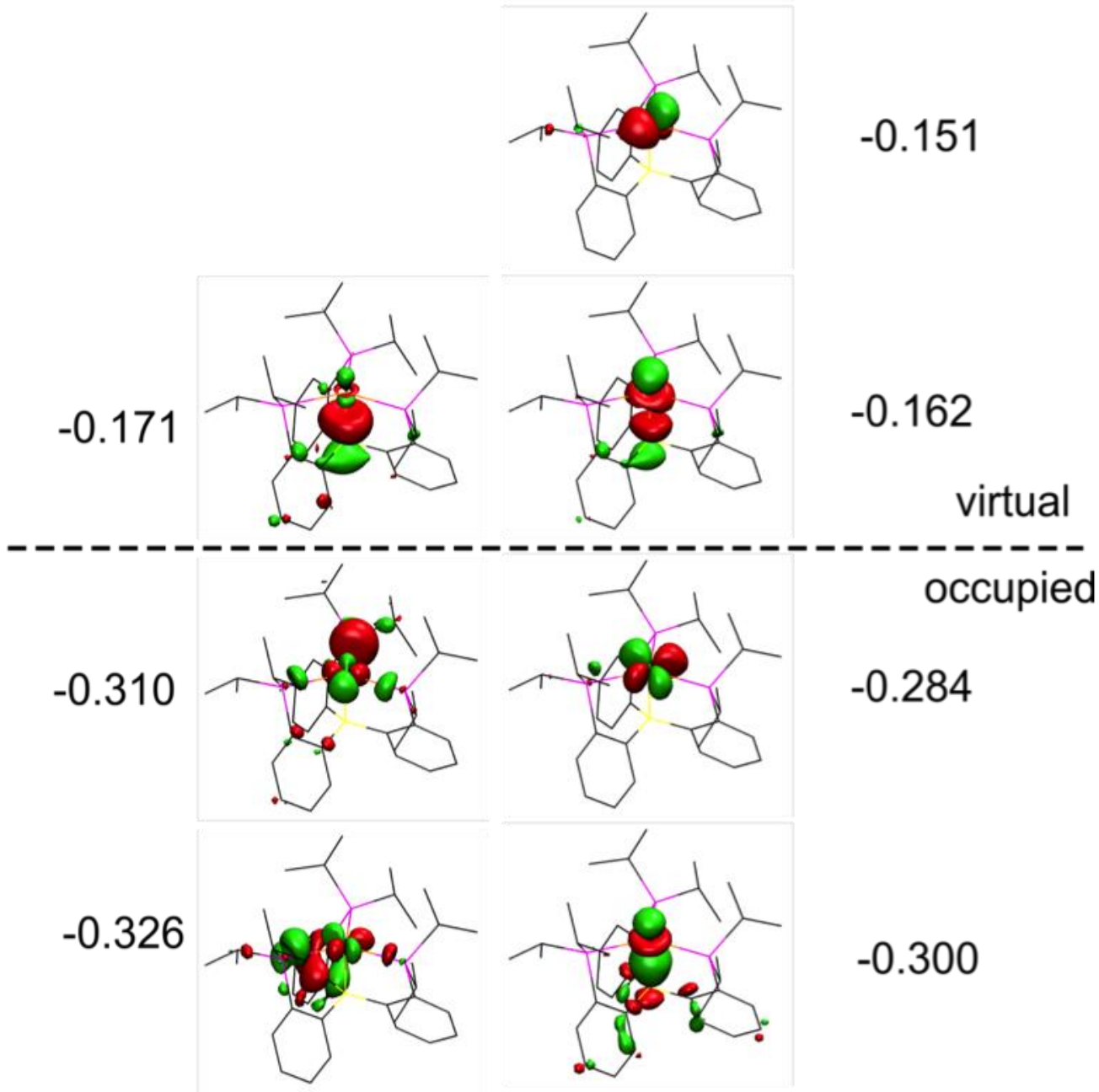
Figure A2.5. MO diagram addressing the T-shaped distortion in 3.2.

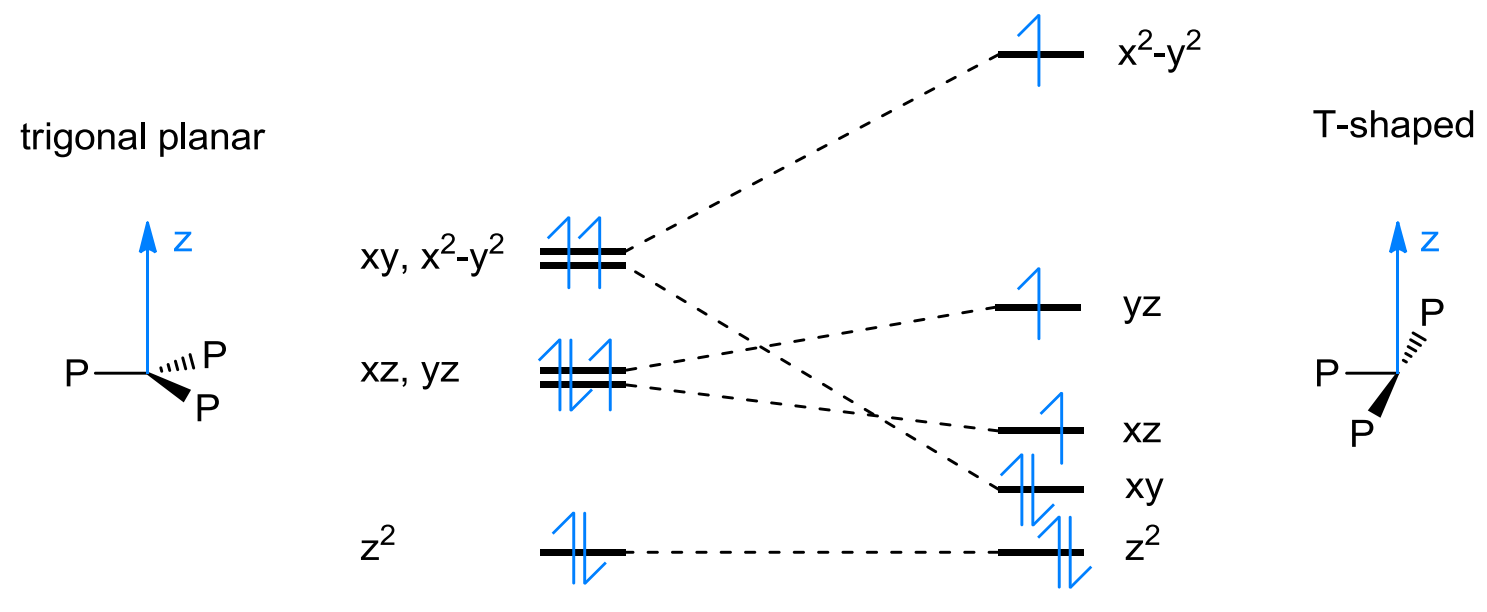

Highest doubly occupied $d$ orbital:
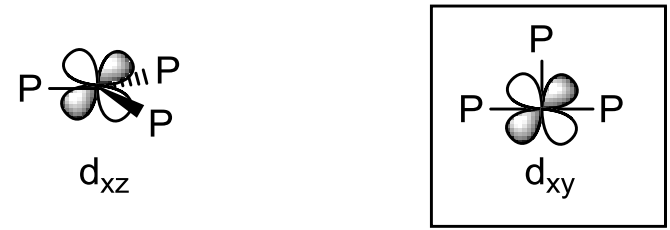

strong p-backdonation with all three phosphine ligands 
Figure A2.6. Variable Temperature Magnetic data for 3.2-3.5.

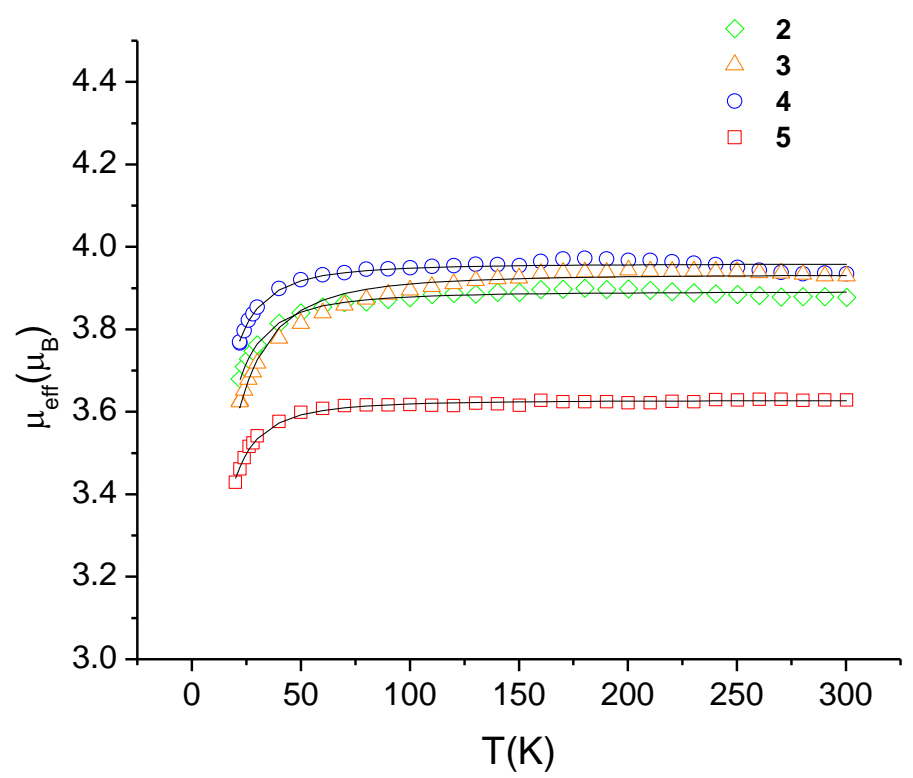

Data corrected for $\sim 15 \%$ diamagnetic impurity of 12 -crown-4, verified by ${ }^{1} \mathrm{H}$ NMR integration, in 3.5.

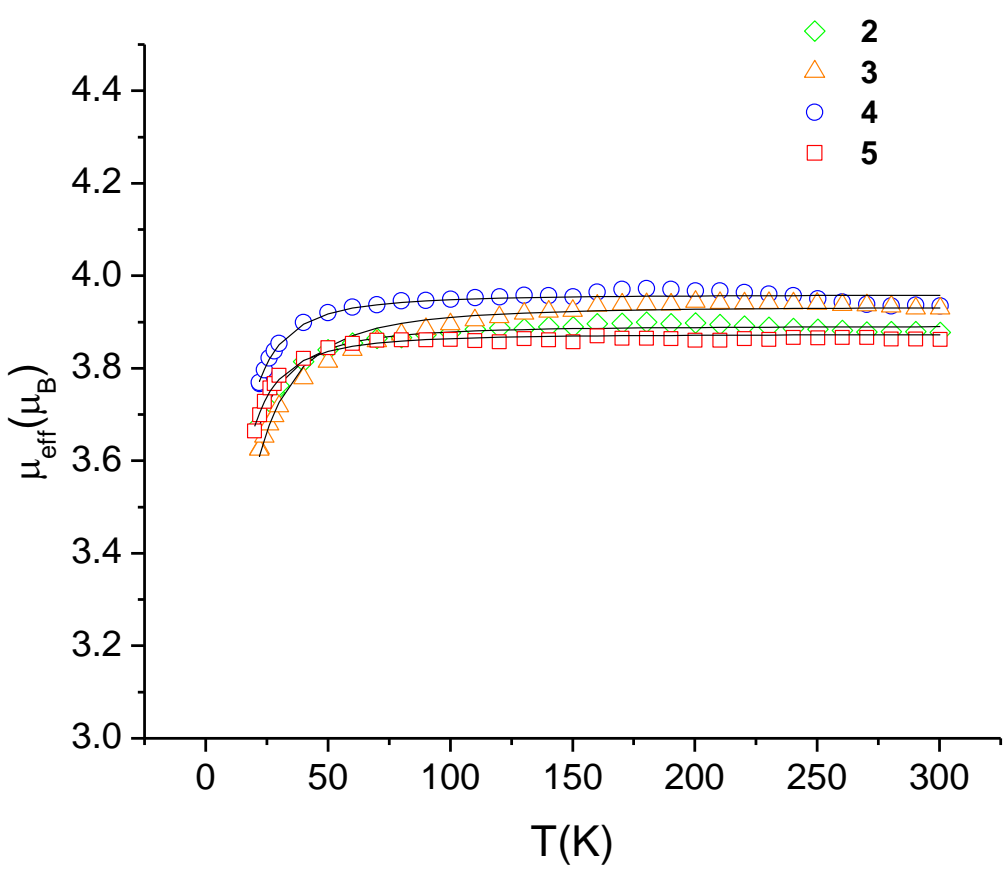


Table A2.8. Simulation parameters for the variable temperature data for complexes 3.2-

3.5.

\begin{tabular}{cccc}
\hline Compound & $S$ & $\mathrm{~g}$ & $\mathrm{D}\left(\mathrm{cm}^{-1}\right)$ \\
\hline$\left[\mathrm{TPB}^{\mathrm{iPr}} \mathrm{Fe}\right]\left[\mathrm{BAr}_{4}{ }_{4}\right]$ & $3 / 2$ & 2.009 & 13.933 \\
{$\left[\mathrm{TPB}^{\mathrm{iPr}} \mathrm{Fe}\left(\mathrm{N}_{2} \mathrm{H}_{4}\right)\right]\left[\mathrm{BAr}{ }_{4}\right]$} & $3 / 2$ & 2.031 & 19.937 \\
{$\left[\mathrm{TPB}^{\mathrm{iPr}} \mathrm{Fe}\left(\mathrm{NH}_{3}\right)\right]\left[\mathrm{BAr}_{4}{ }_{4}\right]$} & $3 / 2$ & 2.044 & 12.162 \\
$\left(\mathrm{TPB}^{\mathrm{iPr}}\right) \mathrm{Fe}\left(\mathrm{NH}_{2}\right)$ & $3 / 2$ & 2.000 & 11.348 \\
\hline
\end{tabular}


Table A2.9. B3LYP/6-31G(d) DFT Optimized coordinates $[\AA]$ for $[(\mathrm{TPB}) \mathrm{Fe}]^{+}($3.2).

\begin{tabular}{|c|c|c|c|}
\hline $\mathrm{Fe}$ & 0.00415000 & -0.16241600 & -0.77675900 \\
\hline $\mathrm{P}$ & -2.16349100 & -1.24719000 & -0.66738800 \\
\hline $\mathrm{P}$ & 2.39121900 & -0.83777200 & -0.74771500 \\
\hline $\mathrm{P}$ & -0.31345400 & 2.27645200 & -0.74537300 \\
\hline $\mathrm{C}$ & 2.09021700 & -1.73435800 & 0.82972400 \\
\hline $\mathrm{C}$ & 4.02952400 & 1.02631900 & 0.64266200 \\
\hline $\mathrm{H}$ & 3.98567100 & 0.45071500 & 1.57275400 \\
\hline $\mathrm{H}$ & 3.19104000 & 1.72365500 & 0.64140500 \\
\hline $\mathrm{H}$ & 4.95767100 & 1.60939200 & 0.65520800 \\
\hline $\mathrm{C}$ & -2.51735800 & -0.85749000 & 1.09566800 \\
\hline $\mathrm{C}$ & -2.75787900 & 2.84164700 & 0.59302900 \\
\hline $\mathrm{H}$ & -2.24972100 & 3.20855200 & 1.49066600 \\
\hline $\mathrm{H}$ & -2.90111300 & 1.76680700 & 0.71127400 \\
\hline $\mathrm{H}$ & -3.74621500 & 3.31410800 & 0.55282800 \\
\hline $\mathrm{C}$ & 0.96713000 & -1.34366200 & 1.61726000 \\
\hline $\mathrm{C}$ & 0.68267900 & 1.41376900 & 1.69824000 \\
\hline $\mathrm{C}$ & -3.77585900 & -1.11913600 & 1.66212900 \\
\hline $\mathrm{H}$ & -4.53614800 & -1.64204200 & 1.09100300 \\
\hline $\mathrm{C}$ & -1.50541500 & -0.21277600 & 1.85301900 \\
\hline $\mathrm{C}$ & -1.85207300 & 0.20954700 & 3.15263700 \\
\hline $\mathrm{H}$ & -1.11562400 & 0.74145000 & 3.74897600 \\
\hline $\mathrm{C}$ & 0.63534800 & 3.23145700 & -2.06275600 \\
\hline $\mathrm{H}$ & 0.57728600 & 4.28918000 & -1.78194000 \\
\hline $\mathrm{C}$ & 1.88147700 & 2.83955400 & 3.29296500 \\
\hline $\mathrm{H}$ & 2.40769300 & 2.94283300 & 4.23815900 \\
\hline $\mathrm{C}$ & 0.69310600 & -2.13340400 & 2.75608400 \\
\hline $\mathrm{H}$ & -0.16599700 & -1.88793000 & 3.37259400 \\
\hline $\mathrm{C}$ & 4.03129200 & 0.10104900 & -0.58072200 \\
\hline $\mathrm{H}$ & 4.06604600 & 0.72216800 & -1.48419000 \\
\hline $\mathrm{C}$ & 1.38189800 & 1.59489600 & 2.90786900 \\
\hline $\mathrm{H}$ & 1.54195100 & 0.73989400 & 3.56048800 \\
\hline B & 0.03447200 & -0.03107800 & 1.40854000 \\
\hline $\mathrm{C}$ & 5.27977700 & -0.79677000 & -0.55921200 \\
\hline $\mathrm{H}$ & 6.17024200 & -0.16055800 & -0.49330400 \\
\hline $\mathrm{H}$ & 5.38965200 & -1.41148800 & -1.45674600 \\
\hline $\mathrm{H}$ & 5.28761200 & -1.45308000 & 0.31716600 \\
\hline $\mathrm{C}$ & 1.72157800 & 3.94568000 & 2.45737900 \\
\hline $\mathrm{H}$ & 2.12008100 & 4.91463800 & 2.74408600 \\
\hline $\mathrm{C}$ & 1.05459100 & 3.79624400 & 1.24157800 \\
\hline $\mathrm{H}$ & 0.95646000 & 4.65573100 & 0.58420600 \\
\hline $\mathrm{C}$ & 2.77223500 & -2.14130600 & -2.05044100 \\
\hline $\mathrm{H}$ & 3.66239200 & -2.68641700 & -1.71685100 \\
\hline $\mathrm{C}$ & -4.07155000 & -0.72325700 & 2.96514500 \\
\hline $\mathrm{H}$ & -5.04800100 & -0.93619400 & 3.3 \\
\hline
\end{tabular}


190

$\begin{array}{lrrr}\mathrm{C} & -3.10700900 & -0.04189100 & 3.70690700 \\ \mathrm{H} & -3.32936500 & 0.29181200 & 4.71691400 \\ \mathrm{C} & 2.87573600 & -2.83838200 & 1.19803000 \\ \mathrm{H} & 3.71142600 & -3.14386600 & 0.57548300 \\ \mathrm{C} & -1.96911100 & 3.20280400 & -0.67407900 \\ \mathrm{H} & -2.51737400 & 2.81757600 & -1.54509900 \\ \mathrm{C} & 1.62859900 & -3.14880400 & -2.20719100 \\ \mathrm{H} & 0.71343900 & -2.65749200 & -2.56047300 \\ \mathrm{H} & 1.40294400 & -3.66587600 & -1.27050000 \\ \mathrm{H} & 1.89809900 & -3.90564800 & -2.95299300 \\ \mathrm{C} & 1.49436100 & -3.21131000 & 3.13086000 \\ \mathrm{H} & 1.25256900 & -3.77768600 & 4.02619200 \\ \mathrm{C} & 2.11687300 & 2.84858500 & -2.14500700 \\ \mathrm{H} & 2.24202800 & 1.80944900 & -2.46700100 \\ \mathrm{H} & 2.62947700 & 2.97816400 & -1.18858400 \\ \mathrm{H} & 2.61717700 & 3.48566700 & -2.88385400 \\ \mathrm{C} & -2.49731300 & -3.09116600 & -0.81402900 \\ \mathrm{H} & -3.54555800 & -3.21968300 & -0.51323400 \\ \mathrm{C} & 2.59216700 & -3.56984800 & 2.34988300 \\ \mathrm{H} & 3.21486600 & -4.41610400 & 2.62556400 \\ \mathrm{C} & -1.61976400 & -3.87498400 & 0.17378600 \\ \mathrm{H} & -1.85554000 & -4.94310500 & 0.10319500 \\ \mathrm{H} & -1.78498100 & -3.56065100 & 1.20749500 \\ \mathrm{H} & -0.55428900 & -3.75363600 & -0.04648600 \\ \mathrm{C} & 0.53094900 & 2.55057600 & 0.86165400 \\ \mathrm{C} & -1.86943800 & 4.73224900 & -0.80367000 \\ \mathrm{H} & -2.87736400 & 5.16043800 & -0.75057800 \\ \mathrm{H} & -1.42999600 & 5.06125000 & -1.74899100 \\ \mathrm{H} & -1.29175300 & 5.16729800 & 0.01900400 \\ \mathrm{C} & -2.95949200 & -0.11225400 & -3.13193300 \\ \mathrm{H} & -2.81329100 & -1.04459900 & -3.68700100 \\ \mathrm{H} & -2.00927500 & 0.43395300 & -3.13573300 \\ \mathrm{H} & -3.68632300 & 0.48853300 & -3.69112200 \\ \mathrm{C} & -3.47778300 & -0.36144900 & -1.70257400 \\ \mathrm{H} & -3.55367100 & 0.61070400 & -1.20046300 \\ \mathrm{H} & -2.34128800 & -3.61958100 & -2.24860700 \\ \mathrm{H} & -1.32591600 & -3.46834000 & -2.62965700 \\ \mathrm{H} & -3.03896300 & -3.15266000 & -2.94927700 \\ \mathrm{H} & -2.53763200 & -4.69785800 & -2.26329900 \\ \mathrm{H} & -1.096475900 & 3.05060900 & -3.43027100 \\ \mathrm{H} & 3.00786500 & 2.00371300 & -3.75748600 \\ \mathrm{H} & & -1.45897600 & -3.39314100 \\ \mathrm{H} & -22923900 & -0.88166100 & -3.75845100\end{array}$




$\begin{array}{llll}\mathrm{C} & -4.87834200 & -0.99390800 & -1.73157800 \\ \mathrm{H} & -5.54599600 & -0.36236200 & -2.32962300 \\ \mathrm{H} & -4.87513300 & -1.98675200 & -2.19255400 \\ \mathrm{H} & -5.32164500 & -1.07767600 & -0.73669900 \\ \mathrm{H} & 0.47189800 & 3.64859800 & -4.18772700\end{array}$


Table A2.10. B3LYP/6-31G(d) DFT Optimized coordinates $\left[\AA\right.$ ] for $\left[\left(\mathrm{Me}_{2} \mathrm{PhP}\right)_{3} \mathrm{Fe}\right]^{+}$.

\begin{tabular}{|c|c|c|c|}
\hline $\mathrm{Fe}$ & 0.15864700 & -0.18495700 & -0.99760500 \\
\hline $\mathrm{P}$ & -0.96396300 & 1.83613500 & -1.46879900 \\
\hline $\mathrm{P}$ & -0.45971000 & -2.22271000 & -0.05600500 \\
\hline $\mathrm{P}$ & 2.48332300 & -0.04211700 & -1.31271800 \\
\hline $\mathrm{C}$ & -2.26951200 & -2.22907300 & 0.27519800 \\
\hline $\mathrm{C}$ & -1.24228800 & 2.66879600 & 0.14383800 \\
\hline $\mathrm{C}$ & -2.79182200 & -2.06800000 & 1.56749900 \\
\hline $\mathrm{C}$ & 4.03948300 & -1.45884400 & 0.61288100 \\
\hline $\mathrm{C}$ & -0.64552100 & 3.89539800 & 0.47185600 \\
\hline $\mathrm{H}$ & -0.02266300 & 4.41711100 & -0.24807900 \\
\hline $\mathrm{C}$ & -2.04536400 & 2.02460300 & 1.10222300 \\
\hline $\mathrm{C}$ & -2.25786700 & 2.60533100 & 2.35188400 \\
\hline $\mathrm{H}$ & -2.89062600 & 2.10308200 & 3.07801800 \\
\hline $\mathrm{C}$ & 3.22714900 & -1.29680000 & -2.44619800 \\
\hline $\mathrm{H}$ & 4.32141000 & -1.26188800 & -2.43248400 \\
\hline $\mathrm{C}$ & 4.38348500 & -0.67980900 & 2.87994900 \\
\hline $\mathrm{H}$ & 4.81234400 & -0.82007700 & 3.86773800 \\
\hline $\mathrm{C}$ & -4.17301300 & -2.01522100 & 1.77110700 \\
\hline $\mathrm{H}$ & -4.56274900 & -1.90088900 & 2.77861400 \\
\hline $\mathrm{C}$ & 0.31804700 & -2.68760000 & 1.54990900 \\
\hline $\mathrm{H}$ & 1.38960600 & -2.83560300 & 1.38660000 \\
\hline $\mathrm{C}$ & 4.58567000 & -1.63819900 & 1.88602900 \\
\hline $\mathrm{H}$ & 5.17639900 & -2.52519600 & 2.09670500 \\
\hline $\mathrm{C}$ & 3.63159400 & 0.46273300 & 2.59776700 \\
\hline $\mathrm{H}$ & 3.47437400 & 1.21562800 & 3.36480600 \\
\hline $\mathrm{C}$ & 3.08377800 & 0.64390800 & 1.32807100 \\
\hline $\mathrm{H}$ & 2.50486800 & 1.54243900 & 1.12392600 \\
\hline $\mathrm{C}$ & -0.21389600 & -3.73662900 & -1.09026300 \\
\hline $\mathrm{H}$ & -0.63896300 & -4.62100300 & -0.60524200 \\
\hline $\mathrm{C}$ & -0.85737200 & 4.47065600 & 1.72657200 \\
\hline $\mathrm{H}$ & -0.39598100 & 5.42490200 & 1.96403800 \\
\hline $\mathrm{C}$ & -1.66358000 & 3.82933600 & 2.66729400 \\
\hline $\mathrm{H}$ & -1.83040700 & 4.28140300 & 3.64050500 \\
\hline $\mathrm{C}$ & -3.16079100 & -2.32427200 & -0.80796000 \\
\hline $\mathrm{H}$ & -2.78261000 & -2.44971700 & -1.82004800 \\
\hline $\mathrm{C}$ & 3.28247400 & 1.51522500 & -1.91488900 \\
\hline $\mathrm{H}$ & 2.90698900 & 1.75077900 & -2.91604500 \\
\hline $\mathrm{C}$ & -5.04871600 & -2.11906600 & 0.69010800 \\
\hline $\mathrm{H}$ & -6.12191000 & -2.08279500 & 0.85179800 \\
\hline $\mathrm{C}$ & -2.66656800 & 1.64342000 & -2.16885400 \\
\hline $\mathrm{H}$ & -3.18590300 & 2.60610400 & -2.21168900 \\
\hline $\mathrm{C}$ & -4.53907500 & -2.27482500 & -0.60131300 \\
\hline $\mathrm{H}$ & -5.21468500 & -2.36443900 & -1.44718900 \\
\hline 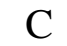 & 3.28537900 & -0.31297600 & 0.31747 \\
\hline
\end{tabular}




$\begin{array}{lrrr}\mathrm{C} & -0.23933400 & 3.11974200 & -2.57722600 \\ \mathrm{H} & 0.77356200 & 3.37847300 & -2.25945300 \\ \mathrm{H} & 2.88637400 & -1.08677000 & -3.46523900 \\ \mathrm{H} & 2.89836600 & -2.30593900 & -2.18218500 \\ \mathrm{H} & 3.02794700 & 2.34344400 & -1.24739500 \\ \mathrm{H} & 4.37260400 & 1.42000600 & -1.95477900 \\ \mathrm{H} & 0.85730500 & -3.89883800 & -1.24746400 \\ \mathrm{H} & -0.68525200 & -3.61298900 & -2.06920800 \\ \mathrm{H} & -0.11632500 & -3.60480000 & 1.96078100 \\ \mathrm{H} & 0.20638200 & -1.87762100 & 2.27591300 \\ \mathrm{H} & -0.85392700 & 4.02578200 & -2.60403500 \\ \mathrm{H} & -0.18044400 & 2.70383300 & -3.58796700 \\ \mathrm{H} & -3.25191000 & 0.95080000 & -1.55774000 \\ \mathrm{H} & -2.59769400 & 1.23085800 & -3.18107000 \\ \mathrm{H} & -2.51936000 & 1.07248800 & 0.87329200 \\ \mathrm{H} & 4.21949800 & -2.21267100 & -0.14752200 \\ \mathrm{H} & -2.13022700 & -1.99363600 & 2.42490400\end{array}$


Appendix 3: Supplementary Data for Chapter 4 
Table A3.1. Crystal data and structure refinement for (TPB)FeCl.

Identification code

Empirical formula

Formula weight

Temperature

Wavelength

Crystal system

Space group

Unit cell dimensions

Volume

Z

Density (calculated)

Absorption coefficient

$\mathrm{F}(000)$

Crystal size

Theta range for data collection

Index ranges

Reflections collected

Independent reflections

Completeness to theta $=40.25^{\circ}$

Refinement method

Data / restraints / parameters

Goodness-of-fit on $\mathrm{F}^{2}$

Final $\mathrm{R}$ indices [I $>2 \operatorname{sigma}(\mathrm{I})]$

$\mathrm{R}$ indices (all data)

Largest diff. peak and hole mem105

C36 H54 B Cl Fe P3

681.81

296(2) K

$0.71073 \AA$

Triclinic

P-1

$\mathrm{a}=10.8929(7) \AA$ $\alpha=91.335(2)^{\circ}$.

$\mathrm{b}=11.5482(7) \AA$ $\beta=97.048(2)^{\circ}$.

$\mathrm{c}=15.8266(9) \AA$ $\gamma=117.325(2)^{\circ}$.

1748.20(18) $\AA^{3}$

2

$1.295 \mathrm{Mg} / \mathrm{m}^{3}$

$0.670 \mathrm{~mm}^{-1}$

726

1.99 to $40.25^{\circ}$.

$-19<=\mathrm{h}<=19,-20<=\mathrm{k}<=20,-28<=\mathrm{l}<=27$

104461

21944 [R(int) $=0.0447]$

$99.9 \%$

Full-matrix least-squares on $\mathrm{F}^{2}$ 21944 / 6 / 417

1.022

$\mathrm{R} 1=0.0363, \mathrm{wR} 2=0.0846$

$\mathrm{R} 1=0.0566, \mathrm{wR} 2=0.0940$

0.668 and -0.982 e. $\AA^{-3}$ 
Figure A3.1. Crystal Structure for (TPB)FeCl with ellipsoids at 50\% and $\mathrm{C}-\mathrm{H}$ hydrogens omitted for clarity.

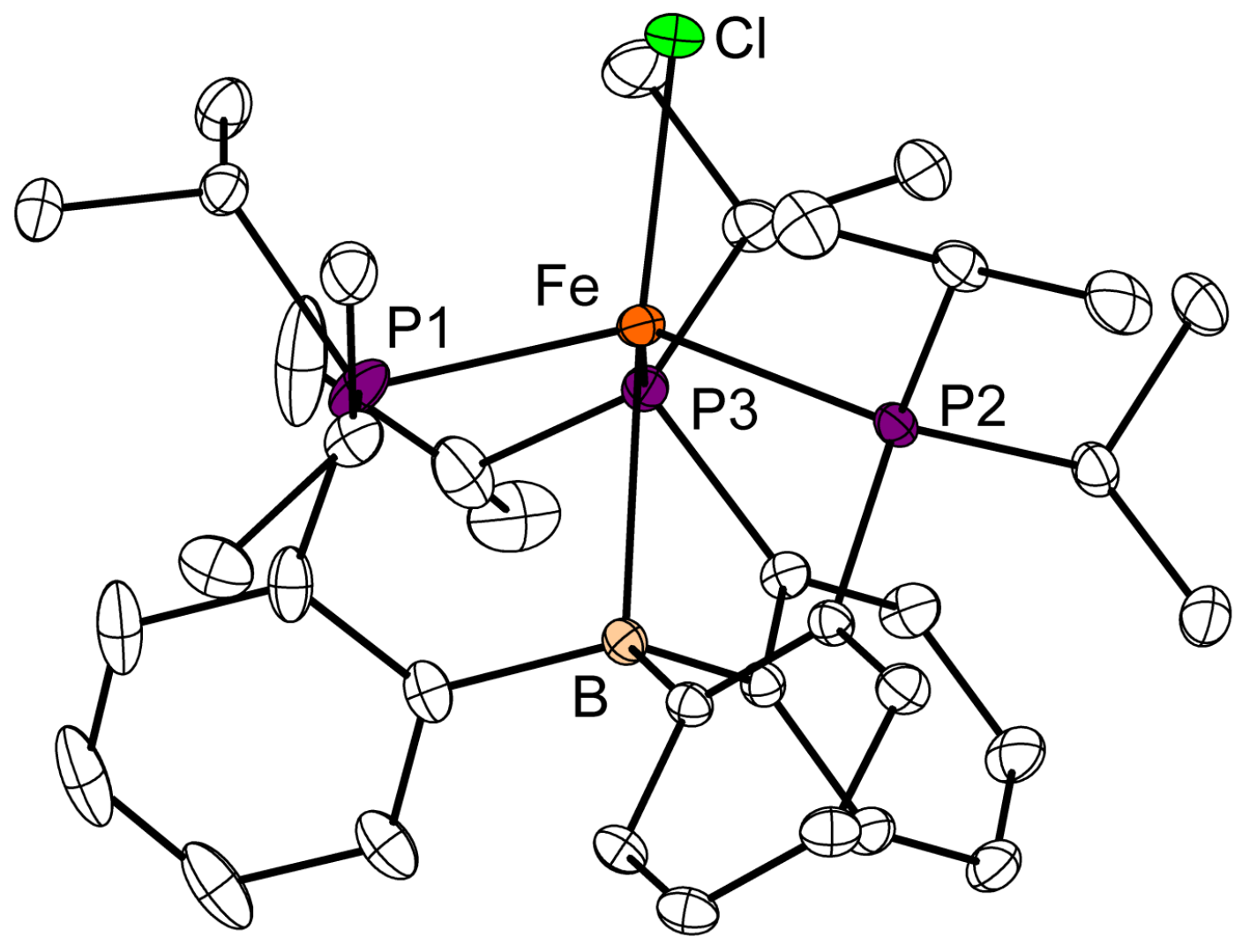


Figure A3.2. ${ }^{1} \mathrm{H}$ NMR spectrum of the reaction mixture following protonation of $\left[(\mathrm{TPB}) \mathrm{Fe}\left(\mathrm{N}_{2}\right)\right]\left[\mathrm{Na}(12 \text {-crown-4) })_{2}\right]$ compared with an authentic sample of $\left[(\mathrm{TPB}) \mathrm{Fe}\left(\mathrm{NH}_{3}\right)\right]\left[\mathrm{BAr}_{4}{ }^{\mathrm{F}}\right]$.
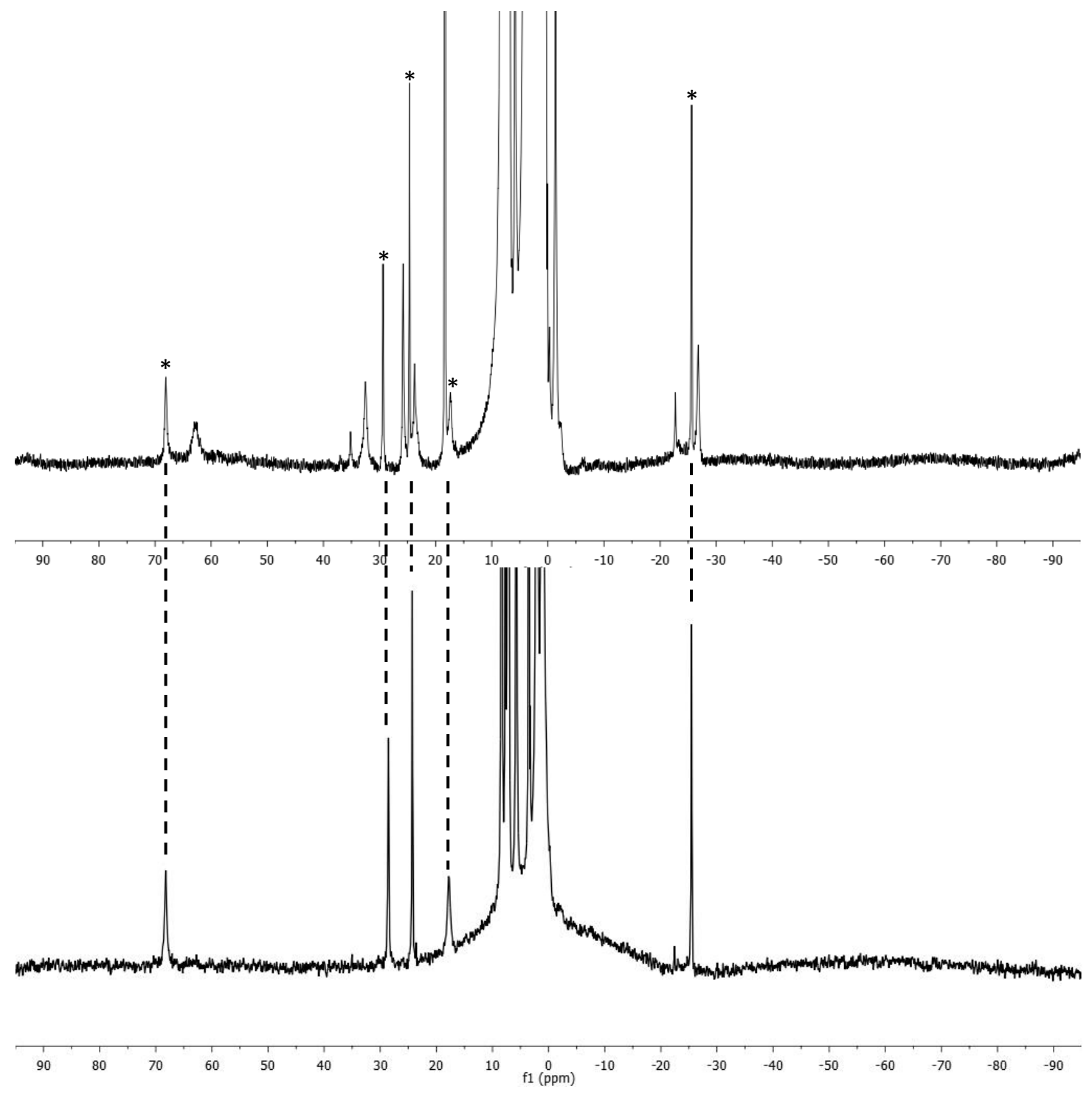

Top: reaction mixture

Bottom: authentic [(TPB)Fe( $\left.\left.\mathrm{NH}_{3}\right)\right]\left[\mathrm{BAr}_{4}{ }_{4}\right]$

Conditions: THF- $d_{8}, 300 \mathrm{MHz}$ 
Figure A3.3. Calibration Curves for $\mathrm{NH}_{3}$ and $\mathrm{N}_{2} \mathrm{H}_{4} \mathrm{UV}-\mathrm{V}$ is quantification.
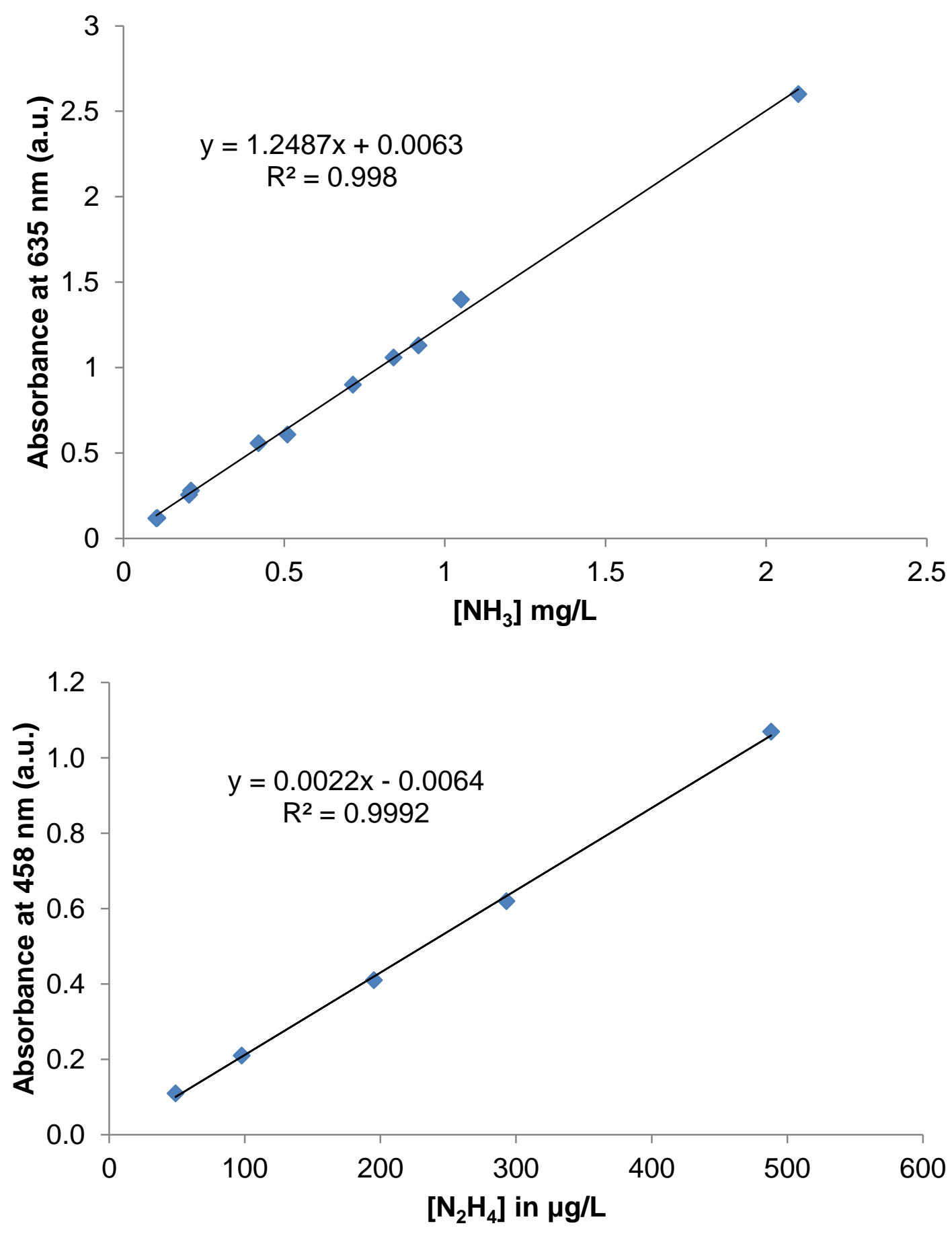
Figure A3.4. IR spectra of addition of 10 equiv $\mathrm{HBAr}_{4} \cdot 2 \mathrm{Et}_{2} \mathrm{O}$ to $\left[(\mathrm{TPB}) \mathrm{Fe}\left(\mathrm{N}_{2}\right)\right]\left[\mathrm{Na}\left(12\right.\right.$-crown-4)2], followed by 12 equiv $\mathrm{KC}_{8}$.

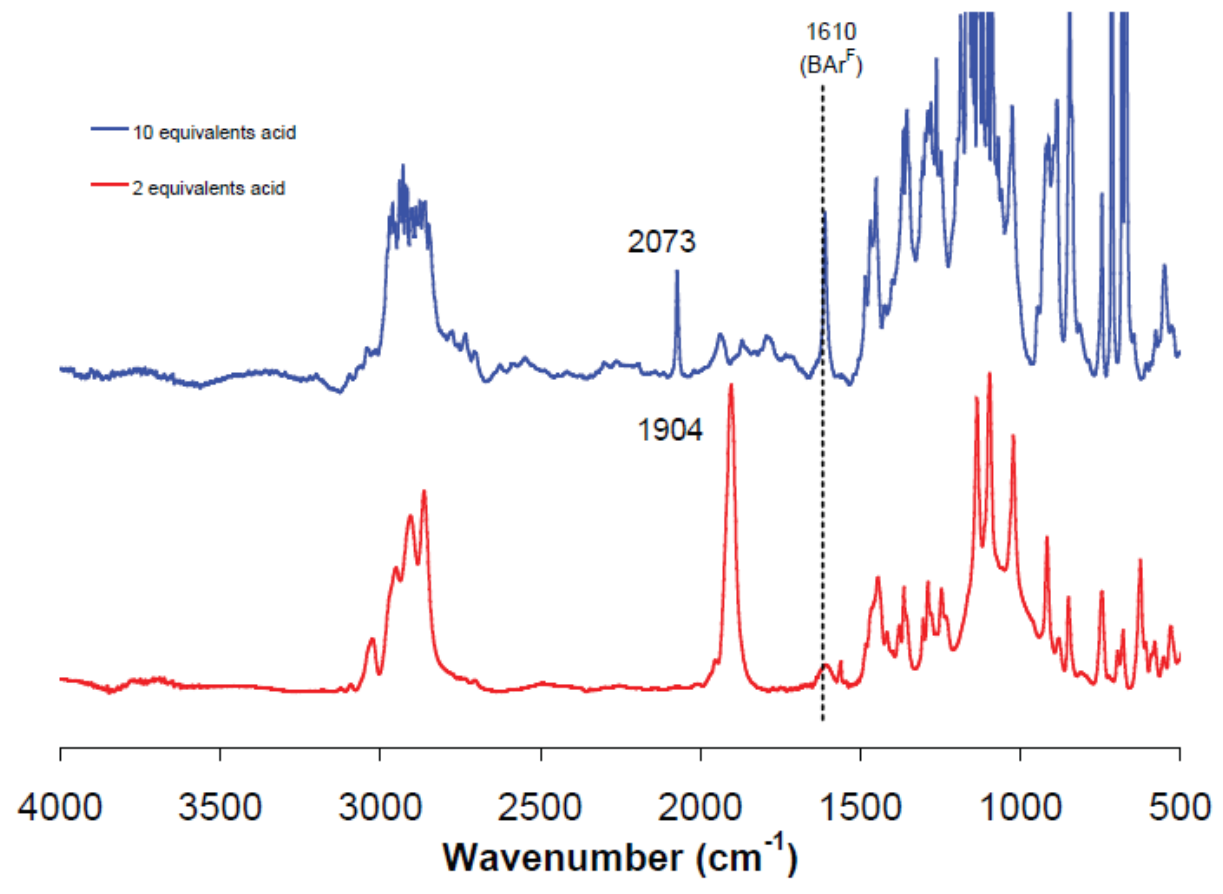


Figure A3.5. ${ }^{31} \mathrm{P}\left\{{ }^{1} \mathrm{H}\right\}$ NMR spectra of addition of 10 equiv $\mathrm{HBAr}^{\mathrm{F}} \cdot 2 \mathrm{Et}_{2} \mathrm{O}$ to $\left[(\mathrm{TPB}) \mathrm{Fe}\left(\mathrm{N}_{2}\right)\right]\left[\mathrm{Na}\left(12\right.\right.$-crown-4)2], followed by 12 equiv $\mathrm{KC}_{8}$.

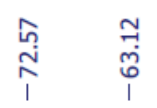<smiles>Pc1ccccc1</smiles>

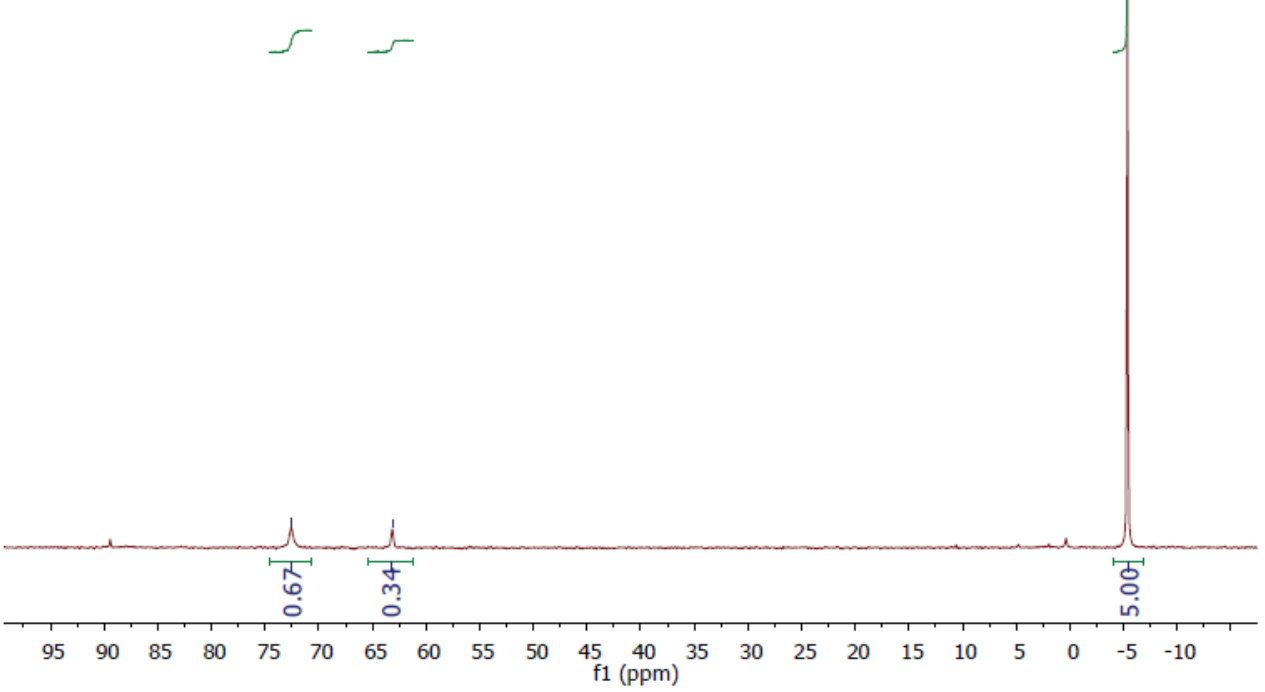




\section{Catalytic Runs}

All runs were analyzed via the methods indicated in chapter 4. Absorbances indicated are from runs using a $20 \mu \mathrm{L}$ aliquot from the aqueous $1 \mathrm{~mL}$ stock solution of the chloride salts. Runs denoted with an asterisk indicate use of a $40 \mu \mathrm{L}$ aliquot.

Table A3.2. $\mathrm{N}_{2}$ reduction catalysis absorption data using $\left[(\mathrm{TPB}) \mathrm{Fe}\left(\mathrm{N}_{2}\right)\right][\mathrm{Na}(12$-crown$\left.4)_{2}\right]$.

\begin{tabular}{cccc}
\hline Run & Absorbance & Equiv $\mathrm{NH}_{3} / \mathrm{Fe}$ & $\begin{array}{c}\text { \% Yield based on } \\
\mathrm{H}^{+}\end{array}$ \\
\hline $\mathrm{A}^{*}$ & 1.095 & 6.52 & 40.7 \\
$\mathrm{~B}^{*}$ & 1.150 & 6.84 & 42.7 \\
$\mathrm{C}^{*}$ & 0.724 & 4.30 & 26.9 \\
$\mathrm{D}^{*}$ & 1.105 & 6.58 & 41.1 \\
$\mathrm{E}^{*}$ & 1.165 & 6.93 & 43.3 \\
$\mathrm{~F}^{*}$ & 1.339 & 7.97 & 49.8 \\
$\mathrm{G}^{*}$ & 1.050 & 6.25 & 39.1 \\
$\mathrm{H}^{*}$ & 1.428 & 8.49 & 53.1 \\
$\mathrm{I}^{*}$ & 1.418 & 8.44 & 52.7 \\
$\mathrm{~J}^{*}$ & 1.008 & 6.00 & 37.5 \\
$\mathrm{~L}$ & 0.608 & 7.24 & 45.2 \\
$\mathrm{M}$ & 0.579 & 6.89 & 43.1 \\
$\mathrm{~N}$ & 0.640 & 7.62 & 47.6 \\
$\mathrm{O}$ & 0.592 & 7.05 & 44.1 \\
$\mathrm{P}$ & 0.616 & 7.33 & 45.8 \\
\hline
\end{tabular}

Table A3.3. $\mathrm{N}_{2}$ reduction catalysis absorption data using [(TPB)Fe][BAr ${ }_{4}{ }_{4}$.

\begin{tabular}{cccc}
\hline Run & Absorbance & Equiv NH$/ / F e$ & $\begin{array}{c}\text { \% Yield based on } \\
\mathrm{H}^{+}\end{array}$ \\
\hline $\mathrm{A}^{*}$ & 1.169 & 6.96 & 43.5 \\
$\mathrm{~B}^{*}$ & 1.000 & 5.95 & 37.2 \\
$\mathrm{C}^{*}$ & 0.911 & 5.42 & 33.9 \\
$\mathrm{D}^{*}$ & 1.117 & 6.65 & 41.6 \\
\hline
\end{tabular}


Table A3.4. Attempted $\mathrm{N}_{2}$ reduction catalysis absorption data using (TPB)( $\mu$ $\mathrm{H}) \mathrm{Fe}(\mathrm{H})\left(\mathrm{N}_{2}\right)$.

\begin{tabular}{cccc}
\hline Run & Absorbance & Equiv NH$/ \mathrm{Fe}$ & \% Yield based on \\
& & & $\mathrm{H}^{+}$ \\
\hline $\mathrm{A}^{*}$ & 0.084 & 0.50 & 3.1 \\
$\mathrm{~B}^{*}$ & 0.072 & 0.43 & 2.7 \\
$\mathrm{C}$ & 0.035 & 0.42 & 2.6 \\
$\mathrm{D}$ & 0.055 & 0.65 & 4.1 \\
\hline
\end{tabular}

Table A3.5. Attempted $\mathrm{N}_{2}$ reduction catalysis absorption data using $\mathrm{FeCl}_{2} \cdot 1.5 \mathrm{THF}$.

\begin{tabular}{cccc}
\hline Run & Absorbance & Equiv NH$/ \mathrm{Fe}$ & \% Yield based on \\
& & & $\mathrm{H}^{+}$ \\
\hline A & 0.002 & 0.02 & 0.1 \\
B & 0.011 & 0.13 & 0.8 \\
C & 0.005 & 0.06 & 0.4 \\
D & 0.007 & 0.08 & 0.5 \\
\hline
\end{tabular}

Table A3.6. Attempted $\mathrm{N}_{2}$ reduction catalysis absorption data using $\mathrm{FeCl}_{3}$.

\begin{tabular}{cccc}
\hline Run & Absorbance & Equiv NH$/ \mathrm{Fe}$ & \% Yield based on \\
& & & $\mathrm{H}^{+}$ \\
\hline $\mathrm{A}$ & -0.0021 & 0 & 0 \\
$\mathrm{~B}$ & -0.0002 & 0 & 0 \\
$\mathrm{C}$ & 0.0002 & 0.002 & 0.01 \\
$\mathrm{D}$ & 0.0010 & 0.01 & 0.06 \\
\hline
\end{tabular}

Table A3.7. Attempted $\mathrm{N}_{2}$ reduction catalysis absorption data using $\mathrm{Fe}(\mathrm{CO})_{5}$.

\begin{tabular}{cccc}
\hline Run & Absorbance & Equiv NH$/ \mathrm{Fe}$ & $\begin{array}{c}\text { \% Yield based on } \\
\mathrm{H}^{+}\end{array}$ \\
\hline A & 0.016 & 0.19 & 1.2 \\
B & 0.003 & 0.04 & 0.2 \\
C & 0.004 & 0.05 & 0.3 \\
D & 0.006 & 0.07 & 0.4 \\
\hline
\end{tabular}


Table A3.8. Attempted $\mathrm{N}_{2}$ reduction catalysis absorption data using $\mathrm{FeCp}_{2}$.

\begin{tabular}{cccc}
\hline Run & Absorbance & Equiv NH$/ \mathrm{Fe}$ & \% Yield based on \\
$\mathrm{H}^{+}$
\end{tabular}

Table A3.9. Attempted $\mathrm{N}_{2}$ reduction catalysis absorption data in the absence of an $\mathrm{Fe}$ precursor.

\begin{tabular}{cccc}
\hline Run & Absorbance & Equiv $\mathrm{NH}_{3} / \mathrm{Fe}$ & $\%$ Yield based on \\
$\mathrm{H}^{+}$
\end{tabular}

Table A3.10. $\mathrm{N}_{2}$ reduction catalysis absorption data using (TPB)FeCl.

\begin{tabular}{cccc}
\hline Run & Absorbance & Equiv $\mathrm{NH}_{3} / \mathrm{Fe}$ & $\begin{array}{c}\text { \% Yield based on } \\
\mathrm{H}^{+}\end{array}$ \\
\hline A & 0.320 & 3.81 & 23.8 \\
B & 0.266 & 3.17 & 19.8 \\
C & 0.209 & 2.49 & 15.6 \\
\hline
\end{tabular}

Table A3.11. $\mathrm{N}_{2}$ reduction catalysis absorption data using (TPB) $\mathrm{FeN}_{2}$.

\begin{tabular}{cccc}
\hline Run & Absorbance & Equiv NH$/ \mathrm{Fe}$ & $\begin{array}{c}\text { \% Yield based on } \\
\mathrm{H}^{+}\end{array}$ \\
\hline A & 0.177 & 2.11 & 13.2 \\
B & 0.158 & 1.88 & 11.7 \\
$\mathrm{C}^{*}$ & 0.396 & 2.36 & 14.7 \\
$\mathrm{D}^{*}$ & 0.580 & 3.45 & 21.6 \\
$\mathrm{E}^{*}$ & 0.378 & 2.25 & 14.1 \\
$\mathrm{~F}^{*}$ & 0.423 & 2.52 & 15.7 \\
$\mathrm{G}^{*}$ & 0.191 & 1.14 & 7.1 \\
$\mathrm{H}^{*}$ & 0.460 & 2.74 & 17.1 \\
\hline
\end{tabular}


Table A3.12. Attempted $\mathrm{N}_{2}$ reduction catalysis absorption data using $\left[(\mathrm{TPB}) \mathrm{Fe}\left(\mathrm{NH}_{3}\right)\right]\left[\mathrm{BAr}_{4}^{\mathrm{F}}\right]$.

\begin{tabular}{cccc}
\hline Run & Absorbance & Equiv NH$/ \mathrm{Fe}$ & $\begin{array}{c}\text { \% Yield based on } \\
\mathrm{H}^{+}\end{array}$ \\
\hline A & 0.475 & 5.65 & 35.3 \\
B & 0.487 & 5.80 & 36.2 \\
C & 0.493 & 5.87 & 36.7 \\
D & 0.472 & 5.62 & 35.1 \\
\hline
\end{tabular}

Table A3.13. Attempted $\mathrm{N}_{2}$ reduction catalysis absorption data using $\left[(\mathrm{TPB}) \mathrm{Fe}\left(\mathrm{N}_{2} \mathrm{H}_{4}\right)\right]\left[\mathrm{BAr}_{4}{ }_{4}\right]$.

\begin{tabular}{cccc}
\hline Run & Absorbance & Equiv $\mathrm{NH}_{3} / \mathrm{Fe}$ & $\begin{array}{c}\text { \% Yield based on } \\
\mathrm{H}^{+}\end{array}$ \\
\hline A & 0.531 & 6.32 & 39.5 \\
B & 0.417 & 4.96 & 31.0 \\
C & 0.580 & 6.90 & 43.1 \\
D & 0.441 & 5.25 & 32.8 \\
\hline
\end{tabular}

Table A3.14. Absorption data for a standard catalytic run in which $\mathrm{N}_{2} \mathrm{H}_{4}$ was added prior to $\left[(\mathrm{TPB}) \mathrm{Fe}\left(\mathrm{N}_{2}\right)\right][\mathrm{Na}(12$-crown-4) 2$]$ acid and reductant.

\begin{tabular}{ccccc}
\hline Run & Abs. for $\mathrm{N}_{2} \mathrm{H}_{4}$ & Equiv $\mathrm{N}_{2} \mathrm{H}_{4} / \mathrm{Fe}$ & Abs. for $\mathrm{NH}_{3}$ & Equiv $\mathrm{NH}_{3} / \mathrm{Fe}$ \\
\hline A & 0.085 & 0.16 & 0.771 & 9.18 \\
B & 0.116 & 0.22 & 0.424 & 5.05 \\
\hline
\end{tabular}

Table A3.15. Absorption and gas chromatograph integration data for standard catalytic runs.

\begin{tabular}{ccccc}
\hline Run & Absorbance & Equiv $\mathrm{NH}_{3} / \mathrm{Fe}$ & $\begin{array}{c}\text { \% Yield based on } \\
\mathrm{H}^{+}\end{array}$ & $\begin{array}{c}\text { \% Yield of } \\
\mathrm{H}_{2}\end{array}$ \\
\hline $\mathrm{A}$ & 0.500 & 5.95 & 37.2 & 30 \\
$\mathrm{~B}$ & 0.365 & 4.34 & 27.1 & 40 \\
\hline
\end{tabular}


Table A3.16. Gas chromatograph $\mathrm{H}_{2}$ yields for runs in the absence of an Fe precursor.

\begin{tabular}{cc}
\hline Run & \% Yield of $\mathrm{H}_{2}$ \\
\hline A & 61 \\
B & 88 \\
\hline
\end{tabular}


Appendix 4: Supplementary Data for Chapter 5 
Table A4.1. Crystal data and structure refinement for $\left[\left(\mathrm{TPB}^{\mathrm{Cy}}\right) \mathrm{Fe}\left(\mathrm{N}_{2}\right)\right]\left[\mathrm{Na}(12 \text {-crown-4 })_{2}\right]$ (5.1).

Identification code

Empirical formula

Formula weight

Temperature

Wavelength

Crystal system

Space group

Unit cell dimensions

Volume

$\mathrm{Z}$

Density (calculated)

Absorption coefficient

$\mathrm{F}(000)$

Crystal size

Theta range for data collection

Index ranges

Reflections collected

Independent reflections

Completeness to theta $=26.38^{\circ}$

Absorption correction

Max. and min. transmission

Refinement method

Data / restraints / parameters

Goodness-of-fit on $\mathrm{F}^{2}$

Final $\mathrm{R}$ indices [I $>2 \operatorname{sigma}(\mathrm{I})]$

$\mathrm{R}$ indices (all data)

Largest diff. peak and hole jsa32_0m

C70 H114 B Fe N2 Na O9 P3

1310.19

296(2) K

$0.71073 \AA$

Orthorhombic

Pbca

$$
\begin{array}{ll}
\mathrm{a}=20.9220(11) \AA & \alpha=90^{\circ} . \\
\mathrm{b}=21.8896(13) \AA & \beta=90^{\circ} . \\
\mathrm{c}=32.1770(19) \AA & \gamma=90^{\circ} .
\end{array}
$$$$
\text { 14736.2(15) } \AA^{3}
$$

8

$1.181 \mathrm{Mg} / \mathrm{m}^{3}$

$0.328 \mathrm{~mm}^{-1}$

5656

$0.45 \times 0.27 \times 0.03 \mathrm{~mm}^{3}$

1.60 to $26.38^{\circ}$.

$-26<=\mathrm{h}<=25,-27<=\mathrm{k}<=27,-39<=\mathrm{l}<=39$

228826

$14997[\mathrm{R}(\mathrm{int})=0.1023]$

$99.4 \%$

Semi-empirical from equivalents

0.9902 and 0.8663

Full-matrix least-squares on $\mathrm{F}^{2}$

14997 / 1861 / 1041

1.046

$\mathrm{R} 1=0.0567, \mathrm{wR} 2=0.1260$

$\mathrm{R} 1=0.0965, \mathrm{wR} 2=0.1458$

0.964 and -0.495 e. $\AA^{-3}$ 
Table A4.2. Crystal data and structure refinement for $\left[(\mathrm{DPB}) \mathrm{Fe}\left(\mathrm{N}_{2}\right)\right]\left[\mathrm{K}(\mathrm{Bz} 15 \text {-crown-5) })_{2}\right]$ (5.3).

Identification code

Empirical formula

Formula weight

Temperature

Wavelength

Crystal system

Space group

Unit cell dimensions

Volume

Z

Density (calculated)

Absorption coefficient

$\mathrm{F}(000)$

Crystal size

Theta range for data collection

Index ranges

Reflections collected

Independent reflections

Completeness to theta $=25.00^{\circ}$

Absorption correction

Max. and min. transmission

Refinement method

Data / restraints / parameters

Goodness-of-fit on $\mathrm{F}^{2}$

Final R indices [I>2sigma(I)]

$\mathrm{R}$ indices (all data)

Largest diff. peak and hole dlms 120

C66 H89 B Fe K N2 O12 P2

1270.09

100(2) K

$0.71073 \AA$

Triclinic

P-1

$\mathrm{a}=15.072(4) \AA \quad \alpha=65.274(8)^{\circ}$.

$\mathrm{b}=16.020(2) \AA \quad \beta=67.441(8)^{\circ}$.

$\mathrm{c}=16.354(3) \AA \quad \gamma=76.842(10)^{\circ}$. $3301.5(11) \AA^{3}$

2

$1.278 \mathrm{Mg} / \mathrm{m}^{3}$

$0.400 \mathrm{~mm}^{-1}$

1350

$0.30 \times 0.10 \times 0.10 \mathrm{~mm}^{3}$

1.69 to $30.19^{\circ}$.

$-21<=\mathrm{h}<=21,-22<=\mathrm{k}<=21,-22<=1<=22$

119765

$18004[\mathrm{R}(\mathrm{int})=0.0608]$

$100.0 \%$

Semi-empirical from equivalents

0.9611 and 0.8893

Full-matrix least-squares on $\mathrm{F}^{2}$

18004 / 848 / 797

1.024

$\mathrm{R} 1=0.0476, \mathrm{wR} 2=0.1120$

$\mathrm{R} 1=0.0840, \mathrm{wR} 2=0.1279$

1.100 and -0.812 e. $\AA^{-3}$ 
Table A4.3. Crystal data and structure refinement for $\left(\mathrm{TPB}^{\mathrm{Cy}}\right) \mathrm{FeCl}(\mathbf{5 . 9})$.

Identification code

Empirical formula

Formula weight

Temperature

Wavelength

Crystal system

Space group

Unit cell dimensions

Volume

$\mathrm{Z}$

Density (calculated)

Absorption coefficient

$\mathrm{F}(000)$

Crystal size

Theta range for data collection

Index ranges

Reflections collected

Independent reflections

Completeness to theta $=33.14^{\circ}$

Absorption correction

Max. and min. transmission

Refinement method

Data / restraints / parameters

Goodness-of-fit on $\mathrm{F}^{2}$

Final $\mathrm{R}$ indices $[\mathrm{I}>2 \operatorname{sigma}(\mathrm{I})]$

$\mathrm{R}$ indices (all data)

Largest diff. peak and hole jsa31_0m

C54 H78 B Cl Fe P3

922.18

296(2) K

$0.71073 \AA$

Triclinic

P-1

$\mathrm{a}=20.7382(9) \AA \quad \alpha=88.578(3)^{\circ}$.

$\mathrm{b}=21.9442(10) \AA \quad \beta=73.669(2)^{\circ}$.

$\mathrm{c}=23.5705(11) \AA \quad \gamma=88.726(2)^{\circ}$.

10289.3(8) $\AA^{3}$

8

$1.191 \mathrm{Mg} / \mathrm{m}^{3}$

$0.472 \mathrm{~mm}^{-1}$

3960

$0.21 \times 0.21 \times 0.11 \mathrm{~mm}^{3}$

1.37 to $33.14^{\circ}$.

$-31<=\mathrm{h}<=31,-33<=\mathrm{k}<=33,-36<=\mathrm{l}<=36$

456639

$77830[\mathrm{R}(\mathrm{int})=0.0761]$

$99.2 \%$

Semi-empirical from equivalents

0.9499 and 0.9073

Full-matrix least-squares on $\mathrm{F}^{2}$

77830 / $2511 / 2412$

1.119

$\mathrm{R} 1=0.0704, \mathrm{wR} 2=0.1691$

$\mathrm{R} 1=0.1044, \mathrm{wR} 2=0.1862$

2.352 and -0.854 e. $\AA^{-3}$ 
Table A4.4. Crystal data and structure refinement for $\left(\mathrm{TPB}^{\mathrm{Ph}}\right) \mathrm{FeCl}(\mathbf{5 . 1 0})$.

Identification code

Empirical formula

Formula weight

Temperature

Wavelength

Crystal system

Space group

Unit cell dimensions

Volume

Z

Density (calculated)

Absorption coefficient

$\mathrm{F}(000)$

Crystal size

Theta range for data collection

Index ranges

Reflections collected

Independent reflections

Completeness to theta $=33.16^{\circ}$

Absorption correction

Refinement method

Data / restraints / parameters

Goodness-of-fit on $\mathrm{F}^{2}$

Final $\mathrm{R}$ indices [I $>2 \operatorname{sigma}(\mathrm{I})]$

$\mathrm{R}$ indices (all data)

Largest diff. peak and hole snm03

C54 H42 B Cl Fe P3

885.90

296(2) K

$0.71073 \AA$

Monoclinic

$\mathrm{P} 2(1) / \mathrm{c}$

$\mathrm{a}=12.9941(8) \AA \quad \alpha=90^{\circ}$.

$\mathrm{b}=17.1371(11) \AA \quad \beta=98.255(3)^{\circ}$.

$c=19.5570(11) \AA \quad \gamma=90^{\circ}$.

4309.9(5) $\AA^{3}$

4

$1.365 \mathrm{Mg} / \mathrm{m}^{3}$

$0.562 \mathrm{~mm}^{-1}$

1836

1.58 to $33.16^{\circ}$.

$-19<=\mathrm{h}<=19,-26<=\mathrm{k}<=26,-30<=\mathrm{l}<=29$

92375

$16422[\mathrm{R}(\mathrm{int})=0.0535]$

$99.8 \%$

Semi-empirical by equivalents

Full-matrix least-squares on $\mathrm{F}^{2}$

16422 / 0 / 541

1.015

$\mathrm{R} 1=0.0408, \mathrm{wR} 2=0.0957$

$\mathrm{R} 1=0.0643, \mathrm{wR} 2=0.1063$

1.247 and -0.403 e. $\AA^{-3}$ 
Table A4.5. Crystal data and structure refinement for (TPB ${ }^{\mathrm{Ph}}$ ') (5.11).

Identification code

Empirical formula

Formula weight

Temperature

Wavelength

Crystal system

Space group

Unit cell dimensions

Volume

$\mathrm{Z}$

Density (calculated)

Absorption coefficient

$\mathrm{F}(000)$

Crystal size

Theta range for data collection

Index ranges

Reflections collected

Independent reflections

Completeness to theta $=30.51^{\circ}$

Absorption correction

Refinement method

Data / restraints / parameters

Goodness-of-fit on $\mathrm{F}^{2}$

Final $\mathrm{R}$ indices [I $>2 \operatorname{sigma}(\mathrm{I})]$

$\mathrm{R}$ indices (all data)

Absolute structure parameter

Largest diff. peak and hole snm01

C56 H42 B Fe O P3

890.47

296(2) K

$0.71073 \AA$

Orthorhombic

P2(1)2(1)2(1)

$\mathrm{a}=10.8211(6) \AA \quad \alpha=90^{\circ}$.

$\mathrm{b}=18.6466(12) \AA \quad \beta=90^{\circ}$.

$\mathrm{c}=23.1518(13) \AA \quad \gamma=90^{\circ}$.

4671.5(5) $\AA^{3}$

4

$1.266 \mathrm{Mg} / \mathrm{m}^{3}$

$0.465 \mathrm{~mm}^{-1}$

1848

$0.259 \times 0.192 \times 0.085 \mathrm{~mm}^{3}$

1.76 to $30.51^{\circ}$.

$-15<=\mathrm{h}<=15,-26<=\mathrm{k}<=26,-33<=\mathrm{l}<=32$

60196

$14181[\mathrm{R}(\mathrm{int})=0.0531]$

$99.9 \%$

Semi-empirical by equivalents

Full-matrix least-squares on $\mathrm{F}^{2}$

14181 / 0 / 598

1.039

$\mathrm{R} 1=0.0582, \mathrm{wR} 2=0.1551$

$\mathrm{R} 1=0.0778, \mathrm{wR} 2=0.1673$

$0.182(16)$

1.518 and -0.983 e. $\AA^{-3}$ 


\section{Catalytic Runs}

All runs were analyzed via the methods indicated in Chapter 4. Absorbances indicated are from runs using a $20 \mu \mathrm{L}$ aliquot from the aqueous $1 \mathrm{~mL}$ stock solution of the chloride salts. Runs denoted with an asterisk indicate use of a $40 \mu \mathrm{L}$ aliquot.

Table A4.6. $\mathrm{N}_{2}$ reduction catalysis absorption data using $\left[\left(\mathrm{TPB}^{\mathrm{Cy}}\right) \mathrm{Fe}\left(\mathrm{N}_{2}\right)\right][\mathrm{Na}(12$-crown4) 2$](5.1)$.

\begin{tabular}{cccc}
\hline Run & Absorbance & Equiv $\mathrm{NH}_{3} / \mathrm{Fe}$ & $\begin{array}{c}\text { \% Yield based on } \\
\mathrm{H}^{+}\end{array}$ \\
\hline A & 0.275 & 3.27 & 20.4 \\
B & 0.254 & 3.02 & 18.9 \\
C & 0.278 & 3.31 & 20.7 \\
\hline
\end{tabular}

Table A4.7. $\mathrm{N}_{2}$ reduction catalysis absorption data using $\left[\left(\mathrm{TPB}^{\mathrm{Ph}}\right) \mathrm{Fe}\left(\mathrm{N}_{2}\right)\right][\mathrm{Na}(12$-crown4) 2$](5.2)$.

\begin{tabular}{cccc}
\hline Run & Absorbance & Equiv NH$/ \mathrm{Fe}$ & $\begin{array}{c}\text { \% Yield based on } \\
\mathrm{H}^{+}\end{array}$ \\
\hline $\mathrm{A}$ & 0.155 & 1.84 & 11.5 \\
$\mathrm{~B}$ & 0.155 & 1.84 & 11.5 \\
$\mathrm{C}$ & 0.209 & 2.49 & 15.6 \\
$\mathrm{D}$ & 0.222 & 2.64 & 16.5 \\
\hline
\end{tabular}

Table A4.8. Attempted $\mathrm{N}_{2}$ reduction catalysis absorption data using $\left[(\mathrm{DPB}) \mathrm{Fe}\left(\mathrm{N}_{2}\right)\right]\left[\mathrm{K}(\mathrm{Bz} 15-\text { crown-5) })_{2}\right](\mathbf{5 . 3})$.

\begin{tabular}{cccc}
\hline Run & Absorbance & Equiv $\mathrm{NH}_{3} / \mathrm{Fe}$ & $\begin{array}{c}\text { \% Yield based on } \\
\mathrm{H}^{+}\end{array}$ \\
\hline A & 0.133 & 1.73 & 10.8 \\
B & 0.131 & 1.70 & 10.6 \\
C & 0.170 & 2.10 & 13.1 \\
\hline
\end{tabular}


Table A4.9. Attempted $\mathrm{N}_{2}$ reduction catalysis absorption data using $\left[\left(\mathrm{SiP}^{\mathrm{iPr}}{ }_{3}\right) \mathrm{Fe}\left(\mathrm{N}_{2}\right)\right]\left[\mathrm{Na}(12-\text { crown-4) })_{2}\right]$.

\begin{tabular}{|c|c|c|c|}
\hline Run & Absorbance & Equiv $\mathrm{NH}_{3} / \mathrm{Fe}$ & $\begin{array}{c}\% \text { Yield based on } \\
\mathrm{H}^{+}\end{array}$ \\
\hline $\mathrm{A}^{*}$ & 0.203 & 1.21 & 7.5 \\
\hline $\mathrm{B}^{*}$ & 0.059 & 0.35 & 2.1 \\
\hline $\mathrm{C}^{*}$ & 0.064 & 0.38 & 2.3 \\
\hline $\mathrm{D}^{*}$ & 0.183 & 1.09 & 6.8 \\
\hline
\end{tabular}

Table A4.10. Attempted $\mathrm{N}_{2}$ reduction catalysis absorption data using $\left[\mathrm{PhBP}_{3}^{\mathrm{iPr}}\right] \mathrm{FeN}_{2} \mathrm{MgCl} \cdot 2 \mathrm{THF}$.

\begin{tabular}{cccc}
\hline Run & Absorbance & Equiv $\mathrm{NH}_{3} / \mathrm{Fe}$ & $\begin{array}{c}\text { \% Yield based on } \\
\mathrm{H}^{+}\end{array}$ \\
\hline A & 0.115 & 1.37 & 8.6 \\
B & 0.112 & 1.33 & 8.3 \\
C & 0.085 & 1.01 & 6.3 \\
D & 0.088 & 1.05 & 6.6 \\
\hline
\end{tabular}

Table A4.11. Attempted $\mathrm{N}_{2}$ reduction catalysis absorption data using $\left(\mathrm{C}_{2} \mathrm{H}_{4} \mathrm{PCy}\right)_{3} \mathrm{PFe}\left(\mathrm{N}_{2}\right)$.

\begin{tabular}{cccc}
\hline Run & Absorbance & Equiv NH$/ \mathrm{Fe}$ & $\begin{array}{c}\text { \% Yield based on } \\
\mathrm{H}^{+}\end{array}$ \\
\hline A & 0.102 & 0.74 & 4.6 \\
B & 0.068 & 0.50 & 3.1 \\
C & 0.122 & 0.75 & 4.7 \\
\hline
\end{tabular}

Note that that the amount of catalyst varied in these runs, so the usual correlation between absorbance and equiv. of $\mathrm{NH}_{3}$ is off. 
Table A4.12. Attempted $\mathrm{N}_{2}$ reduction catalysis absorption data using $\mathrm{Fe}(\mathrm{depe})_{2} \mathrm{~N}_{2}$.

\begin{tabular}{cccc}
\hline Run & Absorbance & Equiv NH$/ \mathrm{Fe}$ & \% Yield based on \\
$\mathrm{H}^{+}$
\end{tabular}

Table A4.13. $\mathrm{N}_{2}$ reduction catalysis absorption data using $\mathrm{iPr}_{2} \mathrm{O}$.

\begin{tabular}{cccc}
\hline Run & Absorbance & Equiv NH$/ \mathrm{Fe}$ & $\begin{array}{c}\text { \% Yield based on } \\
\mathrm{H}^{+}\end{array}$ \\
\hline A & 0.578 & 6.88 & 43.0 \\
B & 0.541 & 6.44 & 40.2 \\
C & 0.560 & 6.67 & 41.7 \\
D & 0.516 & 6.14 & 38.4 \\
\hline
\end{tabular}

Table A4.14. $\mathrm{N}_{2}$ reduction catalysis absorption data using DME.

\begin{tabular}{cccc}
\hline Run & Absorbance & Equiv $\mathrm{NH}_{3} / \mathrm{Fe}$ & $\begin{array}{c}\text { \% Yield based on } \\
\mathrm{H}^{+}\end{array}$ \\
\hline $\mathrm{A}^{*}$ & 0.532 & 3.17 & 19.8 \\
$\mathrm{~B}^{*}$ & 0.586 & 3.49 & 21.8 \\
$\mathrm{C}^{*}$ & 0.591 & 3.52 & 22.0 \\
$\mathrm{D}^{*}$ & 0.555 & 3.30 & 20.6 \\
\hline
\end{tabular}

Table A4.15. $\mathrm{N}_{2}$ reduction catalysis absorption data using $\mathrm{Bu}_{2} \mathrm{O}$.

\begin{tabular}{cccc}
\hline Run & Absorbance & Equiv NH$/ \mathrm{Fe}$ & $\begin{array}{c}\text { \% Yield based on } \\
\mathrm{H}^{+}\end{array}$ \\
\hline $\mathrm{A}^{*}$ & 0.534 & & 19.8 \\
$\mathrm{~B}^{*}$ & 0.530 & 3.17 & 19.7 \\
\hline
\end{tabular}


Table A4.16. Attempted $\mathrm{N}_{2}$ reduction catalysis absorption data using toluene.

\begin{tabular}{cccc}
\hline Run & Absorbance & Equiv NH $\mathrm{NH}_{3} / \mathrm{Fe}$ & $\begin{array}{c}\text { \% Yield based on } \\
\mathrm{H}^{+}\end{array}$ \\
\hline $\mathrm{A}^{*}$ & 0.178 & 1.06 & 6.6 \\
$\mathrm{~B}^{*}$ & 0.082 & 0.49 & 3.1 \\
\hline
\end{tabular}

Table A4.17. $\mathrm{N}_{2}$ reduction catalysis absorption data using 1:6 $\mathrm{Et}_{2} \mathrm{O}$ :toluene.

\begin{tabular}{cccc}
\hline Run & Absorbance & Equiv NH$/ \mathrm{Fe}$ & $\begin{array}{c}\text { \% Yield based on } \\
\mathrm{H}^{+}\end{array}$ \\
\hline $\mathrm{A}^{*}$ & 0.535 & 3.18 & 19.9 \\
$\mathrm{~B}^{*}$ & 0.516 & 3.07 & 19.2 \\
\hline
\end{tabular}

Table A4.18. Attempted $\mathrm{N}_{2}$ reduction catalysis absorption data using CoCp* ${ }_{2}$.

\begin{tabular}{cccc}
\hline Run & Absorbance & Equiv NH$/ / F e$ & $\begin{array}{c}\text { \% Yield based on } \\
\mathrm{H}^{+}\end{array}$ \\
\hline A & 0.103 & 1.23 & 7.7 \\
B & 0.062 & 0.74 & 4.6 \\
C & 0.045 & 0.27 & 1.7 \\
D & 0.069 & 0.41 & 2.6 \\
\hline
\end{tabular}

Table A4.19. Attempted $\mathrm{N}_{2}$ reduction catalysis absorption data using $\mathrm{CrCp}^{*}{ }_{2}$.

\begin{tabular}{cccc}
\hline Run & Absorbance & Equiv NH $\mathrm{NH}_{3} / \mathrm{Fe}$ & $\begin{array}{c}\text { \% Yield based on } \\
\mathrm{H}^{+}\end{array}$ \\
\hline $\mathrm{A}$ & 0.012 & 0.14 & 0.9 \\
$\mathrm{~B}$ & 0.016 & 0.19 & 1.2 \\
$\mathrm{C}^{*}$ & 0.022 & 0.13 & 0.8 \\
$\mathrm{D}^{*}$ & 0.007 & 0.04 & 0.2 \\
\hline
\end{tabular}


Table A4.20. Attempted $\mathrm{N}_{2}$ reduction catalysis absorption data using $\mathrm{NaC}_{10} \mathrm{H}_{8}$.

\begin{tabular}{cccc}
\hline Run & Absorbance & Equiv NH$/ \mathrm{Fe}$ & $\begin{array}{c}\text { \% Yield based on } \\
\mathrm{H}^{+}\end{array}$ \\
\hline $\mathrm{A}$ & 0.075 & 0.89 & 5.6 \\
$\mathrm{~B}$ & 0.094 & 1.12 & 7.0 \\
\hline
\end{tabular}

Table A4.21. Attempted $\mathrm{N}_{2}$ reduction catalysis absorption data using $\mathrm{K}$ as the reductant.

\begin{tabular}{cccc}
\hline Run & Absorbance & Equiv NH$/ \mathrm{Fe}$ & $\begin{array}{c}\text { Y Yield based on } \\
\mathrm{H}^{+}\end{array}$ \\
\hline $\mathrm{A}$ & 0.060 & 0.71 & 4.4 \\
$\mathrm{~B}$ & 0.049 & 0.58 & 3.6 \\
$\mathrm{C}$ & 0.025 & 0.30 & 1.9 \\
$\mathrm{D}$ & 0.019 & 0.23 & 1.4 \\
\hline
\end{tabular}

Table A4.22. Attempted $\mathrm{N}_{2}$ reduction catalysis absorption data using $\mathrm{MgC}_{14} \mathrm{H}_{10} \cdot 3 \mathrm{THF}$.

\begin{tabular}{cccc}
\hline Run & Absorbance & Equiv NH$/ \mathrm{Fe}$ & $\begin{array}{c}\text { \% Yield based on } \\
\mathrm{H}^{+}\end{array}$ \\
\hline $\mathrm{A}$ & 0.025 & 0.30 & 1.9 \\
$\mathrm{~B}$ & 0.022 & 0.26 & 1.6 \\
\hline
\end{tabular}

Table A4.23. $\mathrm{N}_{2}$ reduction catalysis absorption data using $\mathrm{Na} / \mathrm{Hg}$.

\begin{tabular}{cccc}
\hline Run & Absorbance & Equiv NH$/ \mathrm{Fe}$ & $\begin{array}{c}\text { \% Yield based on } \\
\mathrm{H}^{+}\end{array}$ \\
\hline $\mathrm{A}$ & 0.170 & 2.02 & 12.6 \\
$\mathrm{~B}$ & 0.179 & 2.13 & 13.3 \\
\hline
\end{tabular}


Table A4.24. Attempted $\mathrm{N}_{2}$ reduction catalysis absorption data using trifluoromethanesulfonic acid.

\begin{tabular}{cccc}
\hline Run & Absorbance & Equiv NH$/ \mathrm{Fe}$ & \% Yield based on \\
$\mathrm{H}^{+}$
\end{tabular}

Table A4.25. Attempted $\mathrm{N}_{2}$ reduction catalysis absorption data using anhydrous $\mathrm{HCl}$.

\begin{tabular}{cccc}
\hline Run & Absorbance & Equiv NH$/ \mathrm{Fe}$ & \% Yield based on \\
& & & $\mathrm{H}^{+}$ \\
\hline A & 0.007 & 0.08 & 0.5 \\
B & 0.005 & 0.06 & 0.4 \\
C & 0.010 & 0.12 & 0.8 \\
D & 0.004 & 0.05 & 0.3 \\
\hline
\end{tabular}

Table A4.26. Attempted $\mathrm{N}_{2}$ reduction catalysis absorption data using [Lutidinium] $\left[\mathrm{BAr}^{\mathrm{F}}{ }_{4}\right]$ as the acid.

\begin{tabular}{cccc}
\hline Run & Absorbance & Equiv $\mathrm{NH}_{3} / \mathrm{Fe}$ & $\begin{array}{c}\text { \% Yield based on } \\
\mathrm{H}^{+}\end{array}$ \\
\hline $\mathrm{A}$ & 0.026 & 0.31 & 1.9 \\
$\mathrm{~B}$ & 0.004 & 0.05 & 0.3 \\
$\mathrm{C}^{*}$ & 0.013 & 0.08 & 0.5 \\
$\mathrm{D}^{*}$ & 0.018 & 0.11 & 0.7 \\
\hline
\end{tabular}

Table A4.27. $\mathrm{N}_{2}$ reduction catalysis absorption data using [2,6-dimethylanilinium][OTf].

\begin{tabular}{cccc}
\hline Run & Absorbance & Equiv NH$/ \mathrm{Fe}$ & $\begin{array}{c}\text { \% Yeld based on } \\
\mathrm{H}^{+}\end{array}$ \\
\hline $\mathrm{A}^{*}$ & 0.415 & & 15.4 \\
$\mathrm{~B}^{*}$ & 0.288 & 2.47 & 10.7 \\
\hline
\end{tabular}


Table A4.28. $\mathrm{N}_{2}$ reduction catalysis absorption data using [2,6dimethylanilinium][BAr$\left.{ }_{4}{ }^{\mathrm{T}}\right]$.

\begin{tabular}{cccc}
\hline Run & Absorbance & Equiv NH$/ 3 / \mathrm{Fe}$ & $\begin{array}{c}\text { \% Yield based on } \\
\mathrm{H}^{+}\end{array}$ \\
\hline $\mathrm{A}$ & 0.255 & 3.03 & 18.9 \\
$\mathrm{~B}$ & 0.233 & 2.77 & 17.3 \\
\hline
\end{tabular}

Table A4.29. Attempted $\mathrm{N}_{2}$ reduction catalysis at RT.

\begin{tabular}{cccc}
\hline Run & Absorbance & Equiv NH$/ \mathrm{Fe}$ & $\begin{array}{c}\text { \% Yield based on } \\
\mathrm{H}^{+}\end{array}$ \\
\hline $\mathrm{A}$ & 0.158 & 1.88 & 11.7 \\
$\mathrm{~B}$ & 0.130 & 1.55 & 9.7 \\
$\mathrm{C}$ & 0.114 & 1.36 & 8.5 \\
$\mathrm{D}$ & 0.045 & 0.54 & 3.4 \\
\hline
\end{tabular}

Table A4.30. $\mathrm{N}_{2}$ reduction catalysis absorption data at $-110{ }^{\circ} \mathrm{C}$.

\begin{tabular}{cccc}
\hline Run & Absorbance & Equiv NH $\mathrm{H}_{3} / \mathrm{Fe}$ & $\begin{array}{c}\text { \% Yield based on } \\
\mathrm{H}^{+}\end{array}$ \\
\hline $\mathrm{A}$ & 0.452 & 5.38 & 33.6 \\
$\mathrm{~B}$ & 0.450 & 5.36 & 33.5 \\
\hline
\end{tabular}


Appendix 5: Supplementary Data for Chapter 6 
Figure A5.1. $77 \mathrm{~K}$ EPR spectrum of the addition of 1 equivalent of $\mathrm{HBAr}^{\mathrm{F}}{ }_{4} \cdot 2 \mathrm{Et}_{2} \mathrm{O}$ to complex 4.1.

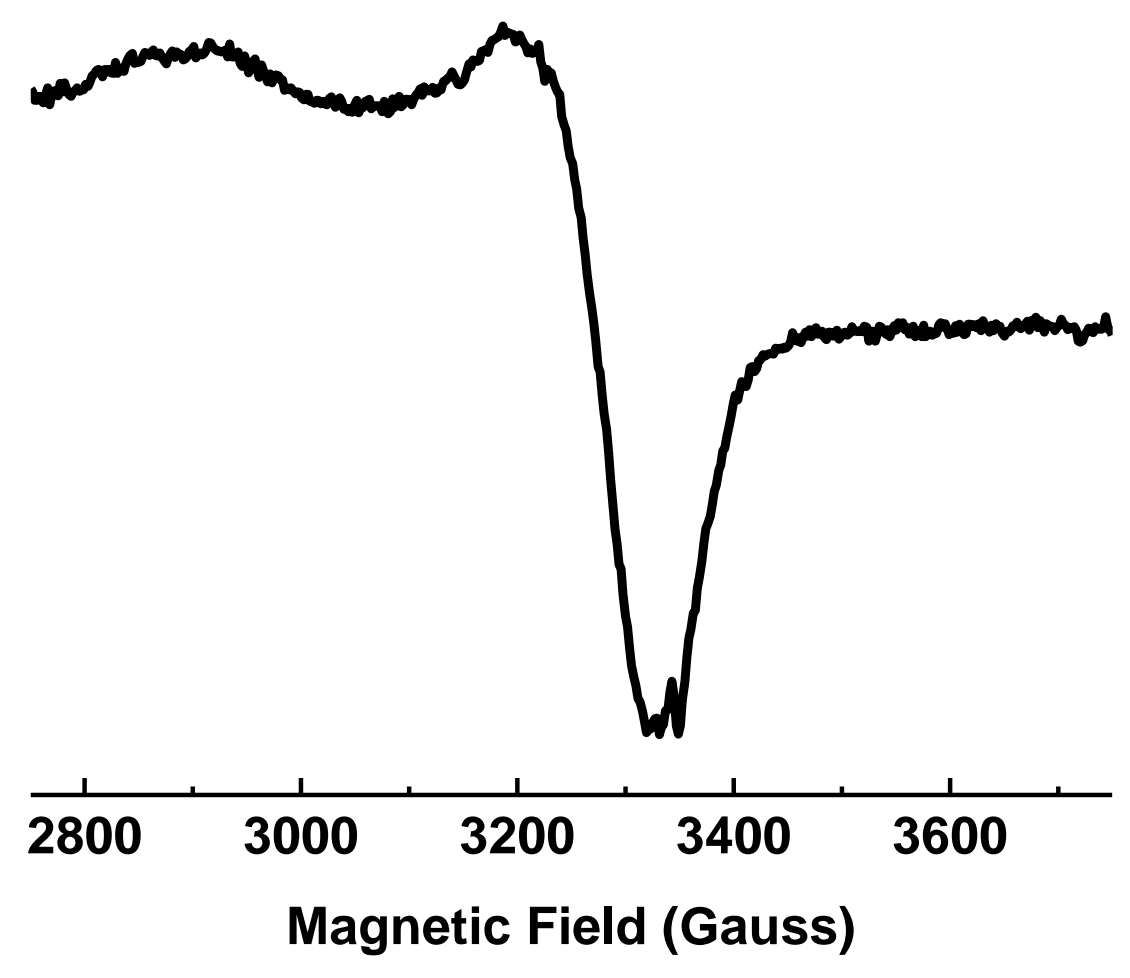


Figure A5.2. $10 \mathrm{~K} \mathrm{EPR} \mathrm{spectrum} \mathrm{of} \mathrm{the} \mathrm{addition} \mathrm{of} 10$ equivalents of $\mathrm{HBAr}_{4}{ }_{4} \cdot 2 \mathrm{Et}_{2} \mathrm{O}$ to complex 4.1 followed by the addition of 20 equivalents of $\mathrm{KC}_{8}$.

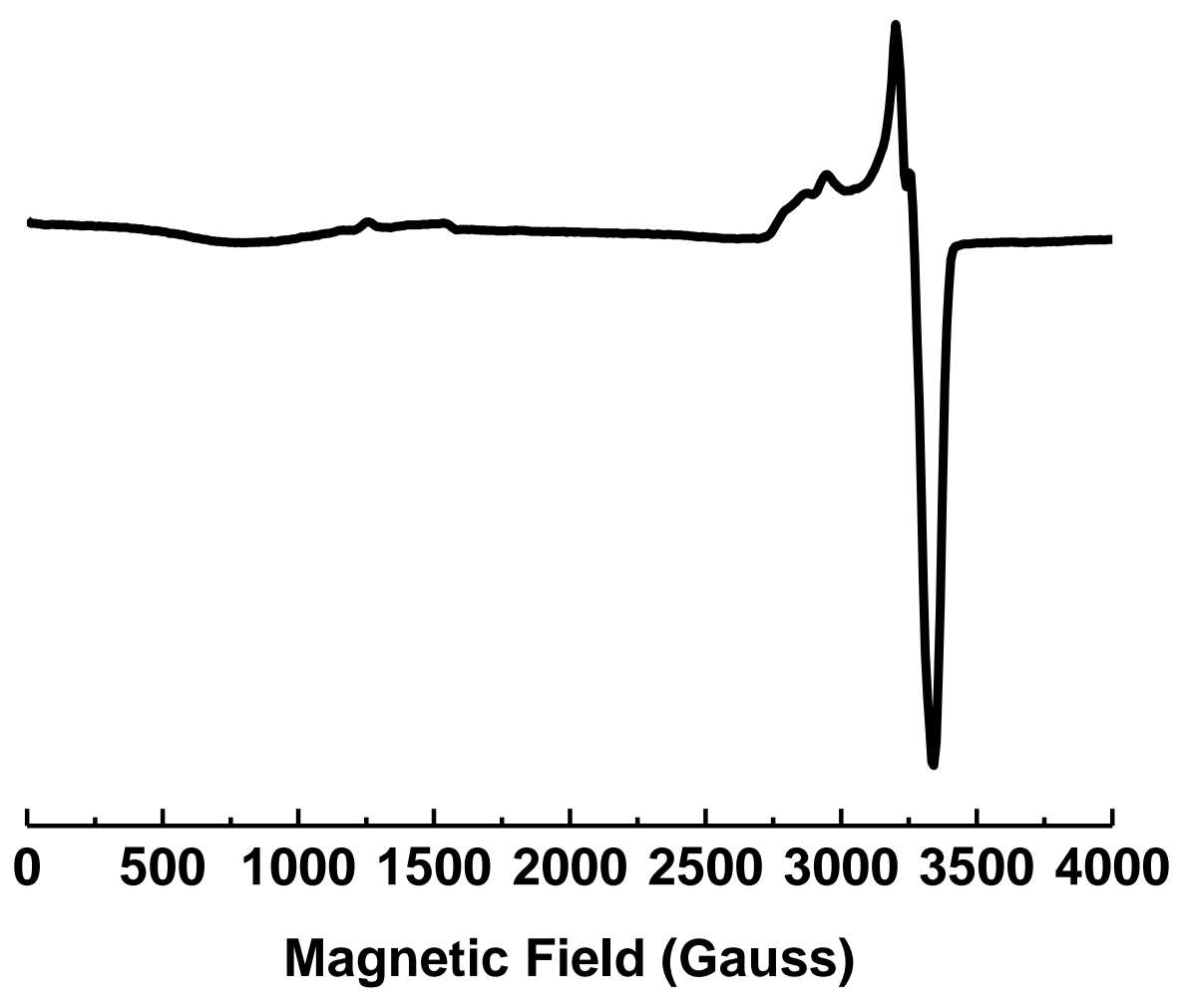


Figure A5.3. M06L/TZVP(Fe)/SVP(P,N,B)/6-31G(C, H) optimized structure of $[(\mathrm{TPB}) \mathrm{Fe}(\mathrm{HNNH})]^{+}$.

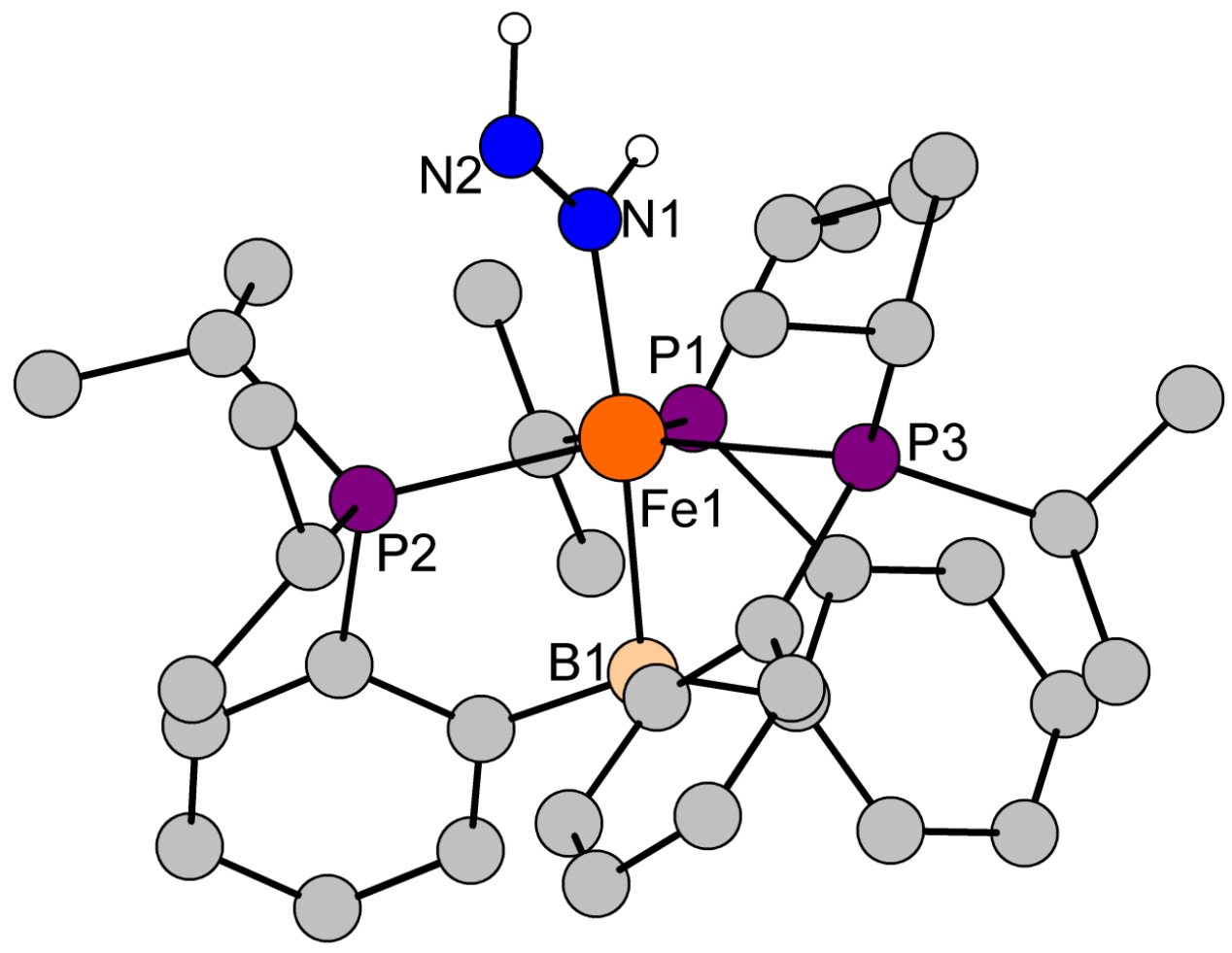

Selected bond lengths $(\AA)$ and angles $\left({ }^{\circ}\right)$ : Fe1-N1 = 1.907, N1-N2 = 1.267, Fe1-P1 = 2.383, Fe1-P2 = 2.301, Fe1-P3 = 2.294, Fe1-B1 = 2.243, P1-Fe1-P2 = 107.42, P2-Fe1-P3 $=149.37, \mathrm{P} 3-\mathrm{Fe} 1-\mathrm{P} 1=98.61$. 
Figure A5.4. M06L/TZVP(Fe)/SVP(P,N,B)/6-31G(C, H) optimized structure of $[(\mathrm{TPB}) \mathrm{Fe}(\mathrm{HNNH})]^{+}$with spin density plotted with an isovalue of 0.006 .

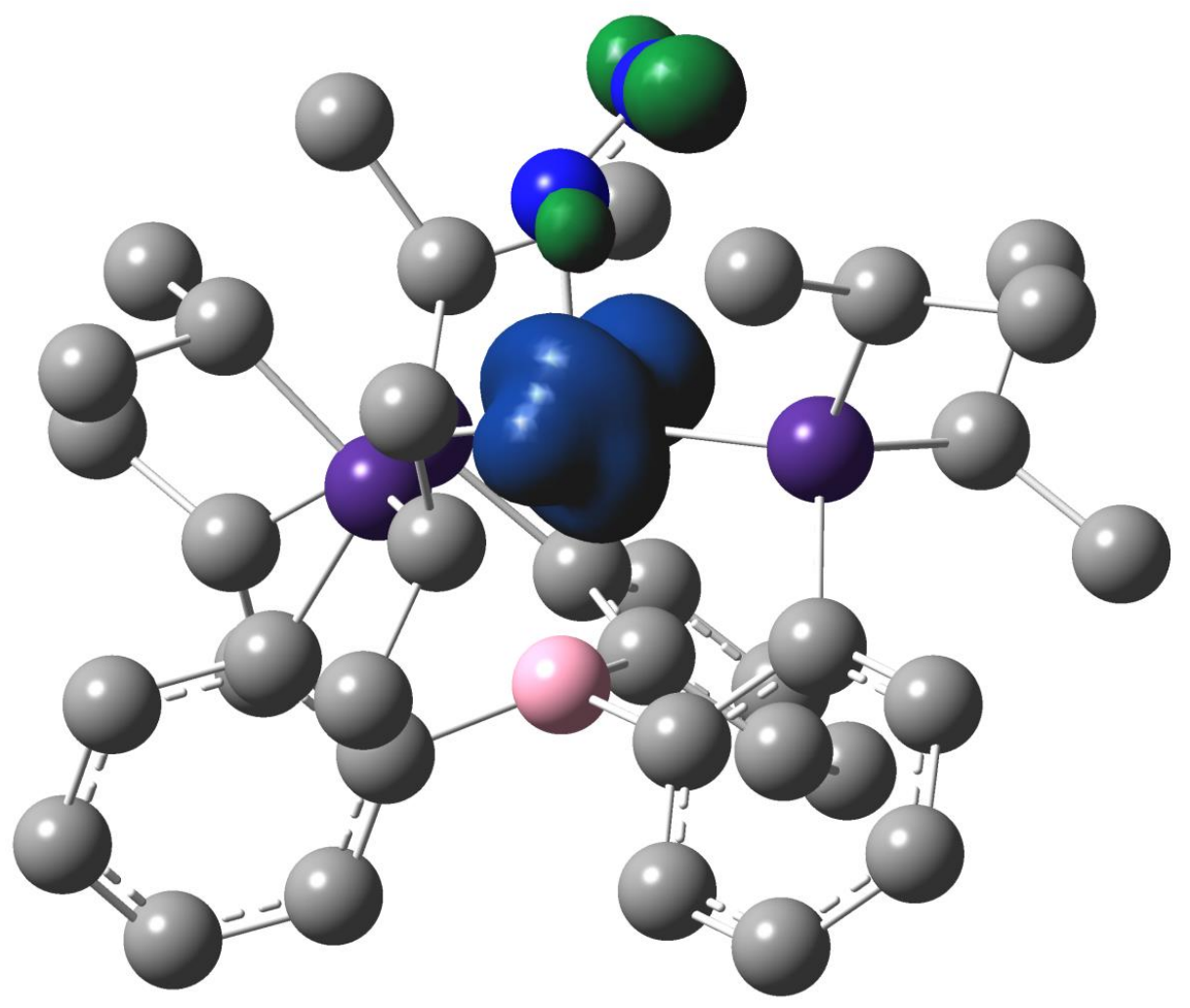


Table A5.1. M06L/TZVP(Fe)/SVP(P,N,B)/6-31G(C, H) DFT Optimized coordinates [ $\mathrm{A}]$

$$
\begin{array}{lrcc}
\text { for }\left[(\mathrm{TPB}) \mathrm{Fe}=\mathrm{N}-\mathrm{NH}_{2}\right], \mathbf{6 . 1} & \\
\mathrm{Fe} & 0.042100 & -0.321600 & -1.074300 \\
\mathrm{P} & -0.433100 & 1.899600 & -0.770400 \\
\mathrm{P} & 2.243600 & -0.595200 & -0.421900 \\
\mathrm{P} & -1.966100 & -1.314100 & -0.315900 \\
\mathrm{~N} & 0.280800 & -0.886100 & -2.660100 \\
\mathrm{C} & -1.220100 & -2.057900 & 1.178300 \\
\mathrm{C} & 2.433700 & -2.402800 & 0.086900 \\
\mathrm{H} & 1.447200 & -2.659500 & 0.495700 \\
\mathrm{C} & -0.222900 & -1.280500 & 1.826500 \\
\mathrm{C} & 2.651100 & 0.414000 & 1.032800 \\
\mathrm{C} & -1.378000 & 2.451200 & -2.292800 \\
\mathrm{H} & -0.648500 & 2.305300 & -3.102500 \\
\mathrm{C} & -1.159400 & 1.230700 & 1.689700 \\
\mathrm{C} & 1.708100 & 1.631800 & 2.896800 \\
\mathrm{H} & 0.844800 & 1.951500 & 3.478600 \\
\mathrm{C} & -2.409300 & -2.791500 & -1.393400 \\
\mathrm{H} & -3.262100 & -3.295100 & -0.909400 \\
\mathrm{~B} & 0.054700 & 0.233300 & 1.427800 \\
\mathrm{C} & 0.426500 & -1.852400 & 2.944600 \\
\mathrm{H} & 1.198900 & -1.277000 & 3.452400 \\
\mathrm{C} & 0.088100 & -3.120600 & 3.419400 \\
\mathrm{H} & 0.598000 & -3.531400 & 4.286900 \\
\mathrm{C} & 3.935900 & 0.828200 & 1.417500 \\
\mathrm{H} & 4.810700 & 0.512100 & 0.858700 \\
\mathrm{C} & -0.916900 & -3.860200 & 2.784000 \\
\mathrm{H} & -1.193000 & -4.842400 & 3.156300 \\
\mathrm{C} & 4.102700 & 1.655800 & 2.532200 \\
\mathrm{H} & 5.097700 & 1.983800 & 2.818900 \\
\mathrm{C} & 2.986100 & 2.060900 & 3.268700 \\
\mathrm{H} & 3.111300 & 2.710500 & 4.131000 \\
\mathrm{C} & 3.482800 & -0.364300 & -1.798300 \\
\mathrm{H} & 3.117800 & -1.093100 & -2.539000 \\
\mathrm{C} & -1.888300 & 1.263800 & 2.892500 \\
\mathrm{H} & -1.661800 & 0.539700 & 3.674200 \\
\mathrm{C} & -1.480300 & 2.176100 & 0.688800 \\
\mathrm{C} & 1.005300 & 3.122800 & -0.638000 \\
\mathrm{H} & 1.835000 & 2.482600 & -0.306200 \\
\mathrm{C} & -3.626700 & -0.603600 & 0.271300 \\
\mathrm{H} & -3.412400 & 0.456500 & 0.461300 \\
\mathrm{C} & -2.488000 & 3.130300 & 0.889300 \\
\mathrm{H} & -2.724400 & 3.866000 & 0.127600 \\
\mathrm{C} & -2.909300 & 2.200800 & 3.088200
\end{array}
$$




$\begin{array}{lrrr}\mathrm{H} & -3.473600 & 2.203500 & 4.017200 \\ \mathrm{C} & -2.815500 & -2.356900 & -2.811500 \\ \mathrm{H} & -3.021900 & -3.243900 & -3.422100 \\ \mathrm{H} & -1.998800 & -1.802500 & -3.288400 \\ \mathrm{H} & -3.706600 & -1.727400 & -2.837100 \\ \mathrm{C} & -3.208300 & 3.133700 & 2.089800 \\ \mathrm{H} & -3.999500 & 3.862200 & 2.242600 \\ \mathrm{C} & -1.232100 & -3.774300 & -1.505300 \\ \mathrm{H} & -1.474700 & -4.560000 & -2.230100 \\ \mathrm{H} & -0.974500 & -4.255300 & -0.559000 \\ \mathrm{H} & -0.336900 & -3.247000 & -1.857500 \\ \mathrm{C} & -1.826100 & 3.931000 & -2.278900 \\ \mathrm{H} & -1.786000 & 4.344800 & -3.292800 \\ \mathrm{H} & -1.216300 & 4.572900 & -1.637200 \\ \mathrm{H} & -2.863600 & 4.010600 & -1.939100 \\ \mathrm{C} & 3.342100 & 1.030500 & -2.413400 \\ \mathrm{H} & 3.989900 & 1.130100 & -3.292000 \\ \mathrm{H} & 3.629400 & 1.812600 & -1.698600 \\ \mathrm{H} & 2.307600 & 1.213400 & -2.723800 \\ \mathrm{C} & -1.566600 & -3.329100 & 1.668000 \\ \mathrm{H} & -2.346500 & -3.910000 & 1.180000 \\ \mathrm{C} & 1.415400 & 3.778200 & -1.969500 \\ \mathrm{H} & 2.429500 & 4.183400 & -1.871500 \\ \mathrm{H} & 0.759500 & 4.613700 & -2.231400 \\ \mathrm{H} & 1.423100 & 3.083000 & -2.814100 \\ \mathrm{C} & -2.587700 & 1.550000 & -2.561400 \\ \mathrm{H} & -3.111200 & 1.878500 & -3.466900 \\ \mathrm{H} & -3.296700 & 1.612700 & -1.725000 \\ \mathrm{H} & -2.296900 & 0.501700 & -2.692000 \\ \mathrm{C} & 2.679600 & -3.310900 & -1.126200 \\ \mathrm{H} & 2.586100 & -4.360700 & -0.826100 \\ \mathrm{H} & 3.680600 & -3.176400 & -1.550600 \\ \mathrm{H} & 1.945600 & -3.126800 & -1.920000 \\ \mathrm{C} & 0.786500 & 4.193000 & 0.442100 \\ \mathrm{H} & 1.689400 & 4.809600 & 0.530300 \\ \mathrm{H} & 0.582000 & 3.751500 & 1.421600 \\ \mathrm{H} & -0.049300 & 4.858800 & 0.193100 \\ \mathrm{H} & 3.466600 & -2.634600 & 1.196800 \\ \mathrm{H} & 3.447400 & -3.689400 & 1.497200 \\ \mathrm{H} & -5.659300 & -2.030600 & 2.082600 \\ \mathrm{H} & -2.400000 & 0.875000 \\ \mathrm{H} & -0.20500 & -1.731800 & -0.978600 \\ \mathrm{H} & -0.191900 & -1.705100 \\ \mathrm{H} & -0.686700 & -1.510100\end{array}$




$\begin{array}{crrr}\mathrm{H} & 5.492800 & -0.801400 & -2.460800 \\ \mathrm{H} & 5.097700 & -1.610300 & -0.941600 \\ \mathrm{H} & 5.448300 & 0.127300 & -0.968900 \\ \mathrm{C} & -4.089300 & -1.245400 & 1.587700 \\ \mathrm{H} & -5.017700 & -0.761200 & 1.913900 \\ \mathrm{H} & -3.352000 & -1.134100 & 2.386800 \\ \mathrm{H} & -4.299900 & -2.315700 & 1.463800 \\ \mathrm{C} & 1.505500 & 0.800200 & 1.777800 \\ \mathrm{~N} & 0.678000 & -1.514300 & -3.702600 \\ \mathrm{H} & 0.679500 & -1.051700 & -4.610700 \\ \mathrm{H} & 0.860300 & -2.519600 & -3.697500\end{array}$


Table A5.2. M06L/TZVP(Fe)/SVP(P,N,B)/6-31G(C,H) DFT Optimized coordinates [ $[\AA]$

$$
\begin{array}{lrcc}
\text { for }[(\mathrm{TPB}) \mathrm{Fe}(\mathrm{HNNH})]^{+} . & \\
& & & \\
\mathrm{Fe} & 0.044400 & -0.524300 & -0.675200 \\
\mathrm{P} & -0.661500 & 1.748300 & -0.807700 \\
\mathrm{P} & 2.333900 & -0.522200 & -0.450200 \\
\mathrm{P} & -1.983900 & -1.486900 & -0.206400 \\
\mathrm{~N} & 0.077800 & -0.726900 & -2.571300 \\
\mathrm{C} & -0.938100 & -2.055400 & 1.163400 \\
\mathrm{C} & 2.911100 & -2.255000 & 0.020600 \\
\mathrm{H} & 2.029400 & -2.678800 & 0.520000 \\
\mathrm{C} & 0.069500 & -1.132800 & 1.595000 \\
\mathrm{C} & 2.687200 & 0.633800 & 0.915300 \\
\mathrm{C} & -1.708400 & 2.120200 & -2.328800 \\
\mathrm{H} & -1.014600 & 1.996000 & -3.176300 \\
\mathrm{C} & -1.201700 & 1.279300 & 1.707600 \\
\mathrm{C} & 1.733000 & 2.068800 & 2.619900 \\
\mathrm{H} & 0.867300 & 2.440800 & 3.165600 \\
\mathrm{C} & -2.364900 & -3.033300 & -1.199600 \\
\mathrm{H} & -3.113100 & -3.614800 & -0.636200 \\
\mathrm{~B} & 0.106800 & 0.459500 & 1.339700 \\
\mathrm{C} & 0.987900 & -1.610000 & 2.578400 \\
\mathrm{H} & 1.767800 & -0.942300 & 2.932700 \\
\mathrm{C} & 0.868700 & -2.869700 & 3.153100 \\
\mathrm{H} & 1.551500 & -3.170200 & 3.943000 \\
\mathrm{C} & 3.968000 & 1.097700 & 1.257000 \\
\mathrm{H} & 4.847400 & 0.710300 & 0.751100 \\
\mathrm{C} & -0.137400 & -3.747900 & 2.722100 \\
\mathrm{H} & -0.238200 & -4.729700 & 3.175800 \\
\mathrm{C} & 4.127300 & 2.055900 & 2.263500 \\
\mathrm{H} & 5.121000 & 2.412900 & 2.518300 \\
\mathrm{C} & 3.006600 & 2.549200 & 2.937900 \\
\mathrm{H} & 3.127600 & 3.297400 & 3.716700 \\
\mathrm{C} & 3.350200 & -0.094400 & -1.954500 \\
\mathrm{H} & 3.053000 & -0.893600 & -2.651000 \\
\mathrm{C} & -1.857100 & 1.320300 & 2.949300 \\
\mathrm{H} & -1.464600 & 0.743700 & 3.785600 \\
\mathrm{C} & -1.731800 & 2.036800 & 0.636700 \\
\mathrm{C} & 0.606200 & 3.166500 & -0.791900 \\
\mathrm{H} & 1.525600 & 2.652300 & -0.477700 \\
\mathrm{C} & -3.615100 & -0.931900 & 0.579500 \\
\mathrm{H} & -3.473500 & 0.138500 & 0.776100 \\
\mathrm{C} & -2.888400 & 2.811000 & 0.798800 \\
\mathrm{H} & -3.296500 & 3.396900 & -0.018900 \\
\mathrm{C} & -3.023900 & 2.077400 & 3.110000
\end{array}
$$




$\begin{array}{lrrr}\mathrm{H} & -3.536100 & 2.089600 & 4.068700 \\ \mathrm{C} & -2.946200 & -2.668500 & -2.578400 \\ \mathrm{H} & -3.195200 & -3.585400 & -3.124200 \\ \mathrm{H} & -2.199800 & -2.127600 & -3.173500 \\ \mathrm{H} & -3.849600 & -2.056600 & -2.529000 \\ \mathrm{C} & -3.538700 & 2.818000 & 2.039500 \\ \mathrm{H} & -4.444000 & 3.404200 & 2.170400 \\ \mathrm{C} & -1.104000 & -3.888700 & -1.427300 \\ \mathrm{H} & -1.354900 & -4.729100 & -2.084800 \\ \mathrm{H} & -0.683200 & -4.301500 & -0.508400 \\ \mathrm{H} & -0.317400 & -3.307600 & -1.924400 \\ \mathrm{C} & -2.266600 & 3.566100 & -2.374000 \\ \mathrm{H} & -2.132800 & 4.003400 & -3.369100 \\ \mathrm{H} & -1.795700 & 4.239000 & -1.653100 \\ \mathrm{H} & -3.341200 & 3.560900 & -2.163100 \\ \mathrm{C} & 2.905700 & 1.242900 & -2.546400 \\ \mathrm{H} & 3.382800 & 1.413400 & -3.518700 \\ \mathrm{H} & 3.181400 & 2.078000 & -1.889700 \\ \mathrm{H} & 1.819000 & 1.269700 & -2.685300 \\ \mathrm{C} & -1.014400 & -3.350000 & 1.718700 \\ \mathrm{H} & -1.789700 & -4.033300 & 1.381400 \\ \mathrm{C} & 0.880400 & 3.830900 & -2.155600 \\ \mathrm{H} & 1.864100 & 4.314700 & -2.124600 \\ \mathrm{H} & 0.147900 & 4.611100 & -2.380900 \\ \mathrm{H} & 0.893100 & 3.130800 & -2.996600 \\ \mathrm{C} & -2.864100 & 1.123300 & -2.477700 \\ \mathrm{H} & -3.453700 & 1.351200 & -3.373400 \\ \mathrm{H} & -3.531500 & 1.200000 & -1.609200 \\ \mathrm{H} & -2.528300 & 0.082200 & -2.543200 \\ \mathrm{C} & 3.181200 & -3.116300 & -1.223800 \\ \mathrm{H} & 3.294600 & -4.163100 & -0.919600 \\ \mathrm{H} & 4.106600 & -2.824300 & -1.732700 \\ \mathrm{H} & 2.361800 & -3.059200 & -1.949800 \\ \mathrm{C} & 0.296300 & 4.242000 & 0.260200 \\ \mathrm{H} & 1.120000 & 4.966200 & 0.292200 \\ \mathrm{H} & 0.180700 & 3.819300 & 1.261700 \\ \mathrm{H} & -0.622700 & 4.792000 & 0.023000 \\ \mathrm{H} & 4.074700 & -2.296700 & 1.018300 \\ \mathrm{H} & 3.253100 & -3.334200 & 1.326900 \\ \mathrm{H} & -5.71780000 & -1.709300 & 1.918200 \\ \mathrm{H} & -1.920400 & 0.583800 \\ \mathrm{H} & -0.709100 & 0.169700 \\ \mathrm{H} & -2.13600 & -2.164100 & -0.553200 \\ \mathrm{H} & -0.128100 & -1.804100\end{array}$




$\begin{array}{crcc}\mathrm{H} & 5.340100 & -0.113500 & -2.799200 \\ \mathrm{H} & 5.242300 & -1.021400 & -1.288700 \\ \mathrm{H} & 5.243900 & 0.754200 & -1.269100 \\ \mathrm{C} & -3.865600 & -1.645000 & 1.915700 \\ \mathrm{H} & -4.799800 & -1.271400 & 2.351900 \\ \mathrm{H} & -3.062600 & -1.465800 & 2.635800 \\ \mathrm{H} & -3.974400 & -2.729500 & 1.783700 \\ \mathrm{C} & 1.535200 & 1.102400 & 1.614400 \\ \mathrm{~N} & 0.696100 & -1.586000 & -3.267700 \\ \mathrm{H} & 0.524200 & -1.437200 & -4.272600 \\ \mathrm{H} & -0.471600 & -0.036500 & -3.111300\end{array}$


Table A5.3. DFT optimized energies $[\mathrm{kcal} / \mathrm{mol}]$ for $\left[(\mathrm{TPB}) \mathrm{Fe}\left(\mathrm{N}_{2} \mathrm{H}_{2}\right)\right]^{+}$congeners of different structures and spin states.

\begin{tabular}{ccc}
\hline Complex & BP86 & M06L \\
\hline$S=1 / 2[(\mathrm{TPB}) \mathrm{Fe}=\mathrm{N}-$ & 0 & 0 \\
$\left.\mathrm{NH}_{2}\right]^{+}$ & 17.0 & 8.2 \\
$S=1 / 2$ & 5.3 & -6.9 \\
{$[(\mathrm{TPB}) \mathrm{Fe}(\mathrm{HNNH})]^{+}$} & 11.0 & -5.6 \\
$S=3 / 2[(\mathrm{TPB}) \mathrm{Fe}=\mathrm{N}-$ & & \\
$\left.\mathrm{NH}_{2}\right]^{+}$ & & \\
$S=3 / 2$ & & \\
{$[(\mathrm{TPB}) \mathrm{Fe}(\mathrm{HNNH})]^{+}$} & &
\end{tabular}

